\title{
Sustainability embedding practices in Dutch listed companies
}

Citation for published version (APA):

Bauer, R., Bauer, T., Olaerts, M., \& van Aartsen, C. (2021). Sustainability embedding practices in Dutch listed companies. Eumedion investor association.

Document status and date:

Published: 01/10/2021

Document Version:

Publisher's PDF, also known as Version of record

\section{Please check the document version of this publication:}

- A submitted manuscript is the version of the article upon submission and before peer-review. There can be important differences between the submitted version and the official published version of record.

People interested in the research are advised to contact the author for the final version of the publication, or visit the DOI to the publisher's website.

- The final author version and the galley proof are versions of the publication after peer review.

- The final published version features the final layout of the paper including the volume, issue and page numbers.

Link to publication

\footnotetext{
General rights rights.

- You may freely distribute the URL identifying the publication in the public portal. please follow below link for the End User Agreement:

www.umlib.nl/taverne-license

Take down policy

If you believe that this document breaches copyright please contact us at:

repository@maastrichtuniversity.nl

providing details and we will investigate your claim.
}

Copyright and moral rights for the publications made accessible in the public portal are retained by the authors and/or other copyright owners and it is a condition of accessing publications that users recognise and abide by the legal requirements associated with these

- Users may download and print one copy of any publication from the public portal for the purpose of private study or research.

- You may not further distribute the material or use it for any profit-making activity or commercial gain

If the publication is distributed under the terms of Article $25 \mathrm{fa}$ of the Dutch Copyright Act, indicated by the "Taverne" license above, 


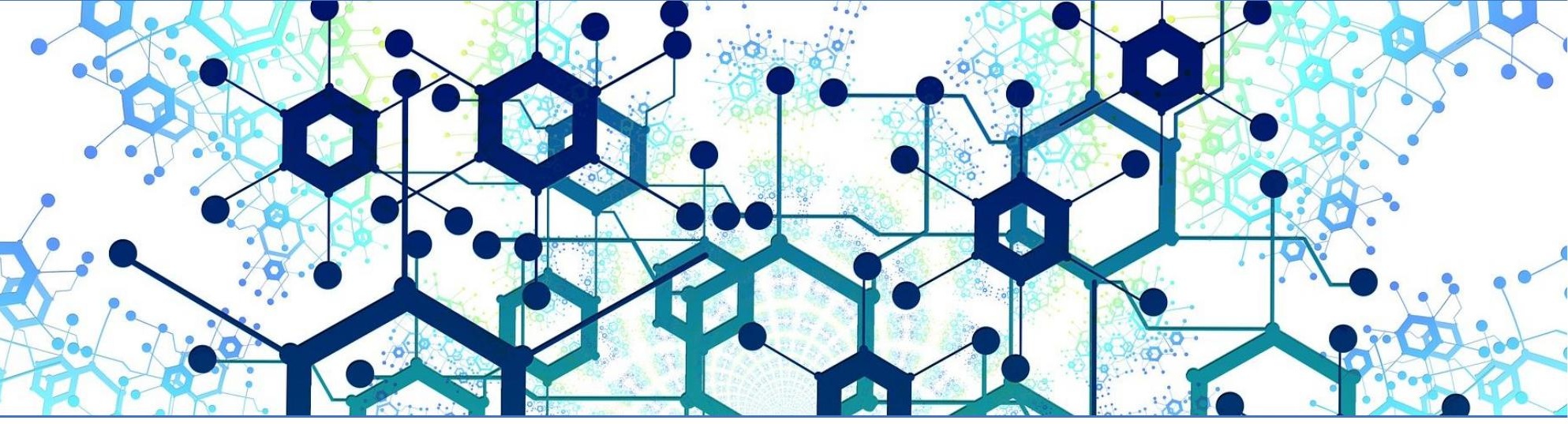

\title{
Sustainability embedding practices in Dutch listed companies
}

\author{
October 2021
}

\section{Maastricht University}




\section{Maastricht University research team}

Prof. Dr. Rob Bauer

Prof. Mr. Mieke Olaerts

Dr. Constantijn van Aartsen

Tereza Bauer
Professor of Finance (chair: Institutional Investors) and holder of the Elverding Chair on Sustainable Business, Culture and Corporate Regulation ${ }^{1}$

Professor of Comparative and National Company Law and holder of the Elverding Chair on Sustainable Business, Culture and Corporate Regulation ${ }^{1}$

Post-Doc Researcher in Private Law for the Elverding Chair on Sustainable Business, Culture and Corporate Regulation ${ }^{1}$

PhD Candidate at the Graduate School of Business and Economics and the Faculty of Law

Prof. Dr. Rob Bauer and Prof. Mr. Mieke Olaerts are appointed to the Elverding Chair on "Sustainable Business, Culture and Corporate Regulation". The Elverding chair is made possible among others by DSM, DNB, ING and Qpark.

The research team is grateful for the desk research assistance of our student researchers Inke Bours, Evgenia (Jenny) Kokkou, Anette Piirsalu, and Laura Winkens. We also thank Colin Tissen for his support with the FactSet data on investor share ownership, and Arabesque for providing ESG data to evaluate the sustainability performance of our sample.

${ }^{1}$ https://www.maastrichtuniversity.nl/events/eu-green-deal-and-future-modern-corporation-elverding-webinar 


\section{Table of contents}

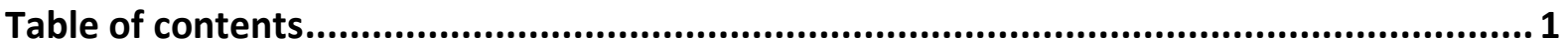

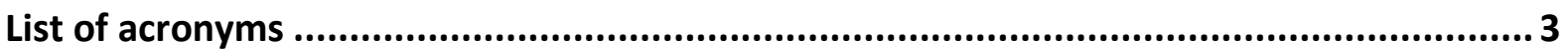

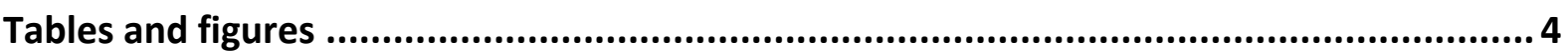

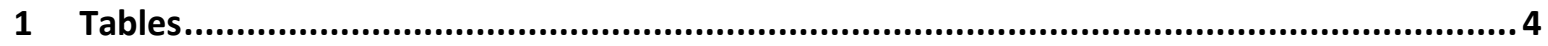

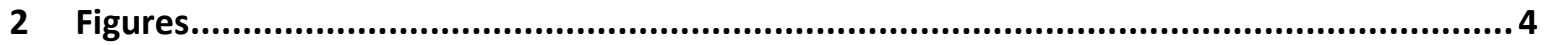

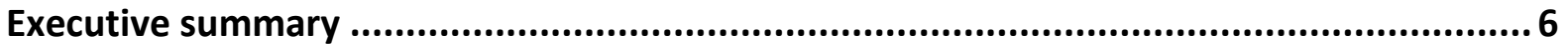

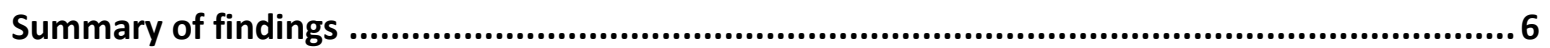

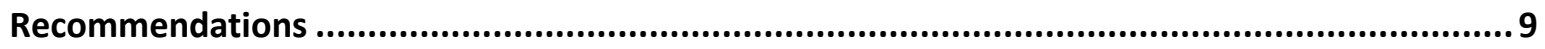

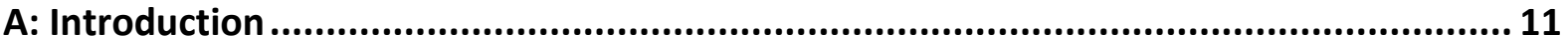

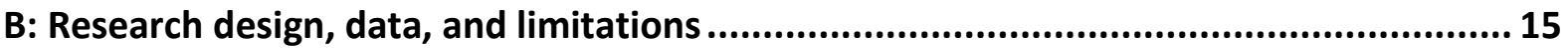

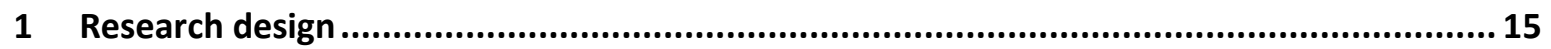

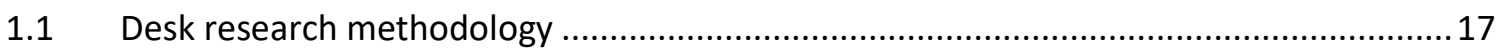

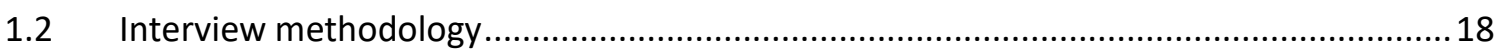

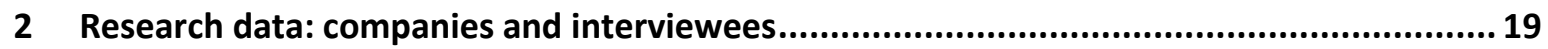

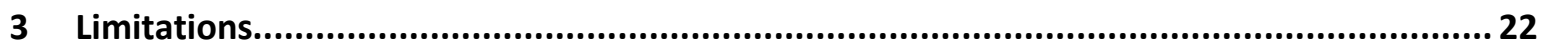

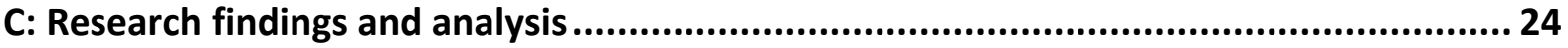

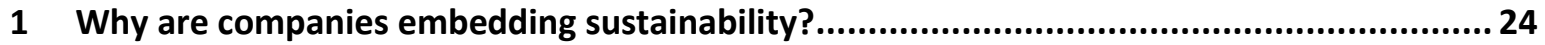

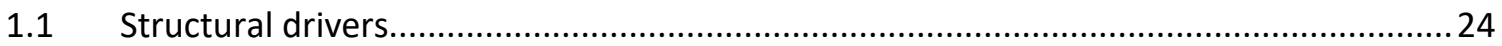

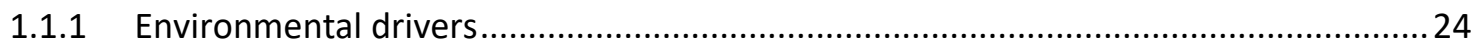

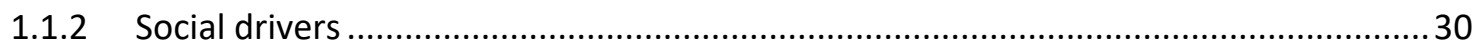

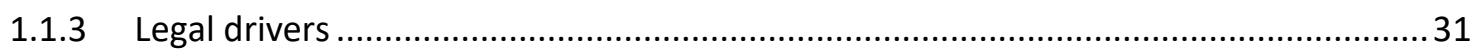

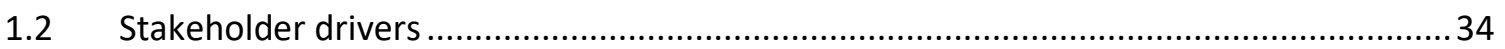

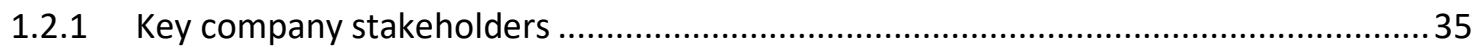

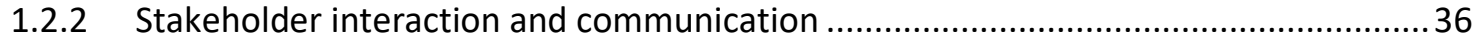

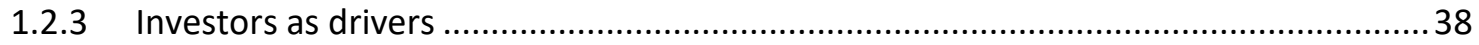

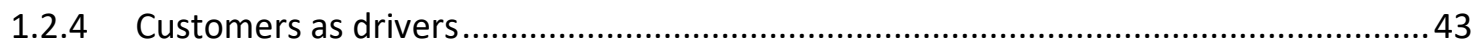

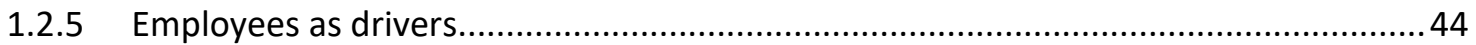

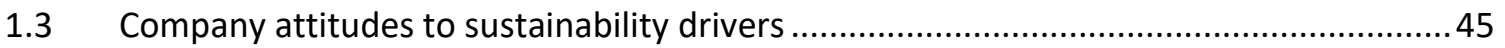

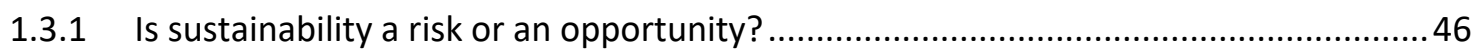

1.3.2 How long has your company been engaged with sustainability? ................................. 47

1.3.3 What is the current state of your sustainability embedding? .......................................4 


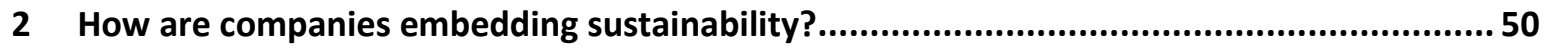

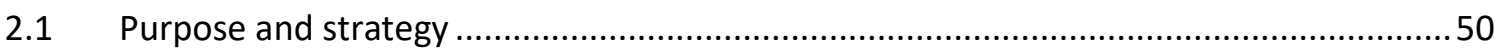

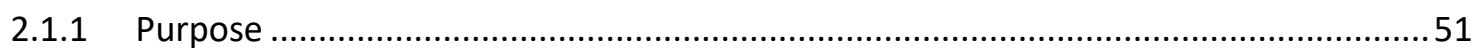

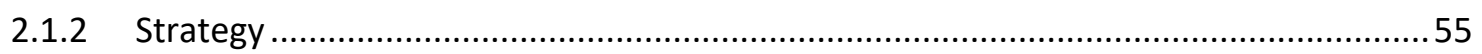

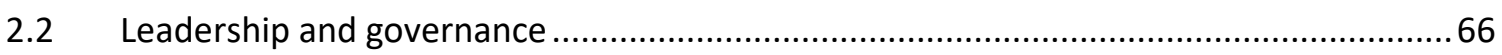

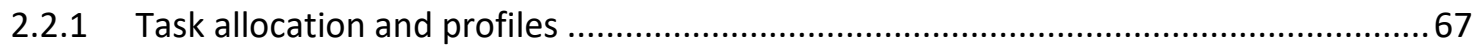

2.2.2 Leadership in sustainability embedding …............................................................. 71

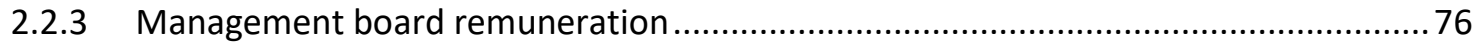

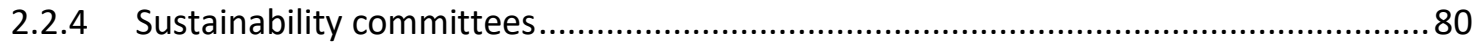

2.3 Supply chains, sustainability reporting, employees and culture .................................... 83

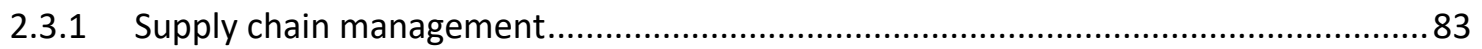

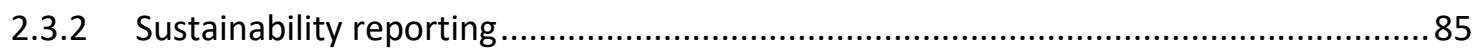

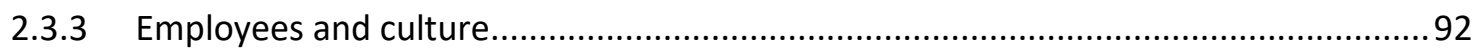

D: Summary of findings and recommendations ......................................................... 99

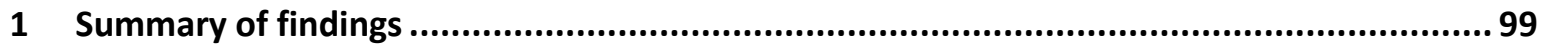

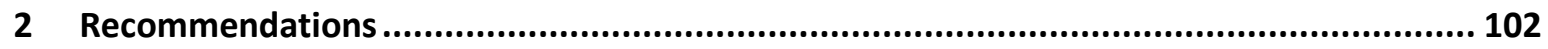

Recommendation 1: Align strategy with planetary boundaries and increase awareness on

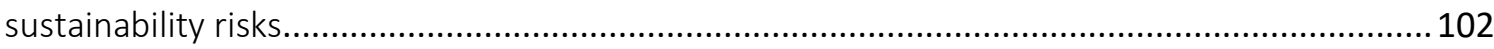

Recommendation 2: Evaluate purpose statements and connect them to strategic objectives and

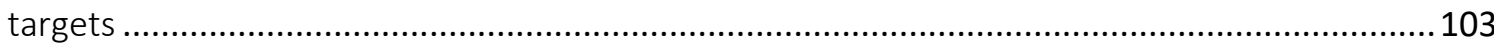

Recommendation 3: Create a leadership and governance context that supports strategic decision-

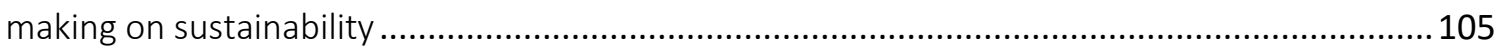

Recommendation 4: Improve quality of interaction and communication with stakeholders ..... 107

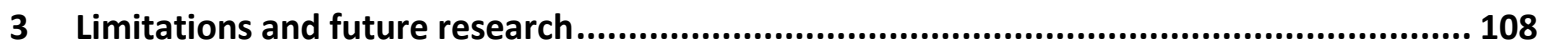

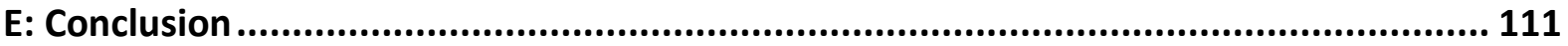

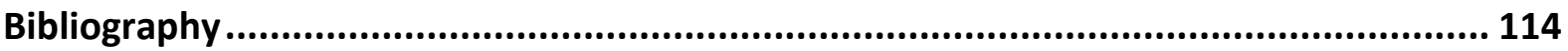

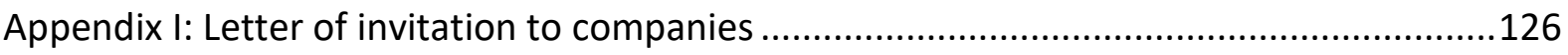

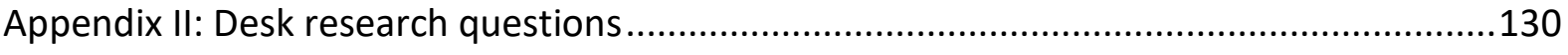

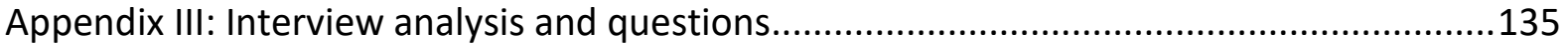

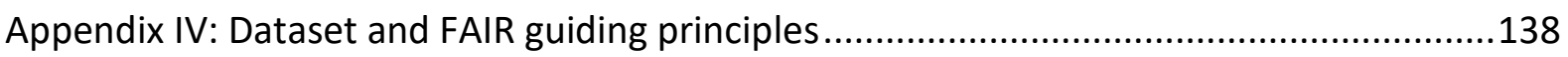

Appendix V: List of reporting and normative standards used by companies......................140 


\section{List of acronyms}

AEX Amsterdam Exchange Index

AMX Amsterdam Midcap Index

AScX Amsterdam Small Cap Index

CDP Carbon Disclosure Project

CEO Chief Executive Officer

CFO Chief Financial Officer

$\mathrm{CO}_{2}$ Carbon Dioxide (greenhouse gas)

COO Chief Operating Officer

CSR Corporate Social Responsibility

CSRD (EU) Corporate Sustainability Reporting Directive

DJSI Dow Jones Sustainability Index

DSGC Dutch Sustainable Growth Coalition

EBIT Earnings before interest and tax

EC European Commission

EEA European Environment Agency

EFRAG European Financial Reporting Advisory Group

ESG Environmental Social Governance

EU European Union

EY Ernst \& Young

FAIR Findable Accessible Interoperable Reusable (Guiding principles for data management)

FLEGT Forest Law Enforcement, Governance and Trade Regulation

GDPR General Data Protection Regulation

GHG Greenhouse Gas (emissions)

GRI Global Reporting Initiative

HR Human Resources

HSSE Health, Safety, Sustainability and Environment

IIRC International Integrated Reporting Council

IPCC Intergovernmental Panel on Climate Change
ISO International Organization for Standardization

KPI Key Performance Indicator

LGBTI+ Lesbian, Gay, Bisexual, Transgender, Intersex (and others)

LTI Long-term incentive

NFRD (EU) Non-Financial Reporting Directive

NGO non-governmental organisation

OECD Organisation for Economic Cooperation and Development

PRI Principles for Responsible Investment

PRIIPS Packaged retail and insurance-based investment products

R\&D Research \& Development

RDS Royal Dutch Shell

SASB Sustainability Accounting Standards Board

SDG (United Nations) Sustainable Development Goals

SFDR Sustainable Finance Disclosure Regulation

STI Short-term incentive

TCFD Taskforce for Climate-Related Financial Disclosures

UK United Kingdom

UN United Nations

UNEP United Nations Environment Programme

UNGP United Nations Guiding Principles on Business and Human Rights

US United States

WBCSD World Business Council for Sustainable Development

WWF World Wildlife Fund 


\section{Tables and figures}

\section{Tables}

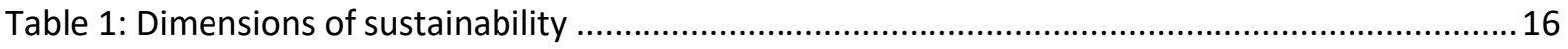

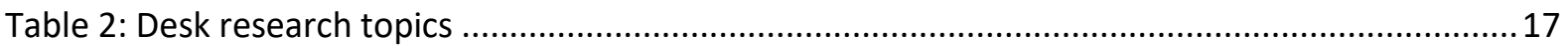

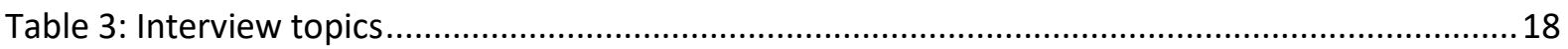

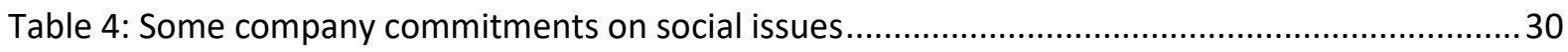

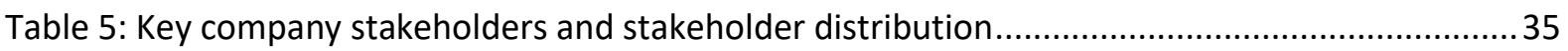

Table 6: Data on investor ownership of company sample ............................................................... 40

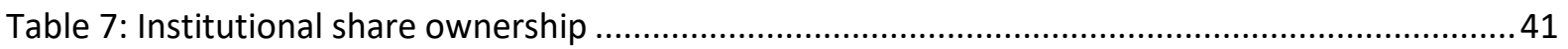

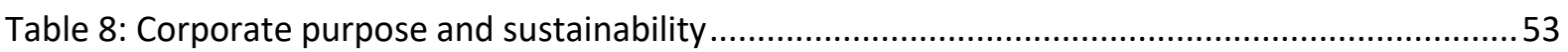

Table 9: Company sector, corporate purpose and sustainability ........................................................ 53

Table 10: Company size, corporate purpose and sustainability ........................................................53

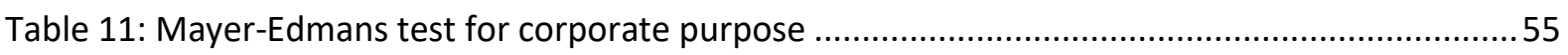

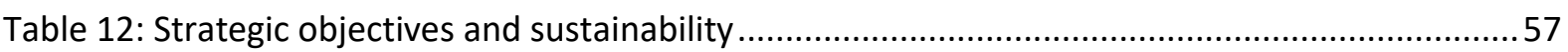

Table 13: Extent to which future sustainability targets are connected to specific deadlines ...............59

Table 14: Number of years for which results are published for sustainability targets.........................59

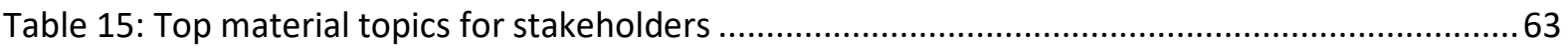

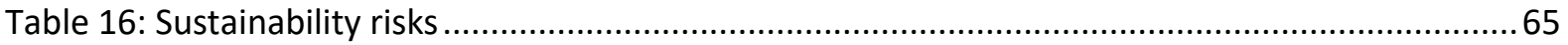

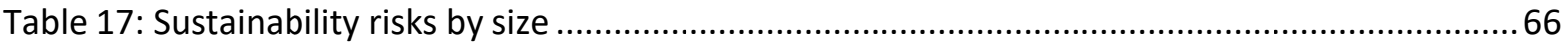

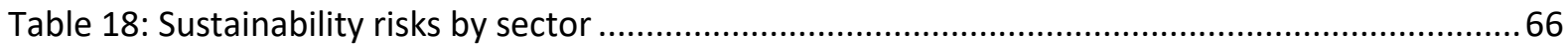

Table 19: Sustainability in management board task allocation and profiles......................................68

Table 20: Size analysis for governance level of internal sustainability committees............................. 82

Table 21: Sector analysis for governance level of internal sustainability committees.......................... 82

Table 22: Reporting frameworks most often referred to by companies in annual reports ................. 85

Table 23: Type and frequency of intensity metrics for $\mathrm{CO}_{2}$ emissions ...........................................89

Table 24: Review of company metrics for environmental reporting..................................................90

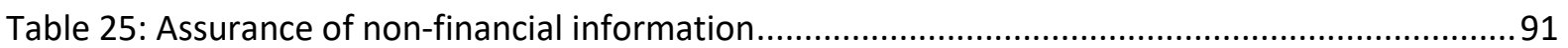

Table 26: Size analysis for assurance of non-financial information.................................................. 91

Table 27: Sector analysis for assurance of non-financial information................................................ 91

Table 28: Company reporting on diversity at employee and management level ................................95 


\section{Figures}

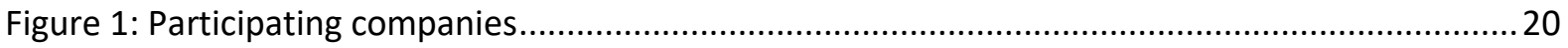

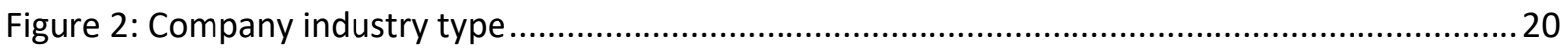

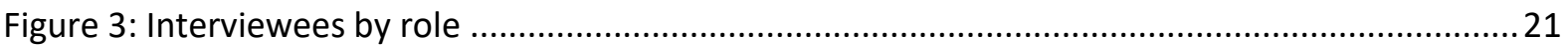

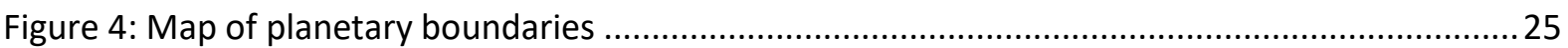

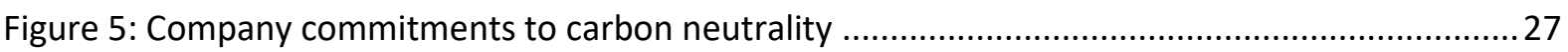

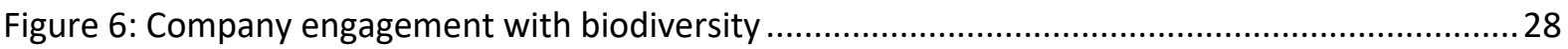

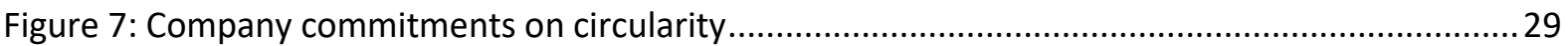

Figure 8: Sustainability topics most frequently raised by shareholders according to interviewees .... 38

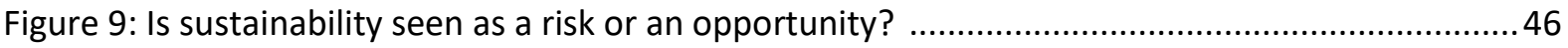

Figure 10: How long has the company been embedding sustainability? .......................................... 47

Figure 11: In what ways is sustainability already embedded in your company? .................................48

Figure 12: Where do you still see gaps or room for improvement in your sustainability embedding?48

Figure 13: How does the company define its sustainability impact and identify issues? ....................60

Figure 14: Key sustainability issues faced by companies.................................................................6

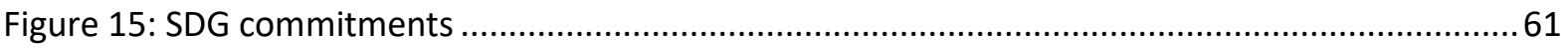

Figure 16: References to sustainability in skills profiles of the supervisory board..............................69

Figure 17: Relevance of sustainability to supervisory board selection............................................ 70

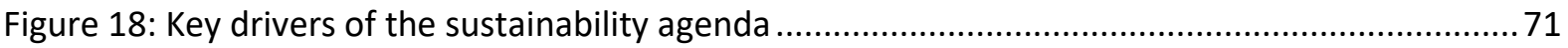

Figure 19: Who is driving sustainability within the top management team?

Figure 20: Top management activities on sustainability .................................................................... 72

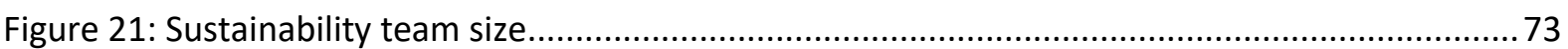

Figure 22: Tasks and activities of sustainability managers / teams ................................................... 74

Figure 23: Supervisory board oversight function regarding sustainability embedding ........................ 75

Figure 24: Company remuneration incentives and sustainability .................................................... 79

Figure 25: Companies with dedicated sustainability committees .................................................... 81

Figure 26: Governance level of internal sustainability committees ................................................. 81

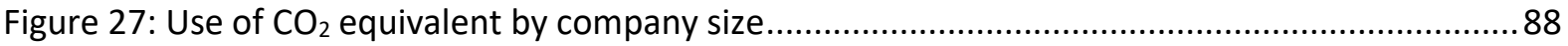

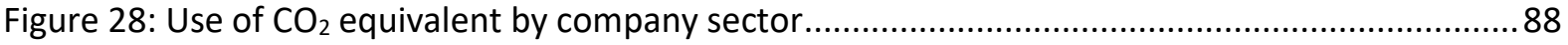

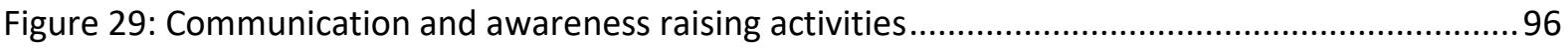

Figure 30: Engaging management layers in sustainability ............................................................ 97 


\section{Executive summary}

This research report examines why and how sustainability is being embedded by Dutch listed companies. It paints a picture of the state of the art in company sustainability embedding for 2020 and has a special focus on the roles of the management and supervisory boards given their prominence in many strategic decisions on sustainability.

In this work, we shed light on the main drivers and motivations for why company leadership sets goals and targets for sustainability embedding. We also examine how companies integrate sustainability into their purpose statements and strategies; how they organise their governance structures to implement and oversee the sustainability embedding process; and how they manage their supply chain, sustainability reporting, employees, and culture as a response to the growing societal demand for transparency in sustainability embedding. Based on these findings, we also provide four recommendations to advise how companies can further improve their sustainability embedding.

Our research design uses both desk research and interviews to examine a sample of 35 Dutch companies listed on the Amsterdam Stock Exchange and which are constituents of the AEX, AMX, and AScX indices. For the desk research, we reviewed the 2020 annual reports and the latest information and documents from company websites. For the interviews, we conducted 88 interviews with 97 interviewees including 14 CEOs, five CFOs, 19 supervisory board members and 31 sustainability managers.

\section{Summary of findings}

In the first part of our findings, we discuss why companies are embedding sustainability. We outline how structural and stakeholder drivers (such as environmental, social, and legal issues and stakeholder pressure) are generally affecting the embedding of sustainability in Dutch listed companies, and reflect on the attitudes of company leadership towards these drivers.

Our main finding in this part is that companies are responding unevenly to various environmental, social, and legal drivers. This is reflected, for example, in our desk research finding that companies have not, in most cases, made sustainability commitments which are in line with planetary boundaries. Our desk research also shows that responses are not only uneven between companies but also differ depending on the sustainability topic. Overall, commitments to reducing $\mathrm{CO}_{2}$ emissions and increasing (gender) diversity are more concrete and ambitious than those made, for example, in relation to circularity or biodiversity.

For planetary boundaries, we find that 24 out of 35 companies have a commitment to $\mathrm{CO}_{2}$ neutrality, while only five companies are committed to becoming fully circular, and only nine companies have in place some type of organisational policy or project regarding biodiversity. For a selection of social topics, we find that 32 companies have made a commitment to respect human rights, 34 have a diversity and inclusion policy for their employees, 31 have a fair tax policy, 25 have a supplier code of ethics, and 12 are committed to paying their employees a living wage.

Our interview findings disclose that most companies view sustainability more from an opportunity than from a risk perspective. They also shed light on the perceived history of embedding and reveal that, from an interviewee perspective, around one-third of companies have been seriously engaged 
with sustainability for less than five years. The interviews show, moreover, that interviewees are more likely to identify achievements rather than gaps in their sustainability embedding.

We suspect that there are numerous reasons for these cross-sectional differences in company sustainability embedding. These include not only a company's unique history and decisions, but also differences in company size and sector (which we examine at appropriate points throughout the report). Also relevant are various stakeholder relationships, for example with (institutional) investors, customers, and employees who are each identified as stakeholders by over $90 \%$ of companies. In this regard it also matters that we find a great deal of variation in institutional share ownership as well as high levels of institutional ownership by investors from common law countries.

The second part of our findings explores how companies are embedding sustainability. It looks first at purpose and strategy; second at leadership and governance; and third at supply chains, sustainability reporting, and employees and culture.

The subsection on purpose shows that 83 percent of the companies in our sample have a reference to sustainability in their corporate purpose, and that 71 percent have a purpose which is externally oriented (i.e., towards the improvement of society rather than the company). However, our analysis also shows that many of these statements are very broadly formulated. Given this, we apply a test for the relative specificity of corporate purposes based on the work of Mayer and Edmans. Using this test, we find that 16 companies try to solve a problem in their purpose statement, and that 16 companies identify one or more material stakeholders (n.b. not the same companies). Only two companies satisfy a strict application of both parts of the test. We acknowledge that the Mayer-Edmans test is only one way to investigate corporate purpose statements.

Even though many companies have a generic corporate purpose, we also see that many of them have more specific sustainability-related targets and objectives in their strategy. Overall, we find a great deal of variability in the approaches that companies use to organise their sustainability strategies, objectives, and targets. Ninety-seven percent of the companies in our sample have sustainabilityrelated strategic objectives, but they often place these objectives in different parts of their annual report. Sixty-three percent place them in their central strategy, while 34 percent place them in a separate sustainability strategy. When it comes to sustainability targets, we see that just over half of our sample has specific deadlines for their sustainability targets and that they report on recent performance for these targets for two or more years. In general, we find that companies have great freedom when it comes to deciding on their ambitions, on when they want to achieve these ambitions, and whether and how they translate their sustainability strategies into actual targets.

We also examine the use of sustainable development goals, stakeholder materiality consultations, and sustainability risks as sources of inspiration for company sustainability embedding. For the SDGs, we find that companies have a primary focus on SDG12 Consumption and production (27 out of 35 companies), SDG8 Decent work and economic growth (26), and SDG13 Climate action (26). Other SDGs are relatively less prominent. For stakeholder materiality consultations, we show that the top priorities relate to climate and emissions (20 companies), employee retention and careers (17), safety (17), employee well-being and health (17), corporate ethics and compliance (17). Circularity was identified as a material topic for 14 companies while biodiversity, ecosystems, and environment are material for only six companies. For sustainability risks, the top risks we identified from the risk management sections of the annual reports include climate change and emissions (26 companies), 
product safety and HSSE (20), employee diversity and human rights (10), circularity, and resource scarcity and waste (9).

The leadership and governance subsections show that top management is (perceived as) the main organisational driver of the sustainability agenda, and is often assisted by a sustainability team or manager. We also find that, according to interviewees, the management board and supervisory board are generally aligned in their views on sustainability. Furthermore, all 19 supervisory board interviewees indicate that sustainability is a responsibility of the whole supervisory board. In general, the supervisory board was rarely mentioned by interviewees as a driver of sustainability embedding.

We found that 27 out of 29 companies that publish their management board regulations have allocated sustainability as one of the tasks of the board or top management team; six companies do not publish these regulations. We also find that 28 companies do not publish a profile for the desired competencies and characteristics of their management board. For the other seven companies that do publish a skills profile, we find that sustainability is included as a specific management board competency. For the supervisory board, we find that all companies include sustainability oversight as one of their tasks (although eight companies only require them to formulate a diversity policy). We find it significant that more than half of the supervisory board skills profiles do not contain any references to sustainability.

Our review of management board remuneration shows that interviewees from a majority of companies are in favour of sustainability-related remuneration targets. Interviewees of a minority of companies express serious doubts about this practice. In line with these findings, the desk research shows that the vast majority of companies integrate sustainability elements into their remuneration policies. However, sustainability is only a relatively small part of short-term and long-term incentives (only 11 percent and 22 percent of their total weight, respectively).

We also examine company sustainability committees and find that companies have a varying number of sustainability-related committees with differing compositions and that they are situated at different levels within the organisation. Only three companies have an external sustainability committee. Seven companies have a sustainability committee at the supervisory board level, three have a committee within the top management team and ten have a committee with a top management team member as the highest-level manager. In general, we suspect that forming a sustainability committee is related to the scope of a company's sustainability challenges, the potential added value of such a committee, and the increased time and resources that such a committee would claim.

The subsection on supply chain management examines whether the human rights and environmental reporting practices of our company sample are in line with anticipated mandatory due diligence requirements. We find that only seven companies satisfy these requirements for human rights, and that zero companies disclose enough information in their annual and sustainability reports for us to properly evaluate whether they satisfy these requirements for environmental due diligence.

Our study on reporting practices finds almost 50 frameworks which companies use as normative and reporting standards for their sustainability reporting. Leading frameworks include the Global Reporting Initiative Standards, the Greenhouse Gas Protocol, the International Integrated Reporting Council's Integrated Reporting Framework, the Carbon Disclosure Project, and the Taskforce on Climate-related Financial Disclosures. The interviews show that companies struggle to strike the right balance between the scope of their reporting, the administrative burden on their organisation, and 
the information needs of stakeholders, while at the same time trying to comply with continuously changing legal requirements.

A close examination of company environmental reporting shows that most companies report on their energy use in detail, and that they provide less information on waste and much less information on both water use and business travel. We also find that 46 percent of the companies provide no external assurance for their nonfinancial information (beyond the basic auditor check of the management report for material misstatements) while 34 percent provide limited assurance and only 20 percent reasonable assurance.

The final subsection of our findings, on employees and culture, uses interview findings to show different perspectives on how sustainability could be embedded into a company's culture. It gives an insight into how companies measure their culture of and attitudes to sustainability; how they create appropriate, sustainability workspaces; and what they report in terms of diversity and inclusion. The latter section shows that 94 percent of companies report on their employee male / female diversity, and that 57 percent of companies report on the (non-boardroom) male / female diversity of their managers. Few companies provide information on diversity in the age and nationality of their employees and non-boardroom managers. We also provide examples of how companies embed sustainability in hiring practices, performance evaluation, onboarding, communication, and education as well as how management layers could be engaged in sustainability.

\section{Recommendations}

We find that there is scope for Dutch listed companies to align their strategy more formally with planetary boundaries, especially with regards to circularity and biodiversity. We identify a crucial role for company leadership to make sure that all management layers and employees are aware of associated sustainability risks. This awareness will help them to respond to risks, prepare for opportunities, and adequately contribute towards the transition to a climate neutral and circular economy. We recommend, therefore, that companies align their strategy with planetary boundaries and increase awareness on sustainability risks.

Based on a synthesis of our desk research and interviews findings, and in light of the relevant literature, we consider that companies could benefit from an improved sustainability culture and decision-making process if they have a well-formulated corporate purpose that is clearly and meaningfully connected to corporate strategy. We recommend, therefore, that companies evaluate their purpose statements and connect them to their strategic objectives and targets.

Companies need to create a context in which top management (CEO role and beyond) and the supervisory board are well prepared to formulate, execute and oversee a sustainability strategy with an appropriate level of ambition and understanding of their societal and environmental relevance and context. Signalling leadership on sustainability, especially when employees perceive top management as trustworthy and ethical, is key to creating an organisational culture that supports strategic sustainability objectives and financial performance. We therefore recommend that companies create a leadership and governance context that supports strategic decision-making on sustainability.

High-quality disclosures by companies lead to improved stakeholder feedback on company activities. Moreover, public information is necessary for external stakeholders to exercise market pressure and reward sustainable companies. In this regard, we find that company-stakeholder relationships are only 
as good as the quality of the information and interaction between them. We therefore recommend that companies improve the quality of their interaction and communication with stakeholders.

Combined, the four recommendations can guide companies in stepping up and further developing their sustainability embedding. We expect that they will be better prepared for responding to sustainability opportunities and risks if their strategies are aligned with planetary boundaries and if their purposes are carefully formulated. The outcome of this process is that companies will be able to focus, for example, on relevant sustainability problems to be solved and / or specific stakeholder groups. In turn, this focus can serve as additional guidance for company decision-making, as inspiration for setting the company strategy, and for defining associated strategic (sustainability) objectives. Governance plays an important role in this process. Top management needs to be prepared and equipped for the job, and the supervisory board needs to have the knowledge and skills to exercise their oversight role in an effective and meaningful way. The importance of company leadership's exemplary role in signaling to employees the importance of sustainability embedding cannot be overstated. Finally, improved interaction and communication with external stakeholders will enhance companies' accountability to society and contribute towards a feedback loop which can boost further sustainability embedding and advance company strategic decision-making. 


\section{A: Introduction}

Environmental and social challenges have pushed companies and investors of all shapes and sizes to increase their sustainability-related business and investment activities over the last few decades (WBCSD 2021; Brundtland et al. 1987; Maas 2018). Whether framed as the integration of corporate social responsibility, an exercise in corporate citizenship, or just good business, this push has left no doubt that sustainability matters.

At the same time, ongoing research is redefining the relationship between the economy and society (Raworth 2018; Pistor 2019), and bringing the sustainability related issues of business practice into clearer focus. While just a few decades ago, the conventional wisdom dictated that companies should generate returns for shareholders to maximise their social value (Hansmann and Kraakman 2001), a wide range of parties now accept, in the 2019 words of the US Business Roundtable, that companies "share a fundamental commitment to all our stakeholders" (Business Roundtable 2019). This is being translated by an increasing number of companies and academics into a call for business to find and act in accordance with a sustainable purpose (Mayer 2018; Edmans 2020; Dutch Sustainable Growth Coalition (DSGC) 2020).

There is a growing consensus that a sustainable economy needs to operate within planetary boundaries and that its activities must be embedded in society and the environment. ${ }^{2}$ The European Union (EU) European Green Deal ${ }^{3}$, Paris Climate Agreement, and the work of the Intergovernmental Panel on Climate Change (IPCC) re-emphasise the World Business Council for Sustainability Development's (WBCSD) conclusion from 2010 that "business-as-usual cannot get us to sustainability or secure economic and social prosperity" (WBCSD 2010: 3). The last five years were the warmest ever recorded (WMO 2020) and UN Secretary-General António Gutierrez recently warned that "we are nowhere near the finish line... and still running behind in the race against time" (UN News 2020). Global biodiversity continues to decline (WWF 2020; UN Environment Programme (UNEP) 2021), while ecosystem services have been depleted by an estimated \$20 trillion between 1997 and 2011 (WBCSD 2020: 9).

The abovementioned issues are leading to a push from regulators and policy-makers to require companies to become more sustainable and to contribute more to these challenges. Traditional soft law approaches seem to be falling out of fashion as regulators at both the national and European level look for more progress on sustainability. The European Green Deal, Sustainable Corporate Governance initiative $^{4}$, Taxonomy Regulation ${ }^{5}$, Sustainable Finance Disclosure Regulation (SFDR) ${ }^{6}$, and draft

\footnotetext{
${ }^{2}$ The World Business Council for Sustainable Development (WBCSD) recently updated its Vision 2050 to help enable "A world in which 9+ billion people live well, within planetary boundaries" (WBCSD 2021: 23), and the UN High Level Panel on Global Sustainability urged that human activities should operate within planetary boundaries (2012).

${ }^{3}$ European Green Deal 'Communication from the Commission to the European Parliament, the European Council, the Council, the European Central Bank, the European Economic and Social Committee and the Committee of the Regions - The European Green Deal.' COM/2019/640 final.

4 https://ec.europa.eu/info/law/better-regulation/have-your-say/initiatives/12548-Sustainable-corporate-governance en 5 Regulation (EU) 2020/852 of the European Parliament and of the Council of 18 June 2020 on the establishment of a framework to facilitate sustainable investment, and amending Regulation (EU) 2019/2088.

${ }^{6}$ Regulation (EU) 2019/2088 of the European Parliament and of the Council of 27 November 2019 on sustainability-related disclosures in the financial services sector.
} 
proposals for mandatory due diligence ${ }^{7}$ and corporate sustainability reporting ${ }^{8}$ are only a few examples of the changing legislative requirements and expectations.

These environmental, social, and legal drivers blend together and influence company interactions with a range of stakeholders. This is manifested, for example, in the rise of ESG investment, investor collaboration on sustainability (e.g., the Net-Zero Asset Owner Alliance ${ }^{9}$ and Climate Action $100+{ }^{10}$ ), the presence of sustainability rating agencies, the behaviour of customers who are willing to pay a premium for sustainable goods and services (e.g., Bauer et al. 2021), companies that are offering sustainable products (Maxwell and Van der Vorst 2003), employees who are looking for satisfying jobs (Edmans 2011, 2014), and investors who are increasingly integrating environmental risks into portfolio allocations due to the costs of climate change (Chava 2014; Cosemans et al. 2021; Pankratz et al. 2021). Investors, too, are subject to sustainability legislation and reporting requirements which, in turn, influence companies (Dimson et al. 2015, 2020). Dynamics in favour of sustainability are strengthened by NGOs and the media which draw regular attention to corporate scandals, environmental harms and social issues (Catá Backer 2013).

In other words, sustainability must be an important item on the corporate agenda. At the same time, it remains difficult for investors, as well as other stakeholders, to evaluate what companies are doing for sustainability (Berg et al. 2020). Corporate disclosures can be difficult to compare (Krüger et al. 2021). Moreover, there is no universal benchmark for sustainable business practices (Berg et al. 2020; Eccles and Stroehle 2018).

It is against the backdrop of these developments and limitations that Eumedion commissioned our research team to investigate the sustainability embedding practices of Dutch listed companies, with a special focus on the roles of the management and supervisory boards given their prominence in setting, implementing, and overseeing corporate strategy. For this purpose, we formulate two main research questions:

1. Why are companies embedding sustainability?

2. How are companies embedding sustainability?

In answering these questions, we recognise that the term sustainability relates to a large variety of issues. Our general approach to this term therefore follows that of the Embedding Project which defines business sustainability as: "Business models and managerial decisions that create value over the short, medium and long term, based on mutually beneficial interactions between the company's value chain and the social and environmental systems on which it depends" (Bertels and Schulschenk 2015: 4). This definition enables a broad understanding of the term sustainability and also allows us to identify what companies themselves view as part of this term.

In relation to the first question, why are companies embedding sustainability, we outline how structural and stakeholder drivers (such as environmental, social, and legal issues and stakeholder

\footnotetext{
${ }^{7}$ European Parliament resolution of 10 March 2021 with recommendations to the Commission on corporate due diligence and corporate accountability (2020/2129(INL)).

8 CSRD Proposal for a directive of the European Parliament and the Council amending Directive 2013/34/EU, Directive 2004/109/EC, Directive 2006/43/EC and Regulation (EU) No 537/2014, as regards corporate sustainability reporting COM/2021/189 final (hereafter 'CSRD Proposal').

${ }^{9}$ https://www.unepfi.org/net-zero-alliance/

10 https://www.climateaction100.org/
} 
pressure) generally affect the embedding of sustainability in Dutch listed companies. We also reflect on the attitudes of company leadership towards these drivers.

When it comes to the second question, how are companies embedding sustainability, it is clear that that embedding sustainability is a dynamic process that goes through various organisational stages and phases (e.g., Maon et al. 2010; DSGC 2013). Moreover, we note that embedding practices can have many different appearances and can take place at different levels of the organisation: it can vary from ensuring sustainable production to abolishing the use of plastic cups in the office. Our focus on the roles of the management and supervisory boards leads us to concentrate on sustainability embedding practices which are directly relevant to company leadership. In this respect, we address three main areas of embedding:

1. Corporate purpose and strategy,

2. Leadership and governance,

3. Supply chains, sustainability reporting, employees and culture.

We first investigate corporate purpose since it is a company's own expression of its "ultimate aim, what it is trying to achieve for society" (Winter et al. 2020: 3). We examine it together with strategy since setting the strategy (and overseeing it) is the main task of the management board (and the supervisory board). Second, we look at the roles of leadership and governance ${ }^{11}$ in supporting the embedding process. Therefore, we examine the roles and task allocations of company leadership and sustainability managers, the embedding of sustainability in the competences of management and supervisory boards, sustainability-related remuneration of the management board, and the role of internal and external sustainability committees. Third, we study sustainability reporting and due diligence practices since these are important tools for embedding sustainability and for companies to communicate transparently with various stakeholders on their progress. We also examine top management's views on employees and culture considering their important influence on sustainability embedding.

Our research findings are based on a sample of 35 companies listed on the Amsterdam Stock Exchange and which are constituents of the AEX, AMX, and ASCX indices. We examine these companies using a combination of desk research and interviews with members of the top management team, ${ }^{12}$ supervisory board members and the management layers immediately below. We do not provide a longitudinal perspective on embedding practices but paint a picture of the state of the art in company sustainability embedding for 2020 . We subsequently use this picture to generate recommendations for areas of improvement by companies. This report does not, however, provide an evaluation of the individual or collective sustainability performance of Dutch listed companies.

We organise the research report as follows:

Part B outlines the research design, data, and limitations of this research project. In it, we explain the desk research and interview methodology, describe our company and interviewee sample in detail, and discuss the limitations of our design.

\footnotetext{
${ }^{11}$ With the term governance we refer to systems to set, oversee, and manage the sustainability agenda.

12 Defined as members of the management board and executive committee.
} 
Part C presents our findings in two subsections according to the two sub-questions mentioned above:

1. Why are companies embedding sustainability?

2. How are companies embedding sustainability?

Part D summarises our research findings and provides recommendations in relation to certain key areas of sustainability embedding. Our recommendations focus on the alignment of company strategies with planetary boundaries, the connection between purpose and strategy, the roles of leadership and governance in relation to sustainability embedding, and the quality of communication and interaction with stakeholders.

Part E provides a conclusion and several suggestions for future research and investigation by companies, investors, researchers, and other stakeholders. 


\section{B: Research design, data, and limitations}

The introduction explained that this report examines the sustainability embedding in Dutch listed companies. Its main purpose is to report on the roles of the management and supervisory boards given their prominence in many of the strategic decisions on sustainability. We are especially interested in the main motivations and drivers of companies in setting goals and targets for embedding sustainability, how companies integrate sustainability into their purpose and strategic objectives, and how companies organise sustainability-related governance as well as their stakeholder relations and supply chain management. This endeavour is captured in the following main research questions:

1. Why are companies embedding sustainability?

2. How are companies embedding sustainability?

We use a combined method, based on desk research and interviews, to answer these questions in an exploratory and descriptive manner using both quantitative and qualitative results (Neuman 2013). The quantitative aspect of our answer is derived from our empirical findings from the desk research and the interviews, while the qualitative aspect emerges from an analysis and interpretation of our findings in the context of the academic literature in several relevant disciplines. Summarising, our results provide a snapshot of sustainability embedding by Dutch listed companies as well as an inside look on the views and beliefs of these organisations' leadership regarding sustainability. We later use these results to make recommendations on this same topic.

The first section on research design explains the methodologies of our desk research and interviews in greater detail. The second section provides the key characteristics of the companies in our sample and the interviewee profiles. The third section outlines the limitations and potential biases that shape the scope of our scientific findings.

\section{Research design}

The introduction noted that the Dutch institutional investor platform, Eumedion, initiated and cofunded this research project. They provided input for our research design and facilitated the contacts with our company sample. However, they did not otherwise influence the research methods, findings, and analyses in this report. It is important to note that Eumedion and our research team from Maastricht University sent out a joint letter of invitation to all companies listed on the Amsterdam Euronext AEX, AMX and ASCX stock indices with a statutory seat in the Netherlands. This invitation asked them to participate in our research project, and 35 out of the 66 contacted companies ultimately accepted the invitation (a response rate of 53 percent). The desk research and interviews of this project, and thus the empirical findings and recommendations of this report, are both focused on this sub-set of Dutch listed companies.

We developed our desk research and interview questions using the following main sources:

- Eumedion's request for information on the roles of the management and supervisory boards in embedding sustainability in the governance and daily business of listed companies in the Netherlands 
- Legal developments such as the Sustainable Corporate Governance initiative, Taxonomy Regulation, and Sustainable Finance Disclosure Regulation

- Academic literature on various aspects of sustainability embedding

- Practitioner literature as published by international organisations and consultancies

- A scan of annual reports and company websites

- Discussions with fellow researchers on corporate sustainability and responsible business

The general topics of our report were selected from the range of practices and activities for sustainability embedding which are described within these sources. We based this selection on a topic's importance in practice, literature, and originality as well as by considering the quality and availability of interview and research data. We will, where necessary, explain our choices as we present our findings.

Our selection of desk research and interview topics was also guided by an expansive approach to sustainability. We believe, given the divergent opinions and practices on sustainability, in combination with the exploratory nature of our research, that a focus on a range of sustainability activities and indicators is better than a specific, debatable definition. We therefore used as a point of departure a broad understanding of the concept of sustainability and included, in this regard, the following dimensions related to the content and implementation process of sustainability:

\section{Table 1: Dimensions of sustainability}

\begin{tabular}{|rl|}
\hline & Dimension \\
\hline $\mathbf{1}$ & Environment (e.g. emissions, biodiversity, waste) \\
\hline $\mathbf{2}$ & Human rights \\
\hline $\mathbf{3}$ & Diversity and inclusion \\
\hline $\mathbf{4}$ & Employee engagement and well-being \\
\hline $\mathbf{5}$ & Responsible procurement and supply chain management \\
\hline $\mathbf{6}$ & Company culture \\
\hline $\mathbf{7}$ & Health and safety \\
\hline $\mathbf{8}$ & Socially responsible investment \\
\hline $\mathbf{9}$ & Sustainable products, packaging and innovation \\
\hline $\mathbf{1 0}$ & Sustainable mobility \\
\hline $\mathbf{1 1}$ & Governance arrangements for these topics \\
\hline $\mathbf{1 2}$ & Local community relations and stakeholder engagement on these topics \\
\hline $\mathbf{1 3}$ & Company reporting on these topics \\
\hline
\end{tabular}

We did not include privacy, digitisation, business, or personal integrity since these are more closely related to general company ethics and operational matters than to sustainability. We also excluded the COVID-19 pandemic from our definition of sustainability, for example when it was mentioned in risk management or employee well-being.

As a final note, we did not examine the current state of board (gender) diversity even though diversity and inclusion are part of our sustainability definition, and despite it being an important area of discussion for board room decision making and sustainability embedding (e.g., Choudhury 2015; Campbell and Mínguez-Vera 2008; Khatib et al., 2021). The reason is that there are several recent reports on the topic of board diversity which provide an overview of current practices in Dutch listed companies (e.g., the 2019 Socio-Economic Council (SER) Report on Diversity in the board room: Time 
to accelerate and the Bedrijvenmonitor Topvrouwen by the Commission on Women at the Top which monitors gender diversity on a yearly basis). However, we do examine reporting on the diversity of employees and other management layers in the section on employees and culture.

\subsection{Desk research methodology}

The desk research comprised a review of publicly available information to answer 76 questions on the sustainability embedding in our sample of 35 companies. These questions were clustered around nine topics:

Table 2: Desk research topics

\begin{tabular}{|ll|}
\multicolumn{2}{|l|}{ Topic } \\
\hline $\mathbf{1}$ & General items \\
\hline $\mathbf{2}$ & Management and supervisory boards \\
\hline $\mathbf{3}$ & Strategy, risk management and reporting \\
\hline $\mathbf{4}$ & Greenhouse gas (GHG) emissions, energy use \& generation, water use, waste \\
\hline $\mathbf{5}$ & Employees \\
\hline $\mathbf{6}$ & Supply chain \\
\hline $\mathbf{7}$ & Stakeholders \\
\hline $\mathbf{8}$ & Company commitments and signalling \\
\hline $\mathbf{9}$ & Shareholders \\
\hline
\end{tabular}

The full list of questions can be found in Appendix II. The findings can be accessed in accordance with the FAIR Guiding Principles for scientific data management and stewardship (for an explanation see Appendix IV). ${ }^{13}$

Answers to the desk research questions were based on publicly available information, in particular the 2020 annual reports and the latest information and documents from company websites (such as supervisory board skills profiles or remuneration policies). This information covered 2020 activities and is backward looking. ${ }^{14}$ We did not provide an extended historical analysis to review company performance over a longer period of time, that is, prior to the latest annual reports.

For some questions we limited the scope of our investigation to certain documents or parts of the annual report. For example, we focused on the risk management section of the annual reports for our identification of sustainability risks and only consulted remuneration policies for remunerationrelated questions. The scope of these limitations again is presented, where necessary, alongside our findings. For transparency, Appendix II also contains a table which indicates the source of information that was used when presenting our findings.

The desk research findings were collected by both student assistants and members of our research team. Most of them were double-checked by one other member of the research team to prevent and minimise errors and the scope of interpretation.

\footnotetext{
${ }^{13}$ Aartsen, Constantijn van; Bauer, Rob; Bauer, Tereza; Olaerts, Mieke, 2021, "Corporate Sustainability Research Project Elverding Chair", https://doi.org/10.34894/4UTK2C, DataverseNL.

${ }^{14}$ The desk research data collection period was concluded at the beginning of October 2021.
} 


\subsection{Interview methodology}

The interviews adopted a semi-structured approach and were targeted at companies' top management, supervisory board and the management layers immediately below. We determined that such high-level interviewees would be best positioned to answer strategic questions on sustainability embedding and the roles of the management and supervisory boards in this process. Moreover, we found that anonymous, semi-structured interviews would provide a better format than closed or open interviews; the former would limit the scope of the relevant information interviewees could share while the latter would undermine comparability between the different companies in our research sample. Anonymity was important to invite truthful answers and to protect the identity of our interviewees.

We interviewed multiple participants from each company to ensure a balanced perspective per company and to improve the robustness of our findings. We asked our company liaisons to plan interviews with the members of the management and supervisory boards given our focus on their roles in embedding sustainability. We also interviewed a range of other high-level managers, most often sustainability managers and investor relations officers. The exact profile of our interviewees is outlined in the research data section (see section 2 below).

Interviewees were provided with the following topics and subtopics in advance of their interviews, which were based on the selection process outlined earlier in our research design:

Table 3: Interview topics

\begin{tabular}{|c|c|}
\hline Topic areas & Sub-topics \\
\hline $\begin{array}{l}\text { 1. Current state of sustainability and } \\
\text { its embedding at the company }\end{array}$ & $\begin{array}{l}\text { - Key sustainability issues for the company } \\
\text { - Sustainability integration at the company }\end{array}$ \\
\hline 2. Role of company leadership & $\begin{array}{l}\text { - Sustainability governance structure, incl. board-and } \\
\text { executive-level functions and roles } \\
\text { - Discussions on sustainability with company leadership }\end{array}$ \\
\hline 3. Corporate strategy & $\begin{array}{l}\text { - Relevance of sustainability to corporate strategy } \\
\text { - Long-term value creation approaches } \\
\text { - Drivers and inputs for sustainability strategy } \\
\text { - Sustainability expertise within the company }\end{array}$ \\
\hline 4. Corporate culture & $\begin{array}{l}\text { - Management of corporate culture and sustainability } \\
\text { - Employee engagement }\end{array}$ \\
\hline $\begin{array}{l}\text { 5. Shareholder/ stakeholder } \\
\text { involvement }\end{array}$ & $\begin{array}{l}\text { - Shareholder sustainability engagement and dialogue } \\
\text { - Stakeholder involvement }\end{array}$ \\
\hline
\end{tabular}

The research team used these topic areas to develop a list of 38 interview questions (including warmup questions and sub-questions). These questions were not provided upfront to the interviewees, but they are now included in Appendix III.

The interview questions were designed to vary slightly depending on the profile of the interviewee. For example, there were more supervisory board-related questions for supervisory board members. 
To avoid missing important topics, we also ended each interview with a question on whether there was anything regarding sustainability embedding that the interviewee would like to add. ${ }^{15}$

Interviews were organised online by using Microsoft Teams, because the COVID-19 pandemic made it impossible to organise in-person interviews (the interviews took place between November 2020 and April 2021). This format may have eased the accessibility of senior-level interview participants and may have mitigated the potential power imbalance between some of the junior interviewers and the relatively high status ('elite') interviewees (Solarino \& Aguinis 2020). We should also note a time discrepancy between the desk research and the interviews; the first covers the 2020 activities of the companies, while the latter were mainly held in 2021.

Participants were also sent a privacy information sheet (to explain the video recordings, citations in the report, anonymity, etc.) and a participant consent form before the interview. We asked them to read and sign the consent forms in advance and we also reiterated the privacy conditions at the start of the interview and before we asked for their verbal consent on record. This process was approved by the university's Ethical Review Committee, and our data processing and storage approach ${ }^{16}$ underwent a positive GDPR assessment by our university Data Privacy Officers.

Please note that ethical constraints influence not only how we could use interview information in this report, but also the amount of interview data which we can make publicly available under the FAIR principles. Our data transcription and analysis approach, and the way it protects the privacy of our interviewees, are described in more detail in Appendix III. At this stage, it is enough to note that this report only contains quotes whose anonymous publication has received explicit permission from our interviewees. For some interviewee quotes we removed job titles, industry, or stock exchange index to ensure anonymity (also towards their colleagues). We also sent companies a draft version of the report (including quotes which already received interviewee approval) and asked if they had any privacy-related concerns about its contents; we did not receive any comments.

\section{Research data: companies and interviewees}

This section outlines the details of our company and interviewee data. As mentioned above, Eumedion and our team sent a joint invitation letter (Appendix I) to all companies with a statutory seat in the Netherlands ${ }^{17}$ which are listed on the Amsterdam Stock Exchange and which are constituents of the $A E X, A M X$, and $A S C X$ indices, asking them to participate in our research project. The following companies replied:

\footnotetext{
${ }^{15}$ We note that very few interviewees took this opportunity to add something new and no new sustainability embedding topics were mentioned.

16 These comprised the use of online video calls, data recording programs, interview transcriptions that used a secure external party, secure data storage on the university network, and privacy information for participants.

${ }^{17}$ Please note that at the beginning of the study this still applied to Unilever. As of November 2020 the company no longer has its statutory seat in the Netherlands.
} 

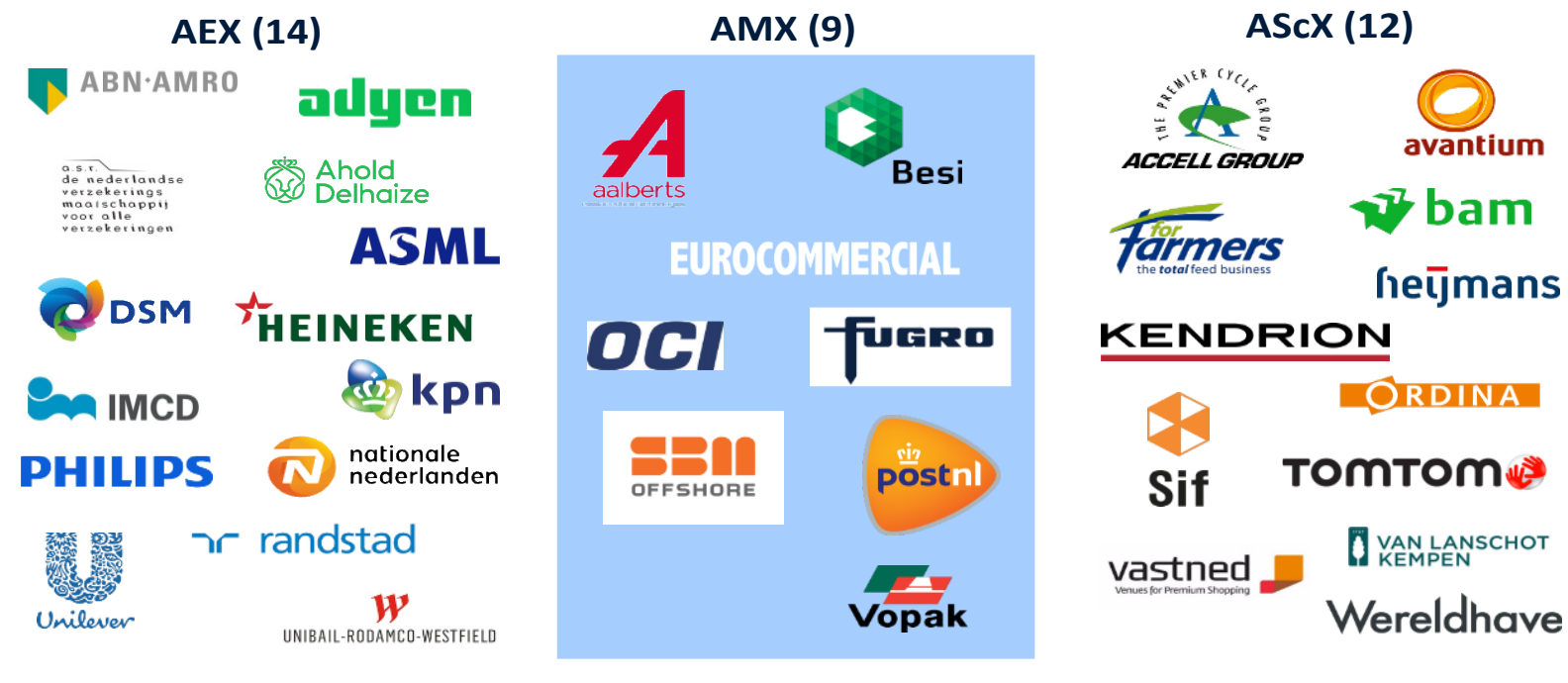

The fact that companies were allowed to self-select their participation in this project introduced a potential bias into our sample. It is possible, for example, that the most sustainable companies in the AEX, AMX, and ASCX indices could have decided to participate while less sustainable companies did not. We checked, using S-Ray data from Arabesque on environmental, social, and governance (ESG) metrics, whether there was a pro-sustainability selection bias in our sample of companies. ${ }^{18}$ We found no such bias using this data, although we must be careful with any statistical inferences as the sample is very small. Nonetheless, we found no clear indication that companies with well-developed sustainability embedding practices are over-represented in our sample.

Our sample of 35 companies was diverse in terms of size and industry. It consisted of 14 companies from the AEX index (40 percent), nine companies from the AMX index (26 percent), and 12 companies from the AScX index (34 percent). Twenty companies could be described as typical industrial companies ( 57 percent). Ten companies were mainly active in the services sector (29 percent), while five companies were active in the real estate sector (14 percent). We sometimes provide additional analysis based on size and sector when this provides further insight into our findings.

Figure 2: Company industry type

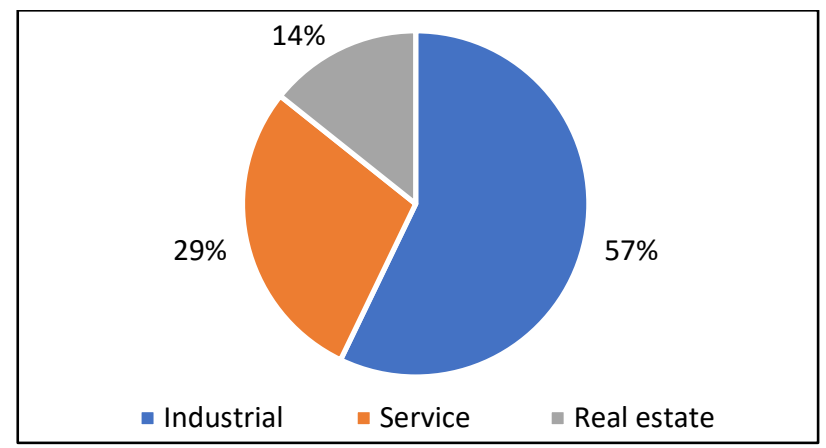

For the interviews, our data were based on 88 interviews conducted with 97 interviewees. Most interviews were held with one interviewee and two interviewers from the research team. The exceptions were eight instances when multiple participants were interviewed at the same time, less

${ }^{18} \mathrm{https} / / / \mathrm{www}$. arabesque.com/s-rav/ 
than five cases where a non-interviewee observer was present by company request, and eight interviews where there was only one interviewer present. The interviews were conducted in English and lasted between 28 and 115 minutes, with an average length of 85 minutes.

In our introductory letter to the 35 participating companies, we expressed our intention to interview:

- one management board member

- one supervisory board member

- one sustainability manager and / or investor relations officer per company.

However, the ultimate selection of interviewees was made by the companies themselves. This selfselection resulted in a different number of interviewees per company as well as interviewees from a range of different roles. Our impression is that the companies provided interviewees who were internally perceived as best positioned to share insights on sustainability embedding. Each company provided between one and five interviewees, with 18 companies providing three participants, nine companies with two participants, four companies with four, three companies with one, and one company with five participants.

Figure 3 shows the job profiles of our interviewee sample: 30 interviewees were from the top management team (defined as members of the management board and executive committee), including 14 CEOs and five CFOs. Nineteen were supervisory board members, 31 were sustainability managers (dedicated or in combination with other responsibilities) ${ }^{19}$, and 10 were investor relations professionals. The rest ('Other') were company representatives in various roles such as general counsel, company secretary, finance, or communication officers.

Figure 3: Interviewees by role

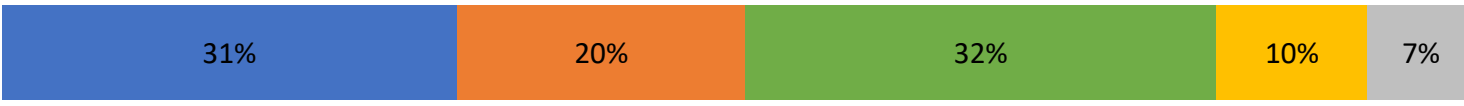

- Top management team $\quad$ Supervisory board $\quad$ Sustainability manager $\square$ Investor relations $\quad$ Other

In our sample, 33 companies had a two-tiered board and only two had a one-tier board with both executive and non-executive directors. We will therefore simplify our terminology and henceforth equate non-executive directors with supervisory board members, and executive directors with the management board throughout this report.

In terms of distributions of sex and age, 34 percent of participants were female, which was based on the perceptions of the researchers (we did not ask about sex or sexual identification). The distribution varied by interviewee role, with the closest to equal being the sustainability manager roles (45 percent female), while among top management team members only 20 percent of interviewees were female. Of the interviewed CEOs, only one was female. Among the 19 supervisory board members that we interviewed, five were female. The average interviewee age was 52 years old with an average age of

19 We use the term sustainability manager to safeguard interviewee anonymity in light of the broad range of job titles for this function (e.g., VP sustainability, Director Sustainable Development, CSR Manager, Head of Corporate Citizenship, etc.). 
53 for top management, 62 for supervisory board members, 46 for sustainability managers, and 49 for investor relations officers.

Most interviewees were native Dutch speakers with a smaller proportion from non-Dutch speaking countries. Regarding ethnicity, the overwhelming majority of interviewees were white and of European origin (as perceived by the researchers).

The average company tenure of an interviewee (excluding supervisory board members) was 12 years, indicating a sample with substantial experience and knowledge of the company. Supervisory board members had a lower average tenure, five years, due to tenure restrictions for their role. Average tenure for other interviewees in their current role was also five years, with a slightly lower average tenure for sustainability managers (three years) and a higher average tenure for top management team members (six years). The highest average tenure was found among CEO interviewees who had 17 years in the company and seven years in their role.

\section{Limitations}

All research suffers from shortcomings and biases, and our report is no different in this regard. We have, where possible, tried to compensate but nevertheless need to identify a number of limitations and biases that come with our context and approach. The first is that the data were collected at one point in time and only provide a single, limited picture of sustainability embedding in Dutch listed companies. It does not, for example, track the development of embedding over time which limits the reasonable scope of interpretation of our findings.

A second limitation is that the research was performed by researchers in company law and sustainable finance. There are, of course, limits in the scope and scientific approach of these disciplines which influence the design and content of the final report. We have no doubt our work could have benefitted from collaboration with other specialists, for example from management science, organisational sociology, climate science, or social psychology. This shortcoming is compounded by potential researcher bias regarding sustainability beliefs and having prior expectations based on knowledge of the academic and practitioner literature on sustainability.

A third limitation relates to potential selection bias in two dimensions. First, companies accepting the invitation to be interviewed might be more inclined to increase the sustainability embedding process in the future. We already mentioned that the sustainability performance (using Arabesque data) of our sample did not differ significantly from the companies who chose not to participate in our project. A second potential bias might arise from the selection of interviewees. The interviewees and the associated roles were selected by companies. This might (or might not) result in a biased interviewee sample that has a more positive stance towards sustainability embedding as well as a greater willingness to share their knowledge and experience with the research team. This bias could affect the generalisability of our results.

A related fourth issue is that the interviewee sample consists of members of the supervisory board, top management team and management layers immediately below. In this regard, our sample does not represent an average cross-sectional view of company employees on sustainability. We estimate that these interviewees are, unlike other employees, more likely to support than criticise the sustainability policies and practices which they have helped to design and implement. 
A fifth issue relates to the elite status of many of our interviewees. As a result of their experience, status, and roles, these company representatives were often skilled communicators who are used to giving interviews, and who are therefore better able to present socially desirable and potentially biased or even misleading answers (Solarino and Aguinis 2020). This is a well-known challenge for research into the upper echelons of organisations which we tried to partly mitigate by interviewing several participants per company and so improving the reliability of our insights.

In the sixth place, our research did not review sustainability performances of individual companies but rather provides an overview of general sustainability embedding practices. This generality limits the applicability of our findings for particular companies.

Finally, the scope of this research project only comprises companies that are publicly listed and incorporated in the Netherlands. However, the topic of sustainability embedding is also relevant for non-listed companies, privately owned companies, and companies in different geographical regions. Studying these contexts would complement the findings of this research project. 


\section{C: Research findings and analysis}

This section brings together the desk research and interview findings on sustainability embedding in our sample of Dutch listed companies. We discuss the findings together with background literature from academic, practitioner, and institutional sources to explain their significance and provide context for the analysis later in the report. The section is divided into two main parts:

1. Why are companies embedding sustainability?

2. How are companies embedding sustainability?

In the first part, we discuss the structural and stakeholder drivers of sustainability to explore why companies embed sustainability. We conclude with a discussion of the attitudes of our company sample towards these drivers. In the second part, we examine company purposes and strategies, the governance of sustainability embedding, supply chain management, sustainability reporting and employee involvement in sustainability.

Our interview findings are reported on an aggregated and anonymised basis per company, or as an anonymous quote from an individual interviewee. The aggregated findings are based on descriptions of practices by interviewees in response to questions which were mostly open-ended and did not list all potential answers. This does not imply that companies whose interviewees did not mention a certain practice are not engaging in that practice. Furthermore, the differing numbers and positions of interviewees per company resulted in varying levels of scope and depth in the interview answers on certain topics. For this reason, the results do not always include all companies, especially if information from some companies was absent or not provided in a clear enough manner to be categorised.

\section{Why are companies embedding sustainability?}

Corporate sustainability is essential for the global transition to a fair and sustainable economy. Therefore, an understanding of some of the main drivers which push companies to engage in sustainability and what their attitudes are towards these drivers is important.

\subsection{Structural drivers}

At a fundamental level, structural drivers shape the context and content of a company's decisions on sustainability embedding. They do not stand in complete isolation from other drivers, but their overarching scale and influence on the substance of sustainability activities sets them apart from the day-to-day influences of company stakeholders.

\subsubsection{Environmental drivers}

A scientific consensus has emerged over the course of the second half of the twentieth century and the first two decades of the twenty-first century that human societies and economies have had a profoundly negative impact on the stability of the global climatic, geological and ecosystem processes (European Environmental Agency (EEA) 2020; UNEP 2021; Meadows et al. 1972). Earth systems scientists have mapped out these environmental impacts and have examined whether, when, and how the aggregate effect of human activities creates a risk for the continued stability of key planetary systems (e.g., the nitrogen cycle and water cycle). These developments were condensed and 
summarized by Rockström et al. (2009a, 2009b) into the concept of planetary boundaries, and updated by Steffen et al. in 2015.

\section{Planetary boundaries}

The concept of planetary boundaries has become a key component of environmental discourse and has increasingly become central to national and international (including European) environmental policies and research (EEA 2020; UNEP 2019). According to our best scientific understanding, this concept demonstrates what outcomes are required to ensure that human societies and economies remain within the safe operating boundaries of nine essential planetary systems.

The significance of the concept of planetary boundaries lies in how it presents, in vivid form, the need to change our societies and economies to minimise the problematic, global environmental impact effect of human activities. The figure below shows how it singles out four key areas which are most urgent due to their high level of risk: climate change, land-system change, biosphere integrity, and biochemical flows.

Figure 4: Map of planetary boundaries ${ }^{20}$

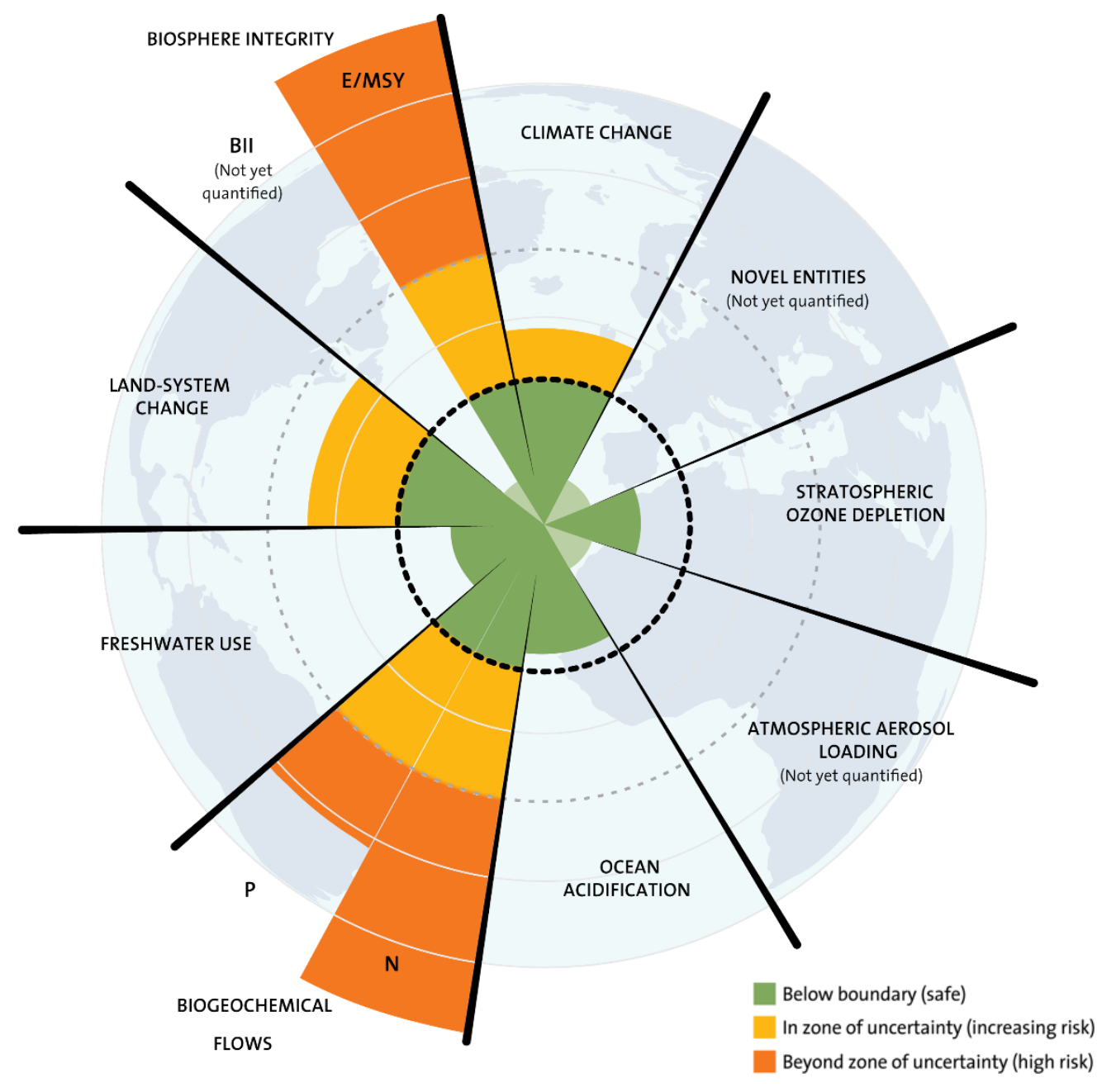

$20 \mathrm{~J}$. Lokrantz/Azote based on Steffen et al. 2015. https://www.stockholmresilience.org/research/planetary-boundaries.html 
The significant, and potentially devastating, effect of these areas on our societies is driving social change and pushing sustainability high onto the agenda. It is, in this regard, unsurprising that the 2021 IPCC report notes that: "Global warming of $1.5^{\circ} \mathrm{C}$ and $2^{\circ} \mathrm{C}$ will be exceeded during the 21st century unless deep reductions in carbon dioxide (CO2) and other greenhouse gas emissions occur in the coming decades" (IPCC 2021).

Of comparable, perhaps even greater, concern is the combined effect of phosphorus and nitrogen emissions, unsustainable land use patterns (e.g., deforestation for farming, subsequent erosion, etc.), and ecosystem degradation on both the degree and scale of biodiversity. As expressed by the UN Secretary-General António Guterres in the 2021 report on Making Peace with Nature: "Humanity is waging war on nature. This is senseless and suicidal. The consequences of our recklessness are already apparent in human suffering, towering economic losses and the accelerating erosion of life on Earth" (UNEP 2021: 4). The Global Resource Outlook identified in 2019 that "90 percent of biodiversity loss and water stress are caused by resource extraction and processing. These same activities contribute to about half of global greenhouse gas emissions" (UNEP 2019: 4). Compounding these environmental impacts is an increasing risk of resource shortages as the growth and requirements of the global economy outpace the availability of our renewable and non-renewable resources.

Given these circumstances, there is little doubt that the transgression of planetary boundaries, and our responses to it, will have a profound impact on our societies and economies, including company activities. Therefore, for the purposes of this report, we have condensed the risk zones of planetary boundaries into two environmental focus areas: climate change and emissions, and biodiversity. We have also added a third area, circularity, since it is central to the shift towards an economic system that operates within the safe limits of planetary boundaries (see, e.g., Korhonen et al. 2018). Moreover, the transition to a circular economy is also a matter of Dutch ${ }^{21}$ and EU policy that will have a great effect on long-term corporate activities.

To start, we identify that only one company in our sample referred to the concept planetary boundaries during the interviews and that this company was also the only one to make a stated commitment in its annual report to remain within planetary boundaries. When asked how a company could tell if it was exceeding planetary boundaries or not, one interviewee from the company replied that:

"[If you] emit greenhouse gas into the atmosphere more than what your products take out of the atmosphere, you already exceed planetary boundaries. [...] If you source raw materials which lead to further expansion of agricultural areas, which means deforestation and loss of species, you certainly exceed planetary boundaries. [...] Circularity is also an aspect, because if you create waste, and you create products which have no other choice but ending up as waste, you exceed planetary boundaries. So are we a company that stays completely in planetary boundaries? [...] The key point is to have a full understanding through the life cycle assessment of your products on all aspects. Only then you will have an understanding if you exceed planetary boundaries or not." [AEX industrial company]

\footnotetext{
${ }^{21} \mathrm{https} / /$ www.government.nl/binaries/government/documents/policy-notes/2016/09/14/a-circular-economy-in-thenetherlands-by-2050/17037+Circulaire+Economie EN.PDF
} 


\section{Company commitments to climate change and emissions}

If we zoom in on climate change and emissions as a driver of company sustainability embedding, then it is interesting to consider the commitments of the companies in our sample with regards to $\mathrm{CO}_{2}$ neutrality. Our research (based on companies' own claims) reveals considerable variation in this regard; six companies are already neutral ${ }^{22}$ and 11 companies have no commitment to carbon neutrality. ${ }^{23}$ A comparison of AEX, AMX, and AScX companies shows that market size does not influence the likelihood of whether companies are committed to $\mathrm{CO}_{2}$ neutrality. These findings are presented in the following figure alongside information on company commitments to be carbon neutral by 2030, 2040, and 2050 respectively:

Figure 5: Company commitments to carbon neutrality

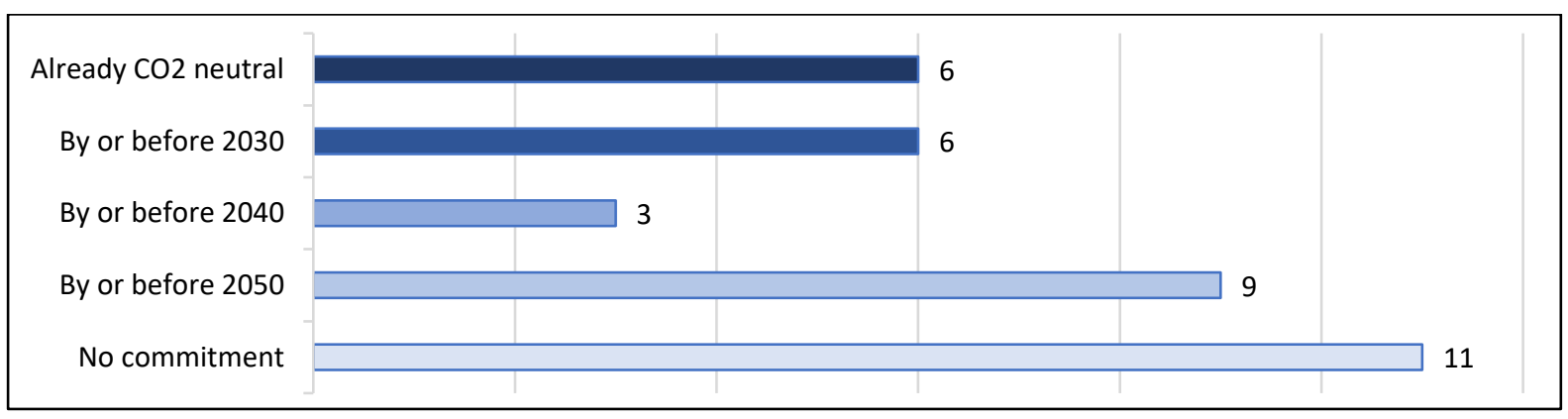

Further analysis by sector indicated that industrial companies are twice as likely as other companies to have no commitment to $\mathrm{CO}_{2}$ neutrality (40 percent of industrial companies, compared to 20 percent for both the service and real estate sectors) and are the least likely to be carbon neutral (only one company). Overall, service companies are the most likely to be carbon neutral (40 percent of the sector). We suspect that these different results are explained primarily by the different business activities, and therefore emissions profiles, of the various sectors.

\section{Company commitments to biodiversity}

Biodiversity is not susceptible to an outcome-based commitment such as $\mathrm{CO}_{2}$ neutrality. Moreover, there is a lack of standardised reporting and comparable company activities in this area (Lambooy et al. 2018). We therefore examined how prominently biodiversity featured in company annual reports and how often company representatives mentioned it during the interviews.

Our main desk research findings are that 40 percent of companies do not mention biodiversity anywhere in their annual report and presumably do not engage in biodiversity at a formal or strategic level. More than half of the companies do recognise that biodiversity is important, i.e., it is an area that the company could negatively affect, that might create a risk for the company, or is a material issue for one of its stakeholders. Only one-quarter of the companies have some kind of organisational policy or project in place for biodiversity. The low threshold for the latter category means that comprehensive company programmes for biodiversity are rare, at least as far we could tell from public reporting. These findings are summarised in the following figure:

\footnotetext{
22 Two of these companies state that they are carbon neutral with regards to scope 1, 2, and 3 emissions; both are service companies. Four are neutral for scope 1 and 2 only (two service, one industrial, and one real estate companies).

${ }^{23}$ However, these companies may have committed to lower levels of carbon emissions, e.g., in accordance with the Paris Agreement 2016.
} 
Figure 6: Company engagement with biodiversity

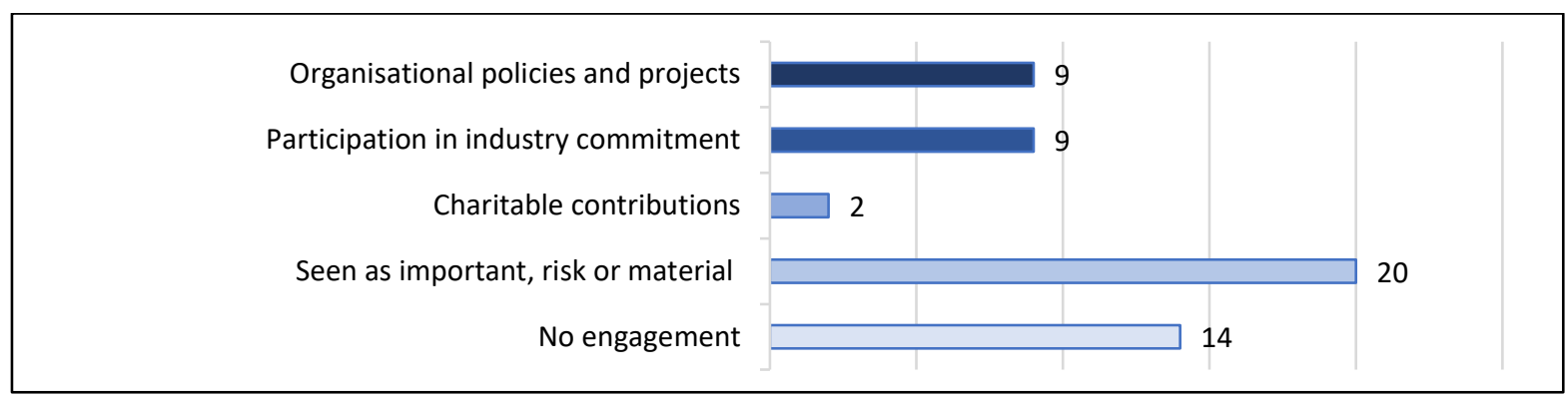

Analysis of our sample based on size shows that AMX and ASCX companies are less likely to engage in biodiversity (44 percent of and 50 percent have no engagement) relative to AEX companies (29 percent). Furthermore, large companies are much more likely to have organisational policies and projects regarding this topic (AEX 43 percent, AMX 11 percent, and ASCX 17 percent). Sector analysis did not show any significant difference on this topic.

In the interviews, 10 companies discussed biodiversity:
"A topic like biodiversity, yeah, we cannot totally stay away from that. We struggle, frankly spoken, a bit with what our position there, how much change can we make, what are our commitments. It is very common that industries commit to deforestation free supply chains. We're moving in this direction, but we are not the key player in this field, although we source more and more bio raw materials, so in this regard it is relevant." [Sustainability manager, AEX industrial company]
"I think biodiversity is becoming more and more important, and what you can do as a company is of course limited. So it needs to be a joint effort and a joint effort can be stimulated by the government in the end, I think. I think they play a crucial role there." [Investor relations, AEX service company]
"This greenhouse warming is a huge issue, besides that I do think another, maybe even bigger issue, is the current speed of decline of biodiversity" [Management board member, AMX industrial company]
"Greenhouse gas is there already for a longer time, but biodiversity it is a real upcoming, for us it's a real upcoming theme. That's the biggest one" [Supervisory board member, AScX industrial company]

Interviewee accounts emphasised the increasing importance of this topic and indicated that they struggle to identify what, exactly, they and their companies could and should do. Research by Lambooy et al. indicates that for biodiversity, "tangible strategies for successfully tackling [biodiversity and natural capital] issues are absent" due to the general absence of a clear link between biodiversity approaches and company risks and opportunities (2018: 1). This absence might explain, at least in part, the limited level of company activity on this topic.

\section{Company commitments to circularity}

For the third environmental focus area, we identified that company engagement with circularity is less prevalent than for climate change and emissions and is more on par with biodiversity engagement. 
For example, there are no circular companies among our sample of Dutch listed companies, and only 5 out of 35 of them state in their annual reports that they are committed to becoming fully circular. ${ }^{24}$

Aside from such a commitment, we found 18 companies that are to varying degrees involved in some circularity projects or practices, while 12 companies do not mention circularity anywhere in their annual reports. These results are summarised in Figure 7 below:

Figure 7: Company commitments on circularity

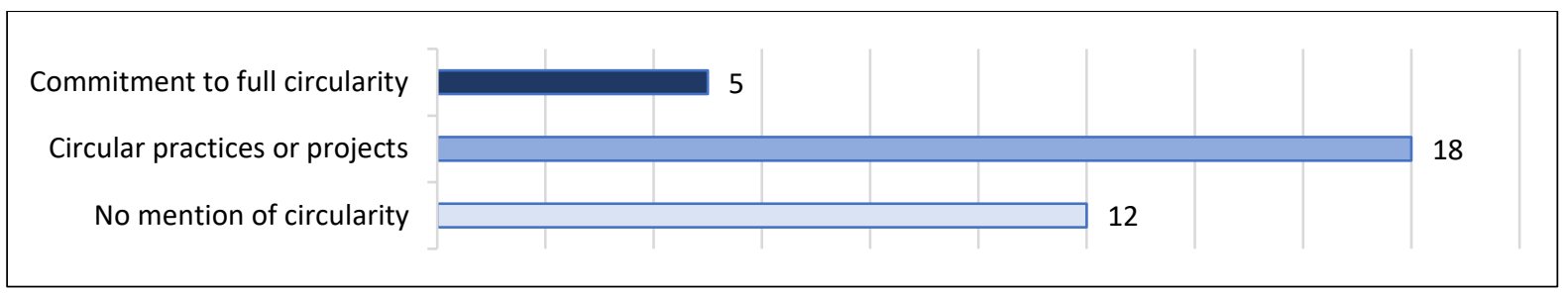

Analysis by size and sector shows that large and medium companies are more likely to be engaged with circularity (AEX 71 percent, AMX 67 percent, and AScX 58 percent) and that only industrial companies have made a commitment to full circularity.

In the interviews, circularity was mentioned by participants from 18 companies. They primarily emphasised the importance of looking at the whole value chain and the difficulties associated with going circular:

"We're trying to move to a circular economy. Right away from the sourcing through to the manufacturing, through to the marketing of the product, through to the advertising and of course the physical products itself, we are encouraging a circular approach. My team has different touch points right the way across that value chain." [Sustainability manager, AEX industrial company]

"The whole market is waiting for a good way to measure circularity. So there are a lot of people who are claiming to have a way of measuring circularity, but you go in depth on that matter and there will always be missing pieces, or it's only applicable to a part of the products that we provide. So there is a gap that we still have to close." [Sustainability manager, AScX industrial company]

"So how do we change something like the $[\mathrm{X}]$ industry, or materials and packaging, and truly make it circular? It has to have new technologies, but it actually has to have a whole value chain, and the whole supply chain think differently about what we do today. And I would love to be able to really figure out that change. Because it is a business model that does not exist today." [Management board member, AScX industrial company]

The overall conclusion of our findings for the three focus areas is that the environmental drivers derived from the concept of planetary boundaries are having a significant, although uneven, effect on companies' commitments and practices.

${ }^{24}$ We did not evaluate the soundness of the approach to circularity that is adopted by these companies. 


\subsubsection{Social drivers}

There are numerous social issues which also drive corporate engagement in sustainability. These include, but are not limited to, labour exploitation, unsafe working conditions, tax evasion, wealth inequality, racism, gender bias, and discrimination (e.g., UN SDGs). We did not examine each of these issues in detail, but we note that they all have a long history and that their existence is both structural and persistent. This imposes a limit on the extent to which individual companies can provide a longterm solution. Nevertheless, it is widely recognised that companies have a moral, if not legal, responsibility for direct and indirect harms that occur within the scope of their operations and international supply chains (e.g., Ruggie 2008). This moral-legal boundary has recently been subject to a great deal of government activity.

For example, in the area of human rights, the UN Guiding Principles for Business and Human Rights (UNGPs) are currently undergoing a 10-year review (UN Working Group on Business and Human Rights 2021). There is also an ongoing initiative to develop a potentially binding treaty for business and human rights (for an overview see Business \& Human Rights Resource Centre 2021). As for taxation and wealth inequality, the years after the Panama Papers and FinCEN leaks have witnessed a flurry of legislative activity, such as the G20 agreement for a minimum corporate tax rate (G20 Ministers and Central Bank Governors Meeting 2021). ${ }^{25}$

These developments, in combination with pressure from market drivers such as those mentioned in the following subsection, are having a noticeable effect on company commitments regarding social issues. Our desk research shows, for example, that all companies except one have a diversity and inclusion policy for their employees. Overall, 91 percent have an explicit commitment to respect human rights in accordance with the UNGPs, and 71 percent have a supplier code of ethics. Further, 88 percent of companies have made a commitment to avoid using tax havens, and just over one-third are committed to paying their employees a living wage. These findings are summarised below:

Table 4: Some company commitments on social issues

\begin{tabular}{|l|c|c|}
\hline & \# of companies & $\%$ of companies \\
\hline Commitment to respect human rights & 32 & $91 \%$ \\
\hline Employee diversity \& inclusion policy & 34 & $97 \%$ \\
\hline Fair tax policy & 31 & $88 \%$ \\
\hline Supplier code of ethics & 25 & $71 \%$ \\
\hline Living wage commitment & 12 & $35 \%$ \\
\hline
\end{tabular}

We find that except for living wage commitments, our sample of Dutch listed companies has made at least a preliminary response to a wide range of social issues that are prevalent in our societies.

In summary, we find that social drivers are also pushing companies to commit to various policies on issues of social concern. Human rights and diversity are prominent parts of these activities, while the payment of a living wage is less common. This difference shows an uneven response to social as well as environmental drivers.

${ }^{25}$ https://www.g20.org/wp-content/uploads/2021/07/Communique-Third-G20-FMCBG-meeting-9-10-July-2021.pdf 


\subsubsection{Legal drivers}

Company sustainability embedding is driven by a variety of legal drivers. It is influenced not only by international, European, and national legal developments, but also by (sometimes sector specific) legislation and litigation within approaches that are characterised by hard law, soft law, and selfregulation. These laws enable and constrain the scope of corporate activities (Mayer 2018) through a combination of standards with sanctions, the (re-)structuring of rights and obligations, or the implementation of market-based approaches (Van Aartsen 2020).

As sustainability concerns many topics and there is a lot of sector specific legislation and regulation, it is not possible to make an inventory here of all rules and regulations that touch on sustainability. However, there are several upcoming legislative developments which touch on sustainability in a broad sense. The most important in terms of their anticipated effects on our sample of Dutch listed companies are the following:

- $\quad$ EU European Green Deal, ${ }^{26}$ the Taxonomy Regulation ${ }^{27}$ and EU Sustainable Finance Disclosure Regulation ${ }^{28}$

- EU Sustainable Corporate Governance initiative, ${ }^{29}$ including the Ernst \& Young study commissioned by the European Commission on Directors' Duties

- Proposal for a Directive on Corporate Sustainability Reporting (CSRD) $)^{30}$ and the Directive on disclosure of non-financial and diversity information (the 'Non-Financial Reporting Directive' $(\text { NFRD) })^{31}$

- Climate litigation such as the Shell case in the Netherlands ${ }^{32}$

- Negotiations for a binding international treaty for business and human rights

- EU plans for mandatory due diligence in the area of human rights, environmental reporting and corruption ${ }^{33}$

- Legislative proposal in the Netherlands on responsible and sustainable international entrepreneurship (Wetsvoorstel verantwoord en duurzaam internationaal ondernemen) ${ }^{34}$

- Dutch national covenants among the government, banks, pension funds, insurance companies, NGOs and trade unions on responsible business and investment ${ }^{35}$

For the companies within the scope of our research, these developments operate in conjunction with the broader set of applicable environmental, labour, competition, human rights, commercial,

\footnotetext{
${ }^{26}$ European Green Deal 'Communication from the Commission to the European Parliament, the European Council, the Council, the European Central Bank, the European Economic and Social Committee and the Committee of the Regions The European Green Deal.' COM/2019/640 final.

27 Regulation (EU) 2020/852 of the European Parliament and of the Council of 18 June 2020 on the establishment of a framework to facilitate sustainable investment, and amending Regulation (EU) 2019/2088.

${ }^{28}$ Regulation (EU) 2019/2088 of the European Parliament and of the Council of 27 November 2019 on sustainability-related disclosures in the financial services sector.

${ }^{29} \mathrm{https}$ ://ec.europa.eu/info/law/better-regulation/have-your-say/initiatives/12548-Sustainable-corporate-governance en

30 CSRD Proposal.

${ }^{31}$ Directive 2014/95/EU of the European Parliament and of the Council of 22 October 2014 amending Directive 2013/34/EU as regards disclosure of non-financial and diversity information by certain large undertakings and groups.

32 The Hague District Court 26 May 2021, ECLI:NL:RBDHA:2021:5339 (Shell).

${ }^{33}$ European Parliament resolution of 10 March 2021 with recommendations to the Commission on corporate due diligence and corporate accountability (2020/2129(INL)).

${ }^{34}$ Kamerstukken I/ 2020/2021 35761.

${ }^{35}$ https://www.imvoconvenanten.nl/en/pension-funds; https://www.imvoconvenanten.nl/en/insurance; https://www.imvoconvenanten.nl/en/banking.
} 
intellectual property, and other laws at the national, EU, and international levels. However, examining all the legal developments in detail is beyond the scope of this report. We refer the reader to our references and limit our review to an indication of some important current and expected impacts on company sustainability embedding.

The European Commission presented the European Green Deal in December 2019. The deal contains a new growth strategy for the EU with "a modern resource-efficient and competitive economy" and an overall aim to be climate neutral in 2050 (European Green Deal: 2). Moreover, it includes an ambition towards circularity insofar as it tries to decouple economic growth from resource use.

Especially important for companies is that the Commission coupled the European Green Deal with the EU Taxonomy Regulation. This Regulation entered into force in July 2020 and is, in the words of the European Commission:

"[A] classification system, establishing a list of environmentally sustainable economic activities. It could play an important role helping the EU scale up sustainable investment and implement the European Green Deal. The EU Taxonomy would provide companies, investors and policymakers with appropriate definitions for which economic activities can be considered environmentally sustainable. In this way, it should create security for investors, protect private investors from greenwashing, help companies to become more climate-friendly, mitigate market fragmentation and help shift investments where they are most needed." ${ }^{36}$

This classification system creates a greater level of certainty on the (un)sustainability of economic activities and thus provides a framework for companies and investors to profile and evaluate their sustainability activities. The commission expects the Taxonomy to generate a significant increase in sustainability-related dialogue between companies and investors and to promote the quality of information that is available for market actors to make decisions regarding sustainability.

It is likely that the EU Taxonomy will soon be complemented by a new Corporate Sustainability Reporting Directive (CSRD). The European Commission has adopted the proposal for such a directive, and it is anticipated that it will extend the current NFRD with various changes, such as a broader scope of application, the mandatory audit of reported information, more detailed reporting standards, and the digital tagging of reported information so that it is machine readable. ${ }^{37}$ The new reporting standards are currently being developed (in several phases) by the European Financial Reporting Advisory Group (EFRAG), and it is expected that their first set of standards will be adopted by October $2022 .{ }^{38}$

Another key legal development relates to the likely arrival of additional mandatory legislation for corporate due diligence in the areas of human rights, environment, and corruption. Such legislation already exists at the EU level for specific sectors (such as the Conflict Minerals Regulation, the Timber

\footnotetext{
${ }^{36} \mathrm{https}$ ://ec.europa.eu/info/business-economy-euro/banking-and-finance/sustainable-finance/eu-taxonomy-sustainableactivities en

37 CSRD Proposal.

${ }^{38} \mathrm{https}$ ://ec.europa.eu/info/business-economy-euro/company-reporting-and-auditing/company-reporting/corporatesustainability-reporting en
} 
Regulation, the Forest Law Enforcement, Governance and Trade Regulation (FLEGT), and the AntiTorture Regulation) and there are signs at both national and European levels that it will be expanded. ${ }^{39}$

Due diligence is a risk management process "through which enterprises identify, prevent, mitigate and account for how they address their actual and potential adverse impacts" 40 in various parts of their activities. Its application to a sustainability-related topic was pioneered for human rights by the UN Guiding Principles on Business and Human Rights (UNGPs). This document's subsequent integration into the OECD Guidelines for Multinational Enterprises has introduced a broadly supported, international soft law expectation that companies engage in human rights due diligence, and a weaker due diligence requirement for other areas of corporate activity such as employment and industrial relations, environment, bribery, and consumer interests.

Developments in this area have inspired a range of EU laws and mandatory, national initiatives such as the French Devoir de vigilance, ${ }^{41}$ the Dutch Wet Zorgplicht Kinderarbeid, ${ }^{42}$ and the legislative proposal on Responsible and sustainable international entrepreneurship which aims to introduce broader human rights and environmental due diligence requirements. ${ }^{43}$ Also noteworthy, in this regard, is the recent proposal by the European Parliament for a directive on corporate due diligence and corporate accountability which includes due diligence requirements on human rights, the environment, and good governance for companies that fall under the scope of the proposal. ${ }^{44}$

Climate change-related litigation has also been driving companies to embed sustainability. A recent landmark case in this respect is the judgement in the Netherlands in relation to Royal Dutch Shell (RDS). ${ }^{45}$ In this case the District Court of The Hague ordered RDS to reduce the CO2 emissions of its entire group by net 45 percent by 2030 . This was based on an:

"[U]nwritten standard of care [and] on the basis of the relevant facts and circumstances, the best available science on dangerous climate change and how to manage it, and the widespread international consensus that human rights offer protection against the impacts of dangerous climate change and that companies must respect human rights." ${ }^{46}$

According to the court:

"The reduction obligation is an obligation of result for the activities of the Shell group, with respect to which RDS may be expected to ensure that the $\mathrm{CO} 2$ emissions of the Shell group are reduced to this level. This is a significant best-efforts obligation with respect to the business relations of the Shell group, including the end-users, in which context RDS may be expected to take the necessary steps to remove or prevent the serious risks

\footnotetext{
${ }^{39}$ Corporate due diligence and corporate accountability European Parliament resolution of 10 March 2021 with recommendations to the Commission on corporate due diligence and corporate accountability (2020/2129(INL)) under Z.

40 https://ec.europa.eu/growth/sectors/raw-materials/due-diligence-ready/explained en

41 Law n² 2017-399 of 27 March 2017.

42 Staatsblad 2019, 401.

43 'Wetsvoorstel verantwoord en duurzaam internationaal ondernemen' Kamerstukken I/ 2020/2021 35761, nr. 2.

${ }^{44}$ Recital 2 of the proposed directive. Corporate due diligence and corporate accountability European Parliament resolution of 10 March 2021 with recommendations to the Commission on corporate due diligence and corporate accountability (2020/2129(INL).

45 The Hague District Court 26 May 2021, ECLI:NL:RBDHA:2021:5339.

464.1 .3 of the case.
} 
ensuing from the $\mathrm{CO} 2$ emissions generated by the business relations, and to use its influence to limit any lasting consequences as much as possible." ${ }^{17}$

It is clear that legal decisions of this kind, which extend human rights protections to the safeguarding of planetary boundaries, can have significant and wide-ranging impacts on company sustainability embedding. Moreover, consider that there are currently 50 climate change cases pending against corporations, and over 400 against public entities, outside of the United States. ${ }^{48}$ It is likely that we have seen only the beginning of this line of case law, and we are still trying to understand the full implications of its effects (Heffron 2021).

It is difficult to measure the precise influence of these legal drivers, especially since sustainabilityrelated laws are changing quickly and many of the abovementioned developments are still pending. However, our interviewees confirmed that they do have an influence on the embedding activities of their companies:

"There's new regulation coming from the EU constantly. Which is good - the taxonomy, all those regulations will really help us move to a more sustainable future. But that's also another challenge. Because the amount and complexity of regulation coming to us, is immense." [Sustainability manager, AEX service company]

"If you see what's happening within the European Green Deal, we follow that closely, being a company with a strong foothold in Europe. If you see the legislation on single-use plastic, that has an impact on packaging materials we use and measures we have to take and user responsiblity schemes. [...] That is a huge driver." [Sustainability manager, AEX industrial company]

"Regulators are very important on this. [...] they will really make money move. That would be the next big step for the financial sector in Europe. Once regulators really model climate risk into their models and into their Solvency regulations. That having investments in fossil fuel will lead to higher solvency claims than if you have it in solar or in different ways of energy." [Supervisory board member, AMX service company]

"Governments play a role [...] If it's compulsory, there is no discussion. It will make things more expensive, but it's compulsory, so no-one questions it anymore." [Supervisory board member, AScX industrial company]

Given this importance, we discuss legal developments at appropriate points in this report.

\subsection{Stakeholder drivers}

All of us are experiencing pressure from environmental, social, and legal drivers whether in the form of new products, higher prices for goods, extreme weather events such as droughts and floods, or the negative effects on health and quality of life due to inequality (Wilkinson and Pickett 2010). These drivers affect not only companies but also their stakeholders such as customers, employees, business partners, and capital providers (Freeman et al. 2010). We are all connected by a complex web of

\footnotetext{
474.1 .4 of the case.

${ }^{48} \mathrm{http}: / /$ climatecasechart.com/climate-change-litigation/non-us-climate-change-litigation/
} 
economic activity, so that each of our economic decisions may push another market actor into a direction that is more or less sustainable.

The push and pull of these incentives naturally mean that corporate sustainability activities can also be driven by the (un)sustainable decisions and behaviours of other stakeholders. Given these interrelationships, it is not surprising that companies commonly scan their environment (Useem 1984) to identify the key stakeholders who influence and are affected by their activities, regardless of sustainability.

\subsubsection{Key company stakeholders}

In our research, we found that 30 out of 35 companies mentioned in their annual reports who they view as their main stakeholders. For the other five companies, we could indirectly infer key stakeholders from the text of their annual reports. The results of this analysis are summarised in the following table:

Table 5: Key company stakeholders and stakeholder distribution

\begin{tabular}{|c|c|}
\hline Key stakeholder & $\%$ of companies \\
\hline Investors & $94 \%$ \\
\hline Customers & $94 \%$ \\
\hline Employees & $91 \%$ \\
\hline Suppliers & $69 \%$ \\
\hline Society & $57 \%$ \\
\hline Business partners & $54 \%$ \\
\hline Governments & $43 \%$ \\
\hline Community & $37 \%$ \\
\hline Trade associations & $20 \%$ \\
\hline NGOs & $17 \%$ \\
\hline Educational institutions & $17 \%$ \\
\hline Creditors & $14 \%$ \\
\hline Environment & $11 \%$ \\
\hline Competitors & $11 \%$ \\
\hline Trade unions & $3 \%$ \\
\hline Future generations & $3 \%$ \\
\hline Media & $3 \%$ \\
\hline
\end{tabular}

\begin{tabular}{|c|c|}
\hline \# of stakeholders & \# of companies \\
\hline $\mathbf{2 - 5}$ stakeholders & 13 \\
\hline $\mathbf{6 - 7}$ stakeholders & 12 \\
\hline $\mathbf{8 - 1 1}$ stakeholders & 10 \\
\hline
\end{tabular}

We identified three tiers of stakeholders in terms of how often they are mentioned by our sample of companies. The first tier comprises investors, customers, and employees and is mentioned by almost all companies with at least a 20 percent greater likelihood than other stakeholders. The second tier consists of suppliers, society, business partners, governments ${ }^{49}$, and the community, each of which is mentioned by between 69 percent and 37 percent of companies. The third-tier stakeholders, with 20 percent or less mentions, includes trade associations, NGOs, educational institutions, creditors, the environment, other competitors, etc. The companies report an average of 6.34 main stakeholders per company, who are distributed as shown in the smaller, right-hand side of the table.

\footnotetext{
${ }^{49}$ Including public oversight bodies and other public agencies.
} 
The findings in this table provide a partial insight into the relative influence of different stakeholders on the company. However, they should not be misinterpreted as an absolute or complete measure of these relationships. It is clear, for example, that governments have more influence over a company than an individual, or even large groups of employees or customers. And the media, identified as a stakeholder by only one company, can have an effect which far outweighs its apparent significance, for example following a corporate scandal. Nonetheless, it does give an indication of which stakeholders feature most prominently in the day-to-day business of the company.

The remainder of this section will first discuss the importance of reporting for stakeholders before discussing how the top tier of stakeholders can drive sustainability embedding. Our focus on investors, customers and employees is intended to provide a snapshot of the way that sustainability embedding is promoted by key stakeholders and should not be taken as evidence that other stakeholders are less important in this regard.

\subsubsection{Stakeholder interaction and communication}

Stakeholder interactions can act as a positive, negative, neutral, or even both positive and negative driver for corporate sustainability embedding. In general, the effectiveness of stakeholders' influence on sustainability - and the expression of their preferences - is amplified or muted by the quality of company sustainability reporting and communication (see, e.g., Krüger et al. 2021).

For example, a market participant can have difficulty in purchasing a sustainable product or in selecting a sustainable supplier when there is no information available regarding the social and environmental performance of a given product or organisation. In this regard, communication is necessary to provide material information for market actors to make rational decisions about sustainability. It provides a valuable contribution to the market efficiency of the economic environment and is not simply an administrative burden or market opportunity (Hayek 1948).

Sustainability reporting is especially relevant to customers, NGOs, sustainability rating agencies, investors such as shareholders, and other stakeholders who provide companies with capital, resources, and reputational support for their activities. There are long-standing concerns, by all parties, regarding the information that is being provided to the market.

Sustainability-oriented customers worry about greenwashing and find it difficult to filter through the information overload they receive about corporate sustainability (Laufer 2003; Ramus and Montiel 2005; Bams et al. 2021). NGOs and investors are short on good information to hold companies accountable for their social and environmental impacts. Sustainability rating agencies struggle to find the right data to provide an illuminating picture of companies' sustainability performance (Eccles and Stroehle 2018, 2020). And providers of capital want to limit their uncertainty and have a good understanding of the sustainability risks and opportunities of a given company. Many times, investors face confusion: rating agencies across the globe use different scopes when studying sustainability components, they use different measurement techniques, and they apply different weights to these categories (Berg et al. 2020). Moreover, Eccles and Stroehle $(2018,2020)$ show that the social origins of sustainability rating institutes play a prominent role in determining the scope and weight of information categories for sustainability. These shortcomings are an important motivation for the development of laws on the transparency and reporting requirements of companies, such as those identified in the previous subsection on legal drivers. 
Also important is that the expectations of consumers, capital providers, and other relevant actors regarding companies' endeavours in embedding sustainability are not one-sided. Companies, too, want clarity about the information needs of external stakeholders for the stability of their long-term planning. As one interviewee explained:

"I asked the majority of the investor community about how important certain ESG benchmarks are for them. And we have set our priorities based on their views. Besides our own internal considerations, we highly value the opinion of our investors." [Investor relations, real estate company]

Moreover, some companies were concerned about the right way to reach customers about their sustainability activities, and the counter-productive effect that marketing can have on the clarity of their communications:

"We need to do a better job of making these choices easier for customers. Right now a lot of that information is hidden and there's a lot of marketing messages you have to cut through in order to find what's the real impact of this... We see those trends happening when you make the information about a product health or sustainability transparent, it does drive shifts in behaviour" [Sustainability manager, AEX industrial company]

This is especially important for companies which work in an industry with a historically troubled relationship to social and environmental performance:

"Thirty years ago, everybody looked at chemistry and thought 'Oh my God, it's a terrible business' - so we always had to justify ourselves as a chemical business, that what we were doing was not so bad as what people thought... So, already embedded in the DNA of an industrial company is that you have to earn your licence to operate and that you have to act responsibly." [Industrial company]

Part of the difficulty in reporting the right information to stakeholders stems from issues in the broader market environment rather than solely from the internal organisation of a particular company. A well-known problem, confirmed by our interviewees, is the existence of divergent standards for sustainability reporting and the additional administrative costs and complexity that this (may) entail (Berg et al. 2020):

"The correlation between the sustainability ratings of rating agencies is 0.61 , while on the credit ratings it's 0.99 . So one who is sustainable according to one sustainability rating, is not sustainable according to another - so it just creates confusion." [Sustainability manager, AEX service company]

"You could spend a whole FTE on filling out ratings. And I don't like that, because I'd rather use that FTE to actually work on our sustainable strategy and activities. So, I also skip a lot of them." [Sustainability manager, AEX service company]

Moreover, several interviewees disclosed how their activities could be subject to the push and pull of conflicting sustainability expectations, especially from investors. Investors voice concerns, on the one hand, about capital expenditures and, on the other hand, about companies not making enough improvements and commitments on sustainability. 
In general, our findings confirm that first-tier stakeholder relations can both support and obstruct the embedding of sustainability in companies and that reporting can help stakeholders effectively express their preferences towards companies. This dual potentiality should be kept in mind throughout the remainder of this report.

\subsubsection{Investors as drivers}

Shareholders, especially institutional investors, have considerably increased their attention to sustainability and the integration of the concept into investment strategies in the past two decades (Gibson et al. 2020). These investors have developed active ownership strategies in which a dialogue with companies they invest in has a prominent role.

Figure 8 highlights, from our interviews, the sustainability topics that are most frequently raised by shareholders when they interact with the companies in our sample. Climate change is the topic mentioned most often by interviewees representing the companies in our sample (57 percent), closely followed by governance and executive remuneration (46 percent). Other less frequently mentioned topics were the company's sustainability strategy, diversity and inclusion, reporting transparency, the sustainability of the product portfolio, and business opportunities that are related to sustainability development.

Figure 8: Sustainability topics most frequently raised by shareholders according to interviewees

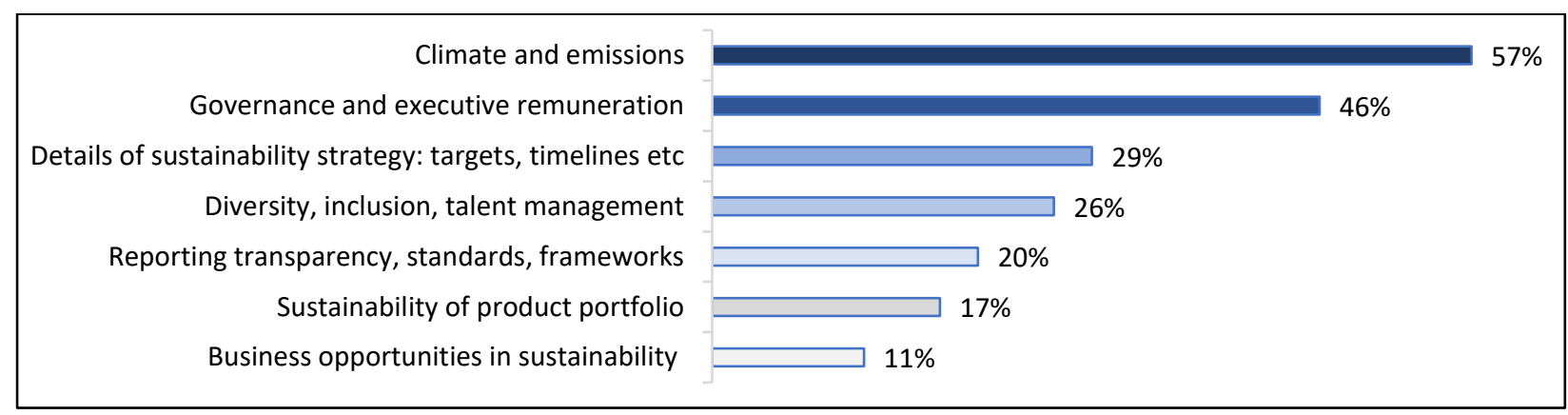

While some of our companies reported that they received conflicting messages from their investors, the overwhelming majority also responded that their shareholders were generally supportive - or at least not pushing against sustainability. This interest in sustainability is, perhaps, not surprising given that many financial institutions, including asset owners and asset managers, have recently stepped up their sustainability efforts by joining and developing collaborative networks such as the Principles for Responsible Investment (PRI) or Climate Action 100+ (Bauer and Smeets 2021). Our interviews confirmed a large degree of engagement from institutional investors relative to other kinds of investors:

It's really the difference between whether I talk to institutional investors for whom it's really important, they have all kinds of criteria in the way they look at your company, or I talk to individual private investors. It's a big difference. I can see that for private individuals, it seems less important than for institutional investors." [CEO, real estate company]

"When I was referring to the questions that I get, I'm referring more to the professional institutional type of investors, and not specifically to the retail shareholders. I have not, I 
must say, received any kinds of questions regarding sustainability from a retail shareholder." [Investor relations, AScX service company]

"Depending on what they know about our industry, you get either highly sophisticated questions about, tell me more about the detail of your emission-zero project, how is this feasible, how can you do it and relate it to some other examples? Or you get very generic questions. But clearly - as I mentioned - the institutional investors' side, they are on top of it. And the level of sophistication is rising fast." [Management board member, AMX industrial company]

In general, institutional investors use investor networks on behalf of their beneficiaries and clients to address global challenges such as climate change, inequality, and human rights and to shape the interactions with their portfolio companies and delegated asset managers. Many pension funds now have a full-fledged sustainable investment policy that they execute and report on (Gibson et al. 2020; Bauer and Smeets 2021). Voting on sustainability- and governance-related topics at annual shareholder meetings across the globe has become an important part of their investment process. Furthermore, EU legislation requires institutional investors and asset managers to monitor investee companies on relevant matters such as non-financial performance, social and environmental impact (see, e.g., art. 3g Shareholder Rights Directive ${ }^{50}$ ). Institutional investors often believe that targeted and collaborative engagement, and the resulting requested changes, will lead to better-performing companies (Bauer and Smeets 2021; Dimson et al. 2015, 2020). There is some evidence in the finance literature to support this belief, but we are careful not to stress it too much as these empirical analyses use specific engagement efforts by individual or collaborative engagement agents and are thus not easily generalisable (Dimson et al. 2020). The interviews showed in any case, that engagement can and does lead to changes in the sustainability activities of companies:

"Three years ago [our annual shareholder meeting] talked about living wage for our employees. [...] We haven't given it a lot of attention because we didn't think it was a real issue with us. But the question from an outside perspective was real. So the following year we did our own internal assessment, living wage comparison, etc., we could now fullheartedly say, "yes, we've done a full assessment, 10.000 people, we've seen five anomalies, we've rectified it and it's all good. But in hindsight, because they [...] just kept on talking about this, drove us to be more clear about it, disclosed about it, transparent in our annual report, and that way set the tone for years to come because obviously every year now, and just the other day we had the 2020 living wage analysis because I said we need to report on it again next year." [Sustainability manager, AMX industrial company]

The extent to which companies in our sample are subject to this increased engagement pressure might be related to their level and structure of institutional ownership. Dimson et al. (2020) show that companies with institutional ownership that jointly target these companies on environmental and social issues are more likely to respond to the engagement. Dyck et al. (2019) show that across 41 countries, institutional ownership is positively associated with environmental and social performance and use additional tests to indicate that this relation is causal.

\footnotetext{
50 Directive (EU) 2017/828 of the European Parliament and of the Council of 17 May 2017 amending Directive 2007/36/EC as regards the encouragement of long-term shareholder engagement.
} 
In our company sample, using data retrieved by FactSet (end of July 2021), the (unweighted) average institutional ownership is around 40 percent. ${ }^{51}$ However, the institutional ownership ranges from 12 percent to more than 70 percent. Also, insider ownership ${ }^{52}$ varies considerably between companies. The (unweighted) average insider ownership is 23 percent, but some companies in our sample have no insider ownership whatsoever, while others have more than 70 percent. The cross-sectional differences in both ownership categories may to some extent explain the variation in attention to sustainability embedding. However, on average, 37 percent of the companies is owned by private investors or by other institutional owners who cannot be identified directly. ${ }^{53}$

Table 6: Data on investor ownership of company sample

\begin{tabular}{|c|c|c|c|c|}
\hline Investor share ownership \% & Full sample & AEX & AMX & AScX \\
\hline $\begin{array}{l}\text { Insider } \\
\text { Min } \\
\text { Mean } \\
\text { Max }\end{array}$ & $\begin{array}{c}0,13 \\
\mathbf{2 2 , 5 2} \\
70,97\end{array}$ & $\begin{array}{c}0,72 \\
19,57 \\
58,83\end{array}$ & $\begin{array}{c}0,13 \\
23,83 \\
70,97\end{array}$ & $\begin{array}{c}5,40 \\
24,97 \\
56,56\end{array}$ \\
\hline $\begin{array}{l}\text { Institutional (total) } \\
\text { Min } \\
\text { Mean } \\
\text { Max }\end{array}$ & $\begin{array}{l}11,90 \\
39,65 \\
71,92\end{array}$ & $\begin{array}{l}19,76 \\
44,03 \\
71,92\end{array}$ & $\begin{array}{l}19,76 \\
43,15 \\
70,39\end{array}$ & $\begin{array}{l}11,90 \\
31,91 \\
66,43\end{array}$ \\
\hline $\begin{array}{l}\text { Institutional (active) } \\
\text { Min } \\
\text { Mean } \\
\text { Max }\end{array}$ & $\begin{array}{c}7,04 \\
35,10 \\
67,11\end{array}$ & $\begin{array}{l}16,24 \\
37,97 \\
67,11\end{array}$ & $\begin{array}{l}18,57 \\
37,90 \\
65,46\end{array}$ & $\begin{array}{c}7,04 \\
29,64 \\
66,36\end{array}$ \\
\hline $\begin{array}{l}\text { Institutional (passive) } \\
\text { Min } \\
\text { Mean } \\
\text { Max }\end{array}$ & $\begin{array}{l}0,00 \\
4,28 \\
9,72\end{array}$ & $\begin{array}{l}2,51 \\
5,65 \\
9,72\end{array}$ & $\begin{array}{l}1,92 \\
4,89 \\
6,73\end{array}$ & $\begin{array}{l}0,00 \\
2,21 \\
7,22\end{array}$ \\
\hline $\begin{array}{l}\text { Institutional (unassigned) } \\
\text { Min } \\
\text { Mean } \\
\text { Max }\end{array}$ & $\begin{array}{l}0,00 \\
0,28 \\
1,78\end{array}$ & $\begin{array}{l}0,05 \\
\mathbf{0 , 4 1} \\
1,60\end{array}$ & $\begin{array}{l}0,00 \\
0,36 \\
1,78\end{array}$ & $\begin{array}{l}0,00 \\
0,05 \\
0,37\end{array}$ \\
\hline
\end{tabular}

The largest part of the institutional ownership is managed in active portfolios (35 percent), while passive investors hold a minority (4 percent). ${ }^{54}$ Again, for both categories of investors there is a similar level of cross-sectional variation in our sample. The companies are, on average, mainly held by

\footnotetext{
${ }^{51}$ Institutional ownership, based on FactSet data, is defined as mutual fund organizations, pension funds, investment advisors (a FactSet classification that also encompasses institutional asset managers), hedge funds, and other (consisting of sovereign wealth funds, insurance companies, and other non-classified institutional investors).

${ }^{52}$ Based on FactSet data: Ownership positions held by non-buy-side entities such as officers, directors, public and private companies (including holding companies), private equity and venture capital firms, and Employee Stock Option Plans. These ownership positions are referred to by FactSet as 'stakeholder ownership'.

${ }^{53}$ We cannot rule out that the FactSet underreports institutional ownership data as not all institutional ownership is publicly available.

${ }^{54}$ FactSet classifies institutional owners as "Yield", "Deep Value", "Value", "Growth", "Aggressive Growth", "Growth at a reasonable Price (GARP)", or "Index" managers. In Table 6, "Index" is labelled as "Institutional (passive)". The other, active categories combined are labelled as "Institutional (active)".
} 
investment adviser firms ${ }^{55}$ ( 28 percent), followed by mutual funds ${ }^{56}$ ( 5 percent), hedge funds ( 1 percent), and pension funds (1 percent).

Table 7: Institutional share ownership

\begin{tabular}{|c|c|c|c|c|}
\hline Institutional Ownership \% & Full sample & AEX & $\mathbf{A M X}$ & AScX \\
\hline $\begin{array}{l}\text { Institutional type (mean) } \\
\text { Mutual Fund } \\
\text { Pension Fund } \\
\text { Investment Adviser (Asset Manager) } \\
\text { Hedge Fund } \\
\text { Other (incl. sovereign wealth funds) }\end{array}$ & $\begin{array}{c}5,44 \\
1,41 \\
28,46 \\
1,48 \\
2,86\end{array}$ & $\begin{array}{c}6,94 \\
1,10 \\
30,82 \\
1,12 \\
4,05\end{array}$ & $\begin{array}{c}5,34 \\
0,54 \\
32,29 \\
2,72 \\
2,27\end{array}$ & $\begin{array}{c}3,76 \\
2,41 \\
22,83 \\
0,97 \\
1,93\end{array}$ \\
\hline $\begin{array}{l}\text { Institutional (civil) } \\
\text { Min } \\
\text { Mean } \\
\text { Max } \\
\text { Institutional (common) } \\
\text { Min } \\
\text { Mean } \\
\text { Max }\end{array}$ & $\begin{array}{c}3,57 \\
15,98 \\
47,88 \\
\\
0,01 \\
23,66 \\
56,78\end{array}$ & $\begin{array}{c}4,46 \\
13,79 \\
29,43 \\
\\
9,89 \\
30,24 \\
56,78\end{array}$ & $\begin{array}{c}5,07 \\
14,51 \\
27,10 \\
\\
17,51 \\
28,64 \\
50,92\end{array}$ & $\begin{array}{c}3,57 \\
19,65 \\
47,88 \\
\\
0,01 \\
12,26 \\
36,66\end{array}$ \\
\hline Top 5 countries & $\begin{array}{l}\text { US }(13,29) \\
\text { UK }(8,92) \\
\text { NL }(6,26) \\
\text { FR }(2,88) \\
\text { NO }(2,04)\end{array}$ & $\begin{array}{c}\text { US }(17,80) \\
\text { UK }(10,27) \\
\text { FR }(3,25) \\
\text { NL }(2,74) \\
\text { NO }(2,39)\end{array}$ & $\begin{array}{c}\text { US }(15,42) \\
\text { UK }(11,40) \\
\text { NL }(3,91) \\
\text { FR }(2,41) \\
\text { NO }(2,23)\end{array}$ & $\begin{array}{l}\text { NL }(12,12) \\
\text { US }(6,44) \\
\text { UK }(5,49) \\
\text { FR }(2,80) \\
\text { NO }(1,48)\end{array}$ \\
\hline
\end{tabular}

A relatively large part of the companies ( 24 percent) is owned by investors based in common law countries ${ }^{57}$ who might have a different stance on sustainability and who are regulated in a different legal regime (Bauer and Smeets 2021). Common law investors' institutional ownership ranges from 0 to 57 percent. Interestingly, Dutch institutional ownership of the companies in our sample is only 6 percent.

In the interviews, a number of companies confirmed that there has been an increasing level of engagement from shareholders over the past few years, although the depth of their discussions varies with company size and, relatedly, ownership structure and geographic background of the shareholders. The larger companies were more likely to report receiving a lot of interest and regular and detailed discussions on sustainability with their shareholders. Smaller companies were more likely to respond that investor engagement on sustainability remains infrequent and that their questions are usually exploratory or motivated by 'box-ticking':

\footnotetext{
55 Based on FactSet: An entity that provides investment advice and manages a portfolio of securities. A firm will be coded investment advisor if most of its asset under management come from the institutional accounts they manage.

${ }^{56}$ Based on FactSet: An investment firm with most of the assets they manage coming from the mutual funds they manage. A mutual fund manager raises money from shareholders and reinvests the money in securities.

${ }^{57}$ Common law countries' regimes are considered to be relatively more liberalized with a shareholder-oriented view; the corporation is seen as a private entity, and its primary purpose is to maximize shareholder wealth (Liang and Renneboog, 2017). In civil law countries, there are relatively more mandatory rules, and a stakeholder-oriented view is more common; the corporation has both public and private roles, and its primary purpose is to serve the interests of a broader range of stakeholders (Harper Ho, 2009).
} 
"I perceive the investors are asking from more of a tick-the-box exercise. They want to see that we are a socially responsible company so that they can include us as a socially responsible stock." [Investor relations, AScX service company]

Moreover, many companies mentioned that they have to carefully explain their sustainability investments to their shareholders and have to clarify how the investments are expected to bring value in the long-term.

An important investor-related market driver for sustainability is that capital providers (debt and equity) may require lower risk premiums if the company performs well on material factors in the sustainability dimension. ${ }^{58}$ In the past decade, a stream of literature has emerged on determining the relationship between companies' sustainability performance and the cost of capital. For example, Chava (2014) finds that shareholders demand significantly higher expected returns from companies that have more environmental concerns (e.g., if they produce hazardous chemicals or are emissions intensive). Lenders also charge a significantly higher interest rate on bank loans issued to firms with these environmental concerns. However, this view is not undisputed in the finance literature. Edmans (2021a) argues that the relationship between sustainability performance and the cost of capital is significantly more complex. He stresses an important distinction between the impact of sustainability on two separate channels: companies' expected cash flows and the cost of capital. Expected cash flows may be impacted by sustainability risk and opportunities. The cost of capital will only be negatively affected by sustainability risk if it is systemic (undiversifiable) and not if it is idiosyncratic (diversifiable) risk. Notably, Cosemans et al. (2021) show that equity risk premiums are likely to rise with increasing temperatures. This rise will eventually reduce the optimal allocation to equity for longhorizon investors which will potentially have long-term consequences for company financing. One of our interviewees stressed that:

"If you look at our weighted average cost of capital, studies do point out that if you are an underperformer, [...] you have a negative impact on the valuation of your company because of a higher weighted average cost of capital, which you do not experience if you're average or above average. And if you compare positive performance results on sustainability compared to laggards, then there's a very much large difference between the growth profile expected by investors, which is logical, if you're the Tesla in a market you're expected to outgrow [...] the market. [...] So the important conclusion [...] is that this could create a problem in the governance of your company - because installing solar panels is not interesting for a business line which is judged based on its profit and loss statements, because they will not earn more money. But at the corporate performance level it will have a very large impact, but it means that [...] at the corporate level [the executive committee] needs to undertake action to do more than what the business line would automatically do itself." [Sustainability manager, AEX industrial company]

In summary, over the past decades many institutional investors have made explicit their investment beliefs regarding the risks and opportunities of sustainability, either inspired by soft law (covenants in $\mathrm{NL}$ ) or hard law (national and EU regulation) or by their own stakeholder base. It can be expected that these investors will increasingly target companies on relevant and material sustainability issues and that their market activities will help drive greater levels of company sustainability embedding.

58 https://www.sasb.org/standards/materiality-map/ 


\subsubsection{Customers as drivers}

Customers come in a range of different types, varying from individual one-time consumers to longterm organisational clients and everything in between. Each purchase has the potential to influence whether a company becomes more or less sustainable in both the short and long term (John and Klein 2003; Bauer and Smeets 2015).

For example, a lack of willingness or ability to pay for a more sustainable product can be a significant constraint on the company's attempt to market this product. Alternatively, customers can also act as drivers of sustainability when they demand, and are willing to pay a premium for, high sustainability performance. Both the limiting and enabling aspects of customer-company relationships were emphasised throughout the interviews:

"It is also dependent on the market development. You can have sustainability high on your own agenda, but if your customers are not interested in it, then it's more difficult to drive this forward." [Management board member, AScX industrial company]

"Everybody is going to say yes to sustainability. But when you look at it, are companies going to pay for it? For us to be successful, [...] we need those that [...] have the capital, to actually go with us. But instead, we get locked up into a very basic transactional thing: oh, are you going to be more expensive?" [Management board member, AScX industrial company]

"We have an audit almost every day, from clients. So, they come to factory and they examine the work, they look at the working conditions.... If your clients are not happy, you don't get a next deal." [Investor relations, AScX industrial company]

Our interviews also confirmed that reputation and trust could have an important influence on customer relationships (see also Servaes and Tamayo 2013). Past and recent scandals, either individual or industry-wide, have had a profound influence on some of our companies' sustainability approaches and their relationship to customers. Many interviewees from the financial sector referred to the 2008 Financial Crisis and the concomitant loss of faith in financial institutions as a defining moment and wake-up call for their embedding of sustainability:

"The financial crisis is something that we certainly have not forgotten - we, the financial industry, lost the trust of consumers and we've had to build that up and we're very aware that we had have to keep that and respect that trust. So that's also very much a part of the discussions that we have." [Investor relations, AEX service company]

Legal changes can also influence customer-company relationships. For example, the EU PRIIPs Delegated Regulation will require the financial sector to provide key information documents for packaged retail and insurance-based products ${ }^{59}$ from August 2022, and the amended Directive on

\footnotetext{
59 PRIIPs Delegated Regulation (EU) 2017/653 of 8 March 2017 supplementing Regulation (EU) No 1286/2014 of the European Parliament and of the Council on key information documents for packaged retail and insurance-based investment products (PRIIPs) by laying down regulatory technical standards with regard to the presentation, content, review and revision of key information documents and the conditions for fulfilling the requirement to provide such documents 2017/5653.
} 
Financial Instruments ${ }^{60}$ will require the necessary information about clients' financial risk preferences regarding sustainability.

In effect, these regulations will require companies to provide sustainable services alongside their other activities. It is expected that this will drive financial services companies to provide financial investment advice and products that are consistent with consumers' sustainability preferences, while maintaining the obligation to provide suitable portfolios in which financial and sustainability risks are taken into consideration.

This will lead, in turn, to greater efforts by financial institutions to engage with companies on sustainability-related topics. Companies will most likely experience an even larger demand for information on the risks and opportunities in the domain of sustainability, either from (institutional) investors directly or by rating agencies that service these investors or NGOs that increasingly also focus on influencing institutional investors (next to companies).

Overall, there is a wide range of customer relationships that have the potential to promote or hinder the embedding of sustainable corporate practices. This is influenced by the nature of the goods and services being sold by the company, the characteristics of the customer, and the legal environment as well as the historical social and environmental performance of the company's industry.

\subsubsection{Employees as drivers}

A distinguishing feature of the employee stakeholder group is that companies are concerned with both current and future employees. The two groups are not equally important on a day-to-day basis, with current employees receiving the lion's share of a given company's attention. However, it is important to note that the treatment and working conditions of current employees in addition to the nature of the job and employer can have a significant effect not only on individual motivation (Huselid 1995) but also on the attraction and retention of new employees. In this regard, there is an important continuity and shared interest between actual and potential employees from both a company and employee perspective. For instance, Akerlof (1982) argues that employees may view a positive working environment as a 'gift' from the firm and for that reason increase their effort. The same logic may hold for attracting and retaining new staff.

Several studies focusing on economies with flexible labour markets (Edmans 2011, 2014; Edmans et al. 2020) show that companies with high levels of employee satisfaction are associated with superior long-run stock returns. These results are consistent with job satisfaction having a positive influence on the recruitment, retention, and motivation of employees. In these markets, firms face fewer constraints on hiring and firing and employees have a greater incentive to respond to higher satisfaction levels. Interestingly, these studies do not find the same effect in countries with more regulated and rigid labour markets (such as Germany and the Netherlands) indicating that employees view the potential job satisfaction less as a gift (it is a 'must' for the company). Nonetheless, many of the (large) companies in our sample have subsidiaries and staff in countries with flexible labour markets.

\footnotetext{
${ }^{60}$ Directive 2014/65/EU of the European Parliament and of the Council of 15 May 2014 on markets in financial instruments and amending Directive 2002/92/EC and Directive 2011/61/EU.
} 
A sustainable culture both transcends and is embedded in a company. For example, consider how a company in which sustainability is well embedded is more likely to satisfy the expectations of an external pool of potential employees who are interested in sustainability; it shapes decisions both inside and outside of the company. As one of our interviewees explained:

"I'm in my sixties. As a generation, we did a lot of good for the next generations in the economical sense, and we did a very lousy job on maintaining the planet - and my children have made that very clear to me as well." [Supervisory board member, AScX Indsutrial company]

“Young people don't want to work for a company that doesn't have a strong sustainability approach. We take a hundred new school graduates on board each year. And in their first set of questions there's always this question, what is your sustainability approach? So we would kill ourselves if we were not serious about this." [Sustainability manager, AScX industrial company]

Culture has, in this regard, both internal and external, short-term, and long-term effects, and can have a positive or negative effect on the attraction and retention of employees (Guiso et al. 2015a, 2015b).

An important consequence of the generational shift in favour of sustainability may be that it can give companies a competitive edge in their recruitment processes. This is supported by our desk research findings which show that 17 percent of our companies identify educational institutions as one of their key stakeholders. Moreover, it is confirmed by the remarks of some of our interviewees:

"We do have a challenge in getting the right people into our company, so we are focusing on future employees, and we also started sponsoring sustainability projects at universities" [Sustainability manager, AScX industrial company]

Twenty-nine percent of our interviewed companies even indicated that sustainability is one of the main reasons that employees decided to join them:

"If I talk to new hires, and I ask them 'Why did you choose to come work for us?' In nine out of ten answers sustainability is part of the answer." [CEO, AEX service company]

"The vast majority [of employees] thinks that sustainability is the most important thing there is and they want to contribute to a more sustainable future, they want to make an impact." [CEO, AScX industrial company]

It is interesting to see, given the above, that there may be a virtuous cycle between employee interests in sustainability and companies' search for talented employees. Companies embed sustainability because they want highly motivated and talented employees which in turn drives the embedding that might draw in more sustainability-minded employees.

\subsection{Company attitudes to sustainability drivers}

We use interview data in this subsection to examine interviewees' attitudes towards structural and stakeholder drivers. Aggregated at the company level, we first show whether company representatives see these developments as a risk, an opportunity, or a combination of both. Second, we examine interviewees' perceptions of how long their company has been working on embedding 
sustainability. Lastly, we examine what interviewees view as the overall gaps and successes of their company's journey in embedding sustainability.

\subsubsection{Is sustainability a risk or an opportunity?}

When asked whether sustainability is a risk or an opportunity, interviewees from 51 percent of the companies responded that sustainability topics are both a risk and an opportunity for their management and often referred to the potential of transforming risks into opportunities:

"If there are incidents, it's a huge risk of course. The care for the safety and the health of the people and the environment should always be the first priority. Also you can get fines, your permission could be withheld by governments. So, that is a risk. It's also an opportunity to be best in class. Then you can also win new clients and you can show the world: we're doing an excellent job, you better give your work to us" [Supervisory board member, AMX industrial company]

Interviewees of 29 percent of the companies responded that while they do consider elements of sustainability-related risk in their discussions, the opportunity perspective was much more prevalent. Interestingly, 17 percent of the companies viewed sustainability almost exclusively as an opportunity:

"There's a lot of business opportunity here as well in this area. It sometimes surprises me how people only look at the negatives, instead of seeing the opportunities." [CEO, AScX industrial company]

Overall, we found that there are more companies of which the interviewees emphasise the opportunity rather than risk side of sustainability. Interviewees from zero companies responded that sustainability is predominantly a source of risk. These findings are captured in the following figure:

Figure 9: Is sustainability seen as a risk or an opportunity? ${ }^{61}$

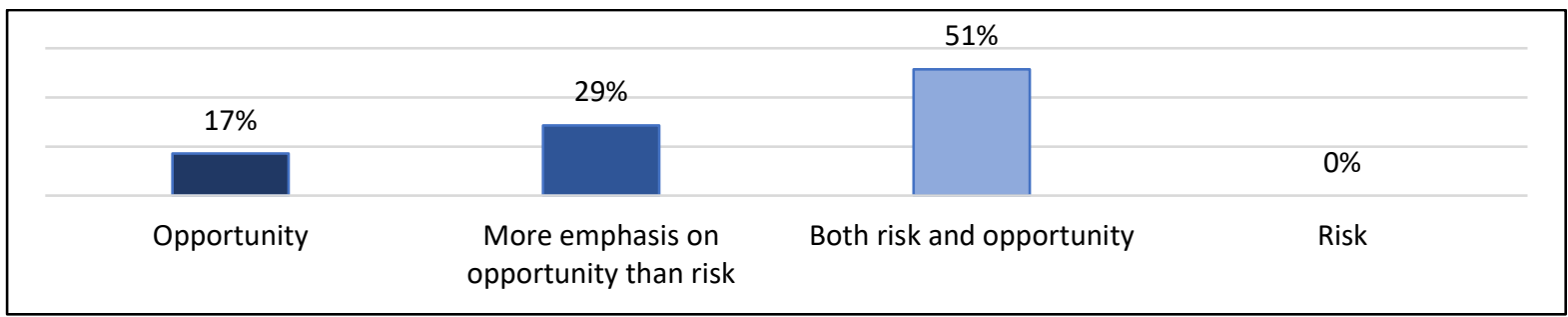

Also interesting is that interviewees of 43 percent of the companies view sustainability as a potential source of competitive advantage:

"Sustainability has a narrow window where it's a competitive advantage. If you're smart, you can take advantage. But then often somebody wakes up, whether it's society, whether it's the legislator, whether it's the investors - and then it's a level playing field because everybody needs to do it. And then if you don't do it, it becomes a reputational risk." [Sustainability manager, real estate company]

Several interviewees argued that the advantages from this topic would gradually disappear because more and more companies are embedding sustainability and because they expect the imposition of

${ }^{61}$ N.b. this question was answered by 34 out of 35 companies, hence the percentages add up to $97 \%$ rather than $100 \%$. 
regulatory standards. If correct, then this suggests that more companies will, over time, view sustainability as a risk rather than an opportunity.

\subsubsection{How long has your company been engaged with sustainability?}

Not all interviewees were asked how long their companies have been engaged with embedding sustainability in their governance and operations, but all provided information on this topic in the introductory part of their interviews. We emphasise that interviewees are generally consistent about the amount of time that their companies have been embedding sustainability. We found that 40 percent of interviewees, again aggregated at the company level, indicate that their company has been engaged, formally or informally, in sustainability for more than 10 years (sometimes since founding): 62

"[In] how we do things, sustainability is always in the equation and has been from the start. Which is different from other companies who started out selling something [which has] nothing to do with sustainability, and then only later on started to think about it." [Supervisory board member, AEX service company]

For 26 percent of the companies, interviewees perceive that sustainability has become a focus area over the past 6-10 years, and for 34 percent of companies in the sample interviewees indicated that it was only in the past 1-5 years that their company has become more deeply engaged with sustainability. This is captured in the following figure:

Figure 10: How long has the company been embedding sustainability?

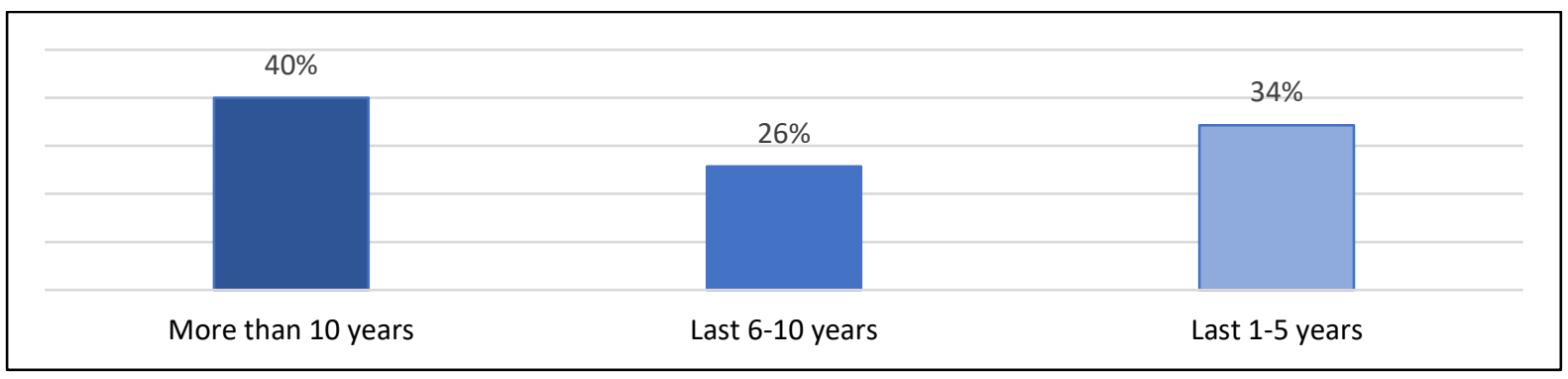

Most companies with a longer history in embedding sustainability are AEX companies, while AMX and AScX companies seem to have initiated their sustainability journey more recently. Even for several of the companies who have been focused on embedding sustainability for a longer time, a formalisation and strategic positioning of the topic was a more recent development.

\subsubsection{What is the current state of your sustainability embedding?}

The literature and policy proposals, such as the EU sustainable corporate governance initiative, provide various ideas on how companies can embed sustainability. However, to not rule out any practices, we started each interview by asking interviewees about the ways that sustainability is already embedded in their company. The responses of our interviewees re-emphasised many of the focus areas in this report.

When asked about the extent to which the company has already embedded sustainability, interviewees most often referred to having company-wide sustainability targets and KPIs, including

62 We note that interviewees generally agreed about the length of time that their company has been embedding sustainability. 
sustainability targets in management remuneration, involving top management in sustainability, making business units responsible for sustainability, integrating sustainability into product development and innovation, integrating sustainability into strategy, and integrating sustainability into the annual report. These results are shown in the following figure:

Figure 11: In what ways is sustainability already embedded in your company?

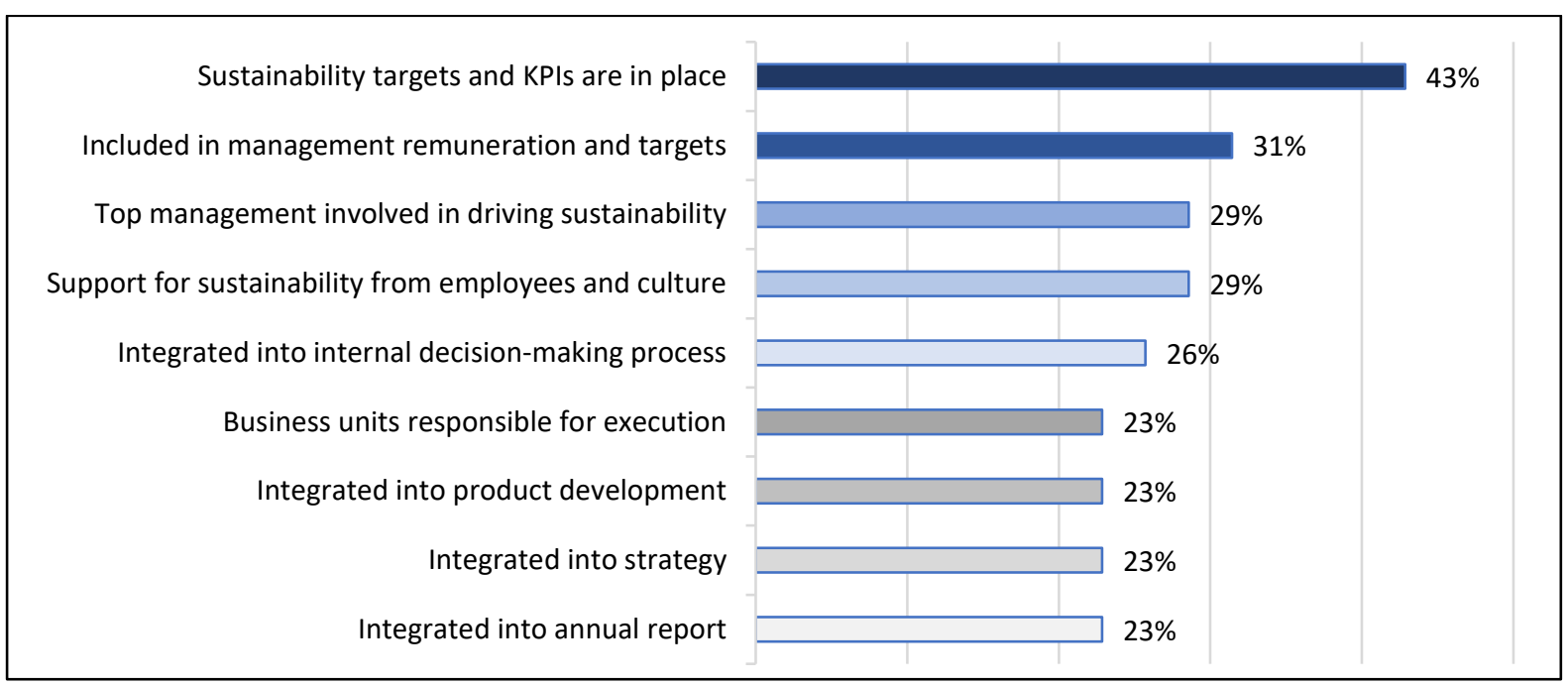

When asked about gaps and areas of improvement in their sustainability embedding, interviewees answered most often that their companies need to step up with embedding sustainability into the mentality and behaviour of employees. They also mention that they need to work on engaging stakeholders and other actors in their supply chain and integrating the embedding of sustainability more formally into their decision-making processes. Interviewees also felt that their companies needed to improve the data collection and monitoring of sustainability, that they could be more ambitious on $\mathrm{CO}_{2}$ reductions, and that their reporting could be more detailed and coherent. This is summarised in the following figure:

\section{Figure 12: Where do you still see gaps or room for improvement in your sustainability embedding?}

Embedding deeper in employee mentality \& behavior

Engaging stakeholders and value chain actors

Rigorous embedding in decision-making processes

Translating sustainability into products and services Improving data collection and monitoring Increasing ambition for $\mathrm{CO} 2$ reduction More detailed and coherent reporting

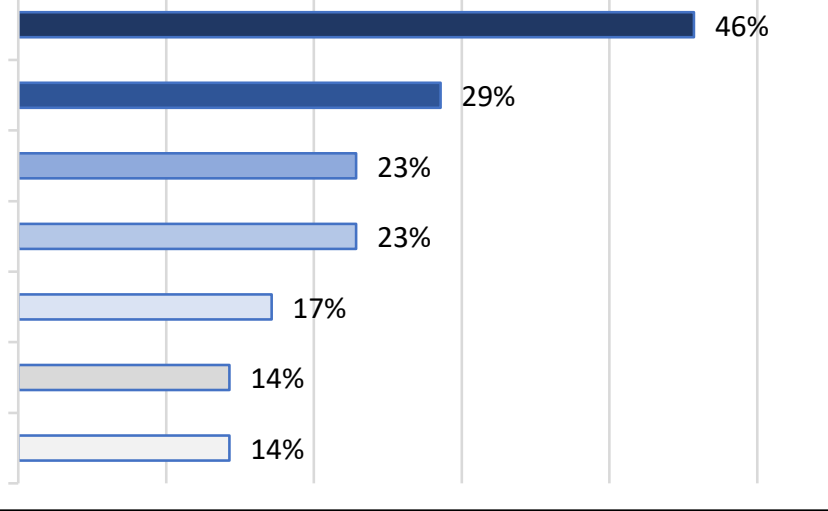

It is interesting to mention that interviewees had considerably more to say about their company's achievements in embedding sustainability than their gaps (an average of 3.8 successes vs. 2.3 gaps).

We mapped the reported sustainability successes and room for improvement (gaps) against the length of time for which companies have been embedding sustainability and found that in companies with a 
longer history of sustainability ( $5+$ years), interviewees are more likely to mention a greater number of successes and a similar number of embedding gaps (4.5 successes and 2.4 gaps). Interviewees of these companies are almost twice as likely to mention long-term targets and KPIs, and twice as likely to mention top management involvement in sustainability, as part of their successes. They are also generally more likely to mention that sustainability is integrated in international decision-making processes and that it is integrated into company strategy and the annual report. However, they are not more likely to note that sustainability has been included in their purpose, mission, or values statements.

Interviewees from companies with a relatively short history of sustainability embedding (1-5 years) were much less likely to identify product development and innovation as part of their successful embedding and very likely to identify them as gaps in their activities. Interviewees from these companies, remarkably, do not identify a lack of sustainability expertise as an embedding gap, while this was recognised as an issue by a minority of interviewees from companies with proclaimed medium and long histories of sustainability embedding. Furthermore, interviewees from companies with a short history of sustainability embedding did not point out a gap in the scope and quality of their sustainability reporting, although this gap was mentioned by numerous companies with a medium and long history of sustainability embedding. A similar absence can be noted for diversity and inclusion among the companies which started embedding sustainability only recently.

Forty-four interviewees from 27 companies also disclosed what they perceive as a desired, ideal state of sustainability embedding. The following are a few examples of these desired or ideal states of embedding:

"I would see as embedding that everybody in the company is aware of the topic and also takes action on the topic, so that it becomes part of the culture." [Sustainability manager, AMX industrial company]

"Embedding is about having people understand that they have an impact: that in everything we do, there's a choice that we have, and it all builds to something. [...] I don't think that measurements should be, do you have a department and how many people do you have in it? It is more important to me that it's in everybody's heads when they're doing their job every day." [Management board member and sustainability sponsor AScX industrial company]

"My perfect view of the world, if everything was working the way it should in a fully sustainable way, is that everybody in the company understands sustainability in the same way they understand basic business principles, how to calculate the sales and EBITs of the company. If everybody understood the sustainability impacts of their decision the way they understand the financial impacts of the decisions, then we've made it - sustainability is embedded. Because it's a different way of thinking about the business and about the business impacts." [Sustainability manager, AEX industrial company]

In this section we have examined why companies embed sustainability in response to structural and stakeholder drivers in addition to company attitudes to these drivers and how company interviewees perceive their company's state of sustainability embedding. We now turn to examine how companies are embedding sustainability. 


\section{How are companies embedding sustainability?}

The companies in our sample have different sizes, market segments, employee numbers, ownership compositions and operate in different jurisdictions. As a result, each company responds to sustainability drivers differently (Halme et al. 2018; Bams et al. 2021). Some companies have a business model that is highly dependent on fossil fuels or energy-intensive production processes which produce higher emission levels. Others have a complex international supply chain which they need to navigate to minimise their social and environmental impacts. Still another category of companies is smaller and has relatively fewer resources and employees available to implement sustainability, or has a high degree of dependence on the actions of larger parties in their supply chain. These variations make it difficult, if not impossible, to develop a comprehensive one-size-fits-all model for the embedding of sustainability in companies.

At the same time, there is a great deal of commonality between companies. There are similarities in legal structure; shared ideas about effective management and governance; regular exchanges of best practices; and a host of other cultural, economic, and organisational interactions which tend toward, but never achieve, a full convergence in company activities. It is therefore a truism, in light of these contradictions, that each company exists as a tangled mix of unique and common elements.

In this part of our findings section, our aim is to identify and distil different sustainability embedding practices in Dutch listed companies. However, we are not reviewing the sustainability performance of individual companies but are providing an overview of general practices. Therefore, these findings are not an evaluation nor a critique of any given company in our sample, and we do not refer to individual companies in our results.

We divide our results on the sustainability embedding of Dutch listed companies into three sections:

1. Purpose and strategy

2. Leadership and governance

3. Supply chains, sustainability reporting, employees and culture

The first subsection covers the highest-level aspects of embedding sustainability. It presents findings on the question of whether sustainability is an explicit part of the process of defining the company's purpose. Moreover, we explore whether companies integrate sustainability in the formulation of their strategic objectives and targets. In the second subsection, we discuss our findings on the governance of this embedding process by exploring who drives and leads the companies' sustainability embedding, the roles of top management and the supervisory board in this process, the functioning of sustainability managers and sustainability teams in support of top management, the remuneration of the management board, and the skill profiles of the management and supervisory boards. We also review the role of sustainability committees in the governance of sustainability embedding. The third subsection presents our research findings on the sustainability dimension of supply chain management and reporting as well as our interview insights into employees and culture.

\subsection{Purpose and strategy}

One way of embedding sustainability that the recent literature has extensively discussed is by means of defining a specific corporate purpose (Mayer 2018; Edmans 2020; Sjåfjell 2020; Mayer et al. 2020). The underlying idea is that the traditional dichotomy between the shareholder model, which sees the 
corporate purpose as maximising shareholder value, and the stakeholder model, which sees the corporate purpose as balancing stakeholder interests and serving society, needs to be transcended and replaced. The shareholder model is perceived by many as too short-termist and is widely considered to pay insufficient attention to the social and environmental consequences of corporate activities (Sjåfjell et al. 2015; EY 2020), whereas the stakeholder model is too difficult to operationalise and organise in terms of oversight and accountability (Bebchuk and Tallarita 2020). One of the proposed solutions in the academic literature is to define more clearly what the company wants to achieve, to clarify what parties can contribute to that goal, and what their interests are while ensuring that the company does not profit from activities which destroy social or environmental value (Mayer 2020). The idea is that this definition avoids the negative externalities of the first model while avoiding the ambiguities of the latter.

The corporate purpose can be used to define a company's mission and ambitions. From there on it can further serve as a guidance tool to define corporate strategies which can in turn serve as the basis for corporate policies at various levels throughout the company. The corporate purpose and its further elaboration in the company's strategy can serve as a basis for supervision by the supervisory board to see whether or not the company reaches its goals (Olaerts 2020). It can also be used for setting targets in directors' remuneration and as a basis for stakeholder engagement.

This section presents our findings on the corporate purposes of our company sample. We assess whether they have a defined corporate purpose, whether it includes sustainability, and whether it is oriented towards the improvement of the company or the solution of problems for society. We also look at how companies in our sample include sustainability into their strategy. We discuss different ways in which this can be done and examine various sources of inspiration which companies use to determine the substance of their sustainability activities.

\subsubsection{Purpose}

Corporate purposes can be included in a company's articles of association or in other company documents such as a mission statement, motto, or slogan. The inclusion of a (sustainable) purpose in the articles of association (as part of the 'objects' of the company, in Dutch: 'statutaire doelomschrijving') requires a vote by the shareholders at a general meeting (art. 2:121 of the Dutch Civil Code (DCC)). Purpose statements that are not included in the articles of association are in principle decided on by the management board and generally do not require any shareholder ratification (see, e.g., Garcia Nelen 2020; Timmerman 2020).

A purpose statement in the articles of association represents a deeper integration of the corporate purpose into the company's internal decision-making structure. Some legislators have invited companies to adopt such purposes voluntarily and make explicit their intended role in society and what they aim to achieve; the idea is that this can serve as a basis for company policy choices. This is for example the case in France with the Loi Pacte. Since embedding sustainability in articles of association is still a rather rare phenomenon for listed companies incorporated in the Netherlands, ${ }^{63}$ the focus of our study is on the other, less formalised types of purpose statements.

\footnotetext{
${ }^{63}$ We found that only one company in our sample refers to sustainability issues in its articles of association and another which refers to making sustainable products as one of its objects. Other companies refer broadly to stakeholders but not in a way that emphasises sustainability but rather the Dutch stakeholder model.
} 
Purpose statements were not the subject matter of a standard question during the interviews, but we nonetheless found that the topic was raised by some of the interviewees. In their view, a purpose can be reconceptualised and used as a potential tool for embedding sustainability by guiding decisions on strategy, leadership, and culture (see also Eccles et al. 2014):

"When you talk about the story or the DNA of the company, you also have identified - if that is my long-term reason of existence, what kind of people, what kind of culture do I need? What kind of of leadership do I need?" [Supervisory board member, AEX service company]

"There are hundreds of decisions each of us takes every day, and not all of these decisions are governed by processes. That would drive us crazy, right? That's why I think it's so important to make that part of the autopilot of the mindset of the leaders to be able to say "Does it really align with the purpose of the company?" [Sustainability manager, AEX industrial company]

However, one interviewee acknowledged that a mere purpose statement does not suffice. To be effective, the company needs to put the wording into practice, to make it more tangible, and to ensure that it leads to specific actions:

"We have our purpose, [...] which I think is a good purpose, but at the same time it's only a phrase. So what we're trying to do is to make that impact more tangible. So, we have discussions with people, how can we make that more tangible, what can we do to describe that better, what can we measure?" [Sustainability manager, AMX industrial company]

Furthermore, the company can use the concept of a corporate purpose to engage employees internally (Linnenluecke and Griffiths 2010) and to communicate externally to stakeholders, including potential employees. One of the interviewees mentioned along this line of reasoning:

"Being purpose-driven, [the company purpose] and our whole ESG and sustainability thinking behind that is an extremely powerful recruitment tool. People want to work for us because they buy into that idea and to the fact that it really is a part of who we are." [Management board member, AEX industrial company]

In our desk research we also examined the corporate purposes of our sample. We found that not all companies have a clear or obvious purpose statement and that there is often a great deal of overlap between purpose and other concepts such as mission and vision. We felt, therefore, that it would not be justified to limit our analysis to statements that are explicitly labelled by companies as purpose statements. It did not seem reasonable to misrepresent companies with purpose-like statements for the mere reason that they were not named as such. As one CEO explained:

"I think corporate purpose is a modern way, or an alternative, for what we used to call mission... For me it's basically the same. To bring alive what is driving us and why we are here? And what are we here to create?" [CEO, AScX industrial company]

With these concerns in mind, we examined annual reports for statements of mission, purpose, vision, etc. for the overall direction of the company. These statements needed to be included in the first pages of the annual report or as a clear part of the central strategy section. Sometimes this yielded only a few words, other times it generated one or more sentences. There was some room for 
interpretation, so we double-checked the purpose statements with multiple researchers and read purpose (and purpose-like) statements within the context of their position within the annual report.

Using this approach, we found that 29 out of 35 companies (83 percent) either directly or indirectly include sustainability in their corporate purpose. Direct inclusion (22 companies) entailed that sustainability is an explicit part of the company's purpose and purpose-like statements. Indirect inclusion (seven companies) means that the importance of sustainability was inferred from the text which surrounds such statements. For the other six companies we found either that they do not have an identifiable corporate purpose (two companies), or that their purpose makes no direct or indirect reference to sustainability (four companies). These results are summarised in the following table:

Table 8: Corporate purpose and sustainability

\begin{tabular}{|l|c|c|}
\hline & \# of companies & $\%$ of companies \\
\hline No clear corporate purpose & 2 & $6 \%$ \\
\hline Purpose without sustainability & 4 & $11 \%$ \\
\hline Indirectly sustainable purpose & 7 & $20 \%$ \\
\hline Directly sustainable purpose & 22 & $62 \%$ \\
\hline
\end{tabular}

A sector-by-sector analysis (table below) shows that 90 percent of industrial companies directly or indirectly included sustainability in their purpose, as compared to 70 percent and 80 percent of service and real estate companies.

Table 9: Company sector, corporate purpose and sustainability

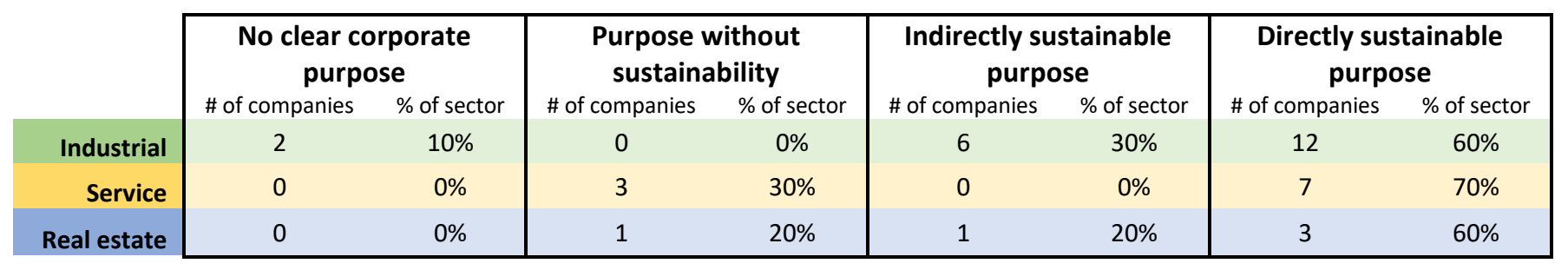

An analysis of size by market capitalisation shows that $A E X$ and $A M X$ companies are more likely to adopt a sustainable corporate purpose than ASCX companies ( 86 percent and 100 percent respectively as compared to 67 percent). The results are shown in the table below:

Table 10: Company size, corporate purpose and sustainability

\begin{tabular}{r|cc|cc|cc|cc|}
\hline & \multicolumn{2}{|c|}{$\begin{array}{c}\text { No clear corporate } \\
\text { purpose }\end{array}$} & \multicolumn{2}{c|}{$\begin{array}{c}\text { Purpose without } \\
\text { sustainability }\end{array}$} & \multicolumn{2}{c|}{$\begin{array}{c}\text { Indirectly sustainable } \\
\text { purpose }\end{array}$} & \multicolumn{2}{c|}{$\begin{array}{c}\text { Directly sustainable } \\
\text { purpose }\end{array}$} \\
AEX & \# of companies & $\%$ of index & \# of companies & $\%$ of index & \# of companies & $\%$ of index & $\#$ of companies & $\%$ of index \\
AMX & 2 & $14 \%$ & 0 & $0 \%$ & 4 & $28 \%$ & 8 & $57 \%$ \\
AScX & 0 & $0 \%$ & 0 & $0 \%$ & 2 & $22 \%$ & 7 & $78 \%$ \\
\hline
\end{tabular}

We also examined whether purpose statements, regardless of whether they include sustainability, have an internal or external orientation, that is, whether they aim to improve the company, or aim to improve something outside of the company. Of the 33 companies with purpose statements, 25 have an external orientation while eight have an internal focus. Larger companies are more likely to have externally oriented purpose statements than small companies (83 percent AEX, 78 percent AMX, 67 percent AScX). We found no significant difference for a comparison of sectors. 


\section{Mayer-Edmans test for corporate purpose}

The literature on corporate purpose defines it as an expression of the aim that a company is trying to achieve in society, and an indication of the values and principles that it considers leading in order to guide future company decisions (Winter et al. 2020). There are two leading strands in the corporate governance literature on corporate purpose, namely those of Mayer and Edmans (2018; 2020). They have similar, but not identical, approaches to purpose; the overlap is not surprising given that both researchers are involved in The Purposeful Company project. ${ }^{64}$ To further analyse purpose statements, we created a test based on the synthesised work of these authors to evaluate how companies in our sample defined their corporate purposes. We should note that the test in this subsection is, of course, only one way to investigate the relative specificity of corporate purpose statements.

Edmans' approach to corporate purpose is grounded in his broader concept of Pieconomics which provides a framework for how companies can transcend the traditional shareholder-oriented paradigm and create both profits and "social value, which includes externalities" (Edmans 2020: 57). He explains that corporate purposes should not be too broad and that they should have a specific 'why' and 'who'. "[T]he why should be based on the principle of comparative advantage and the who should be based on the principle of materiality" (Edmans 2020: 198). This establishes two requirements for a corporate purpose: first, it should be dedicated to a particular activity in which the company has a comparative advantage; and second, it should be dedicated to the welfare of one or more specified groups of material stakeholders.

These two conditions are broadly compatible with the approach to purpose suggested by Mayer:
"Purpose should be neither mundane nor aspirational. It is not purely descriptive of what a business does - a mission statement - nor unrealistic about what it seeks to do - an aspirational vision statement to save the world. It is about solving problems, 'to produce profitable solutions to the problems of people and planet' and 'not to profit from producing problems for people or planet'... Purpose is, therefore, about finding ways of solving problems profitably where profits are defined net of the costs of avoiding and remedying problems" (Mayer 2020: 889).

The second condition is absent from Mayer's proposal, but his focus on solving problems is broadly synonymous with Edman's recommendation to identify a particular activity in which the company has a comparative advantage. When we combine the two, it yields the following two-fold Mayer-Edmans test for corporate purposes:

1. Is the corporate purpose oriented towards solving a problem?

2. Does the purpose identify one or more material stakeholders for the company?

We should note that before applying this test to our sample, both authors - whether through the inclusion of externalities, or the definition of profits as value created minus the net costs of avoiding and remedying problems - suggest that profits are illegitimate if they impose more costs on society and the environment than the value they generate. They posit this as a fundamental pre-condition for responsible business and it is, unfortunately, not testable within the scope of this research.

\footnotetext{
64 https://thepurposefulcompany.org/steering-group/
} 
Regarding the first part of the Mayer-Edmans test, we found that 16 companies have a purpose which specifies, directly or indirectly, a problem which the company is trying to solve. An analysis of company size shows no influence on this part of the test, while sector analysis shows that only industrial companies (60 percent) and service companies (40 percent) include a problem description in their purpose (vs. real estate at 0 percent).

For the second part of the test, the desk research again found that there are 16 companies which have a purpose which identifies one or more material stakeholders. Ten of these companies are the same as those which satisfied the first requirement. However, only three of this group of 16 companies identified a material stakeholder group which was not too broad or generic; five companies referred broadly to, for example, society and future generations, while eight companies referred to generic stakeholder groups such as customers, employees, and shareholders. Only three companies identify a specific, non-generic stakeholder group (a general example would be Dutch flower cultivators as opposed to customers). If we read the test in a strict manner (i.e., we demand a specific stakeholder group), then there are only three companies which satisfy the second requirement.

We ultimately found that only two companies in our sample satisfy both the first and strict second requirement of the Mayer-Edmans test for corporate purpose. Our overall results are summarised in the table below:

Table 11: Mayer-Edmans test for corporate purpose

\begin{tabular}{|l|c|c|}
\hline Requirement & \# of companies & $\%$ of companies \\
\hline 1. Companies which solve a problem in their purpose & 16 & $46 \%$ \\
\hline 2. Companies which identify a material stakeholder group in their purpose & 16 & $46 \%$ \\
\hline \multicolumn{1}{|c|}{ Companies which satisfy both requirements } & 2 & $6 \%$ \\
\hline
\end{tabular}

Applying the Mayer-Edmans test may seem unjust given that some companies, such as large consumer goods companies, might struggle to identify a specific kind of customer stakeholder. At the same time, even these kinds of companies could be dedicated to a more specified material stakeholder, for example customers who are looking for circular products at a reasonable price.

\subsubsection{Strategy}

As mentioned above, the corporate purpose statement can form the basis of the company's strategy and strategic objectives (DSGC 2020). It is important for these topics to be connected. As Edmans explains, "A purpose statement is meaningless unless it translates into action... A company's purpose should shape the activities its involved in" (Edmans 2020: 208). The link between sustainability and strategy has also received attention at the European level. In its action plan on financing sustainable growth, the European Commission mentioned in action 10 the idea of requiring boards to develop and disclose a sustainable strategy, including due diligence and measurable sustainability targets. ${ }^{65}$ The Commission has furthermore suggested in its consultation document on sustainable corporate governance the potential implementation of an EU-level duty requiring directors to identify stakeholder interests, ${ }^{66}$ manage the risks for the company in relation to stakeholder interests, and to identify opportunities. A company can also achieve each of these aims through its strategy.

\footnotetext{
${ }^{65}$ Action Plan: Financing Sustainable Growth $\operatorname{COM(2018)~} 97$ final.

${ }^{66}$ Sustainable corporate governance initiative Summary report - public consultation.
} 
Given the importance of strategy for embedding sustainability (Eccles et al. 2014), we examined whether and how companies integrate sustainability into their strategic objectives and targets. We also investigated whether companies report on their historical performance on sustainability targets, and whether they connected the targets' attainment to a specific deadline. We relied primarily on the 2020 annual reports (which were published in 2021 and disclose performance over 2020), although we also consulted other publicly available documents, such as separate sustainability reports, when necessary.

\section{The relationship between strategy and sustainability}

The desk research clearly shows that there are different ways in which sustainability and strategy can be interconnected. Some companies have a separate sustainability strategy while others see sustainability as a foundation or core pillar of their central strategy. Overall, there is a great deal of variability in sustainability strategies and targets, and the strategies are difficult to classify into categories. It is also difficult to conclude from this variability which approach is relatively better or worse with regards to sustainability performance.

The desk research therefore reveals various ways in which sustainability and strategy can be connected to each other. To categorise these options, we first assessed whether sustainability is included in a company's strategic objectives. Different companies have different idioms for this, but most have between three and five of these objectives, strategic pillars, or some equivalent that is not merely an outcome of the strategy. For example, this approach meant that emissions-free production could be included as a strategic objective while achieving a top sustainability ranking would not be seen as a sustainability objective.

The second distinction which we relied on for our review of sustainability strategies was whether sustainability-related strategic objectives are included in either the main or central strategy section of the annual report, or as part of a separate sustainability strategy in the annual report or another document. Central strategies are generally found near the beginning, i.e. within the first 20 pages of an annual report, while separate sustainability strategies are usually found further down or are presented in a way which is distinct from the central section. When companies provide minimum details on sustainability in their central strategy section and refer to another section for further details, we still interpreted this as being part of the central strategy.

These two distinctions allowed us to classify the strategies of our company sample according to whether sustainability is included in the strategic objectives: (1) not at all or incidental, (2) as a separate sustainability strategy, (3) or as a foundation or pillar (meaning that sustainability objectives pervade, or are one or more parts of, the central strategy).

Using this approach, we found that 97 percent of our sample has sustainability-related strategic objectives. Twenty-two companies (63 percent) have sustainability strategic objectives as a foundation or pillar in their central strategy, ${ }^{67}$ and 12 of them (34 percent) have a separate sustainability strategy.

\footnotetext{
${ }^{67}$ It is not easy, and often feels arbitrary, to distinguish between companies with sustainability as a foundation or pillar in their central strategies. This seems to depend more on framing and language than content, so we did not make a further distinction on this point.
} 
Table 12: Strategic objectives and sustainability

\begin{tabular}{|l|c|c|}
\hline & \# of companies & $\%$ of companies \\
\hline Sustainability objectives in central strategy & 22 & $63 \%$ \\
\hline Sustainability objectives in separate strategy & 12 & $34 \%$ \\
\hline No strategic sustainability objectives & 1 & $3 \%$ \\
\hline
\end{tabular}

We also asked our interviewees about the relationship between sustainability and their strategy, and it should be noted that their answers were not equivalent to the findings of the desk research, that is, their idea of sustainability as a foundation or a pillar does not necessarily overlap with the approach adopted for the desk research.

During the interviews it became clear that some companies consider integrating sustainability into strategy an important and helpful part of embedding sustainability (consider also Figure 11 in which 23 percent of companies referred to strategy as one of the ways that sustainability is already embedded in their company):

"Integrating sustainability in strategy is the advice I would give everybody. Strategy is now truly integrated, and also the management information system around it. And not only for the annual report, but by consistently measuring your progress throughout the year." [Sustainability manager, AEX service company]

"Three pillars everyone can relate to. Also the leadership can easily reflect, digest, communicate, and convey whatever we need to do this area... If you have an unstructured, not-visualized approach, then it also becomes more difficult for leadership to translate that into the organisation...Now they know - natural capital, social and human capital, responsible business conduct. Really clear, straightforward, everyone can relate to those topics." [Sustainability manager, AScX industrial company]

They emphasised that if sustainability is mentioned in the company's purpose or mission (which is the case with many of the surveyed companies), then it should also be reflected in strategy formulation:

"If we wouldn't have done that people could say - because optics need to match reality 'If I look at your strategy and your [pillars], I don't see any sustainable initiatives anywhere, this is strange. So your strategies do not really match up with your mission."' [Management board member, AScX service company]

However, some companies mentioned that the relationship between sustainability and strategy had not been formalised even though they recognised its potential relevance:

“That's work in progress, I would say. It's not something that's written out from the beginning, but it's there as a factor" [Sustainability manager, real estate company]

Several interviewees even stated that explicitly integrating sustainability into the wording of the strategy is not crucially important:

"We are not the type of company that makes strategy papers. We embarked on this venture, years ago, with a clear vision that we put on one A4 paper, and that's about it. Talking about strategy is not something that we do." [Management board member, AEX industrial company] 
"There are people that say you need to have the word "environment" or "ESG" in your strategy. I say, it speaks for itself if you read our strategy. It's 100 percent embedded in who we are and what we do." [Management board member, AMX industrial company]

The interviews also disclosed different ideas on whether sustainability is best integrated into the strategy as a foundation or as a separate pillar. Some interviewees expressed a dislike for the idea of having a 'sustainability strategy' and argued that this could point to a lack of embedding. Other interviewees did not find this an issue so long as the two are connected:

"Maybe we call it CSR strategy. But in the same way that we would talk about an innovation strategy - is that another part of the total business strategy? Of course it is an integral part, but it's a sub-element of it... I don't mind that they call it still a CSR strategy, as long as it doesn't conflict with the business strategy and it is more or less interlinked" [Supervisory board member, AScX industrial company]

The above shows that most companies in our sample have integrated sustainability into their strategic objectives. ${ }^{68}$ However, they have different ways to do this and it is difficult to compare the benefits and disadvantages of these approaches, or to firmly establish that one is necessarily better than the other for embedding sustainability. It remains, in any case, important to see how companies further operationalise and implement sustainability, for example by setting targets.

\section{Strategic targets, deadlines and reporting on past results}

As mentioned above, the company can further operationalise the strategy by putting in place specific sustainability-related targets. The EU Accounting Directive (as amended by the Non-Financial Reporting Directive) already requires companies to include in their management report a nonfinancial statement concerning the impact of their activities in relation to at least environmental, social and employee matters, human rights and anti-corruption and bribery and to include among other things the nonfinancial key performance indicators relevant to the business. ${ }^{69}$ Therefore, companies falling under the scope of this Directive have to show, at a minimum, their impact on certain sustainability areas as well as the KPIs they have in this respect. However, despite this requirement, the European Commission (EC) in the explanatory memorandum to the CSRD proposal recently recognized that practices differed a lot in terms of what companies disclose in this respect (CSRD: 2-3). Although it is not our aim to examine whether companies live up to these reporting requirements, our study clearly shows that companies have great freedom when it comes to deciding on their ambitions, on when they want to achieve these ambitions, and whether and how they translate their sustainability strategies into actual targets.

Our desk research on annual reports and sustainability reports showed that 34 of the companies in our sample have specific sustainability targets. When it comes to finding sustainability targets and the achieved results, some companies provide a clear, concise overview of their targets, deadlines, and past performance. Others provide little information on past performance and spread their targets throughout various sections of the annual report or sustainability report. For many companies it was difficult to compile the full list of targets; we assumed that getting a clear overview would be even

\footnotetext{
68 N.b. the 23 percent of companies that integrate sustainability into their strategy in Figure 11 does not automatically mean that the other 77 percent do not do this. It only means that it was not mentioned during interviews, hence our desk research findings are leading for this topic.

${ }^{69}$ Article 19 a Directive 2013/34/EU.
} 
more difficult for other stakeholders who are not collecting data. In general, it would promote transparency and reduce information overload for companies to provide an overview of sustainability targets (if they do not do so already), either in an appropriate section of the report or in an appendix.

Overall, we found that nine companies have less than half of their sustainability targets connected to a specific year (i.e., most targets have no deadlines). Six companies have more than half, but not all, of their sustainability targets connected to a specific year. Nineteen companies connect all of their sustainability targets to specific years.

Table 13: Extent to which future sustainability targets are connected to specific deadlines

\begin{tabular}{|l|c|c|}
\hline Extent of targets & \# of companies & $\%$ of companies \\
\hline Not applicable & 1 & $3 \%$ \\
\hline Less than half of targets & 9 & $26 \%$ \\
\hline More than half of targets & 6 & $17 \%$ \\
\hline All targets & 19 & $54 \%$ \\
\hline
\end{tabular}

In terms of operationalising their strategy, companies can not only set sustainability-related targets and clear deadlines, but they can also report on their progress for these targets over recent years. In our sample, we found that most companies disclose the results that they have achieved in the past years with regard to their targets. Only four companies show no results for the past years for these targets. Eleven companies show results for one year for these targets while 19 companies show results for more than one year for these targets. The results are shown in the table below:

Table 14: Number of years for which results are published for sustainability targets

\begin{tabular}{|l|c|c|}
\hline Number of years & \# of companies & $\%$ of companies \\
\hline Not applicable & 1 & $3 \%$ \\
\hline 0 years & 4 & $11 \%$ \\
\hline 1 year & 11 & $31 \%$ \\
\hline 2 or more years & 19 & $54 \%$ \\
\hline
\end{tabular}

\section{Identifying strategic priorities for sustainability}

Now that we have seen that sustainability can be embedded in the corporate purpose, and further operationalised in the strategy by setting (and reporting on) specific sustainability objectives and targets, the next question is: How do companies decide on their sustainability strategy and targets? It is well-known that sustainability is a broad term that can encompass many different issues and that business activities can influence a wide range of stakeholders and affect society and the environment in many ways. This multiplicity of interests means that companies have to make choices in terms of which sustainability issues to pursue or give priority to.

There are various ways in which companies can do this. They can rely, for example, on the knowledge of their employees, their internal risk management processes, input from their stakeholders, or on guidance from authoritative guidelines such as the UN Sustainable Development Goals or the Paris Agreement. Our interviewees were not asked directly, but they mentioned the following ways to identify the impact of their company and to decide on the sustainability issues at stake: 
Figure 13: How does the company define its sustainability impact and identify issues?

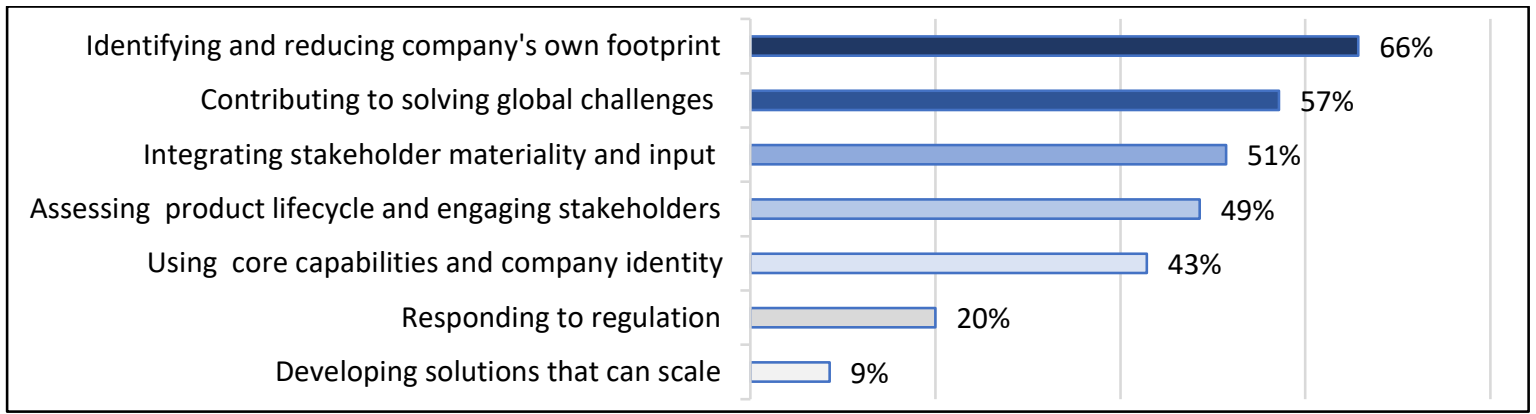

The figure shows that companies, when selecting sustainability issues, are mostly concerned with reducing their own environmental impact, contributing towards global challenges, the opinions of their stakeholders, and the overall impact of their supply chain. Moreover, many companies are concerned with using their core capabilities and staying close to the comparative advantage and essence of their business. It is interesting to note that upcoming regulation was only mentioned in a few cases. This suggests that interviewees experience considerably more push from the impact and (un)sustainability of their business, their willingness to make a positive contribution, and their stakeholders, than they do from legal drivers.

When it comes to what issues are then important for the company with regard to sustainability, the following key sustainability issues were mentioned during the interviews.

Figure 14: Key sustainability issues faced by companies

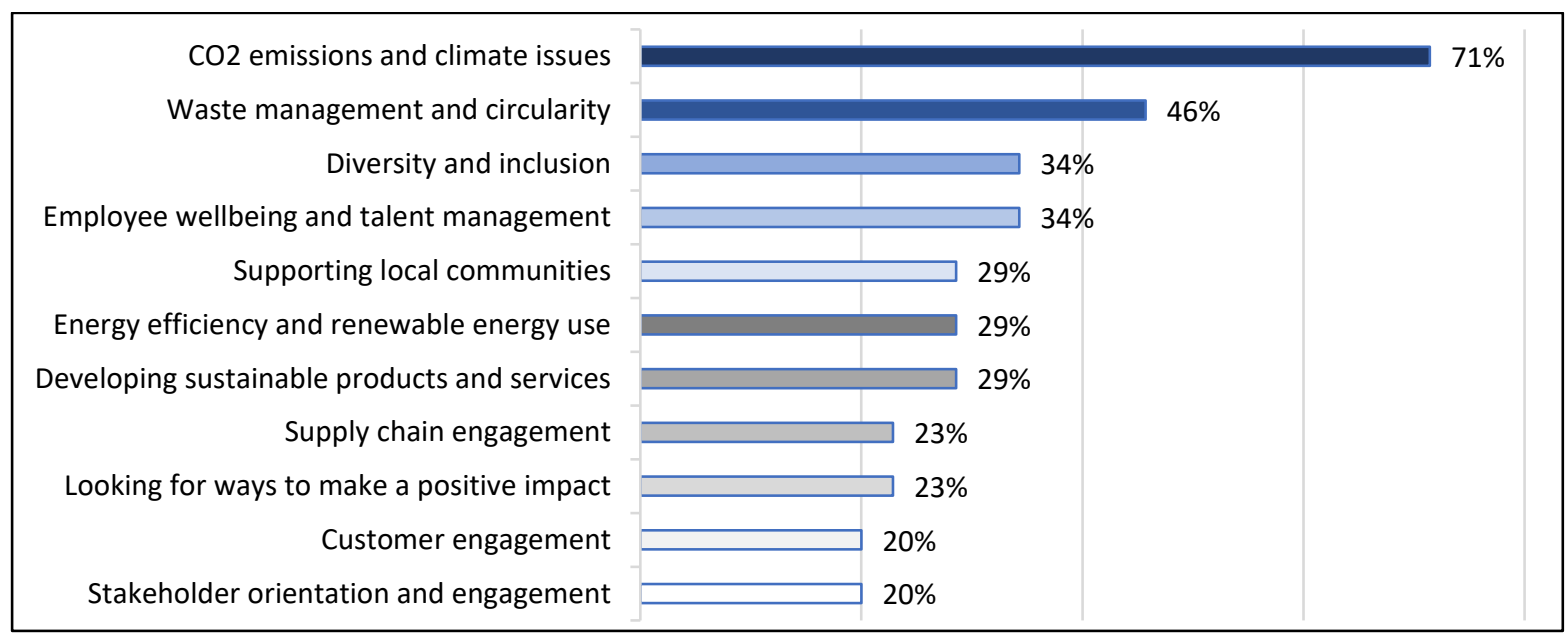

The interviewees indicated that $\mathrm{CO}_{2}$ emissions and climate issues, waste management and circularity are the two main sustainability issues which their companies are facing. In light of this finding, it is noteworthy that we found earlier that only five companies have committed to becoming fully circular and that 11 companies do not have a commitment to $\mathrm{CO}_{2}$ neutrality. In this regard, we found a disconnect between the key sustainability issues identified by interviewees and the formal commitments of their companies.

In the desk research, we also examined what companies disclose in their annual reports about three sources of potential inspiration for determining key sustainability issues: the UN Sustainable Development Goals (SDGs), stakeholder materiality consultation, and sustainability risks. We present findings for each in turn. 


\section{Sustainable Development Goals}

All companies refer to the SDGs in their annual reports. They mention an average of six SDGs per company, with larger companies mentioning slightly more SDGs relative to smaller companies (AEX 6.57, AMX 6.11, and ASCX, 5.67). As shown in the figure below, we found that the following topics are the most important: there is a primary focus on SDG12 responsible consumption and production; SDG8 decent work and economic growth; SDG13 climate action; SDG7 affordable and clean energy; SDG9 industry, innovation, and infrastructure; and SDG3 good health and well-being. The other categories are a lot less prominent.

We found it remarkable that gender equality plays a small role despite almost all companies having diversity policies. Furthermore, life on land, life below water, and poverty and inequality goals received little overall attention in our sample.

\section{Figure 15: SDG commitments}

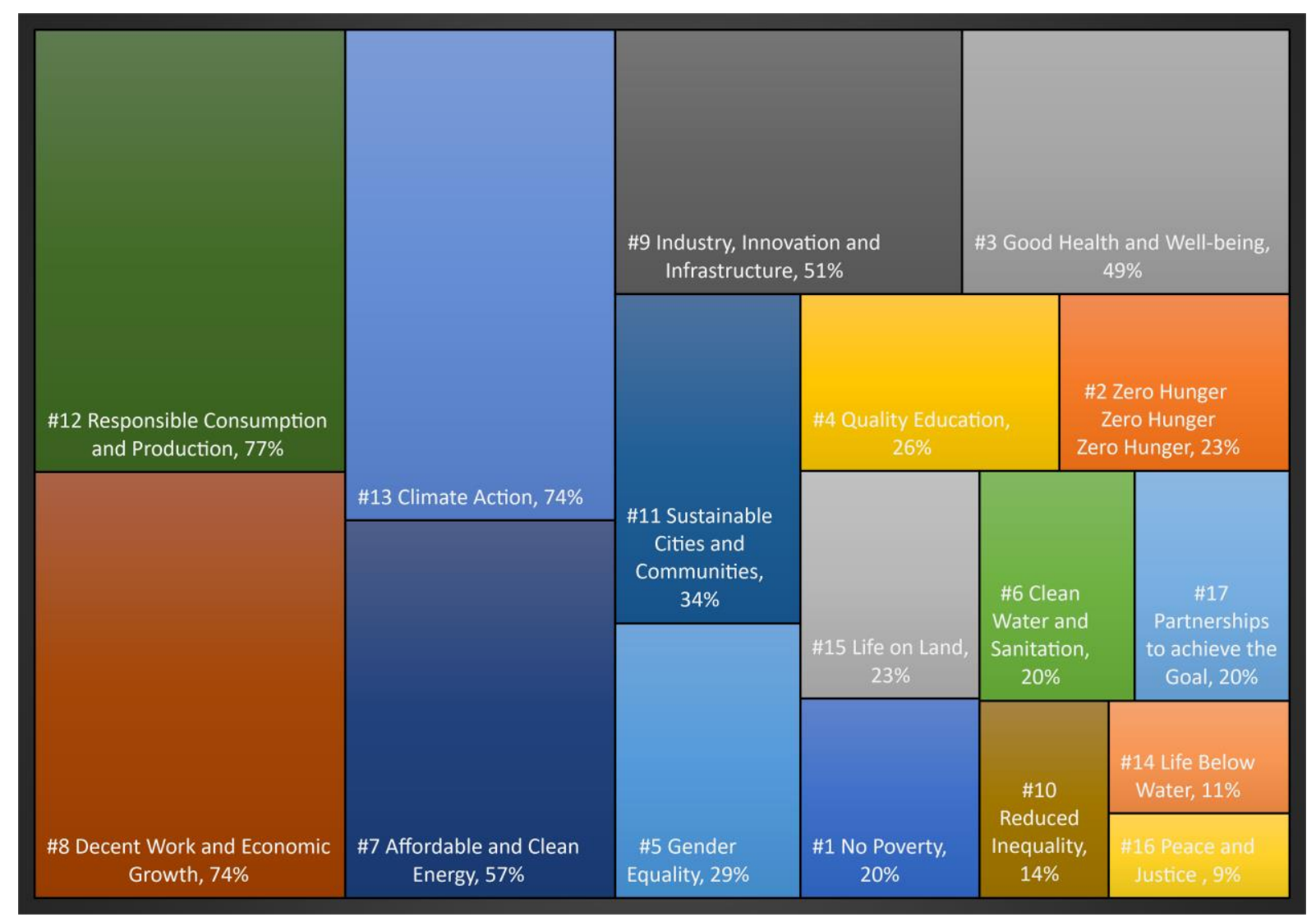

Size analysis showed no significant influence on SDGs 12, 13, and 8. SDG 7 on affordable and clean energy is much less prominent for large companies (29 percent of AEX companies vs. 89 percent of AMX and 67 percent of ASCX). By contrast, SDG 3 on good health and well-being is a lot more prominent for large companies (71 percent for AEX, 22 percent for $A M X$, and 42 percent for ASCX). SDG 10 on reduced inequality is only mentioned by AEX companies, and gender equality is also mentioned more often by them ( 43 percent of AEX, 11 percent AMX, and 25 percent ASCX).

Sector analysis showed no significant difference for SDG 13 and 3 on climate change and good health and well-being. It also disclosed, perhaps unsurprisingly, that SDG 11 on sustainable cities and communities is mentioned by all real estate companies. SDG 12 on responsible consumption and 
production is less emphasised by service companies (60 percent vs. 90 percent of industrials and 80 percent of real estate). SDG 7 on affordable and clean energy is identified by all real estate companies relative to 60 percent of industrials and 40 percent of service companies. SDG 8 decent work and economic growth is mentioned by fewer industrials ( 60 percent) compared to 90 percent of service companies and all real estate companies.

When it comes to including SDGs in their sustainability frameworks, several companies reported in the interviews having detailed discussions at the top levels of the company in order to choose the correct SDGs to commit to:

"If you read through [our] annual report, when it comes to the SDGs, we had zero, we had two, now we have four. That's based on lots of discussion, which you do in your executive board and which you do with your supervisory board." [CEO, AMX service company]

"We have three SDGs that we focus on more specifically - those are at the heart of our sustainability program. Part of that is responsible consumption and production, climate action and health and wellbeing, so those are the three that we have chosen to elevate." [Management board member, AEX industrial company]

One company in particular decided to build its entire sustainability programme around the SDGs due to the high salience of this framework among stakeholders, but also because of its usefulness as an engagement tool with the company's employees:

"We look at highest standards to execute our business. The United Nations Sustainable Development Goals are typically seen as the pinnacle of sustainability... There are a lot of organisations that are moving in line with those...

This SDG framework is quite rich in terms of guidance [...] What is working really well is that the definitions are easy to understand, there are materials available. And we can engage internally with employees and with the sustainability ambassadors so that they can define their activities and objectives in a relatively straightforward way...

We have company targets which are SDG-based. For each of these selected SDGs we provide guidance to all the business units, to ensure that they in their annual budgeting process plan for sustainability initiatives, and that they set targets on those initiatives. In that way, they take ownership of defining sustainability action." [Sustainability manager, AMX industrial company]

\section{$\underline{\text { Stakeholder materiality topics }}$}

In their annual reports, companies also often mention the results of their consultations with stakeholders for identifying material topics. In our sample, we found that 30 out of 35 companies disclose this information. ${ }^{70}$ The results are shown in the table below:

\footnotetext{
${ }^{70}$ N.b. This is higher than the $49 \%$ of companies identified by interviewees in Figure 13 . We presume that interviewees did not provide an exhaustive range of answers, and that their responses are indicative (especially of prominence) rather than that they provide a full overview.
} 
Table 15: Top material topics for stakeholders

\begin{tabular}{|r|l|c|c|}
\hline \multicolumn{1}{|c|}{ Rank } & Material stakeholder issue & \# of companies & $\%$ of companies \\
\hline 1 & Climate and emissions (GHG, CO2, nitrogen, etc.) & 20 & $67 \%$ \\
\hline 2 & Employee retention \& careers & 17 & $57 \%$ \\
\hline 3 & Safety (incl. but not limited to employee safety) & 17 & $57 \%$ \\
\hline 4 & Employee wellbeing \& health & 17 & $57 \%$ \\
\hline 5 & Corporate ethics \& compliance & 17 & $57 \%$ \\
\hline 6 & Customer needs, safety, prices \& satisfaction & 16 & $53 \%$ \\
\hline 7 & Product innovation \& design & 16 & $53 \%$ \\
\hline 8 & Financial, economic and operational performance & 15 & $50 \%$ \\
\hline 9 & Sustainable, high-quality \& healthy products & 15 & $50 \%$ \\
\hline 10 & Culture, diversity \& Inclusion & 14 & $47 \%$ \\
\hline 11 & Circularity, resource management and waste & 14 & $47 \%$ \\
\hline 12 & Energy & 12 & $40 \%$ \\
\hline 13 & Digital transformation \& IT systems & 11 & $37 \%$ \\
\hline 14 & Cybersecurity, IP \& data privacy & 10 & $33 \%$ \\
\hline 15 & Responsible procurement \& supply chain & 10 & $14 \%$ \\
\hline 16 & Community \& stakeholder engagement & 9 & $33 \%$ \\
\hline 17 & Water use & 6 & $30 \%$ \\
\hline 18 & Human rights \& labour practices & 6 & $20 \%$ \\
\hline 19 & Biodiversity, ecosystems \& environment & 6 & $17 \%$ \\
\hline 20 & Sustainable mobility & 5 & $17 \%$ \\
\hline & & & 14 \\
\hline
\end{tabular}

The top 20 topics show a mix between environmental, employee, customer, and operational concerns. The top priorities relate to climate and emissions (20 companies), employee retention and careers (17), safety (17), employee well-being and health (17), corporate ethics and compliance (17). Circularity is an identified material topic for 14 companies, while biodiversity, ecosystems, and environment are material for only six companies. In order of priority, the other sustainability issues are sustainable, high-quality and healthy products, culture, diversity and inclusion, energy, responsible procurement and supply chain, community and stakeholder engagement, water use, human rights and labour practices, and sustainable mobility.

During the desk research we found that companies disclose little, if any, information on the details of the consultation process. We rarely know how many people were consulted, who was consulted, how many times, in what format, or whether and how the company filtered the input from its stakeholders. It is difficult, in this regard, to make a qualitative comparison between stakeholder consultations and an identification of their level of representativeness or the reliability of their findings.

Overall, our desk research confirmed that conducting a stakeholder materiality analysis is a regular part of setting the sustainability agenda and that a large number of companies disclose it in their annual report. The topic was also mentioned by many interviewees as a key part of their process for

\footnotetext{
${ }^{71}$ This is out of the 30 companies that provide material topics.
} 
selecting relevant sustainability issues. However, they acknowledge that the company also influences the stakeholder materiality process:

"There are a thousand things we can do, but we cannot do those thousand things, so we need to have focus. So going through [the stakeholder materiality] process helped us to bring focus. Obviously, you are in control of the outcome as well. And so you on the one hand you use it to focus, on the other hand you use it also to steer focus" [Sustainability manager, AMX industrial company]

The outcome of the materiality analysis was also discussed with top management to validate and further prioritise relevant topics:

"We carry out materiality assessment to determine which topics are most relevant for our stakeholders and for [the company] to make societal impact. That gives us a priority list of key material topics, which we validate with the board of management and our executive committee." [Sustainability manager, AMX service company]

Furthermore, since the materiality analyses are conducted on a regular basis (annually or every two to three years), companies can also use the outcomes to identify societal shifts over time. However, the low responsiveness of external stakeholders to stakeholder materiality questions can be a constraint to getting a balanced view on issues:

"You want to do surveys, among your own people and then in the market - what do people consider important? But I learned ... it's very difficult to get feedback from the market. Everybody is talking about it, but if you send somebody a questionnaire that they can fill in in five or ten minutes, you need to push people ten times, and your response rate is around ten percent ... it's terrible." [Management board member, AEX industrial company]

On the other hand, interviewees also stated that the perspectives of the different stakeholders are not always easy or straightforward to reconcile:

"You start talking to the external stakeholders... but the outcome is such a large variety that it doesn't really help to calibrate the materiality matrix. So it is useful, but not as useful as I thought." [Sustainability manager, AMX industrial company]

Moreover, some interviewees expressed a concern that the outcomes of the materiality analysis do not necessarily paint an accurate picture of the company's priorities and plans - which might be challenging to explain to external stakeholders who look at the materiality matrix in the annual report:

“Our stakeholder materiality index... is painting a skewed view of the world. I don't think that what we put there is truly what we feel, or how we act. It's the outcome of a process, but, that doesn't mean it's the truth. If we ask a hundred people and a hundred people give input, that doesn't mean that the sum of all the answers is necessarily true. This is how stakeholders think about the company; it's not how the company thinks about the company" [Supervisory board member, AScX service company]

Overall, our findings show that a stakeholder materiality consultation is useful for companies trying to select from a wide range of potential sustainability topics. It helps them focus, although it is by no 
means the only influence on their sustainability agenda. When reading the annual reports and stakeholder materiality information, it is important to note that the presented information is interpreted and influenced by the company in question; it is not a neutral reflection of stakeholder interests.

We do not endorse companies to reflexively follow the material interests of their stakeholders, but we do think they can be more transparent about their stakeholder consultation processes: how did they identify their stakeholders? On what basis was this determination made? Who did they subsequently invite and why? How many people and in what format? This information, which should be easy to share, can help external stakeholders understand the extent to which a company is open to sustainability drivers and other inputs from its external environment.

It is also interesting to note different priorities between the stakeholder materiality analysis and the previous subsection on SDGs. Affordable and clean energy is an important SDG for 20 companies, but it is only material for the stakeholders of 12 companies. Moreover, sustainable, high-quality, and healthy products are material for only 15 companies but were identified as a relevant SDG by 27 companies. A similar but smaller discrepancy was identified for diversity and inclusion (which is material for stakeholders of 14 companies but only part of the SDGs for 10 companies). These findings show that the selection of SDGs by companies is not simply a reflection of material stakeholder interests. It also provides some insight into the differences between company and stakeholder selection of material sustainability topics.

\section{Sustainability risks}

Companies can also rely on the identification of nonfinancial, sustainability risks as a third source of inspiration for their sustainability activities. Companies falling under the NFRD are required to disclose this information, and our desk research examines whether companies report on these risks in their annual report section on risk management. ${ }^{72}$ It is important to note that sustainability risks are not synonymous with nonfinancial risks; the latter is broader and can also include operational concerns such as management effectiveness or digitisation. Therefore, we did not equate sustainability risks with nonfinancial risks. Using this approach, we found that 31 companies mention sustainability risks in their risk management section. These risks are distributed as follows:

Table 16: Sustainability risks

\begin{tabular}{|c|l|c|c|}
\hline \multicolumn{2}{|l|}{ Sustainability risk } & \# of companies & $\%$ of companies \\
\hline 1 & Climate change and emissions & 26 & $74 \%$ \\
\hline 2 & Product safety and HSSE & 20 & $57 \%$ \\
\hline 3 & Employees, diversity and human rights & 10 & $29 \%$ \\
\hline 4 & Circularity, resource scarcity and waste & 9 & $26 \%$ \\
\hline $\mathbf{5}$ & Company sustainability performance & 8 & $23 \%$ \\
\hline 6 & Pollution (air, water, plastic) & 3 & $9 \%$ \\
\hline 7 & Biodiversity and ecosystems & 1 & $3 \%$ \\
\hline
\end{tabular}

\footnotetext{
72 We did not examine other parts of the annual report. We recognise that some sustainability risks may have been excluded by this approach but felt that this was necessary for a more robust inter-company comparison.
} 
The results show that sustainability risks - other than climate change and emissions, product safety, and HSSE (health, safety, security, and environment) - play a limited role in company risk assessments. The fact that circularity, resource scarcity and waste are mentioned by only nine companies and biodiversity by only one company is surprising given the risks posed by the transgression of planetary boundaries.

Analysis by size shows that AEX companies are most likely to identify sustainability risks, and ASCX companies are least likely. These findings indicated that size has a strong influence on the scope of a company's (sustainability) risk management processes.

Table 17: Sustainability risks by size

\begin{tabular}{|ll|c|c|c|c|c|c|}
\cline { 3 - 8 } \multicolumn{2}{c|}{} & \multicolumn{2}{c|}{ AEX } & \multicolumn{2}{c|}{ AMX } & \multicolumn{2}{c|}{ AScX } \\
\cline { 2 - 8 } \multicolumn{2}{l|}{ Sustainability risk } & \# of companies & $\%$ of index & \# of companies & $\%$ of index & \# of companies & $\%$ of index \\
\hline $\mathbf{1}$ & Climate change and emissions & 13 & $93 \%$ & 8 & $89 \%$ & 5 & $42 \%$ \\
\hline $\mathbf{2}$ & Product safety and HSSE & 9 & $64 \%$ & 5 & $56 \%$ & 6 & $50 \%$ \\
\hline $\mathbf{3}$ & Circularity, resource scarcity and waste & 5 & $36 \%$ & 3 & $33 \%$ & 2 & $17 \%$ \\
\hline $\mathbf{4}$ & Employees, diversity and human rights & 6 & $43 \%$ & 2 & $22 \%$ & 1 & $8 \%$ \\
\hline $\mathbf{5}$ & Company sustainability performance & 3 & $21 \%$ & 3 & $33 \%$ & 2 & $17 \%$ \\
\hline $\mathbf{6}$ & Pollution (air, water, plastic) & 1 & $7 \%$ & 2 & $22 \%$ & 0 & $0 \%$ \\
\hline $\mathbf{7}$ & Biodiversity and ecosystems & 1 & $7 \%$ & 0 & $0 \%$ & 0 & $0 \%$ \\
\hline
\end{tabular}

Analysis by sector shows that industrial and service companies are much more likely to identify sustainability risks than real estate companies. Product safety and HSSE risks are, unsurprisingly, prominent for industrial companies and less relevant for service and real estate companies.

Table 18: Sustainability risks by sector

\begin{tabular}{|c|c|c|c|c|c|c|c|}
\hline & \multirow[b]{2}{*}{ Sustainability risk } & \multicolumn{2}{|c|}{ Industrial } & \multicolumn{2}{|c|}{ Service } & \multicolumn{2}{|c|}{ Real estate } \\
\hline & & \# of companies & $\%$ of sector & \# of companies & $\%$ of sector & \# of companies & $\%$ of sector \\
\hline 1 & Climate change and emissions & 16 & $80 \%$ & 7 & $70 \%$ & 2 & $40 \%$ \\
\hline 2 & Product safety and HSSE & 17 & $85 \%$ & 1 & $10 \%$ & 2 & $40 \%$ \\
\hline 3 & Circularity, resource scarcity and waste & 7 & $35 \%$ & 3 & $30 \%$ & 0 & $0 \%$ \\
\hline 4 & Employees, diversity and human rights & 7 & $35 \%$ & 2 & $20 \%$ & 0 & $0 \%$ \\
\hline 5 & Company sustainability performance & 3 & $15 \%$ & 3 & $30 \%$ & 2 & $40 \%$ \\
\hline 6 & Pollution (air, water, plastic) & 2 & $10 \%$ & 1 & $10 \%$ & 0 & $0 \%$ \\
\hline 7 & Biodiversity and ecosystems & 0 & $0 \%$ & 1 & $10 \%$ & 0 & $0 \%$ \\
\hline
\end{tabular}

In summary, there are many sources of inspiration that companies can use to identify their focus topics for sustainability. All companies in our sample make use of the SDGs, and most of them also use stakeholder materiality consultations. Our impression is that sustainability risks, at least those presented in the risk management section of the annual report, are less influential on the company's selection of sustainability topics.

\subsection{Leadership and governance}

Leadership and governance are both key to embedding sustainability. The actions of top management have a crucial effect on (sustainable) decision-making and behaviour throughout the company (see 
e.g., Wall and Berrone 2017; Guiso et al. 2015b), and organisational structures help determine how decisions are made and on what basis.

As background, we need to emphasise that Dutch company law is built on a stakeholder model which requires both management and supervisory board members to take into account the interest of the company and its related enterprise (art. 2:129-5/140-2 of the Dutch Civil Code (DCC)). ${ }^{73}$ Moreover, the management board is responsible for setting the strategy of the company (art. 2:129-1 DCC). In doing so, the Dutch Corporate Governance Code expects the management board to take into account all relevant stakeholder interests and pursue long-term value creation (2016: principle 1.1). These facts shape both the leadership and governance of Dutch listed companies and pave the way for embedding sustainability.

In this section, we discuss four topics which contribute to the embedding of sustainability at the board level. First, we discuss the role of sustainability in the task allocation and selection profiles of management and supervisory board members. Second, we discuss leadership for sustainability (i.e., who drives and manages the company's sustainability agenda) in relation to top management, sustainability managers and the supervisory board. Third, we review the role of sustainability in company remuneration policies for the management board. The fourth sub-section is dedicated to the governance role of sustainability committees at various levels in the company.

\subsubsection{Task allocation and profiles}

The management board is generally responsible for managing the business, including setting and executing the (sustainability) strategy. In doing so, the Dutch Corporate Governance Code establishes in best practice 1.1.1 that the board should pay attention to various items, including "any other aspects relevant to the company and its affiliated enterprise, such as the environment, social and employee-related matters, the chain within which the enterprise operates, respect for human rights, and fighting corruption and bribery". The supervisory board provides advice and supervises, which includes oversight on (sustainability) strategy execution. ${ }^{74}$ It is important, in this regard, for both the management and supervisory boards to have sufficient knowledge on sustainability topics that are material to the company. If sustainability knowledge and associated skills are available, they are more likely to respond adequately to sustainability developments, opportunities, and risks (EY study 2020: 122). Therefore, this subsection examines whether sustainability is present in the task allocation and selection profiles of the management and supervisory boards. We also examine interviewee remarks on the importance of sustainability for the supervisory board selection process.

\section{Management board task allocation and profiles}

In this subsection we examine, first, whether sustainability is included in the task allocation (tasks, duties, or responsibilities) of the management board (or top management team) as specified in company regulations such as the articles of association, rules of procedure or management board bylaws. Second, we check whether companies publish a profile or required competencies to guide the selection of management board members and whether these include sustainability. These two reviews allow us to distinguish, on the one hand, between the tasks and responsibilities of the

\footnotetext{
73 HR 04 April 2014, ECLI:NL:HR:2014:799, ECLI:NL:PHR:2013:1826 JOR 2014/290 m.nt. R.J.G. de Haan (Cancun).

${ }^{74}$ Art. 2:129-1 and 2:140-2 DCC.
} 
management board and, on the other hand, the competencies that companies are looking for with regard to those carrying out these tasks and responsibilities.

In general, we note that many companies in our sample include sustainability as an important task for their management board. This is probably an influence of best practice 1.1.1 of the Dutch Corporate Governance Code given that its phrasing is often mirrored in company regulations.

Table 19: Sustainability in management board task allocation and profiles

\begin{tabular}{|l|c|c|}
\hline & \# of companies & \% of companies \\
\hline Sustainability included in management board task allocation & 27 & $77 \%$ \\
\hline Sustainability included in management board profiles & 7 & $20 \%$ \\
\hline
\end{tabular}

We found that 27 out of 29 companies that publish their management board regulations have allocated sustainability as one of the tasks of the board or top management team; six companies do not publish these regulations. We also find that 28 companies do not publish a profile for the desired competencies and characteristics of their management board. For the other seven companies that do publish a skills profile, we find that sustainability is included as a specific management board competency.

In conclusion, these findings show that even though 27 companies include sustainability as part of the task allocation for the management board or top management team, only seven companies publish a profile on the kind of competencies that they require for the fulfilment of these tasks. This suggests that there is considerable scope for companies to communicate about the kinds of competencies (including sustainability) that they want on the management board.

\section{Supervisory board task allocation and profiles}

This subsection first investigates whether sustainability oversight is included in the task allocation of the supervisory board and second examines whether and how sustainability features in skills profiles for the selection of supervisory board members.

To determine whether sustainability is included in the task allocation of the supervisory board, we investigated company regulations such as the articles of association and supervisory board rules of procedure (charters, by-laws, etc.) which are available on the corporate governance section of company websites. Using these documents, we identified that sustainability oversight is allocated as a task of the supervisory board for all 35 companies in our sample. On closer examination, we distinguished between companies which include sustainability oversight as a broad task for their supervisory board (27 companies) and those which only instruct the supervisory board to formulate a board level policy for diversity (eight companies). The latter group's narrow approach to sustainability seems to do no more than mirror principle 2.1.5 of the Corporate Governance Code. ${ }^{75}$

In the company regulations we also find other methods that companies use to emphasise the role of the supervisory board with regards to sustainability. For example, some companies stipulate that sustainability should be on the supervisory board's agenda at least once per year, or specify that major

\footnotetext{
75 "The supervisory board should draw up a diversity policy for the composition of the management board the supervisory board and, if applicable, the executive committee. The policy should address the concrete targets relating to diversity and the diversity aspects relevant to the company, such as nationality, age, gender, and education and work background" (Principle 2.1.5 of the Dutch Corporate Governance Code).
} 
decisions by the management board which relate to company sustainability or corporate social responsibility need to be approved by the supervisory board.

When we turn to supervisory board skills profiles, our starting point is to emphasise that it is important for supervisory boards to have the right information and to be able to ask the right questions on sustainability matters. The issue of board composition and skills was addressed in the EY Study on directors' duties (2020) and also raised during the EC consultation on sustainable corporate governance. ${ }^{76}$ The Dutch Corporate Governance Code best practice 2.1.1 requires the supervisory board to prepare a profile for the appointment of new supervisory board members. ${ }^{77}$ It indicates that this profile should include, amongst other things, the desired expertise and background of the members and the desired composition of the supervisory board. The profile has to be published on the company website so that it is part of the public domain and can usually be found in the corporate governance section of the website (as a separate document, a text on the website, or as part of their regulations for the supervisory board).

We reviewed these documents and found that the skills profiles of supervisory board members for most companies (54 percent) do not contain any references to sustainability. A general reference to social experience or an awareness of e.g., social or environmental developments did not qualify for our test as a specific competence in a sustainability-related topic. The results are captured in the figure below: ${ }^{78}$

Figure 16: References to sustainability in skills profiles of the supervisory board

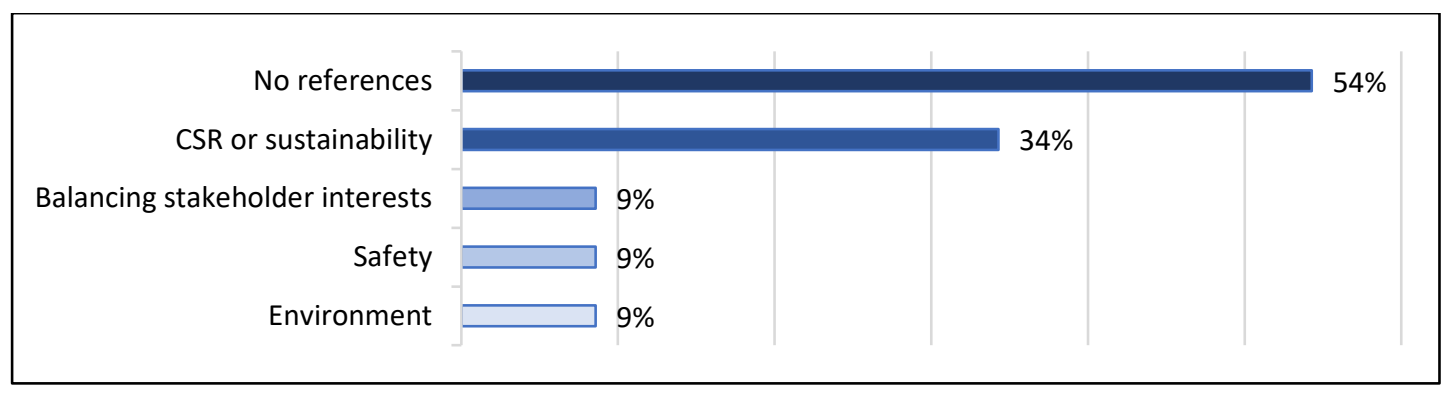

If we include references to 'employee relations' and similar phrases as sustainability references, then 43 percent of companies have no references to sustainability in their supervisory board skills profile. We excluded these phrases from our assessment because their relationship to sustainability is often ambiguous.

The limited references to sustainability in supervisory board skills profiles is surprising given the important oversight role of the supervisory board. It is also surprising in light of the interview remarks from all supervisory board members that sustainability is a responsibility of the whole board. These interviewees had the following to say about the importance of the supervisory board:

"The world is changing, and expectations from boards are changing. So the really important thing a supervisory board member can do, is to bring those changing expectations into the boardroom. That is one of the key roles of a board; to give a long-

\footnotetext{
76 Sustainable corporate governance initiative Summary report - public consultation.

77 Such a profile is also a legal requirement for companies that fall under the Dutch regime of the 'structuurvennootschap' art. 2: 158-3 DCC.

78 Please note that a company can have more than one reference to sustainability (e.g. safety and the environment).
} 
term external perspective towards what is going on in the company. Which may be more focused on the day-to-day and the status quo." [Supervisory board member, AScX service company]

"Increasingly shareholders want to communicate also with the chair of the supervisory board, to see whether these ESG-issues - which are on the agenda of the supervisory board - get enough attention" [Supervisory board member, AEX service company]

"We look to all stakeholders, and by law, in a supervisory board, you have to take them all into account when you make a decision." [Supervisory board member, AScX industrial company]

These findings are also significant in light of interlocking corporate directorships (Useem 1984) and the potential of these relationships for the exchange of (sustainability) practices and information between companies (see also Ortiz de Mandojana and Aragon-Correa 2015). The importance of these interrelationships was confirmed in our interviews:

"What I like to do as a non-executive - I'm involved in four companies now, I've been involved in eight companies - and I like to share learning curves from one industry to another." [Supervisory board member, AEX service company]

"My whole management experience was built up within [another company]. You kind of expect other companies to behave that way or to have the same diligence or the same intellectual intelligence - well, the world is slightly different [...] When you come [to a different company] and you start to ask questions ... for me it was learning in terms of [the] automatic assumption that people think that way - [it] is not there. [...] I would fully subscribe to [the insight] that cross-company functional influence is big. " [Supervisory board member, AScX industrial company]

Overall, we find that there is scope for more companies to include sustainability in their skills profiles.

\section{Interviewee comments on the supervisory board selection process}

We asked interviewees whether sustainability knowledge is a selection criterion for their supervisory board members. They provided a range of responses which help shed light on why companies may choose to have (or not have) supervisory board members with a background in sustainability:

Figure 17: Relevance of sustainability to supervisory board selection

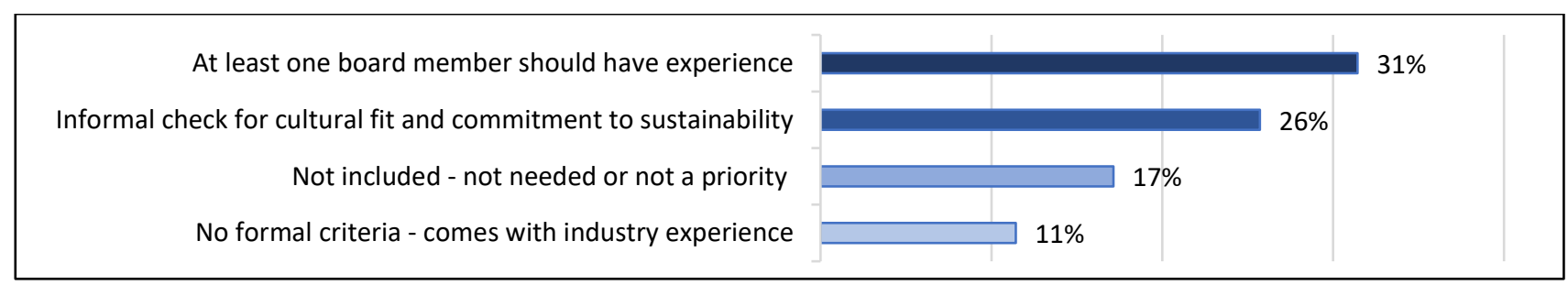

Figure 17 shows that interviewees of nearly a third of the companies (31 percent) mentioned that they wish to have at least one supervisory board member with relevant sustainability knowledge. Furthermore, 26 percent of the companies (only industrials and service companies) put forward that commitment to sustainability and a cultural fit with the company would be a requirement for becoming a supervisory board member: 
"We would be looking for people that understand what the company stands for. They understand the stakeholder model, they understand the approach to sustainability... And if you do not feel comfortable with that, then don't become a supervisory board member. Because then it will be a difficult period for both of us." [Supervisory board member, AEX service company]

28 percent of the companies claimed that they are not looking for specific sustainability expertise at this level, either because it is not a priority (17 percent) or because it comes automatically with industry experience (11 percent):

"We look at people that have knowledge in our field or adjacent areas, and automatically, all those people have experience with sustainability. Because this industry is so in the middle of anything that needs to be sustainable... It's not possible to drive a business like this and not be involved in sustainability challenges. It's always part of the package." [Sustainability manager, AScX industrial company]

"I don't think we're missing much. [...] And in addition, I get inspired and challenged when I exchange ideas with other companies, universities, NGOs and outside consultants." [Management board member, AMX industrial company]

\subsubsection{Leadership in sustainability embedding}

In this subsection, we use interviewee perceptions to examine who drives and manages the company's sustainability agenda, to investigate the role of sustainability managers, and to look more closely at the supervisory board oversight function.

In general, interviewees disclose a range of drivers which promote sustainability in the company. In almost all company interviews (97 percent), members of the top management team (management board and executive committee) were mentioned as the key driver of change regarding sustainability. This indicates that the sustainability agenda is generally managed top-down. The sustainability manager or team, a staff function that often directly reports to top management, also plays a crucial role in setting the sustainability agenda ( 43 percent). In a smaller number of cases, business unit directors are also key influencers of the sustainability agenda (20 percent), although some are potentially also part of the top management team. Interestingly, supervisory board members were rarely mentioned as drivers and promotors of sustainability embedding (11 percent).

Figure 18: Key drivers of the sustainability agenda

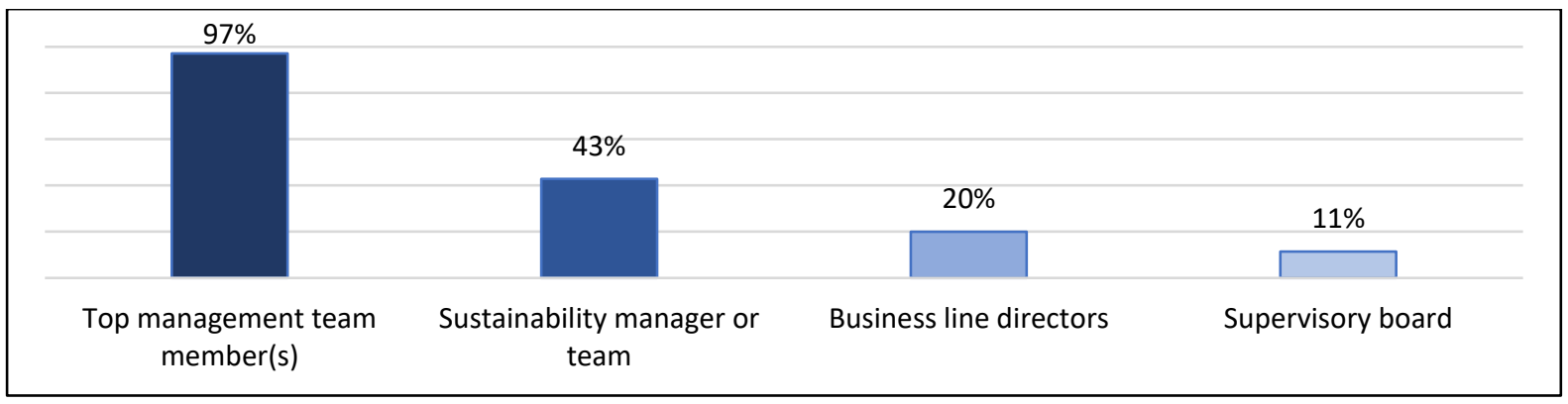




\section{Top management and sustainability embedding}

The interviews showed that for many companies the role of the CEO in promoting sustainability is crucial. CEOs are deemed to be proactive and important drivers of the sustainability embedding process:

"Of course the CEO plays a central role. He demands from the teams, also from me, that we come up with an approach that answers to today's challenges. And if we run behind, or new issues pop up, he will ask one of the people to work on them and to come up with a solution." [Sustainability manager, AScX industrial company]

The interviews identified the CEO as the main driver of sustainability in 83 percent of the companies. However, driving sustainability was often also a team effort. Most interviewees stressed that the CEO is jointly leading this effort with selected top management representatives ( 37 percent) or even with all members of top management (31 percent). In 26 percent of the companies, one dedicated member of top management is driving, but we cannot rule out that others are not involved informally.

\section{Figure 19: Who is driving sustainability within the top management team?}

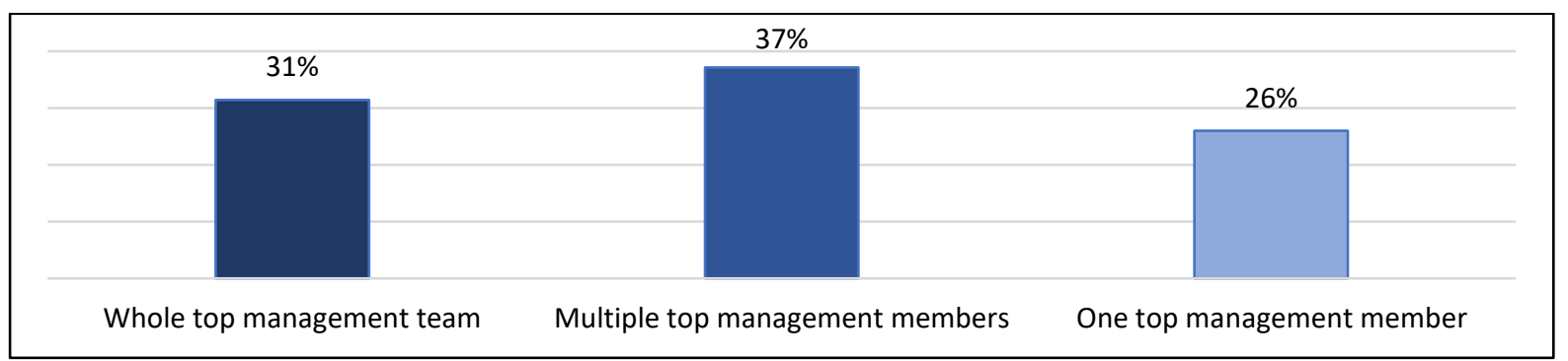

When asked how often sustainability-related topics are discussed in meetings of the management board, the majority of the interviewees (69 percent of companies) mentioned that it is being discussed quarterly or more often, indicating that sustainability is a regular topic on its agenda. We also discussed the range of top management activities on sustainability with our interviewees. These findings can be found in Figure 20:

Figure 20: Top management activities on sustainability

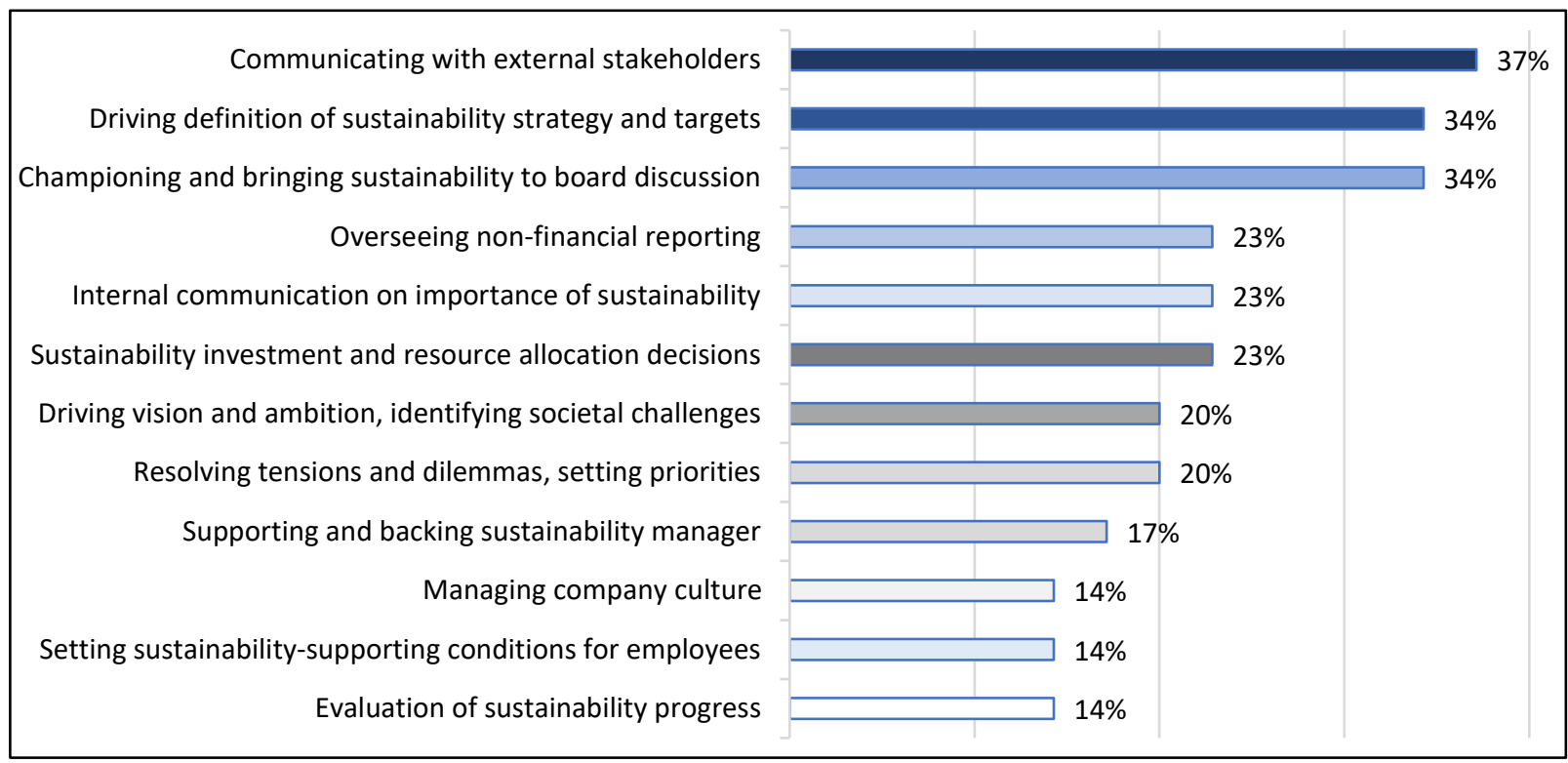


The figure shows that defining and driving the vision and ambition in sustainability embedding, signalling its importance to the organisation, and communicating with internal and external stakeholders are self-reported key activities undertaken by top management.

\section{Sustainability managers and sustainability embedding}

We showed above that management boards play an important role in the embedding of sustainability. Many companies establish staff roles or teams that support top management with the planning, implementation, and dissemination of sustainability programmes in their organisations. These are generally labelled sustainability managers or sustainability management teams.

During our interviews, we talked to 31 sustainability managers. A 'sustainability manager' is the person in charge of sustainability and, if applicable, leading the sustainability team. Since not all companies have a dedicated full-time sustainability role, we also viewed a person who performs this role alongside of their other functions as a sustainability manager (as indicated by interviewees from 14 percent of companies).

Most companies have a sustainability manager, or a sustainability team, including those that said they were engaged with sustainability for many decades. Remarkably, even among the larger companies, core sustainability teams remain relatively small in terms of full-time equivalents.

Figure 21: Sustainability team size

\begin{tabular}{|c|c|c|c|}
\hline \multicolumn{4}{|c|}{$37 \%$} \\
\hline \multicolumn{4}{|l|}{$26 \%$} \\
\hline & & $11 \%$ & $14 \%$ \\
\hline $\begin{array}{l}\text { One sustainability manager } \\
\text { (part-time or full-tiime) }\end{array}$ & Small team 2-4 people & Team of 5-10 people & Team of more than 10 people \\
\hline
\end{tabular}

As a reason for these relatively small teams, some interviewees mentioned that, after a phase of starting up the sustainability program, the actual execution of sustainability initiatives gets distributed into business units. In fact, interviewees from several companies described a process of starting out with a larger sustainability department which they ended up downsizing as the sustainability responsibilities got dispersed throughout the rest of the organisation:

"In the old days we had a whole CSR department with many people working there, but the problem was that it wasn't incorporated in the different business units, so we decided to make a small headquarter department, where we make targets, advice and support. But the business is responsible for the execution of the targets." [Sustainability manager, AMX service company]

"There used to be more, but we reorganised the team. [...]To develop and sell sustainable products, you need to be very close to your customers and that is something that part of my team was trying to do and frankly we weren't successful at that. And the reason we weren't successful is that we were too far away from where the business is being done." [Sustainability manager, AScX industrial company] 
However, the differences in sustainability team sizes are partly influenced by company size, with nearly all companies that have a team of more than five people being larger AEX companies, while those with one sustainability manager are almost exclusively smaller or mid-size companies. We find less influence from sector on the size and composition of the sustainability team.

Sustainability managers and teams can be situated at various levels within an organisation. One common denominator is that for many of the companies, the sustainability manager reports directly to a member of the top management team. Despite the broad variety in the composition of sustainability teams and the location of the function within the organisational structure, the list of tasks and activities of the sustainability manager is rather similar across companies of different sizes and different industries.

Figure 22: Tasks and activities of sustainability managers / teams

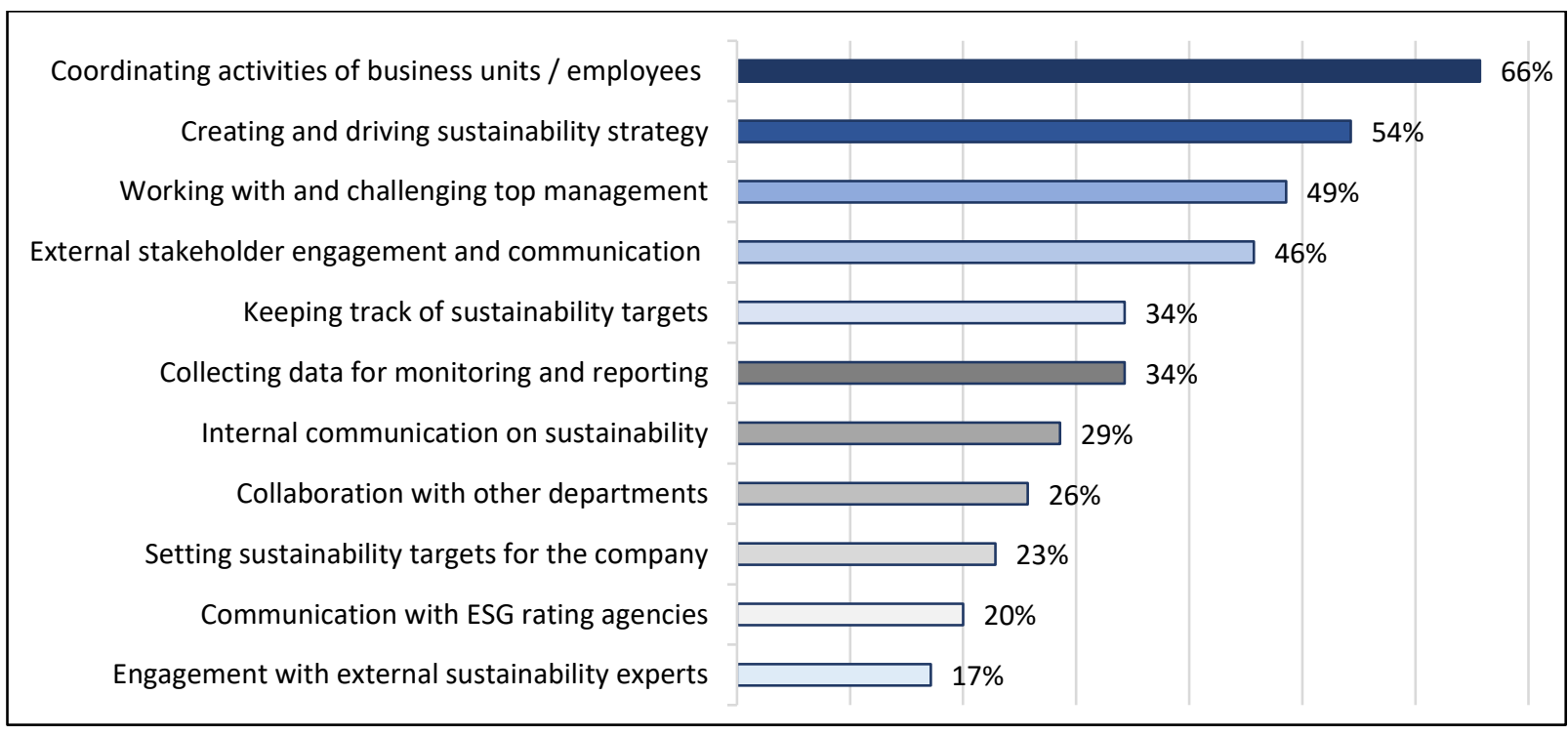

The main activities of the sustainability manager involve coordination and communication rather than the operational aspects of sustainability, which is most often delegated or dispersed to other business units. Most of the job involves stakeholder management and serving as a connection between the top management team and the rest of the business regarding sustainability topics. In some cases, they additionally coordinate and support the hiring of external expertise to advise on the design of the sustainability framework or selected sustainability topics that are relevant to the company or parts of the company.

Sustainability managers and teams can serve as an important knowledge provider for sustainability. The sustainability team serves as a centre of expertise that advises the rest of the company in 40 percent of the companies:

"Sustainability is not a standalone thing, but you need a functional expertise centre. A community of experts that really deeply understands what are Science-Based Targets, where do you need to be in terms of climate action, how do you implement an eco-design program, what is purpose-driven innovation, how do you issue social impact bonds... That's where you need a staff department that has the expertise and empowers people and coordinates all these activities." [Sustainability manager, AEX industrial company] 
Interviewees of approximately one-third of the companies also mentioned, aside from their sustainability teams, that they have subject matter experts located within their business units who have knowledge on a particular aspect of sustainability (such as energy reduction or diversity and inclusion).

Summarising, top management is responsible for the embedding of sustainability. Sustainability managers support management with the planning and implementation of sustainability initiatives. They can also support the onboarding and education of management and supervisory board members.

\section{Supervisory board and sustainability embedding}

At the beginning of this section on leadership and governance, we discussed that sustainability oversight is allocated as a task of the supervisory board for all 35 of the companies in our sample. The issue of the supervisory boards' role in relation to sustainability also came up during the interviews. All 19 of the supervisory board members that we interviewed indicate that sustainability is the responsibility of the whole board. This underscores the importance of adequate sustainability knowledge and skills at this level of the company.

Figure 23 draws on the full interviewee sample and shows a wide range of activities that supervisory board members are involved in when it comes to sustainability supervision. Board members are regularly involved in discussions on sustainability reporting, the role of sustainability in strategy (and purpose), the role of culture in the embedding process, and setting targets related to sustainability.

Figure 23: Supervisory board oversight function regarding sustainability embedding

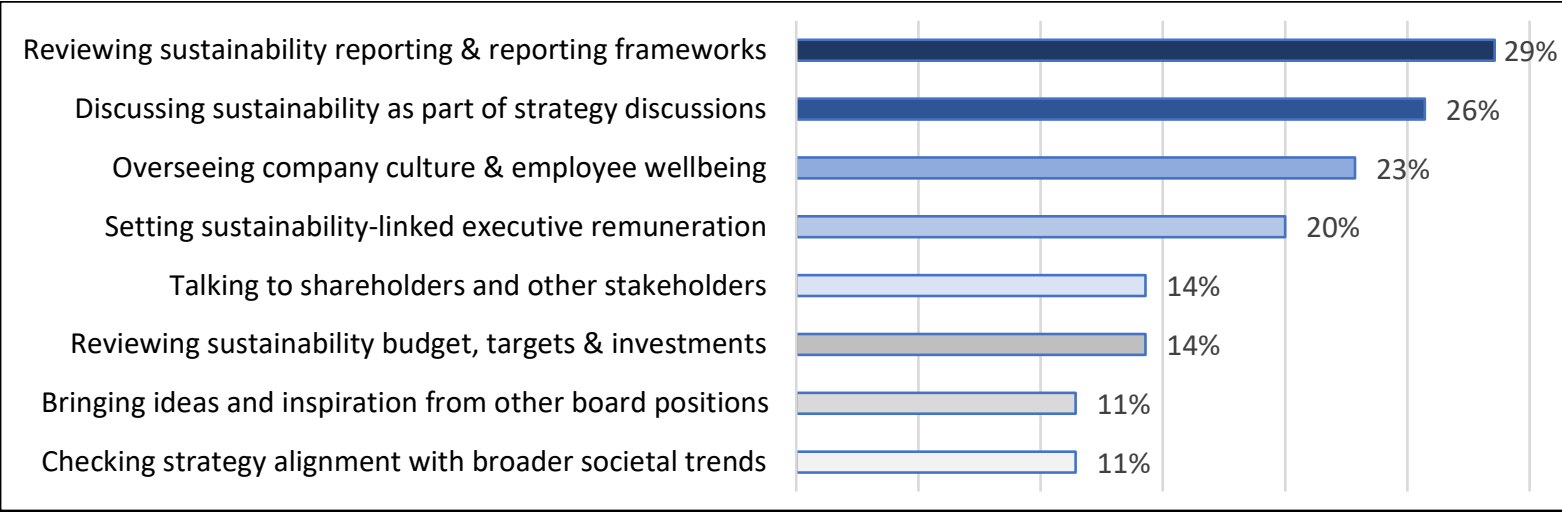

While there are only seven companies with a dedicated sustainability committee on the supervisory board (discussed in section 2.2.4), interviewees from several companies pointed out that sustainability is on the agenda of other supervisory board committees. For example, the remuneration committee discusses sustainability-related remuneration targets, the nomination committee plays an important role in the selection of management and supervisory board members, and the audit committee also oversees nonfinancial reporting.

Since supervisory boards only meet a few times per year, the frequency of discussions on sustainability is lower than that for the management board. The most common response is that sustainability is a fixed item on the supervisory board agenda at least once or twice a year; mainly during meetings in which the board discussed the annual review and strategy planning for the following year. For some companies, the sustainability topic is also part of the quarterly update process and performance reporting that is delivered to the supervisory board. 
In general, most interviewees reported a strong level of alignment between supervisory and management boards on the direction of the company's sustainability and strategic positioning. This is despite differences in perspective that were reported to arise due to the various board members' roles and functions ( 26 percent of companies) or differing preferences on the speed or ambition of the company's sustainability transition (23 percent of companies). While not every company has board members that are all committed and passionate about the topic, none reported having board members who deny the importance of the topic or fight against the embedding of sustainability.

\subsubsection{Management board remuneration}

Top management remuneration is often controversial given its potential, when poorly designed, to exacerbate corporate short-termism, to create negative externalities, and to contribute to inequality (EY 2020; Edmans 2021b). This controversy is partially due to broader social issues such as disparities in pay between, for example, CEO remuneration and average incomes, but also arises from the way that remuneration packages may generate perverse incentives at the expense of the long-term interests of the company, society, and the environment. We do not address pay levels and issues of inequality since these are beyond the scope of this report, but focus our discussion in this subsection on the structure of remuneration packages for the management board and their relationship to sustainability.

In this regard, the main development is the recent trend for companies to link the management board's remuneration to corporate sustainability objectives (Ikram et al. 2019; EY 2021; PWC 2020; Eccles et al. 2014). Research has shown that this "leads to an increase in long-term orientation; ii) an increase in firm value; iii) an increase in social and environmental initiatives; iv) a reduction in emissions; and v) an increase in green innovations" (Flammer et al. 2019: 1). Moreover, it finds that companies with a stakeholder corporate governance model (such as the Netherlands) should benefit from a "large positive impact on human resources, environmental, and human rights performance" if they adopt sustainability-related remuneration (Cavaco et al. 2020: 240). Moreover, sustainability remuneration targets can be used to signal externally and internally how important the topic is to the company. They can also be used as a test to check whether the company is fulfilling its purpose and related strategy (PWC 2020: 6, 29); these targets were cited in the 2021 Shell case as evidence of their sustainability activities (Milieudefensie $v$. Shell).

However, contrary views also exist which claim that installing ESG targets in executive remuneration can in some instances have a downside (Edmans 2021b). For example, they could kerb intrinsic motivation or decrease shareholder value (PWC 2020). Moreover, setting sustainability targets is not always easy and it may be difficult to evaluate whether they have been achieved (PWC 2020; Edmans 2021b).

Aside from its merits, integrating sustainability-related remuneration targets may also be at the explicit wish of shareholders. Recent changes to the Shareholder Rights Directive (SRD), implemented in art. 2:135a of the Dutch Civil Code (DCC), give shareholders a strong influence over director remuneration. Companies that are listed on stock exchanges in the European Economic Area should have a remuneration policy that is adopted by the general meeting at least once every four years with a three-quarters majority vote. Every year the company must also submit to the general meeting a remuneration report for an advisory vote (art. 2:135b DCC). The adoption of the remuneration proposals can be delegated by the general meeting to another body, for example the supervisory 
board. However, even if this has been delegated the general meeting will nevertheless have to provide approval if the remuneration proposal includes compensation by means of shares or option rights (art. 2:135-5 DCC). Companies are required, when setting the remuneration policy, to explain how it contributes to the strategy, long term value creation, and sustainability of the company as well as how public opinion has been taken into account (art. 2:135a-6 DCC).

\section{Remuneration as a driver}

As shown above, the literature is ambiguous on whether management board remuneration is always a useful tool for embedding sustainability (Flammer et al. 2019; Maas 2018; Edmans et al. 2021). We found a similar ambiguity among our interviewees, with the majority of the surveyed companies expressing a positive opinion on the topic:

"Ultimately, I still believe that, if it is in your KPIs, people want to meet that KPI - so it helps" [Supervisory board member, AMX service company]

"People make decisions based on money, so having bonus pay that depends also on sustainability performance is an absolute must to fully embed the sustainability culture in the organisation. Otherwise it's a very half-hearted commitment." [Sustainability manager, AEX industrial company]

"To have a system where you benchmark performance against targets is helpful, because it brings focus. So, to have it on your scorecard and to have it at the end of the day also as part of your remuneration, I think, is important. I would clearly recommend that if companies want to go into certain directions and you want to drive certain activity, you have to make it also part of the remuneration." [Management board member, AMX industrial company]

Interviewees from a minority of companies expressed their reservations regarding variable remuneration and sustainability:

“My personal learning is that variable rewards just don't work. It intensifies the wrong behaviour. As soon as people have targets on certain issues, their focus will be on those issues, and those become isolated from the whole strategy of the company...

"I rewarded a colleague with a certain bonus because he met his agreed targets and did the job well and he walked away happy. Next day he heard that his colleague got a reward that was slightly higher. From that moment he was unhappy with his bonus and he remained unhappy for months. So I've seen all the negative impacts of variable rewards." [CEO, AEX service company]

"You have to be careful not to give mixed incentives to the executives. Because if you say, 'I'm going to reward you on the share price and on achieving your revenue and profit targets, but I'm also going to reward you on sustainability', and the two are in conflict, then the executive will choose whichever is more financially rewarding to him or her." [Supervisory board member, AMX industrial company]

An interesting finding, aside from these divergent opinions, is that the most frequently mentioned benefit of sustainability-linked remuneration was not that it would have a significant effect on individual behaviour. Instead, interviewees from almost half of our companies described it as a 
signalling device for the benefit of external and internal stakeholders (consistent with Maas 2018). As explained by one management board member:

"If you want to integrate everything, you need to align it all. If you decide sustainability is a key strategic topic for your company, and you work with a variable remuneration framework, then you should include non-financial KPIs next to the financial KPIs; otherwise you make the non-financial KPIs again less important than the financial ones." [Management baord member, AEX service company]

However, interviewees from roughly one-third of companies did argue for various reasons that sustainability remuneration has an effect on individual behaviour:

"I want to focus on it and this is going to keep me honest on it." [CEO, AMX industrial company]

"It's like - why do we have speed limits on the highway? Why do you ever have any specific quantifiable expression of what success looks like, or where the boundaries are? It's because it drives behavior." [Top management team member, AEX industrial company]

"There are many studies that show if you have a performance-based payment scheme it doesn't need to be more than $2 \%$ or $3 \%$ to influence the psychology." [Sustainability manager, AEX industrial company]

This effect stands in contrast to the accounts of management board members from nine of our sample companies who stated that they, personally, are not driven by their remuneration targets:

"I don't care about any target, I just do what's right. So, if they put certain targets in my bonus, I'm not looking at it. At the end of the year they need to calculate it and that's it. Same for long-term incentives, I'm not working towards the targets or the metrics... I just do what's right." [Management board member, AMX industrial company]

"I don't think I would work any differently with regards to sustainability or otherwise if there was a bonus attached to it" [Management board member, service company]

\section{Sustainability embedding in remuneration policies}

Before turning to the desk research results on remuneration, we briefly discuss the EY Report on Executive Remuneration in the Netherlands 2021. ${ }^{79}$ This study reviewed the 2020 implementation of remuneration policies for the full range of 66 AEX, AMX, and ASCX companies (it has, in other words, a larger sample than our report). The study found that sustainability was included in the short-term incentives (STI) of only 26 percent of companies, and in the long-term incentives (LTI) of only 35 percent of companies. The average weight of sustainability remuneration was 19 percent for STIs and 20 percent for LTIs.

It should be noted, however, that the EY study and this report do not share the same definition of sustainability. In our review we included various aspects of safety, diversity, and strategy as part of a

\footnotetext{
${ }^{79}$ There is also a survey by PWC on Executive and Non-Executive Remuneration 2020. We do not discuss this report because it analyses non-financial remuneration which, for the same reasons as noted for non-financial risks in section 2.1.2, cannot be equated with sustainability.
} 
broad approach to sustainability while the EY study defined sustainability more narrowly and created separate categories for people, health and safety, and strategy. We felt that it would be redundant for this report to simply repeat the findings of the EY study with a different set of definitions, so we decided to focus our desk research efforts on remuneration policies, rather than remuneration reports which show how remuneration was awarded over the past year.

We found that 86 percent of our sample companies include sustainability, broadly defined, as part of their remuneration package. Twenty-six percent of companies include sustainability only in their STIs, 23 percent of companies only include it in their LTIs, and 37 percent of companies include it in both their STIs and LTIs. These percentages are shown in the following figure:

Figure 24: Company remuneration incentives and sustainability

\begin{tabular}{|r|c|}
\hline Not included & $14 \%$ \\
STI only & $26 \%$ \\
\hline LTI only & \\
\cline { 2 - 2 } Both STI and LTI & $23 \%$ \\
\cline { 2 - 2 } & \\
\cline { 2 - 2 } & \\
\hline
\end{tabular}

Looking at the 22 companies which include sustainability ${ }^{80}$ as part of their STIs (or both STIs and LTIs), we found that 16 of them do not disclose how much weight will be given to sustainability in 2021 (or upcoming years). For the six companies that do provide this information, we found that sustainability will be between 6 percent and 17.5 percent of the total STI, with an average weight of 11 percent. This group of 22 companies commonly referred to sustainability objectives in a generic manner, for example, 'sustainability' rather than something more specific like diversity targets, GHG emissions reduction or employee engagement scores. Only 41 percent of them give a clear indication of what sustainability performance will be required for 2021, and none of them disclose the expected KPIs for sustainability performance.

Next, we considered the 21 companies with sustainability in their LTIs. Our results show that nine of them do not clearly specify how much weight will be given to sustainability in 2021 (or upcoming years). For the other 12 companies we found that sustainability will count for between 6 percent and 50 percent of total LTI, with an average weight of 22 percent. Of the full group of 21 companies, only 52 percent have specific rather than generic sustainability objectives, and only two companies include KPIs.

We also identified that, of the whole group of 30 companies with sustainability in their STI, LTI, or both, 16 of them do not disclose whether their future sustainability remuneration targets are related to benchmarks which are internal or external to the company (e.g., an internal benchmark is their GHG emissions while an external target is a ranking on the Dow Jones Sustainability Index). For the companies that do disclose this information, we found that nine of them connect their sustainability remuneration to internal benchmarks, two of them to external benchmarks, and three companies to both internal and external benchmarks.

\footnotetext{
${ }^{80}$ We did not include 'nonfinancial performance' in our definition of sustainability since this could also relate to other management ambitions (e.g., digitisation).
} 
Overall, it is noteworthy that companies disclose only limited information about the prospective application of their remuneration policy. While to an extent, this dearth can be justified for competitive reasons, it may also undermine the signalling function of sustainability remuneration that was identified by many of our interviewees as the key reason to connect sustainability and variable remuneration. Our interview findings suggest this effect may be due to difficulties in setting appropriate sustainability targets, with 37 percent of companies voicing reservations about difficulties involved with sustainability targets. One interviewee shared that:

"Many companies struggle with what is the right target setting for sustainability in longterm incentives. We have also spent quite some time on this. We now have a number of good sustainability targets. We will have to see how that works." [Management board member, AEX industrial company]

These difficulties - in addition to the relative novelty of these incentives - may also explain the modest share of sustainability-related remuneration in the overall remuneration packages of the management board.

\subsubsection{Sustainability committees}

Sustainability can also be integrated into governance using dedicated sustainability committees. These committees can take various forms and sizes and can be located at different levels within the company. A primary distinction can be drawn between internal committees which consist only of people who work within the company, and external ones which include stakeholders or sustainability specialists from outside the company (but may be chaired by insiders such as the CEO or chairman of the supervisory board).

Internal committees can be further divided into those which operate at the supervisory board, top management and other management levels (e.g., a business unit or production site) of the company. Research on board committees shows that they can improve the effectiveness and design of sustainability strategies (Orazalin 2020). They can also signal a company's shift towards a more stakeholder-oriented direction (Burke et al. 2019) and may be installed for reputational reasons or following a request by shareholders (Dixon-Fowler et al. 2017). In general, these committees can help set goals and promote accountability for sustainability embedding, although the literature on their performance and effect on sustainability performance remains inconclusive (for an overview see Orazalin 2020).

External committees are less common, although they are gaining more and more attention in the literature and corporate practice (Winter et al. 2021; De Jongh 2021). The idea is that these committees can be used as a stakeholder management tool and to enhance the company's knowledge of sustainability and related issues. These committees are not a formal part of the governance structure, but usually have an advisory role regarding certain sustainability topics or sustainability in general. Looking at current corporate governance developments, we expect that these committees will play an important role in the future. Some authors in the Dutch literature propose to include the addition of these committees (maatschappelijke raad) to the Dutch Corporate Governance Code (Winter et al. 2021; De Jongh 2021). The European Parliament also supports the introduction of company advisory committees with stakeholder representatives; these committees could be given the right to request an independent audit if there are concerns regarding the implementation of the sustainability strategy (European Parliament resolution (2020/2137(INI)). 
In our desk research, we examined how many companies have internal or external sustainability committees, and how many of these committees they have. We searched annual reports, company websites, and a range of public sources for this information and adopted a broad understanding of the term 'sustainability committee' for any collective decision-making or advisory body which is dedicated to sustainability-related topics. The figure below shows how many companies have no committees, and how many of them have one, two, three or more.

Figure 25: Companies with dedicated sustainability committees

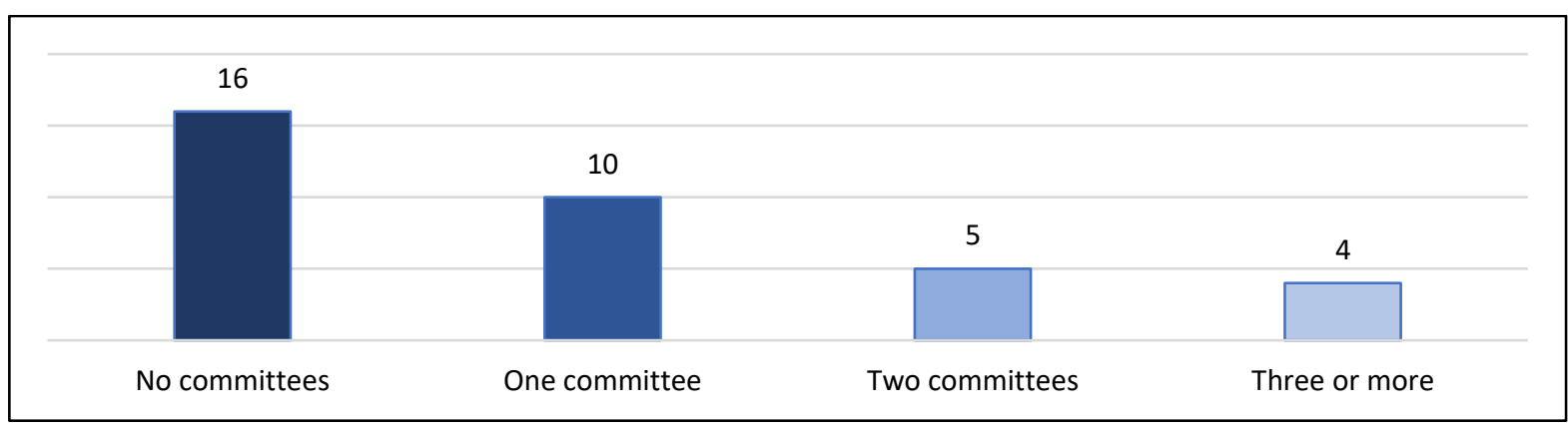

Sixteen companies do not seem to have a sustainability committee, at least according to their public information. Ten companies have one committee, five companies have two committees, and four companies have three or more sustainability committees. We also examine for internal sustainability committees the level of the hierarchy at which they operate:

Figure 26: Governance level of internal sustainability committees

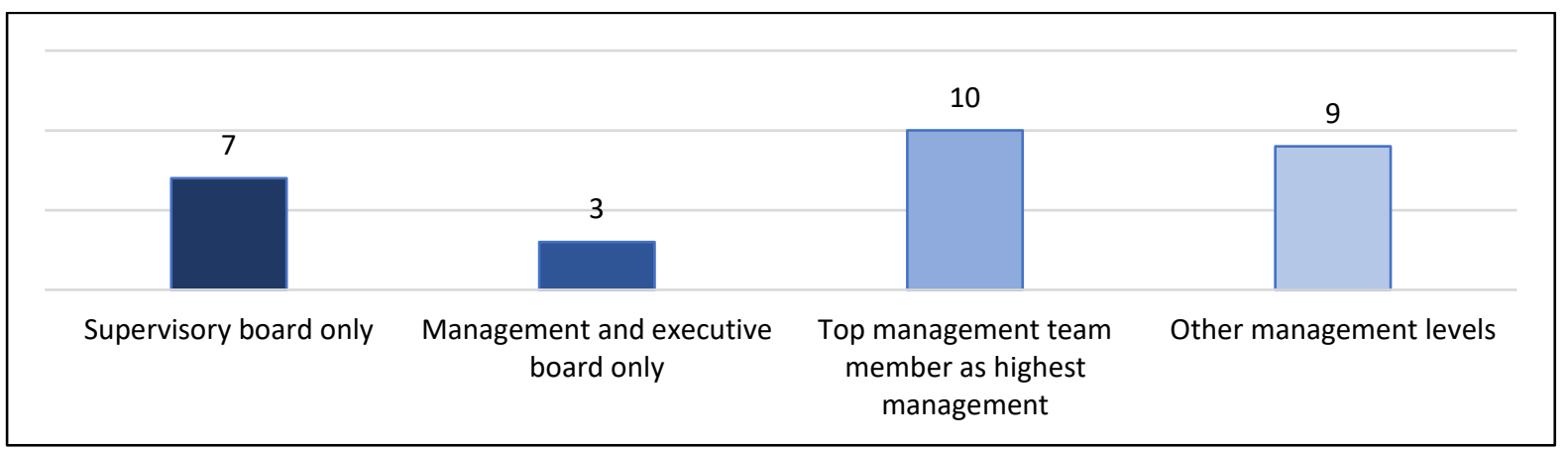

Seven companies have a sustainability committee at the supervisory board level. Three companies have a sustainability committee with only management and executive board members. Ten companies have a sustainability committee where a member of the top management team is the highest-level management (other management levels are also involved). Nine companies have sustainability committees at other management levels, for example for business units or production sites.

Size analysis (see Table 20 below) showed that AEX companies are considerably more likely to have an internal sustainability committee at the level of the supervisory board or to have a committee with a member of top management as the highest level of management. 
Table 20: Size analysis for governance level of internal sustainability committees

\begin{tabular}{|c|c|c|c|c|c|c|}
\hline & \multicolumn{2}{|c|}{ Supervisory board only } & \multicolumn{2}{|c|}{ Top management only } & \multicolumn{2}{|c|}{$\begin{array}{l}\text { Top management member as } \\
\text { highest management }\end{array}$} \\
\hline & \# of companies & $\%$ of index & \# of companies & $\%$ of index & \# of companies & $\%$ of index \\
\hline AEX & 5 & $36 \%$ & 1 & $7 \%$ & 6 & $43 \%$ \\
\hline AMX & 1 & $11 \%$ & 2 & $22 \%$ & 1 & $11 \%$ \\
\hline AScX & 1 & $8 \%$ & 0 & $0 \%$ & 3 & $25 \%$ \\
\hline
\end{tabular}

Sector analysis (see Table 21) showed that industrial companies are most likely to have an internal sustainability committee at the supervisory board level and that real estate companies are the most likely to have a committee which consists solely of the top management team.

Table 21: Sector analysis for governance level of internal sustainability committees

\begin{tabular}{|c|c|c|c|c|c|c|}
\hline & \multicolumn{2}{|c|}{ Supervisory board only } & \multicolumn{2}{|c|}{ Top management only } & \multicolumn{2}{|c|}{$\begin{array}{c}\text { Top management member as } \\
\text { highest management }\end{array}$} \\
\hline & \# of companies & $\%$ of sector & \# of companies & $\%$ of sector & \# of companies & $\%$ of sector \\
\hline Industrial & 6 & $30 \%$ & 1 & $5 \%$ & 6 & $30 \%$ \\
\hline Service & 1 & $10 \%$ & 0 & $0 \%$ & 3 & $30 \%$ \\
\hline Real estate & 0 & $0 \%$ & 2 & $40 \%$ & 1 & $20 \%$ \\
\hline
\end{tabular}

Regarding external sustainability committees, we found that only three companies have such a committee. This is in line with the EY Study which highlighted that the use of such advisory bodies is not (yet) a widespread practice (EY 2020).

We also discussed with our interviewees whether it could be useful to introduce a sustainability committee at the board level during the interviews. They expressed a range of opinions, with interviewees from a majority of companies saying that sustainability is a whole board topic and that there is therefore no need for a separate committee. Others responded that a sustainability committee has a preparatory role but that the topic is still decided by the full board.

The most common argument for a sustainability committee was that it responded to the need to go into more detail than would be possible at regular board meetings, while not denying that the topic also needs to be discussed with the full board:

"Sustainability is so important and has a broad impact that we discuss it at both a subcommittee level i.e. at the Corporate Responsibility Committee, the Audit Committee and the Remuneration Committee, and then again at the board. This gives the opportunity to ensure it is covered in enough granularity" [Risk manager, AEX industrial company]

"In a way it's a whole board issue. But you can't do the depth of discussion and analyses we do on the sustainability committee. We then report out to the full board" [Supervisory board member, AEX industrial company]

The most common argument against a separate sustainability committee was that the topic should be part of the usual board agenda. There were also interviewees from three companies who explained that they had so few board members that forming another committee would be unfeasible:

"Supervisory board members feel it's such an important element it should not be delegated to a committee but it should be discussed in the full supervisory board. They 
are also a bit afraid of 'Well, then I do not hear all the discussions and I only hear the summary of the discussions'." [Supervisory board member, AMX industrial company]

"It was a deliberate choice to make it part of normal management instead of having a separate committee discussing sustainability. It does not fit our culture - our culture is much more bringing about sustainability via line management" [CEO, AMX service company]

Among the companies that have a board-level sustainability, nearly all of them are larger AEX industrial companies - therefore, the decision of forming a dedicated committee seems to partially depend on company size and resources.

However, more importantly, forming a sustainability committee seems to be a function of the scope of the sustainability challenges of the company and of considering the added value that would counterbalance the increased time and resource expenditure that the committee would claim.

\subsection{Supply chains, sustainability reporting, employees and culture}

Corporate purpose, strategy, leadership, and governance are important, but they are by themselves not enough to ensure that a company comprehensively embeds sustainability. Equally important, as noted in the earlier subsection on stakeholder drivers, are the connections between the company and its stakeholders (Freeman 2010). These parties can have a positive and negative influence on sustainability embedding, and it is important for the company to be aware of them and to navigate their interests in a way which contributes towards alignment with planetary boundaries and company success. Managing relationships with stakeholders is therefore an essential part of sustainability embedding for any company (Eccles et al. 2014).

This section reviews three areas of stakeholder management for our sample of Dutch listed companies: supply chain management, sustainability reporting, and employees and culture. Each of these areas is discussed in turn together with our desk research and interview findings.

\subsubsection{Supply chain management}

Supply chain management is an essential part of company operations and sustainability (Pankratz and Schiller 2021). It is necessary for reliable and efficient coordination of production and services, and for understanding the direct and indirect scope of a company's social and environmental risks and impacts (Pankratz and Schiller 2021). Moreover, it provides a vital input for product life cycle assessments, which in turn is key to circularity, emissions reduction, and staying within planetary boundaries (Blass and Corbett 2018).

We previously noted that 71 percent of our company sample has a supplier code of ethics, and we found that 56 percent of them provide some details on the application, auditing, or identification and handling of breaches of these codes. However, it was difficult using publicly disclosed information to obtain a picture of how supply chain relationships and sustainability are mediated by supplier codes. For this reason, we focus our assessment of supply chain management on the company's due diligence. 


\section{Due diligence}

The section on legal drivers explained that due diligence requirements for sustainability-related topics are receiving increased attention from national and European legislators. Further, the European Parliament recently adopted a recommendation to the commission for a proposed Directive with a mandatory requirement for supply chain due diligence on human rights, the environment and good governance (European Parliament resolution (2020/2129(INL)). Moreover, the Accounting Directive established that EU companies falling within its scope should disclose the "due diligence processes implemented by the undertaking, also regarding ... its supply and subcontracting chains, in order to identify, prevent and mitigate existing and potential adverse impacts" (Recital 6) in their annual report, as reflected in article 19a of the directive.$^{81}$ It is because of these existing expectations and anticipated requirements that we examine the due diligence practices of our company sample.

For the purpose of this section, we have assumed that the content of future mandatory legislation in this area will follow the due diligence process that was pioneered by the UNGPS. This process entails four general steps (if we exclude access to remedies ${ }^{82}$ ):

1. Assessing actual and potential human rights impacts

2. Integrating and acting on the findings

3. Tracking responses

4. Communicating about how impacts are addressed

We examined what our company sample reports on in relation to these steps and identified the following information from their annual reports. For this assessment, we searched for named due diligence approaches, that is, for activities which companies themselves identified as a due diligence process. However, companies might engage in more due diligence-type activities than we identified. We nonetheless felt that it would be insightful to examine the current gap between the human rights and environmental due diligence of the companies and the likely content of upcoming due diligence standards.

For human rights, we identified that 12 out of 35 companies (34 percent) have a named due diligence process. Only seven of these 12 companies report on all four steps. Therefore, the preliminary assessment shows that only 20 percent of our company sample satisfied the due diligence expectations of the corporate responsibility to respect human rights (as currently included in both the UNGPS and the OECD Guidelines).

For the environment, we found that only three out of 35 companies ( 9 percent) have a named due diligence process for environmental harms. Insufficient information was available to evaluate whether these companies report on all four steps of the due diligence process. To add nuance to these results, it is worth recalling that 71 percent of the companies have a supplier code which may also include environmental aspects. Moreover, we found that 62 percent of the companies have a responsible procurement policy in place which partially overlaps with due diligence requirements for the environment.

\footnotetext{
81 Directive 2013/34.

82 This is justified since it closely overlaps with the requirements of the EU whistleblower directive (Directive (EU) 2019/1937 of the European Parliament and of the Council of 23 October 2019 on the protection of persons who report breaches of Union law).
} 


\subsubsection{Sustainability reporting}

The section on stakeholder drivers explained how company reporting provides stakeholders with valuable information for their decision-making. Moreover, the section on legal drivers showed that not only the EU Taxonomy and NFRD, but also a newly proposed directive on corporate sustainability reporting, are driving activity on company sustainability reporting. Working together, these drivers make it possible for governments, NGOs, customers, investors, and others to incentivise or hold companies accountable and help competitors, investors, and rating agencies understand what is happening in the market. It is in support of these purposes that this subsection examines the sustainability reporting practices of our company sample.

We will first present an overview of the reporting frameworks that are used by the companies. Second, we will review the opinions of our interviewees regarding the role of reporting in sustainability embedding. Third, we will examine company reporting practices on various topics which relate to our section on environmental drivers. We will lastly present what companies are doing to provide assurance regarding their sustainability reporting.

\section{Sustainability reporting frameworks}

Our company sample uses a wide range of reporting frameworks and normative standards to guide their reporting and embedding of sustainability. Their annual reports show that they refer to almost 50 different frameworks and standards to guide their activities (see Appendix V).

If we set aside the UN SDGs and various ISO certificates, then companies refer most often in their annual report to the GHG Protocol from the World Resources Institute and the World Business Council for Sustainable Development (86 percent of companies), the Global Reporting Initiative's (GRI) Standards (77 percent), the Carbon Disclosure Project (57 percent), Taskforce on Climate-Related Financial Disclosures (54 percent), and the International Integrated Reporting Council's (IIRC) International Integrated Reporting Framework (49 percent). Companies refer, on average, to three of these reporting frameworks in their annual report, with nine companies referring to all five.

Table 22: Reporting frameworks most often referred to by companies in annual reports

\begin{tabular}{|lcc|}
\hline GHG Protocol & \# of companies & $\%$ of companies \\
\hline GRI Standards & 30 & $86 \%$ \\
\hline Carbon Disclosure Project & 27 & $77 \%$ \\
\hline Taskforce on Climate-Related Financial Disclosures & 19 & $54 \%$ \\
\hline IIRC Integrated Reporting Framework & 19 & $54 \%$ \\
\hline
\end{tabular}

Other noteworthy reporting and normative frameworks include the UN Global Compact, the OECD Guidelines for Multinational Enterprises, Institutional Shareholder Services' ESG ratings, the Sustainability Accounting Standards Board (SASB) standards, $\mathrm{MSCl}$, European Public Real Estate Reporting Guidelines, the UN Guiding Principles on Business and Human Rights, and the Dow Jones Sustainability Index.

However, we suspect that our list only gives a partial view of company reporting practices since, for example, 86 percent of the companies have a value creation model in their annual report (as 
recommended by the IIRC reporting framework) but only 49 percent of them actually refer to the IIRC. Moreover, this list does not capture legal requirements such as those of the NFRD.

\section{Interviewees' perspectives on sustainability reporting}

The semi-structured interviews did not explicitly raise the topic of reporting, but it was mentioned by interviewees of 23 percent of the companies as a significant form of sustainability embedding and as important for engaging external stakeholders. They also noted that preparing the sustainability section of the annual report had served as a source of new ideas for sustainability action, and that it stimulated further internal discussion on sustainability topics and processes:

"I find it very important that sustainability is an integrated part in our annual report and therefore also an integrated part in the work of the auditor" [CEO, AMX service company]

"To officially publish it in your annual report also helps you to get it even more straight, because before you publish it to the outside world, there will be a little bit more discussion about it" [Sustainability manager, AMX industrial company]

"[Sustainability reporting] was driven by market expectations. It was a commercial tool that everybody should have. It was a bit of a formalization of an internal process. It started creating awareness internally." [Management board member, AEX industrial company]

Six companies also mention that they recently increased the scope of their disclosure in the sustainability section of their annual report, while three stated that they reduced the number of disclosed KPIs in order to prioritise quality over quantity.

Many companies were also critical about current practices and developments in sustainability reporting. Interviewees from 26 percent of the companies expressed frustration about the lack of standards, consistency, and comparability. Several interviewees wondered how much real action on sustainability was actually being done given the incentives towards portraying an excessively positive picture of sustainability performance:

"Start reading these sustainability reports and it looks like everybody is best in class." [Investor relations, AScX industrial company]

"Why is the language in these corporate reports the same? Because companies are checking boxes. The rating frameworks do not judge whether you're a good performer, they will look at whether you have a specific sentence in your annual report, yes or no. If the answer is yes, then you tick the box and you get three points" [Sustainability manager, AEX industrial company]

"Everybody now has the feeling like you have to be green, so all of a sudden you see all kinds of industries becoming green where you really wonder - how did you do that in a year? How were you able to turn your company around? That's almost impossible. So there must also be a lot of green washing in the whole ESG story for a lot of companies." [Investor relations, AEX industrial company]

"Too many companies are incentivized to have this marketing perspective related to sustainability performance, just telling how great they are, have a report with solar panels 
and windmills on every other slide - which is not really helping and informing." [Sustainability manager, AEX industrial company]

Interviewees of 20 percent of the companies raised an objection to the amount of time and resources being spent on sustainability reporting and to the continuous increases in reporting requirements. Interestingly, this concern was not exclusive to smaller companies but spanned all sizes and industries:

"If you follow the number of pages of annual reports over the last ten years, there's one trend very visible - it's growing, growing and growing... I find it over the top. I find the annual report less and less readable." [Supervisory board member, AScX industrial company]

"The external and internal demands are increasing very, very fast. Legislation in this area is moving fast, but there are also new models, new charters and covenants, new disclosure standards, and new ratings... if you want to do it all you almost need a small specialized army." [Management board member, AEX service company]

"I would need to hire ten people to comply with all reporting frameworks and requirements that are out there, which increases cost of doing business, especially for smaller companies." [CEO, AMX industrial company]

"[There is] a risk that the reporting standards are going to outgrow our company practice - it could be that we wake up one day and we need to report all these things, but we have no idea how to report on them." [Sustainability manager, Real estate company]

"The biggest risk for us right now is that we are not able to comply on time with all this reporting stuff. And that's a big reputation offense because you present yourself as a frontrunner, and then you're not even able to comply with this regulation - that's silly." [Sustainability manager, AEX service company]

Interviewees of a similar number of companies were also concerned that the culmination of reporting requirements could divert attention from more concrete action on sustainability:

"The GRI model is really extensive, really elaborate. And my critique on that framework is that for our company, it distracts from the focus we need in our sustainability program, to actually have an impact." [Sustainability manager, AScX industrial company]

"You have to make significant efforts to adapt to the new world that is out there. And it doesn't happen by filling in something in GRI format or something like that. [...] You have to connect with the business and embark everybody on this journey. That's the only way to make a difference. Then you can start to report. But it doesn't work the other way around." [ExCo member, AMX industrial company]

Overall, the interviews raised many of the same issues with reporting that have been identified in the literature (Bams et al. 2021; Eccles et al. 2019; Berg et al. 2020). Moreover, they showed that not only stakeholders but also companies struggle with this topic.

\section{Environmental reporting}

In this subsection, we investigate the reporting of our company sample for various environmental topics which relate to our subsection on environmental drivers: Greenhouse gas (GHG) emissions, 
energy, water, waste, and business travel. It is not exhaustive and only intends to provide an impression of company practices.

We found that 34 companies (97 percent) report on their GHG emissions. Twenty-seven of these companies report on their scope 1,2, and 3 emissions while six companies only report on scope 1 and 2. Twenty-four companies measure and report on their $\mathrm{CO}_{2}$ equivalent emissions, and not just on their $\mathrm{CO}_{2}$ emissions. Size analysis showed that large companies are significantly more likely to report on $\mathrm{CO}_{2}$ equivalence:

Figure 27: Use of $\mathrm{CO}_{2}$ equivalent by company size

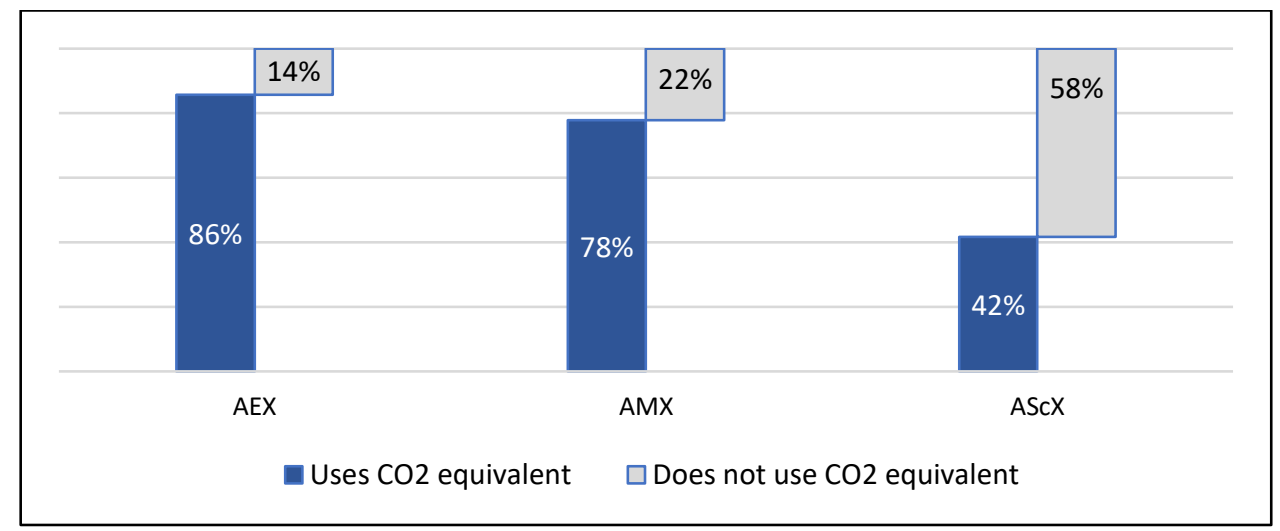

Sector analysis showed that all real estate companies report on the basis of $\mathrm{CO}_{2}$ equivalence as compared to 60 percent of industrials and 70 percent of service companies:

Figure 28: Use of $\mathrm{CO}_{2}$ equivalent by company sector

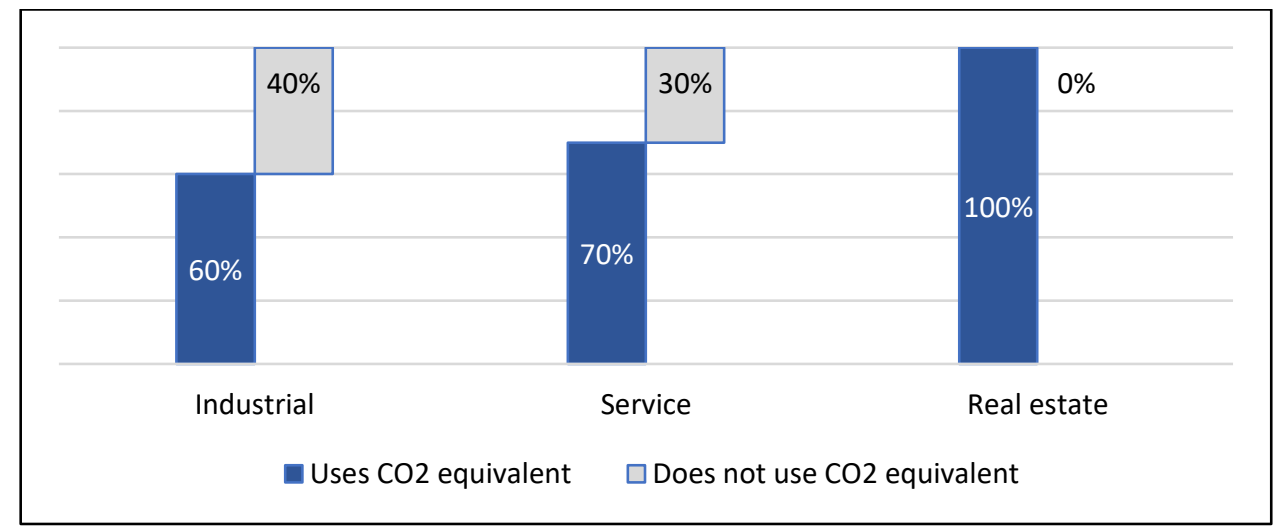

We also found that there are 24 companies that provide an intensity metric for their GHG emissions (e.g., emissions per tonne of product and per euro earned). There is a great deal of variation in the intensity metrics used by companies: 11 different kinds. The most common are $\mathrm{CO}_{2}$ emissions per $€$ million revenues or sales (7 companies), per weight of product (6), per $\mathrm{m} 2$ (5), per number of products (3) and per FTE (3). The results are listed in the table below (note that some companies provided more than one intensity metric). The metrics with a $\left(^{*}\right)$ have been singled out because they are especially difficult, if not impossible to compare between companies. These can only provide a standard of individual company performance over time and are not suitable for an intercompany comparison. 
Table 23: Type and frequency of intensity metrics for $\mathrm{CO}_{2}$ emissions

\begin{tabular}{|llc|}
\multicolumn{2}{|l|}{ Intensity metric for $\mathrm{CO}_{2}$} & Frequency \\
\hline $\mathbf{1}$ & per $€$ million revenues or sales & 7 \\
\hline $\mathbf{2}$ & per weight of product & 6 \\
\hline $\mathbf{3}$ & per $\mathrm{m} 2$ & 5 \\
\hline $\mathbf{4}$ & per number of products $\left(^{*}\right)$ & 3 \\
\hline $\mathbf{5}$ & per FTE & 3 \\
\hline $\mathbf{6}$ & per visitor & 2 \\
\hline $\mathbf{7}$ & per operational day & 1 \\
\hline $\mathbf{8}$ & per consumer use of product $\left(^{*}\right)$ & 1 \\
\hline $\mathbf{9}$ & per $€$ million invested & 1 \\
\hline $\mathbf{1 0}$ & per $€$ million added value & 1 \\
\hline $\mathbf{1 1}$ & per \% of assets under management & 1 \\
\hline
\end{tabular}

We also investigated how many metrics (i.e., how many different kinds of data points) companies are reporting on for their energy use, water use, waste produced, and business travel. Research shows that companies with high performance on sustainability are more likely to disclose nonfinancial information (Eccles et al. 2014), and we expect that greater levels of reporting reveal a better developed internal system of environmental management and a better understanding of the company's environmental footprint. This reporting, in turn, should lead to more potential points of management intervention and more action on sustainability. However, we concede that publicly available information may create an imperfect picture of these internal systems.

Overall, we find that 31 companies (89 percent) report on their energy use, 21 companies (60 percent) on their water use, 26 companies ( 75 percent) on their waste, and 20 companies ( 57 percent) on their business travel. We found the following results in terms of whether companies were providing three or more metrics, or only one or two metrics, for each of these environmental topics:

- For energy use, 27 companies (77 percent) provide three or more metrics while four companies (11 percent) provide only one or two metrics.

- For water use, 11 companies (31 percent) provide three or more metrics, and nine companies (29 percent) provide one or two metrics.

- For waste, 16 companies (46 percent) provide three or more metrics, and 10 (29 percent) provide one or two metrics.

- $\quad$ For business travel, eight companies (23 percent) provide three or more metrics, and 12 companies (34 percent) provide one or two metrics.

We also found that 15 companies (43 percent) provide an intensity metric for their energy use, eight companies ( 23 percent) provide an intensity metric for their water use, and six companies (17 percent) provide an intensity metric for their waste. These results have been combined with those for GHGs and included in the following table:

Table 24 (below) highlights several cells to show that the vast majority of our sample companies report on their energy use in detail. They provide less information on waste, and much less on both water use and business travel. 
Table 24: Review of company metrics for environmental reporting

\begin{tabular}{|c|c|c|c|c|}
\hline Company reporting & $3+$ metrics & 1-2 metrics & None & Intensity metric? \\
\hline GHG emissions & - & - & $9 \%$ & $69 \%$ yes \\
\hline Energy & $77 \%$ & $11 \%$ & $11 \%$ & $43 \%$ yes \\
\hline Water & $31 \%$ & $29 \%$ & $40 \%$ & $23 \%$ yes \\
\hline Waste & $46 \%$ & $29 \%$ & $26 \%$ & $17 \%$ yes \\
\hline Business travel & $23 \%$ & $34 \%$ & $43 \%$ & - \\
\hline
\end{tabular}

As a final area of investigation, we also researched what companies disclose about their use of renewable energy. The main finding was that 40 percent of the companies do not provide clear figures on the overall extent of their renewable energy use. Even within the majority of companies who do report on this topic, it is often unclear whether they distinguish between renewable energy and renewable electricity; the former is a broader metric that should also incorporate when energy is used outside of the electricity grid (e.g., petrol in cars). We did not examine renewable energy further because of these difficulties in comparing company activities.

\section{Information on assurance}

The subsection on drivers noted that the European Commission has adopted a proposal for a CSRD (an update of the NFRD) as part of its Green Deal and sustainable finance package. ${ }^{83}$ This proposal is still awaiting debate and approval from the European Parliament and European Council but is expected to mandate that companies obtain auditor assurance for their reported sustainability information. If passed, it will apply to "all large companies and all companies listed on regulated markets (except listed micro-enterprises)" 84 and will require them to "seek limited assurance for reported sustainability information, while including an option to move towards a reasonable assurance requirement at a later stage" ${ }^{85}$

The proposal explains the distinction between limited and reasonable assurance as follows:

"The assurance profession distinguishes between limited and reasonable assurance engagements. The conclusion of a limited assurance engagement is usually provided in a negative form of expression by stating that no matter has been identified by the practitioner to conclude that the subject matter is materially misstated. The auditor performs fewer tests than in a reasonable assurance engagement. The amount of work for a limited assurance engagement is therefore less than for reasonable assurance. The work effort in a reasonable assurance engagement entails extensive procedures including consideration of internal controls of the reporting undertaking and substantive testing, and is therefore significantly higher than in a limited assurance engagement. The conclusion of this type of engagement is usually provided in a positive form of expression and states an opinion on the measurement of the subject matter against previously defined criteria." ${ }^{\prime 86}$

\footnotetext{
83 https://ec.europa.eu/info/publications/210421-sustainable-finance-communication en

84 CSRD Proposal, p. 5.

85 CSRD Proposal, p. 10

${ }^{86}$ CSRD Proposal, p. 37
} 
We felt that given these upcoming developments, it would be interesting to examine whether and to what extent our company sample is auditing their sustainability reporting. For this purpose, we searched the 2020 annual reports for auditor statements on the level of assurance of nonfinancial information.

Our research showed that 46 percent of companies have no assurance of their nonfinancial information. ${ }^{87} 34$ percent provide limited assurance and 20 percent provide reasonable assurance. The results are summarised in the table below:

Table 25: Assurance of non-financial information

\begin{tabular}{|rcc|}
\hline Type of assurance & \# of companies & $\%$ of companies \\
\hline No assurance & 16 & $46 \%$ \\
\hline Limited assurance & 12 & $34 \%$ \\
\hline Reasonable assurance & 7 & $20 \%$ \\
\hline
\end{tabular}

Size analysis (see Table 26 below) disclosed that smaller and medium size companies are more likely to have no assurance (29 percent of AEX compared to 67 percent of AMX and 50 percent of ASCX). Large companies were most likely to have either limited or reasonable assurance. These results suggest that companies with greater resources are more likely to have assurance (and more of it), although it could also be due to greater levels of visibility and external pressure from, for example, investors, customers, and NGOs.

Table 26: Size analysis for assurance of non-financial information

\begin{tabular}{r|cc|cc|ccc|}
\cline { 2 - 7 } & \multicolumn{2}{|c|}{ No assurance } & \multicolumn{2}{c|}{ Limited assurance } & \multicolumn{2}{c|}{ Reasonable assurance } \\
AEX & 4 & \# companies & \% index & \# of companies & $\%$ of index & \# of companies & $\%$ of index \\
AMX & 6 & $67 \%$ & 6 & $43 \%$ & 4 & $29 \%$ \\
AScX & 6 & $50 \%$ & 4 & $22 \%$ & 1 & $11 \%$ \\
\hline
\end{tabular}

Sector analysis (see Table 27) showed that real estate companies are most likely to have no assurance of nonfinancial information (80 percent) compared to industrial and service companies (both 40 percent). It also showed that industrial companies are three times more likely to provide limited rather than reasonable assurance, while by contrast service companies are twice as likely to provide reasonable rather than limited assurance. These results suggest first that assurance of nonfinancial information is not (yet) as material for real estate companies and second that sector profiles (industry vs. services) have a considerable effect on whether companies opt for negative or positive assurance statements.

Table 27: Sector analysis for assurance of non-financial information

\begin{tabular}{|r|cc|cc|cc|}
\cline { 2 - 7 } & \multicolumn{2}{|c|}{ No assurance } & \multicolumn{2}{c|}{ Limited assurance } & \multicolumn{2}{c|}{ Reasonable assurance } \\
Industrial & \# of companies & $\%$ of sector & \# of companies & $\%$ of sector & \# of companies & $\%$ of sector \\
Service & 8 & $40 \%$ & 9 & $45 \%$ & 3 & $15 \%$ \\
Real estate & 4 & $40 \%$ & 2 & $20 \%$ & 4 & $40 \%$ \\
\hline
\end{tabular}

\footnotetext{
${ }^{87}$ Beyond the standard check of the management report for material misstatements by the auditor as required by art. 2:3933 DCC.
} 


\subsubsection{Employees and culture}

The role of employees in corporate sustainability can be viewed from two perspectives: first, employees are significant stakeholders whose well-being can be placed among the company's sustainability objectives; second, employees help execute operations and thus also the company's (sustainability) strategy. The two perspectives are interconnected insofar as employee well-being is linked to both employee and company performance (Huselid 1995). Studies have also recognised company culture as an important factor in influencing the company's sustainability performance (Linnenluecke and Griffiths 2010). Moreover, the Dutch Corporate Governance Code (DCGC) highlights the responsibility of directors in managing the corporate culture towards long-term value creation (DCGC 2016).

The academic literature explains a company's culture as "patterns of meanings that circulate in an organisation and shape members' thoughts and actions about what is appropriate and valued in that setting" (Howard-Grenville and Bertels 2012: 195-196). These shared meanings both influence and are influenced by the members of the organisation and are believed to be relatively persistent over time. They are manifested in expressions such as language, artefacts, and behaviour (Howard-Grenville and Bertels 2012: 203). Sustainability ideas are often 'absorbed' into the existing culture. Cultural context can be crucial for the success of a company's sustainability initiatives (Harris and Crane 2002). This view was reiterated during the interviews by one of the interviewees:

"You can set targets, as many as you like - if people don't believe in them and don't understand why, forget it." [CEO, ASCX industrial company]

When delving into the topic of corporate culture and employee engagement on sustainability, we found that public documents such as annual reports offer limited insight into how companies manage their organisational culture for sustainability. They are a product created primarily for external stakeholders, and they do not, for example, disclose ongoing and deep-seated organisational issues, or what employees 'really' think of management or their company's approach to sustainability. Even information disclosed based on the DCGC requirement that companies explain how they manage their corporate culture for long-term value creation provides little insight. We therefore use the interview data as the primary source of information for this subsection.

We realise that corporate culture is much broader than our discussion of employee engagement from a top management perspective. In this regard, a comprehensive exploration of culture, employees, and sustainability embedding requires further research and a different research methodology. Nevertheless, our interviews do disclose interesting perspectives on different ways that sustainability could be embedded into culture. We use these perspectives as the main foundation for the structure of this section's findings. This section first discusses how companies measure their company culture and attitudes to sustainability. It next examines how to create appropriate, sustainable workspaces and how to organise diversity and inclusion. Subsequently we examine hiring, performance evaluation, onboarding, communication and education. We then zoom in on the way that management layers can be engaged in embedding sustainability. 


\section{Measuring company culture and attitudes to sustainability}

The starting point for managing a company's culture is in obtaining insights into what the current culture is like. This observation can be done, for example, through employee surveys which may also include questions about employee views and attitudes on sustainability:

"We measure this in our employee engagement survey, and we have relatively good insights to how they look at topics like safety, sustainability, how they feel about it, how they can contribute to it, how it's valued in the company" [Sustainability manager, AEX industrial company]

Interviewees from nearly half of the sample companies (46 percent) reported conducting regular employee surveys which include questions on their views of sustainability. Seventeen percent mentioned that they do employee engagement studies but do not integrate questions about sustainability. Nine percent reported that they have a dedicated survey on sustainability for their top management layers.

While the interviewees of a substantial number of companies mention conducting employee surveys, the desk research found that few of them report on the survey results in their annual reports and that not a single company reports on the sustainability results of their surveys. Fourteen percent of the companies report detailed information on employee survey results (but never about sustainability), 40 percent publish their employee engagement score, and 46 percent report no information at all about their employee surveys in the annual report.

When asked about the current employee and cultural attitudes towards sustainability, the interviewees from a large majority of the companies ( 80 percent) claim that their corporate culture is supportive. Interviewees from 29 percent of the companies even believe that sustainability is the reason why many employees choose to join the company. A small proportion of interviewees (14 percent of companies) mentioned that certain groups within the company have a critical stance on engaging in sustainability, and interviewees of a few companies (6 percent) stated that a significant cultural shift will be necessary to get employee support to the desired level. Please note that these responses represent the views of board members and high-level management and that their views are not necessarily identical to those of employees.

Furthermore, some interviewees emphasised the importance of continued attention to employees' attitudes and behaviours regarding sustainability. Regularly spending time on (sustainability) education and raising awareness will facilitate the embedding process in the long term.

"Of course you have to repeat it - every year there are people leaving the company, new people coming. The environment is changing: there are all kinds of distractions, quarterly pressures, COVID disruptions - you name it..." [Sustainability manager, AEX industrial company]

\section{Creating appropriate working conditions and sustainable workplaces}

Managing company culture starts with ensuring good working conditions for the employees. This is particularly salient for industrial companies where the health and safety of employees requires constant attention due to the potentially dangerous nature of the work. In several interviews, participants made unprompted remarks about analogies between safety and sustainability in the 
expectation that sustainability would become as obvious and non-negotiable as health and safety which was also not self-evident several decades ago:

"Thirty years ago, safety was seen as expensive, distracting us from the real thing. The industry now sees safety as something very positive and focus on safety actually reduces costs. This is exactly what we need to do with sustainability: don't treat it as a burden but as an opportunity." [CEO, AScX industrial company]

Decent working conditions can also extend to considerations such as paying employees fairly, offering adequate parental leave, and even caring about employees' mental health and well-being during the COVID pandemic:

"The basic systems have to be right. If people work overtime, they have to see it on their salary slip. If they are ill, they need to feel that they are taken care of. If those fundamentals are not in place, forget all the rest." [CEO, AScX industrial company]

Furthermore, the places where employees carry out their work, such as offices and factories, are also physical embodiments of the company's culture and can embrace sustainability elements. Sustainable characteristics of an office building can also serve as visible symbols of company values:

"[Our building] is full of glass and it's climate neutral. It's totally energy efficient, we have solar panels, heat pumps. So if you're in the building, it stands for openness, transparency, sustainability. It's important to work in a sustainable office - because then it becomes a more normal, mainstream thing to think about or to do - because you just have to look around." [Sustainability manager, AEX service company]

\section{Diversity and inclusion}

Diversity was frequently mentioned by interviewees as a sustainability-related topic, mostly with regards to achieving gender diversity within the company overall, and particularly in top leadership positions. Other types of diversity were mentioned less frequently. These could include attention to cultural and religious differences, LGBTI+ awareness, or considering the needs of employees on the neurodiversity spectrum:

"I have a diversity working group for dialogue with colleagues of bi-cultural background, some of our Muslim people, and this year, for the first time, we will pay attention to the Ramadan - and what it means for our colleagues personally and what it does to their physical well-being. It's interesting to know, when you work with somebody in the team, what this period means to them, and when they haven't eaten or drank for a few hours, that something happens with their energy." [Human resources director, service company]

Diversity factors can also be considered in the design of a new office building to ensure everyone's well-being:

"We're designing our next campus and we are involving [internal] communities to understand whether our chosen solutions work not only for the average person within [our company], but also for everybody else. If you are on the autism spectrum, you cannot be in wide, open space where everybody is talking - you need a little bit of a confined space without distractions. [Women's community] could voice the concern that they would like to have our outdoors places and parking garage well illuminated, so that they 
feel safe when they are walking around. So just to get the input of a very diverse set of people." [Sustainability manager, AEX industrial company]

Our desk research on annual reports showed that with regards to reporting on the diversity among employees and managers (n.b. non-boardroom), gender diversity is the most commonly disclosed topic. Our results are shown below:

Table 28: Company reporting on diversity at employee and management level

\begin{tabular}{|lcc|}
\hline Diversity reporting & Employees & Managers \\
\hline Male / Female & $94 \%$ & $57 \%$ \\
\hline Age & $37 \%$ & $6 \%$ \\
\hline Nationality & $17 \%$ & $6 \%$ \\
\hline
\end{tabular}

Few companies report on the age distribution of their employees and managers, and even fewer report on their nationality. Please note, however, that companies operating in certain countries might face legal restrictions on collecting these types of data.

\section{Hiring and performance evaluation}

When asked about culture management, interviewees of 14 percent of the companies in our sample (largely service companies) mentioned that the cultural and value fit of potential employees is checked already during the hiring process, for instance via a personal conversation with a board member:

"We talk a lot about [company principles] also in the process of hiring people, as a sort of test for them whether they can operate in this culture. And once people started, the general idea is that those principles should be the basis for decision making." [Management board member, AEX service company]

Moreover, we found that the integration of sustainability elements into targets and remuneration schemes for non-management employees is less common compared to the increasing trend on this topic for top management. Interviewees from 29 percent of the companies (mostly the larger) mentioned that they are actively encouraging employees to include sustainability targets in their individual annual goal setting. This is usually on a voluntary basis and at the discretion of employees and their line manager.

One of the companies in our sample embraces a practice of asking every employee to think about their individual sustainability contribution:

"In their performance reviews, everyone is being asked by their manager to come up with at least one way that they can contribute individually to improving our ESG." [CEO, real estate company]

A more indirect way of including sustainability in employee evaluations is by considering their alignment to the company's core values and expected behaviours, which often includes sustainability or a related value. This was mentioned as a practice by interviewees of 17 percent of the companies.

\section{Onboarding, communication and education}

Interviewees from 20 percent of the companies mentioned that sustainability is included as part of their onboarding for new hires. This process is often organised by the sustainability management team 
and provides new employees with an introduction to the company's sustainability strategy as well as opportunities to get involved.

Figure 29 displays communication and awareness raising activities and shows that using internal communication to convey sustainability messages has become a common practice in most companies (80 percent). This is done through internal newsletters and company intranet but also via top management communication during town halls and speeches.

Figure 29: Communication and awareness raising activities

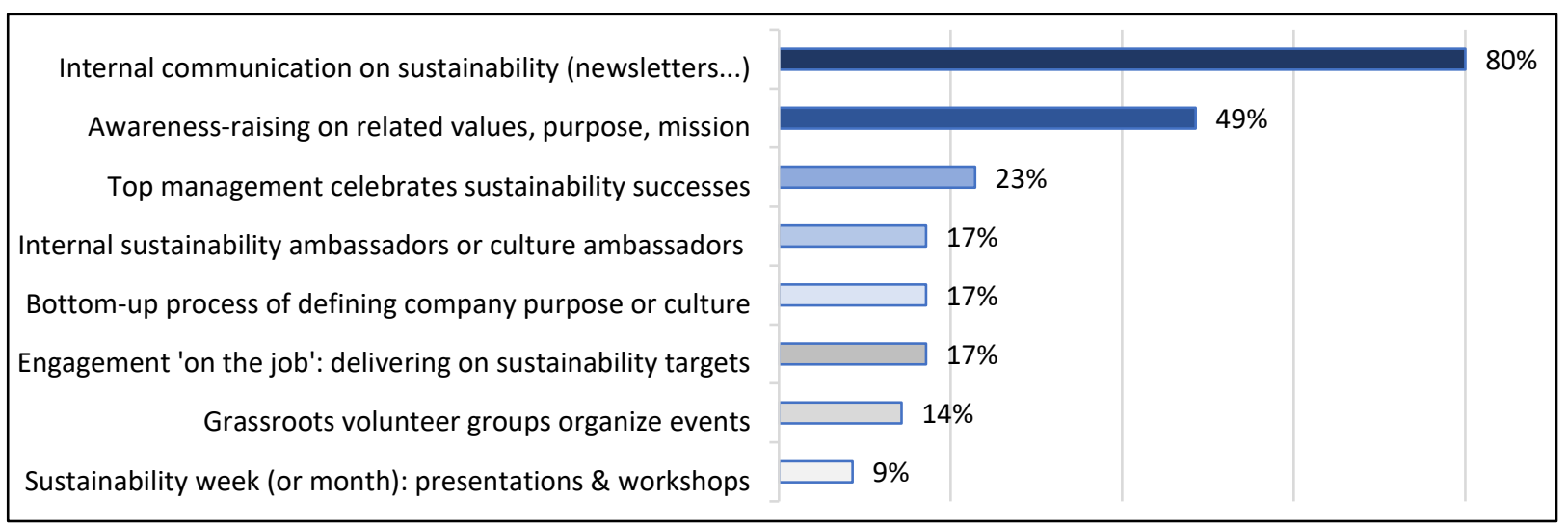

Another form of raising awareness is including sustainability in elements of company strategy or philosophy, such as the purpose, values, vision, or mission (49 percent). To ensure that these truly reflect the organisational reality of the company, the process of articulating them can be built from the bottom up by involving a cross-section of employees from different functions and locations. Moreover, sustainability ambassadors can be used to champion sustainability or to promote a new set of company values.

Sustainability can also explicitly be included in the code of conduct (49 percent). Some companies include training on the company code as part of onboarding and education, and communicate about the code to their employees:

"I don't expect people to read the code of conduct and to know everything by heart. But to understand that their behaviour has an impact. So we focus on expected behaviours. [... ] We made a video where people from across all the locations explained why it is relevant to them. Because if you cannot let people feel why it is relevant, they will also not follow it." [Sustainablity manager, AScX industrial company]

Finally, interviewees of 17 percent of the companies stated that sustainability engagement is best achieved through employees' daily work, by involving them in delivering the company's sustainability targets:

"Having a comprehensive set of metrics, which have been created by a significant number of different teams across the business over a significant period of time, because of the intellectual breadth and rigour needed, reduces the extent to which specific engagement plans are needed - as the whole process has been about engagement." [Risk manager, AEX industrial company] 
While most companies run communication and awareness raising activities on sustainability, formal education courses and programmes for employees are rare and were reported by interviewees from only 23 percent of the (mainly larger) companies. One company decided that employees in all roles need at least a basic knowledge on the topic, and developed a mandatory online learning module:

"Everyone is in some way involved in this topic. So last year we made an e-learning on sustainability, which is obligatory for every employee, to explain what we are doing and why it's important. And this was quite well received - people said they actually learned new things. Of course I hoped that they knew everything already, but you cannot expect that. I was quite happy to hear that they thought it was really worth their time." [Sustainability manager, AEX service company]

\section{Engaging management layers in embedding sustainability}

A top-down approach to culture management requires clear endorsement and role modelling on sustainability not only from top management, but also from middle management layers that are generally in closer contact with most employees (Linnenluecke and Griffiths 2010). Figure 30 provides information on topics that came up in the interviews when discussing how to best align middle management with the embedding of sustainability.

Figure 30: Engaging management layers in sustainability

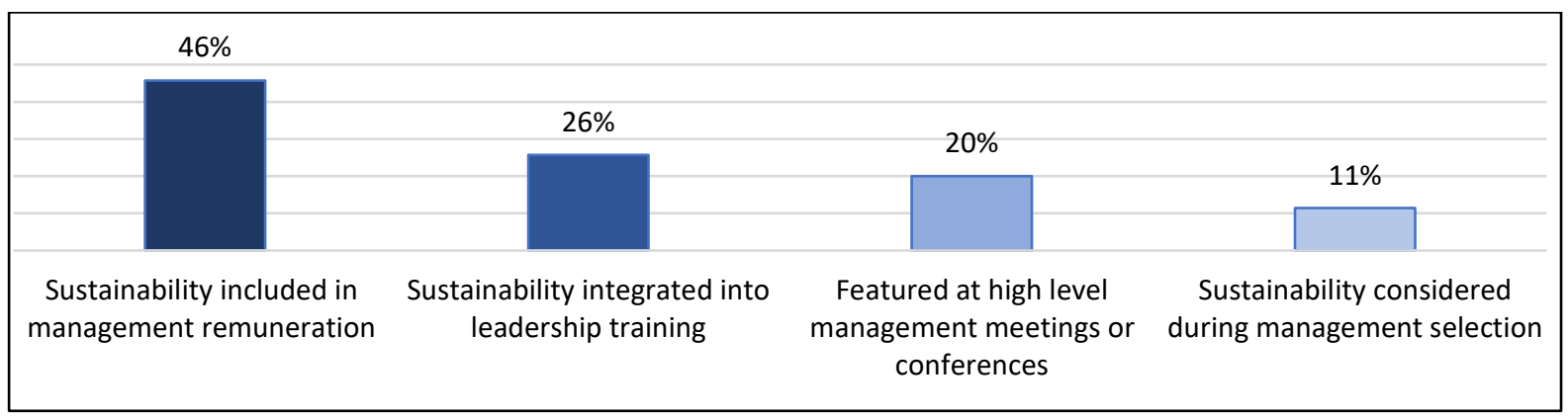

The most common way of aligning management with sustainability ambitions is to integrate sustainability-related targets into their remuneration package (46 percent). Interviewees from 26 percent of companies mentioned that sustainability is integrated into leadership education (e.g., as part of a management training programme or workshops on specific topics such as unconscious bias or sustainable development goals). Communicating regularly about sustainability at high-level management meetings and conferences (20 percent) is also believed to reinforce the perceived importance of the topic:

[From] topics that we do a presentation or a workshop on at management conferences, sustainability is by far the most used - because it's so dynamic, so much in change. And that is also part of corporate culture: if you as senior management talk about it, then people think, 'Eh, apparently it's important'. [Executive committee member, AScX industrial company]

Appointing the right and diverse leaders for the company also plays an important role (11 percent) in choosing managers who are aligned with the company's values and purpose:

"I do link [sustainability] to career progression. To me, it is extremely important as we go through our annual assessments, particularly of the people that we line up for succession, that we look at their track record as it relates to sustainability - what their points of view 
are around sustainability, what their accomplishments are, how central is it to who they are as a professional and as an individual." [CEO, AEX service company]

"Six months ago I got a list of people for senior leadership training - and two thirds were men. So I sent the list back and said, I'm not going to do this." [CEO, AEX service company]

In conclusion, culture management and employee engagement are important aspects of the sustainability embedding process in companies. This embedding can be performed in many ways: in hiring, onboarding, and education to performance evaluation and promotion, to managing employee working conditions and physical working space, and even to communication and incentivisation. All these examples are touchpoints at which the company can communicate the importance of sustainability and clarify its goals and ambitions as well as explaining how employees are expected to contribute to fulfilling them. 


\section{D: Summary of findings and recommendations}

In this section, we first provide a summary of findings based on our desk research, interviews, and the relevant literature. Second, we translate our research results into four recommendations that companies, investors, and other stakeholders can use to further shape the embedding of sustainability in companies. Third, we outline limitations and suggestions for future research.

\section{Summary of findings}

In the first part of our findings, we examined why companies are embedding sustainability. We outlined how structural and stakeholder drivers (such as environmental, social, and legal issues and stakeholder pressure) are generally affecting the embedding of sustainability in Dutch listed companies. We also reflected on the attitudes of company leadership towards these drivers.

Our main finding in this part was that companies are responding unevenly to various environmental, social, and legal drivers. This was reflected, for example, in our desk research which showed that companies have not, in most cases, made sustainability commitments which are in line with planetary boundaries. Our desk research furthermore showed that responses are not only uneven between companies but also differ depending on the sustainability topic. Overall, commitments to reducing $\mathrm{CO}_{2}$ emissions and increasing (gender) diversity were more concrete and ambitious than those made, for example, in relation to circularity or biodiversity.

In relation to planetary boundaries, we found that 24 out of 35 companies have a commitment to $\mathrm{CO}_{2}$ neutrality, while only five companies are committed to becoming fully circular, and only nine companies have in place some type of organisational policy or project regarding biodiversity. For a selection of social topics, we found that 32 companies have made a commitment to respect human rights, 34 have a diversity and inclusion policy for their employees, 31 have a fair tax policy, 25 have a supplier code of ethics, and 12 companies are committed to paying their employees a living wage.

Our interview findings on company attitudes to these sustainability drivers disclosed that most companies view sustainability more from an opportunity than from a risk perspective. They also shed light on the perceived history of embedding and revealed that, from an interviewee perspective, around one-third of companies have been seriously engaged with sustainability for less than five years. The interviews showed, moreover, that interviewees are more likely to identify achievements rather than gaps in their sustainability embedding.

We suspect that there are numerous reasons for these cross-sectional differences in company sustainability embedding. These include not only a company's unique history and decisions, but also differences in company size and sector (as examined at appropriate points throughout the report). Also relevant are various stakeholder relationships, for example with (institutional) investors, customers, and employees who were each identified as stakeholders by over $90 \%$ of companies. In this regard it also matters that there is a great deal of variation in institutional share ownership as well as high levels of institutional ownership by investors from common law countries.

The second part of our findings explored how companies are embedding sustainability. It looked first at purpose and strategy; second at leadership and governance; and third at supply chains, sustainability reporting, and employees and culture. 
The subsection on purpose showed that 83 percent of the companies in our sample have a reference to sustainability in their corporate purpose, and that 71 percent have a purpose which is externally oriented (i.e., towards the improvement of society rather than the company). However, when it came to purpose formulation, our analysis showed that many of these statements are very broad. Following this finding, we applied a test for the relative specificity of corporate purposes based on the work of Mayer and Edmans. Using this test, we found that 16 companies try to solve a problem in their purpose statement, and that 16 companies (not the same) identify one or more material stakeholders. Only two companies satisfy a strict application of both parts of the test. We acknowledge that the MayerEdmans test is only one way to investigate corporate purpose statements.

Even though many companies have a rather generic corporate purpose, we also saw that many companies have sustainability-related targets and objectives in their strategy. We found a great deal of variability in the approaches that companies use to organise their sustainability strategies, objectives, and targets. Overall, we found that 97 percent of the companies in our sample have sustainability-related strategic objectives and that they place these objectives in different parts of their annual report. Sixty-three percent of the companies in our sample place them in their central strategy, while 34 percent place them in a separate sustainability strategy. When it came to sustainability targets, we saw that just over half of our company sample has specific deadlines for their sustainability targets and that they report on their performance for these targets for two or more years. In general, we find that companies have great freedom when it comes to deciding on their ambitions, on when they want to achieve these ambitions, and whether and how they translate their sustainability strategies into actual targets.

We also showed that companies use SDGs, stakeholder materiality consultations, and sustainability risks, to varying extents as sources of inspiration for embedding sustainability. We found that companies have a primary focus on SDG12 Consumption and production, SDG8 Decent work and economic growth, and SDG13 Climate action. Other SDGs are relatively less prominent. Stakeholder consultations showed that the top priorities relate to climate and emissions (20 companies), employee retention and careers (17), safety (17), employee well-being and health (17), corporate ethics and compliance (17). Circularity was identified as a material topic for 14 companies while biodiversity, ecosystems, and environment are material for only six companies. The top sustainability risks identified in the risk management sections include climate change and emissions (26 companies), product safety and HSSE (20 companies), employee diversity and human rights (10 companies), circularity, and resource scarcity and waste (9 companies).

The leadership and governance subsections showed that top management is (perceived as) the main organisational driver of the sustainability agenda, and is often assisted by a sustainability team or manager. We also found that the management board and supervisory board are generally aligned in their views on sustainability, and that all 19 supervisory board members indicated that sustainability is a responsibility of the whole supervisory board. The supervisory board was rarely mentioned by interviewees as a driver of sustainability embedding.

We found that 27 out of 29 companies that publish their management board regulations have allocated sustainability as one of the tasks of the board or top management team; six companies do not publish these regulations. We also find that 28 companies do not publish a profile for the desired competencies and characteristics of their management board. For the other seven companies that do publish a skills profile, we find that sustainability is included as a specific management board 
competency. For the supervisory board, we found that all companies include sustainability oversight as one of their tasks (although eight companies only require them to formulate a diversity policy). We found it significant that more than half of the supervisory board skills profiles do not contain any references to sustainability skills.

Our review of management board remuneration showed that interviewees from a majority of companies are in favour of sustainability-related remuneration targets. Interviewees of a minority of companies expressed serious doubts about this practice, and many interviewees noted how difficult it can be to identify appropriate sustainability targets. In line with these findings, our desk research showed that the vast majority of companies integrate sustainability elements into their remuneration policies. However, sustainability is only a relatively small part of short-term and long-term incentives (only 11 percent and 22 percent of their total weight, respectively).

We also examined company sustainability committees and found that companies have a varying number of sustainability-related committees with differing compositions and that they are situated at different levels within the organisation. Only three companies have an external sustainability committee. Seven companies have a sustainability committee at the supervisory board level, three have one within the top management team and 10 have a committee with a top management team member as the highest-level manager. In general, we suspect that forming a sustainability committee is related to the scope of a company's sustainability challenges, the added value of such a committee, and the increased time and resources that such a committee would claim.

The subsection on supply chain management examined whether the human rights and environmental reporting practices of our company sample are in line with the due diligence requirements that were pioneered by the UNGPs. We found that seven companies satisfy these requirements for human rights and that zero companies disclose enough information in their annual and sustainability reports for us to properly evaluate whether they satisfy these requirements for environmental due diligence.

Our study on reporting practices found almost 50 frameworks which companies use as normative and reporting standards for their sustainability reporting. Leading frameworks include the GRI Standards, GHG protocol, IIRC Integrated Reporting Framework, CDP, and TCFD. The interviews showed that companies struggle to strike the right balance between the scope of their reporting, the demands from rating agencies, the administrative burden on their organisation, and the information needs of stakeholders, while at the same time trying to comply with continuously changing legal requirements.

A closer examination of company environmental reporting shows that most companies report on their energy use in detail, that they provide less information on waste, and much less information on both water use and business travel. We also found that 46 percent of the companies provide no external assurance for their nonfinancial information (beyond the basic auditor check of the management report for material misstatements) while 34 percent provide limited assurance and only 20 percent reasonable assurance.

The final subsection of our findings, on employees and culture, relied on interview findings to disclose different perspectives on how sustainability could be embedded into company culture. It gave an insight into how companies measure their culture of and attitudes to sustainability; how they create appropriate, sustainability workspaces; and what they report in terms of diversity and inclusion. The latter section showed that 94 percent of companies report on their employee male / female diversity, and that 57 percent of companies report on the (non-boardroom) male / female diversity of their 
managers. Few companies provide information on diversity in the age and nationality of their employees and non-boardroom managers. In the employees and culture subsection, we also provided examples of how companies embed sustainability in hiring practices, performance evaluation, onboarding, communication, and education as well as how management layers could be engaged in sustainability.

\section{Recommendations}

This section presents four key recommendations that follow from our research findings on the embedding of sustainability in Dutch listed companies. They can be used by companies to improve their practices, as guidance for investor engagement on sustainability, or by other stakeholders to formulate their expectations of good company practice. The recommendations are as follows:

1. Align strategy on planetary boundaries and increase awareness on sustainability risks

2. Evaluate purpose statements and connect them to strategic objectives and targets

3. Create a leadership and governance context that supports strategic decision-making on sustainability

4. Improve quality of interaction and communication with stakeholders

We discuss each recommendation in turn with a background of the related literature and our desk research and interview findings.

\section{Recommendation 1: Align strategy with planetary boundaries and increase awareness on sustainability risks}

The European Green Deal, Taxonomy Regulation, SFDR, CSRD, and other upcoming legislation for companies and investors are part of a comprehensive attempt by the EU to become a climate neutral and circular continent. Their aim is to tackle climate change, environmental degradation and biodiversity loss while ensuring that no person or country is left behind. It is implicit in this task that European companies and institutions need to align economic objectives with the work of Steffen et al. (2015) on planetary boundaries (Sjåfjell 2020). As the EEA explains, "Achieving the Sustainable Development Goals will be impossible without respecting planetary boundaries... The new European Green Deal announced lately by the European Commission is [an] opportunity for Europe to radically shift course" (EEA 2020: 6).

It is against this background that our findings on structural drivers show that companies react differently to environmental, social, and legal developments. Some companies in our sample have strong commitments on climate change, circularity, and biodiversity, while others have yet to act in response to these major areas of economic, social, and environmental change. Given that organisational change is a long-term and tedious process (e.g., Dahl 2011), we argue that companies with strategic commitments and clearly communicated transition paths in these areas communicated to both internal and external stakeholders - are more likely to respond and adapt in a timely way to opportunities presented by the European Green Deal transition. The increasing engagement of asset owner-led initiatives such as the Transition Pathway Initiative ${ }^{88}$ and the Net-Zero

\footnotetext{
88 https://www.transitionpathwayinitiative.org
} 
Asset Owner Alliance ${ }^{89}$ will further pressure companies to set clear and compelling sustainability targets accompanied by a realistic but ambitious transition path.

It is noteworthy, moreover, that our findings showed that most companies perceive sustainability as more of an opportunity than a risk. The desk research also showed that many companies do not communicate (much) about sustainability risks in their risk management sections. Even climate change and emissions, and product safety and HSSE - the two most often raised sustainability risks - are only mentioned by 26 and 20 companies respectively. However, there is little doubt that the transgression of planetary boundaries creates many material risks for companies (Fiedler et al. 2021). This is reflected not only by successive IPCC reports, record-breaking European rainfall, flooding, fires, and summer temperatures (Reuters 2021; New York Times 2021), but also by an increasing body of multidisciplinary research which shows that climate risks are affecting businesses and investor decision-making (e.g., Fiedler et al. 2021; Pankratz et al. 2021; Ilhan et al. 2019; Sautner et al. 2020).

Given these structural drivers and their associated risks, we find that there is scope for Dutch listed companies to align their strategy more formally with planetary boundaries, especially with regards to circularity and biodiversity (see also Hummels and Argyrou 2021). We identify a crucial role for company leadership to make sure that all management layers and employees are aware of associated sustainability risks. This awareness will help them to respond to risks, prepare for opportunities, and adequately contribute towards the transition to a climate neutral and circular economy. We recommend, therefore, that companies align their strategy with planetary boundaries and increase awareness on sustainability risks.

\section{Recommendation 2: Evaluate purpose statements and connect them to strategic objectives and targets}

Corporate governance literature is increasingly advocating that companies adopt a sustainable corporate purpose in lieu of more traditional discussions on whether companies should take on a shareholder or stakeholder orientation (Mayer 2018; Edmans 2020; Younger et al. 2020). Our desk research shows that many companies in our sample have formulated corporate purpose statements that contain elements of sustainability. Some companies integrate sustainability directly into their purpose. Other companies include sustainability indirectly in the sense that it can be inferred from information surrounding their purpose. Only a few companies do not integrate sustainability in their purpose statements at all.

In addition, some interviewees mention that purpose statements can guide decision-making throughout different levels of the company. This is confirmed by literature that shows that communication and coordination can be difficult in the absence of shared ideas and beliefs about what is important and valued in an organisation (Alvesson 2002; Linnenluecke and Griffiths 2010). The literature also states that a clearly defined, sustainable purpose can act as a reference point and anchor for sustainability-minded employees throughout different levels of the company. Moreover, it can support a formal and informal sustainability culture (Guiso et al. 2015a) and send a clear signal to new generations of (potential) employees who are increasingly interested in sustainability, as our interview findings suggest.

${ }^{89}$ https://www.unepfi.org/net-zero-alliance/ 
To further analyse companies' purpose statements, we created a test based on recent contributions to the literature on how to define a clear, memorable, and compelling corporate purpose (Mayer 2018; Edmans 2020). Applying a synthesised Mayer-Edmans test, our desk research shows that almost none of these purpose statements are very specific when compared to what is expected of a corporate purpose in the contemporary corporate governance literature. The statements are often vague, generic slogans about ambition and positive intent. In our view, it is not sufficient to merely have a sustainable, but unfocused purpose statement. If the purpose statement is to be used as a tool for alignment of culture and decision-making at all levels within the company, then it would in our opinion be more beneficial to make it more specific and targeted.

One way to be more specific could be to direct it towards solving a problem for the benefit of a clearly defined group of material stakeholders. This specificity does not mean that the company should pursue the profit of this material stakeholder group at the expense of all others (Edmans 2020). Company success depends on balancing all stakeholder interests. Reputational and financial losses may occur when there is a material imbalance (Servaes and Tamayo 2013). Instead, having a specified stakeholder group and a specific problem to solve could help to facilitate the long-term balancing act between all these interests, and to push companies to think about who, precisely, they are trying to help with their activities. This whole process occurs with the pre-condition that companies do not profit at the expense of stakeholders or the environment. Profit is a reward for value-added (Edmans 2020), and it is otherwise illegitimate.

Note that the synthesised Mayer-Edmans test is just one way of investigating corporate purpose statements. Alternatively, one could focus mainly on the extent to which companies are contributing to the solution of a problem while upholding their social, natural, and human capital (Mayer 2018) or clearly indicate what the aim of the company is in society and formulate the values and principles that guide that aim (Winter et al. 2020). These approaches would focus the corporate purpose without specifying stakeholders. Defining a clear corporate purpose does not, of course, take away from the primary importance of having an effectively formulated strategy for sustainability.

In any case, a purpose statement has little value if it is not further integrated into the company. Once a company has formulated a clear, memorable, and compelling purpose it is important that they use this as a foundation to formulate their corporate strategy. As explained by Younger et al. (2020: 2), "To deliver value for different stakeholders, purpose has to be more than a marketing slogan or a vague set of values. It has to become an organising principle, the reason why an organisation exists". This includes the adoption of consistent and coherent sustainability objectives and targets. Although we find that companies' purpose statements often lack clarity and focus, our desk research identifies that almost every company in our sample has sustainability-related strategic objectives. Most often companies integrate these objectives as a foundation or pillar in their central strategy. Fewer companies define these objectives in a separate sustainability strategy.

We advise that whenever possible, sustainability objectives and targets should be connected to specific deadlines and presented alongside performance over the past few years (as only 54 percent of our company sample do this). We also recommend that this information is clearly presented in the annual reporting cycle, for example, in a table or appendix with sustainability objectives, targets, deadlines, and performance. The latter is important for stakeholder communication regarding sustainability activities and for the promotion of transparency and comparability on company sustainability activities both inside and outside the firm. 
Please note that our findings do not necessarily establish that sustainability objectives and targets must be included as part of the main strategy. They can also be formulated as a separate sustainability strategy so long as that strategy is closely intertwined with the main strategy and driven and promoted (ideally with formal responsibility) by top management.

Based on the synthesis of desk research and interviews, and in light of the relevant literature, we view that companies can benefit from an improved sustainability culture and decision-making process if they have a well-formulated corporate purpose that is clearly and meaningfully connected to corporate strategy. We recommend, therefore, that companies evaluate their purpose statements and connect them to their strategic objectives and targets.

\section{Recommendation 3: Create a leadership and governance context that supports strategic decision-making on sustainability}

Planetary boundaries and the European Green Deal ensure that sustainability has become a key issue for any Dutch company in any industry (DSGC 2020). In this regard, it is important for all leaders to understand how our societies are developing in terms of $\mathrm{CO}_{2}$ neutrality, circularity, biodiversity, and a range of other social and environmental topics. This awareness is important for ensuring that companies are ready to successfully navigate turbulent times ahead in which sustainability risks and opportunities will arise.

We advise that leadership on sustainability - driving it, promoting it, communicating it externally and internally - is allocated to the management board, ideally with the CEO. The interviews confirmed the importance of the CEO in driving sustainability. Moreover, we identified that companies whose interviewees claim a long history of sustainability embedding were much more likely to cite leadership involvement in sustainability as one of their successes. This is not to say that sustainability is a oneperson job; it concerns all members of top management and oversight bodies, and it is important that formal responsibilities are identified and allocated accordingly.

We found that 27 out of 29 companies that publish their management board regulations have allocated sustainability as one of the tasks of the board or top management team; six companies do not publish these regulations. We also find that 28 companies do not publish a profile for the desired competencies and characteristics of their management board. For the other seven companies that do publish a skills profile, we find that sustainability is included as a specific management board competency. In general, we advise that companies communicate in a clearer fashion about the types of people and competencies (including sustainability) they are looking for on their management board.

Leadership responsibilities and competencies may be complemented by integrating sustainability targets into remuneration policies. Research shows that this can help lead to expand sustainability performance, mitigate corporate short-termism, and improve business performance and governance quality (Flammer et al. 2019).

However, we also note that interviewees had varying opinions regarding the usefulness of connecting variable remuneration to sustainability objectives. There were doubts about the effects of sustainability remuneration on individual behaviour, arguments that it merely provides a signalling function, and concerns that it could even be counter-productive and demotivating for employees (see also Edmans 2021b). At the same time, many interviewees were adamant about the importance of such incentives and the desk research showed that 86 percent of companies include sustainability in 
their short-term and long-term incentives. In any case, we identify that sustainability is only weighted for an average of 11 percent in short-term incentive packages and 22 percent in long-term incentive packages. Considering our recommendation for companies to align their strategy more explicitly with planetary boundaries, we advise companies to re-evaluate the weight and content of sustainabilityrelated targets in their remuneration policies if they do decide to adopt them. In the process, they should be mindful of the difficulties, noted by our interviewees, involved with formulating proper targets for sustainability remuneration.

Supervisory board oversight can make an important contribution to sustainability embedding. Their role is to advise the management board and provide oversight over, amongst other things, the strategy of the company, which includes the sustainability strategy. Given this, it is encouraging that we found that all of the companies in our sample have allocated sustainability as a formal task to the supervisory board (even if eight companies only require them to formulate a diversity policy), and that all of our supervisory board interviewees recognise sustainability as a responsibility of the whole board.

Overall, board members must be able to ask the right questions and challenge the management board with regard to relevant sustainability topics in the short and long term. They have an important influence on selecting top management and can be key to a conducive leadership environment for sustainability. Some of the interviewees suggest, moreover, that cross-pollination between the boards of different companies can have a material effect on sustainability embedding. These reasons make it vital that the supervisory board has the right level of (credible) sustainability knowledge and experience at the whole board level. In this regard, it is possible that the sustainability-promoting potential of supervisory boards is being impeded by the absence of sustainability requirements in skills profiles for supervisory board members. After all, our findings show that 54 percent of companies have no reference to sustainability in their skills profile.

There are various ways in which sustainability can be further embedded in the functioning of the supervisory board. Placing the topic regularly on its agenda for meetings is one way to make sure that sustainability embedding is overseen properly. Alternatively, companies can consider installing a formal sustainability committee (or scheduling dedicated sustainability meetings) at the supervisory board level as a way to provide oversight and give advice on the (sustainability) strategy. At the moment, we see that only seven companies have such a committee. A supervisory board sustainability committee can help place sustainability on the agenda, provide further feedback on sustainability matters, and help educate (supervisory) board members on sustainability risks, opportunities, and developments. Moreover, we recommend that sustainability be included as an important element in the skills profiles of the supervisory board. This inclusion will ensure that companies are prepared for the sustainability transformation that is already underway and will continue for many decades.

Overall, companies need to create a context in which top management (CEO role and beyond) and the supervisory board are well prepared to formulate, execute and oversee a sustainability strategy with an appropriate level of ambition and understanding of their societal and environmental relevance and context. Signalling leadership on sustainability, especially when employees perceive top management as trustworthy and ethical, is key to creating an organisational culture that supports strategic sustainability objectives and financial performance (Alvesson 2002; Guiso et al. 2015b). We therefore recommend that companies create a leadership and governance context that supports strategic decision-making on sustainability. 


\section{Recommendation 4: Improve quality of interaction and communication with stakeholders}

Our review of key stakeholder drivers shows that companies are connected to a wide range of stakeholders and that these parties can have both a positive and negative impact on sustainability embedding. It highlights how important it is for companies to pay close attention to their stakeholder relationships, to think about their information needs, and about how to interact with them. Failures in this area are likely to create reputational risks and expose limits on the contextual awareness and social embedding of a company's activities (Freeman et al. 2007).

The desk research shows that only three companies have in place a formal committee to receive advice from external experts or stakeholders. It also found that although many companies are organising stakeholder consultations, it is often unclear how they are organised, who is invited and why, and how their input is filtered by companies. Shortcomings on these points may undermine the extent to which companies are aware of their external environment, and thus the extent to which they can identify sustainability opportunities and risks.

One way to promote stakeholder engagement in a more formalised way can be to install an external stakeholder committee that provides independent advice to top management on social, environmental, and community issues. This can be accompanied, for example, by including in the annual report a statement from this committee on their advisory activities, their views on the identified risks and opportunities and the company's sustainability embedding practices (Winter et al. 2021). Moreover, we suggest that companies publish information on their stakeholder consultation process to clarify how they identified their stakeholders, who was consulted, how many times, in what format, and how the company filtered and used their input. In general, we advise companies to report more explicitly on how they interact with stakeholders. This can help the company in the evolution from a mindset of one-directional reporting to stakeholders to a mindset of stakeholder dialogue and engagement (DSGC 2013).

The point is not that companies should simply implement the sustainability wishes of their stakeholders. It is rather that these processes can help them develop a deeper, multidimensional understanding of their company's context and environment which can also feed into future purpose and strategy discussions. We are all subject to biases in our decision-making (Kahneman 2011, Kahneman et al. 2011), and exposure to a range of different sources of information and judgement can help leaders develop a more rounded picture of a company's performance. The latter is necessary for them to exercise sound judgement in their responsibility for sustainability embedding.

Companies will receive more useful feedback from stakeholders when they provide them with the information that they need to understand the activities and impacts of the company. There are numerous incentives for companies to greenwash, obfuscate, and provide misleading information, but there are also real long-term benefits to be realised from transparent and open communication. Bams et al. (2021), for example, show that firms which adopt a strategic approach to corporate social responsibility outperform those which merely adopt it as a form of insurance or greenwashing (e.g., Servaes and Tamayo 2013). Moreover, research shows that mandatory sustainability reporting has a positive effect on a company's information environment: analyst earnings forecasts become more accurate and less dispersed after disclosure, sustainability-related incidents become less likely, and the risk of crashes in the stock price declines (Krüger et al. 2021). The importance of mandatory CSR 
disclosure is also confirmed by research in the context of the United States' GHG programmes which shows that public (shareholder) pressure that is fuelled by mandatory disclosure programmes can affect company behaviour (Yang et al. 2021).

It should therefore be part of the company leadership's responsibility to provide internal and external stakeholders with material and salient information about company activities. We identify four areas in which they could provide more, and better, information to stakeholders: due diligence; assurance of nonfinancial information; sustainability remuneration targets; and KPIs for waste, water, and business travel.

The desk research on human rights and environmental due diligence found that only 35 percent and 9 percent of companies have a named due diligence process in place for these areas, and that even fewer report on all four steps of the due diligence process. It is, moreover, unclear whether these companies are adopting a salience rather than a materiality approach to the information being generated by these processes. Given the substantive overlap between due diligence, supplier codes, and responsible procurement, we suspect that companies are doing more on due diligence-type activities than is evident from their public reporting. We therefore advise them to publish this information in a due diligence-format, not only because of upcoming mandatory legislation, but also to demonstrate to stakeholders the effectiveness of their supply chain and risk management processes, and because this may lead to a competitive advantage (Porter and Kramer 2011; Porter and van der Linde 1995; Porter 1985).

Our review of remuneration policies shows that companies are providing little ex ante information on the content of their remuneration targets. This is surprising given the importance of such targets for incentivising sustainable decision-making and signalling to stakeholders, as indicated by many of our interviewees. We concede that some of the information regarding these targets may be sensitive for competitive reasons but nevertheless believe that there is more scope for disclosure than is currently being practiced. It seems to us unlikely, for example, that generally disclosing that a target is connected to $\mathrm{CO}_{2}$ emissions or to performance on an external benchmark such as the DJSI (without revealing the specific target) would place the company at a competitive disadvantage. In these cases, it seems preferable to support the signalling function of the sustainability-related remuneration target rather than to keep the information private.

We also found that many companies are providing limited information on KPIs for their water use, waste, and business travel. We advise companies to disclose additional information in these areas as evidence of their sustainability embedding and to guide stakeholder decision-making and feedback.

High-quality disclosures by companies lead to improved stakeholder feedback on company activities. Moreover, public information is necessary for external stakeholders to exercise market pressure and reward sustainable companies. In this regard, we find that company-stakeholder relationships are only as good as the quality of the information and interaction between them. We therefore recommend that companies improve the quality of their interaction and communication with stakeholders.

\section{Limitations and future research}

We want to reiterate that our research design has several limitations. The first is that the data were collected at one point in time and only provide a single, limited picture of sustainability embedding in Dutch listed companies. 
A second is that researchers in company law and sustainable finance performed the research which limits the scope and content of the final report. We have no doubt our work could have benefitted from collaboration with other specialists from other (science) disciplines.

A third limitation relates to potential selection bias in two dimensions. First, companies accepting the invitation to be interviewed may be more inclined to increase the embedding of sustainability going forward. A second potential bias may arise from the selection of interviewees by companies. This process may result in a biased sample that has a more positive stance towards sustainability embedding and so influences our results.

A related fourth issue is that the interviewee sample consists of members of the supervisory board, top management team (management board and executive committee), and management layers immediately below. Company employees in other levels of the organisation did not participate in the interviews. We estimate that these interviewees are more likely to support than criticise the sustainability policies and practices.

A fifth issue relates to the elite status of many of our interviewees, which is a well-known challenge for qualitative research into the upper echelons of organisations. We tried to partly mitigate this bias by interviewing several participants per company and so improving the reliability of our insights.

Finally, the scope of this research project only includes companies that are publicly listed and incorporated in the Netherlands. Sustainability embedding is, of course, also relevant for privately owned companies and companies in different geographical regions.

Our research findings and associated key recommendations also provide many suggestions for future research in companies' embedding of sustainability. For a non-exhaustive selection of examples:

- Instead of painting a picture of the current state of embedding sustainability, future research projects could follow a longitudinal setup in which, for a larger sample of (European) companies, a long history of sustainability information is collected. This setup would provide more evidence on how companies have responded to past and upcoming changes in regulation, investor and stakeholder preferences, and social norms regarding the embedding of sustainability by listed companies. It would also provide more statistical power than our setup.

- Companies are defining sustainability strategies with ambitious targets. However, what seems to be generally lacking is reporting on how companies transition to targeted objectives. A future research project could study whether companies are on realistic transition paths, how they report on this, and whether and how targets are updated if new information (e.g., on climate change) becomes available or new legislation kicks in.

- "Culture eats strategy for breakfast". ${ }^{90}$ Although companies increasingly formulate sustainable purpose statements and define associated strategies and objectives, these tools will not be effective without the support of employees in all levels of the organisation. Future studies could investigate how employees view and participate in the sustainability embedding process at the company micro-level. Additionally, companies could integrate sustainability more and more explicitly in employee satisfaction surveys.

\footnotetext{
${ }^{90}$ This quote is attributed to famous management scholar Peter Drucker, but it is not clear when and whether he said it...
} 
- Our report shows several upcoming and proposed legislations regarding disclosure and due diligence. Future research could study company responses to these changes in legislation as well as the impact they have on the views and actions of shareholders and other stakeholders. Moreover, it would be interesting to investigate why past soft law initiatives (OECD Guidelines, UNGPS) have not been generally successful in making sure that companies provide highquality reporting to key stakeholders.

- A final suggestion would be to investigate specifically which governance framework is best for overseeing and implementing the embedding of sustainability. Do companies with a sustainability committee at the supervisory board level have better formulated purpose statements? Do they have higher quality processes for embedding sustainability? Do they provide higher quality reporting and due diligence? Do they interact and communicate better with material stakeholders? 


\section{E: Conclusion}

This research report examines why and how sustainability is being embedded by Dutch listed companies, and paints a picture of their current state of sustainability embedding. Its main purpose is to report on the role of the management and supervisory boards given their prominence in many strategic decisions on sustainability. We shed light on the main drivers and motivations for why company leadership sets goals and targets for sustainability embedding. Moreover, we examine how companies integrate sustainability into various manifestations of purpose statements and strategic objectives; how they re-organise their governance to effectively implement and oversee the sustainability embedding process; and how they manage their supply chain, sustainability reporting, employees and culture as responses to the growing societal demand for transparency in sustainability embedding.

Our research design comprises desk research and interviews. The desk research focuses on a review of publicly available information to answer questions on the embedding of sustainability in our sample of 35 companies. Answers to the desk research questions are based on publicly available information, particularly the 2020 annual reports and the latest information and documents from company websites. In the interviews, we apply a semi-structured approach targeted at members of the top management team, supervisory board members and the management layers immediately below.

Our research findings in the part on why companies are embedding sustainability show that companies are responding unevenly to social, environmental, and legal drivers. This is reflected, for example, in our desk research finding that many companies have not made sustainability commitments that are in line with planetary boundaries.

Our interview findings disclose leadership attitudes towards these drivers. We find that most companies view sustainability (embedding) as an opportunity, while a smaller number of companies deem it relevant from a risk perspective. Despite the cumulation of structural and stakeholder drivers surfacing over the past decades, a significant subset of companies seems to be at the start of a sustainability journey: interviewees from around one-third of the companies indicate that they have been more seriously engaged with sustainability for less than five years.

The second part of our findings explores how companies are embedding sustainability. We find that very few companies in our sample define a purpose which is oriented towards solving a problem and which, at the same time, targets one or more material stakeholder groups. We show a high degree of heterogeneity in how companies set sustainability strategies, objectives, and targets. We also find varying intensity levels in using SDGs, stakeholder materiality consultations, and sustainability risks as sources of inspiration for the embedding of sustainability.

The leadership and governance subsections show that top management, largely based on interview findings, is (perceived as) the main organisational driver of the sustainability agenda and is often supported by a sustainability team or manager. Within top management, the CEO is usually seen as the main driver, and sustainability is generally not allocated to a single person. It is unclear for most companies, since there are few published profiles for the selection of management board members, whether sustainability competencies are a current part of their expected skills set. 
The supervisory board is rarely seen as a driver of sustainability embedding. This is consistent with our finding that most skill profiles for the supervisory board do not contain any explicit reference to sustainability. This absence raises the question of whether in some instances, Dutch supervisory boards have the appropriate skill set to oversee the sustainability embedding process. The supervisory board has a crucial role in attracting and evaluating top management and, hence, in setting realistic but ambitious sustainability-related targets. Some companies respond to this gap by setting up a sustainability committee at the supervisory board level, while others organise a pool of knowledge and advice at the management level.

The subsection on supply chain management shows that it is difficult to obtain a detailed picture of supply chain relationships and sustainability embedding even though anticipated mandatory legislation for sustainability-related due diligence is looming on the horizon in addition to potential lawsuits. We find that a small subset of companies satisfies human rights due diligence requirements as were pioneered by the UNGPs. Stakeholders who want to evaluate companies' environmental due diligence face difficulties in finding the right information in the annual reports and websites.

Our investigation of reporting practices shows that many companies draw on leading reporting frameworks such as the GRI Standards, GHG protocol, IIRC Integrated Reporting Framework, CDP, and TCFD. The interviews additionally show that companies struggle in striking a right balance between the scope of their reporting, the administrative burden on their organisation, and the information needs of stakeholders while at the same time trying to comply with continuously changing legal requirements.

The embedding of sustainability requires the support of a specific, important stakeholder group: employees. Top management needs to create a culture in which employees support, implement, and contribute to sustainability embedding. Our interviews disclose different perspectives on how sustainability can be embedded into company culture. They also shed light on how companies measure their culture and attitudes to sustainability; how to create appropriate sustainability workspaces; and how to organise diversity and inclusion.

After summarising our main findings, we derive four key recommendations that, in our view, positively contribute to sustainability embedding in Dutch listed companies. Companies can use this guidance to improve their embedding practices, while investors can use it as input for their sustainabilityrelated engagement to improve company policies and practices. Moreover, our recommendations can help other stakeholders formulate their expectations of good company practice for sustainability embedding. This, in turn, can help create richer dialogues between stakeholders and companies.

The empirical analyses show that there is scope for Dutch listed companies to align their strategy more formally with planetary boundaries. We identify a crucial role for company leadership to make sure that all management layers and employees have knowledge of relevant sustainability risks (and opportunities). This will help them to respond to risks, prepare for opportunities, and adequately contribute towards the transition to a climate neutral and circular economy. We recommend, therefore, that companies align their strategy with planetary boundaries and increase awareness on sustainability risks.

We also find, using a combination of literature, desk research, and interviews, that companies may benefit from an improved sustainability culture and decision-making process if they have a wellformulated corporate purpose which is connected to strategy. We recommend, therefore, that 
companies evaluate their purpose statements and connect them to their strategic objectives and targets.

Overall, companies need to create a context in which top management is prepared to formulate a sustainability strategy with an appropriate level of ambition and understanding of their social and environmental context. Signalling leadership on sustainability to internal and external stakeholders is key, as is installing adequate oversight for the implementation of the sustainability strategy. We therefore recommend that companies create a leadership and governance context that supports strategic decision-making on sustainability.

High-quality disclosure leads to improved stakeholder feedback on company activities. External stakeholders are dependent on having access to high-quality public information which they can use to reward sustainable companies. We find that there is room for improvement in company interactions with and information provision to external parties. We therefore recommend that companies improve the quality of their interaction and communication with stakeholders.

Combined, the four recommendations can guide companies in stepping up and further developing their sustainability embedding. We expect that they will be better prepared to respond to sustainability opportunities and risks if their strategies are aligned with planetary boundaries and if their purposes are carefully formulated. The outcome of this process is that companies will be able to focus, for example, on relevant sustainability problems to be solved and / or specific stakeholder groups. In turn, this focus can serve as additional guidance for company decision-making, as inspiration for setting the company strategy, and for defining associated strategic (sustainability) objectives. Governance plays an important role in this process. Top management needs to be prepared and equipped for the job, and the supervisory board needs to have the knowledge and skills to exercise their oversight role in an effective and meaningful way. The importance of company leadership's exemplary role in signaling to employees the importance of sustainability embedding cannot be overstated. Finally, improved interaction and communication with external stakeholders will enhance companies' accountability to society and contribute towards a feedback loop which can boost further sustainability embedding and advance company strategic decision-making. 


\section{Bibliography}

\section{Academic literature}

Alvesson, M. (2002). Understanding Organizational Culture, London: SAGE Publications.

Akerlof, G. A. (1982). 'Labor Contracts as Partial Gift Exchange.' Quarterly Journal of Economics, 97: 543-569.

Backer, L.C. (2013). 'Transparency between Norm, Technique and Property in International Law and Governance: The Example of Corporate Disclosure Regimes and Environmental Impacts.' Minnesota Journal of International Law, 22(1): 1-70.

Balotti, R. F. and J. J. Hanks Jr. (1998). 'Giving at the Office: A Reappraisal of Charitable Contributions by Corporations.' Business Law, (54): 965.

Bams, D., B. van der Kroft, and K. Maas (2021). 'Heterogeneous CSR Approaches, Corporate Social Performance and Corporate Financial Performance'. Available at SSRN: https://ssrn.com/abstract=3906715

Bauer, R., T. Ruof, and P. Smeets (2021). 'Get Real! Individuals Prefer More Sustainable Investments.' Review of Financial Studies, 34(8): 3976-4043.

Bauer, R. and P. Smeets (2015). 'Social Identification and Investment Decisions.' Journal of Economic Behavior \& Organization, 117: 121-134.

Bauer, R. and P. Smeets (2021). 'Eliciting Pension Beneficiaries' Sustainability Preferences: Why and How?' Wharton Pension Research Council Working Paper No. 2021-12. Available at SSRN: https://papers.ssrn.com/sol3/papers.cfm?abstract id=3890879

Bebchuk, L. A. and R. Tallarita (2020). 'The Illusory Promise of Stakeholder Governance.' Cornell Law Review, 106: 91-178.

Berg, F., J.F. Kölbel, and R. Rigobon (2020). 'Aggregate Confusion: The Divergence of ESG Ratings.' Available at SSRN: $\underline{\text { https://ssrn.com/abstract }=3438533}$

Blass, V. and C. J. Corbett (2018). 'Same Supply Chain, Different Models: Integrating Perspectives from Life Cycle Assessment and Supply Chain Management.' Journal of Industrial Ecology, 22(1): 18-30.

Burke, J. J., R. Hoitasch, and U. Hoitasch (2019). 'The Heterogeneity of Board-Level Sustainability Committees and Corporate Social Performance.' Journal of Business Ethics, 154(4): 1161-1186.

Campbell, K, and A. Minguez-Vera (2008). 'Gender Diversity in the Boardroom and Firm Financial Performance.' Journal of Business Ethics, 83: 435-451.

Cavaco, S., P. Crifo, and A. Guidoux (2020). 'Corporate Social Responsibility and Governance: The Role of Executive Compensation.' Industrial Relations: A Journal of Economy and Society, 59(2): 240274.

Chava, S. (2014). 'Environmental Externalities and Cost of Capital.' Management Science, 60(9): 22232247. 
Choudhury, B. (2015). 'Gender Diversity on Boards: Beyond Quotas.' European Business Law Review, 26(1): 229-243.

Cosemans, M., M. van Dijk, and X. Hut (2021). 'The Impact of Climate Change on Optimal Asset Allocation for Long-Term Investors', Netspar Design Paper No. 173, https://www.netspar.nl/en/publication/the-impact-of-climate-change-on-optimal-assetallocation-for-long-term-investors/

Dahl, M. S. (2011). 'Organizational Change and Employee Stress.' Management Science, 57(2): 240256.

De Jong, B. J. (2021). 'Duurzame corporate goverance: Europese en Nederlandse ontwikkelingen.' Ondernemingsrecht, 2021/33.

Dimson, E., O. Karakas, and X. Li (2015). 'Active Ownership.' The Review of Financial Studies, 28(12): 3225-3268.

Dimson, E., O. Karakas, and X. Li (2020). 'Coordinated Engagements.' European Corporate Governance Institute - Finance Working Paper No. 721/2021. Available at SSRN: https://papers.ssrn.com/sol3/papers.cfm?abstract id=3209072

Dixon-Fowler, H. R., A.E. Ellstrand, and J. L. Johnson (2017). 'The Role of Board Environmental Committees in Corporate Environmental Performance', Journal of Business Ethics, 140(3): 423-438.

Dyck, A., K. V. Lins, L. Roth, and H. F. Wagner (2019). 'Do Institutional Investors Drive Corporate Social Responsibility? International Evidence.' Journal of Financial Economics, 131 (3): 693-714.

Eccles, R. G., I. Ioannou, and G. Serafeim (2014). 'The Impact of Corporate Sustainability on Organizational Processes and Performance.' Management Science, 60(11): 2835-2857.

Eccles, R. G., M.P. Krzus, and C. Solano (2019). 'A Comparative Analysis of Integrated Reporting in Ten Countries.' Available at SSRN: https://papers.ssrn.com/sol3/papers.cfm?abstract_id=3345590.

Eccles, R. G., L. E. Lee and J.C. Stroehle (2020). 'The Social Origins of ESG: An Analysis of Innovest and KLD.' Organization \& Environment, 33(4): 575-596.

Eccles, R. G. and J. C. Stroehle (2018). 'Exploring Social Origins in the Construction of ESG Measures.' Available at SSRN: https://papers.ssrn.com/sol3/papers.cfm?abstract_id=3212685.

Edmans, A. (2014). 'The Link Between Job Satisfaction and Firm Value, With Implications for Corporate Social Responsibility.' Academy of Management Perspectives, 26: 1-19.

Edmans, A., L. Li, and C. Zhang (2020). 'Employee Satisfaction, Labor Market Flexibility, and Stock Returns Around The World.' European Corporate Governance Institute (ECGI) - Finance Working Paper No. 433/2014. https://papers.ssrn.com/sol3/papers.cfm?abstract id=2461003

Edmans, A. (2020). Grow the Pie. How Great Companies Deliver both Purpose and Profit, London, Cambridge University press.

Edmans, A. (2011). 'Does the Stock Market Fully Value Intangibles? Employee Satisfaction and Equity Prices.' Journal of Financial Economics, 101(3): 621-640. 
Edmans, A., T. Gosling, and D. Jenter (2021). 'CEO Compensation: Evidence From the Field.' Working Paper. London Business School.

Elo, S., M. Kääriäinen, O. Kanste, T. Pölkki, K. Utriainen, and H. Kyngäs (2014). Qualitative Content Analysis. SAGE Open, 4(1), 215824401452263. https://doi.org/10.1177/2158244014522633

Fiedler, T., A. J. Pitman, K. Mackenzie, N. Wood, C. Jakob, and S. E. Perkins-Kirkpatrick (2021). 'Business Risk and the Emergence of Climate Analytics.' Nature Climate Change, 11(2): 87-94.

Flammer, C., B. Hong, and D. Minor (2019). 'Corporate Governance and the Rise of Integrating Corporate Social Responsibility Criteria in Executive Compensation: Effectiveness and Implications for Firm Outcomes.' Strategic Management Journal, 40(7): 1097-1122.

Freeman, R.E., J.S. Harrison, and A.C. Wicks (2007). Managing for Stakeholders: Survival, Reputation, and Success. Yale University Press.

Freeman, R. E., J.S. Harrison, A. C. Wicks, B. L. Parmar, and S. De Colle (2010). Stakeholder Theory: The State of the Art, Cambridge University Press.

Garcia Nelen, S. B. (2020). 'De Beursvennootschap, Corporate Governance en Strategie', Instituut voor Ondernemingsrecht, Wolters Kluwer.

Gibson, R., S. Glossner, P. Krüger, P. Matos, and T. Steffen (2021). 'Do Responsible Investors Invest Responsibly?' European Corporate Governance Institute - Finance Working Paper No. 712/2020. Available at SSRN: https://papers.ssrn.com/sol3/papers.cfm?abstract_id=3525530.

Guiso, L., P. Sapienza, and L. Zingales (2015a). 'Corporate Culture, Societal Culture and Institutions.' American Economic Review, 105(5): 336-339.

Guiso, L., P. Sapienza, and L. Zingales (2015b). 'The Value of Corporate Culture', Journal of Financial Economics, 117(1): 60-76.

Halme, M., J. Rintamaki, J. S. Knudsen, L. Lankoski, and M. Kuisma (2018). 'When Is There a Sustainability Case for CSR? Pathways to Environmental and Social Performance Improvements.' Business and Society, 59(6): 1181-1227.

Hansmann, H. and R. Kraakman (2001). 'The End of History for Corporate Law.' The Georgetown Law Journal, 89: 439-468.

Harris, L. C., and A. Crane (2002). 'The Greening of Organizational Culture: Management Views on the Depth, Degree and Diffusion of Change.' Journal of Organizational Change Management, 15(3): 214-234.

Hayek, F. A. (1948). 'The Meaning of Competition.' In F.A. Hayek, Individualism and Economic Order, Chicago, US: University of Chicago Press, pp. 92-106.

Howard-Grenville, J. and S. Bertels (2012). 'Organizational culture and environmental action.' In Bansal, P. and A. J. Hoffman, eds., The Oxford Handbook of Business and the Natural Environment, Oxford, UK: Oxford University Press, pp. 194-210.

Huselid, M. A. (1995). 'The Impact of Human Resource Practices on Turnover, Productivity, and Corporate Financial Performance.' Academy of Management Journal, 38: 635-672. 
Hummels, H. and A. Argyrou (2021). 'Planetary demands: Redefining sustainable development and sustainable entrepreneurship.' Journal of Cleaner Production, 278, article 123804.

Ikram, A., Z. F. Li, and D. Minor (2019). 'CSR-contingent Executive Compensation Contracts.' Journal of Banking \& Finance, article 105655.

Ilhan, E., P. Krüger, Z. Sautner, and L. T. Starks (2020). 'Climate Risk Disclosure and Institutional Investors.' European Corporate Governance Institute - Finance Working Paper No. 661/2020. Available at SSRN: https://papers.ssrn.com/sol3/papers.cfm?abstract id=3437178

John, A. and J. Klein (2003). 'The Boycott Puzzle: Consumer Motivations for Purchase Sacrifice.' Management Science, 49(9): 1196-1209.

Kahneman, D. (2011). Thinking, fast and slow, Macmillan.

Alvesson, M. (2002). Understanding Organizational Culture, London: SAGE Publications.

Kahneman, D., D. Lovallo, and O. Sibony (2011). 'The Big Idea: Before You Make That Big Decision...' Harvard Business Review, June 2011, https://hbr.org/2011/06/the-big-idea-before-you-makethat-big-decision

Khatib, S., D. Abdullah, A. Elamar, and R. Abueid (2020). 'Nudging toward diversity in the boardroom: A systematic literature review of board diversity of financial institutions.' Business Strategy and the Environment, https://doi.org/10.1002/bse.2665.

Korhonen, J., A. Honkasalo, and J. Seppälä (2018). 'Circular Economy: The Concept and its Limitations.' Ecological economics, 143: 37-46.

Krüger, P., Z. Sautner, D. Y. Tang, and R. Zhong (2021). 'The Effects of Mandatory ESG Disclosure Around the World.' European Corporate Governance Institute - Finance Working Paper No. 754/2021. Available on SSRN: https://papers.ssrn.com/sol3/papers.cfm?abstract id=3832745

Lambooy, T. E., K. E. H. Maas, S. van 't Foort, and R. van Tilburg (2018). 'Biodiversity and Natural Capital: Investor Influence on Company Reporting and Performance.' Journal of Sustainable Finance and Investment, 8(2): 158-184.

Laufer, W.S. (2003). 'Social Accountability and Corporate Greenwashing.' Journal of Business Ethics, 43: 253-261.

Liang, H. and L. Renneboog (2017). 'On the Foundations of Corporate Social Responsibility.' Journal of Finance, 72(2): 853-910.

Linnenluecke, M. K. and A. Griffiths (2010). 'Corporate Sustainability and Organizational Culture.' Journal of World Business, 45(4): 357-366.

Lovallo, D. and D. Kahneman (2003). 'Delusions of Success.' Harvard Business Review, 81(7), 56-63

Maas, K. (2018). 'Do Corporate Social Performance Targets in Executive Compensation Contribute to Corporate Social Performance?' Journal of Business Ethics, 148: 573-585.

Maxwell, D. And R. Van der Vorst (2003). 'Developing Sustainable Products and Services'. Journal of Cleaner Production, 11(8): 883-895. 
Mayer, C. (2018). Prosperity: Better Business Makes the Greater Good, Oxford, UK, Oxford University Press.

Mayer, C. (2020). 'The Future of the Corporation and the Economics of Purpose.' Journal of Management Studies, 58(3): 887-901.

Meadows, D. H., J. Randers, and D. L. Meadows (1972).The Limits to Growth: A Report for the Club of Rome's Project on the Predicament of Mankind, 158-175. New York: Universe Books.

Neuman, W. L. (2013). Social Research Methods: Qualitative and Quantitative Approaches, 7th edn., Harlow: Pearson Education Limited.

Olaerts, M. (2020). 'De Raad van Commissarissen in Moeilijke Tijden.' Tijdschrift voor Vennootschapsrecht, Rechtspersonenrecht en Ondernemingsbestuur, 5(1): 168-178.

Orazalin, N. (2020). 'Do Board Sustainability Committees Contribute to Corporate Environmental and Social Performance? The Mediating Role of Corporate Social Responsibility Strategy.' Business Strategy and the Environment, 29: 140-153.

Ortiz-de-Mandojana, N. and J. A. Aragón-Correa (2015). 'Boards and sustainability: The Contingent Influence of Director Interlocks on Corporate Environmental Performance.' Business Strategy and the Environment, 24: 499-517.

Pankratz, N., and C. Schiller (2021). 'Climate Change and Adaptation in Global Supply-Chain Networks.' European Corporate Governance Institute - Finance Working Paper No. 775/2021. https://ecgi.global/working-paper/climate-change-and-adaptation-global-supply-chain networks?mc cid $=5 \mathrm{a} 442530 \mathrm{f} 3 \mathrm{mc}$ eid $=53712 \mathrm{~b} 131$

Pankratz, N., R. Bauer, and J. Derwall (2021). 'Climate Change, Firm Performance, and Investor Surprises.' Available on SSRN: https://papers.ssrn.com/sol3/papers.cfm?abstract_id=3443146

Pistor, K. (2021). The Code of Capital: How the Law Creates Wealth and Inequality, Princeton: Princeton University Press.

Porter, M.E. (1985). Competitive Advantage: Creating and Sustaining Superior Performance, New York, Free Press.

Porter, M.E. and M. R. Kramer (2011). 'Creating Shared Value - How to Reinvent Capitalism - and Unleash a Wave of Innovation and Gorwth.' Harvard Business Review, January-February 2011, 117. https://hbr.org/2011/01/the-big-idea-creating-shared-value

Porter, M. E. and C. van der Linde (1995). 'Toward a New Conception of the EnvironmentCompetitiveness Relationship.' Journal of Economic Perspectives, 9(4): 97-118.

Ramus, C. A. and I. Montiel (2005). 'When Are Corporate Environmental Policies a Form of Greenwashing?' Business and Society, 44(4): 377-414.

Rockström, J., W. Steffen, K. Noone, Å. Persson, F. S. Chapin, E. F. Lambin, T. M. Lenton, et al. (2009a). 'A Safe Operating Space for Humanity.' Nature, 461: 472-475. 
Rockström, J., W. Steffen, K. Noone, Å. Persson, F. S. Chapin, E. F. Lambin, T. M. Lenton, et al. (2009b). 'Planetary Boundaries: Exploring the Safe Operating Space for Humanity.' Ecology and Society, 14(2).

Rubin, H. J. and I. S. Rubin (2011). Qualitative Interviewing: The Art of Hearing Data. SAGE.

Saldaña, J. (2013). Coding Manual: Constitutions. https://doi.org/10.1017/CB09781107415324.004.

Sautner, Z., L. van Lent, G. Vilkov, and R. Zhang (2020). 'Firm-Level Climate Change Exposure.' European Corporate Governance Institute - Finance Working Paper No. 686/2020. Available at SSRN: https://ssrn.com/abstract=3853969

Servaes, H. and A. Tamayo (2013). 'The Impact of Corporate Social Responsibility on Firm Value: The Role of Customer Awareness.' Management Science, 59(5): 1045-1061.

Sjåfjell, B. (2018). 'Redefining the Corporation for a Sustainable New Economy.' Journal of Law and Society, 45(1): 29-45.

Sjåfjell, B. (2020). 'Sustainable Value Creation within Planetary Boundaries-Reforming Corporate Purpose and Duties of the Corporate Board.' Sustainability 12(15): 6245.

Sjåfjell, B., Johnston, A., Anker-Sørensen, L., and D. Millon (2015). 'Shareholder Primacy: The Main Barrier to Sustainable Companies.' In B. Sjåfjell \& B. Richardson, eds., Company Law and Sustainability: Legal Barriers and Opportunities. Cambridge: Cambridge University Press, pp. 79147.

Solarino, A. M. and H. Aguinis (2020). 'Challenges and Best-practice Recommendations for Designing and Conducting Interviews with Elite Informants.' Journal of Management Studies, 58(3): 649-672.

Steffen, W., K. Richardson, J. Rockström, S. E. Cornell, I. Fetzer, E. M. Bennett, et al. (2015). 'Planetary Boundaries: Guiding Human Development on a Changing Planet.' Science, 347(6223).

Timmerman, L. (2020). 'Corporate Governance Codes, Bevoegdheden, Taken, Gedragsregels en Purpose', in: Lückerath-Rovers e.a., eds., Jaarboek Corporate Governance. Editie 2020-2021, Deventer: Wolters Kluwer 2020, par. 1.6.

Useem, M. (1984). The Inner Circle: Large Corporations and the Rise of Business Political Activity in the U.S. and U.K., Oxford, Oxford University Press.

Van Aartsen, C.W. (2020). A Journey into Causes of Corporate Misbehaviour: Why Corporate Legal Disciplines and Regulation Need to be Structurally Reformed. PhD thesis defended at Maastricht University on 14 October 2020.

Velte, P. and M. Stawinoga (2020). 'Do Chief Sustainability Officers and CSR Committees Influence CSR-related Outcomes? A Structured Literature Review Based on Empirical-Quantitative Research Findings.' Journal of Management Control, 31: 333-377.

Walls, J. L. and P. Berrone (2017). 'The Power of One to Make a Difference: How Informal and Formal CEO Power Affect Environmental Sustainability.' Journal of Business Ethics, 145: 293-308.

Wilkinson, R. and K. Pickett (2010). The Spirit Level - Why Equality is Better for Everyone, UK: Allen Lane. 
Winter, J.W., J.M. de Jongh, J.B.S. Hijink, L. Timmerman, G. van Solinge, M.L. Lennarts, J.B. Wezeman, C.D.J. Bulten, S.M. Bartman, E.C.H.J. Lokin, I.S. Wuisman, H.M. Vletter-van Dort, C.A. Schwarz, M.A. Verbrugh, J. Roest, G.T.M.J. Raaijmakers, H. Koster, B. Kemp, M. Olaerts, E.P.M. Joosen, H.E. Boschma, A.F. Verdam, J.N. Schutte-Veenstra, J.H.M. Willems and G.C.J. Rensen (2020). 'Naar een Zorgplicht voor Bestuurders en Commissarissen tot Verantwoordelijke Deelname aan het Maatschappelijk Verkeer', Ondernemingsrecht, 2020/86.

Winter, J.W., J.M. de Jongh, J.B.S. Hijink, L. Timmerman and G. van Solinge (2021). 'Naar een Maatschappelijke Zorgplicht voor Bestuurders en Commissarissen. Een Antwoord op Reacties', Ondernemingsrecht, 2021/6.

Yang, L., N.Z. Muller and P. J. Liang (2021). 'The Real Effects of Mandatory CSR Disclosure on Emissions: Evidence from the Greenhouse Gas Reporting Program' (No. w28984). National Bureau of Economic Research.

\section{News, Information and Opinion Websites}

Business and Human Rights Resource Centre (2021), ' 7 th Session of the IGWG - Binding Treaty: A Brief Overview'. Business and Human Rights Resource Centre, https://www.businesshumanrights.org/en/big-issues/binding-treaty/

Climate Action 100+ (2021). Climate Action 100, https://www.climateaction100.org/

Edmans, A. (2021a). 'Does Sustainability Reduce the Cost of Capital?', Vox EU, 17 March 2021, https://voxeu.org/article/does-sustainability-reduce-cost-capital

Edmans, A. (2021b). 'Why shareholder capitalism benefits wider society', Vox EU, 26 May 2021, https://voxeu.org/article/why-shareholder-capitalism-benefits-wider-society

Embedding Project (n.d.) https://www.embeddingproject.org/about/overview

Friedman, M. (1970). 'A Friedman Doctrine-- The Social Responsibility Of Business Is to Increase Its Profits.' The New York Times, https://www.nytimes.com/1970/09/13/archives/a-friedmandoctrine-the-social-responsibility-of-business-is-to.html

Heffron, R. J. (2021). 'Energy Multinationals Challenged by the Growth of Human Rights.' Nature Energy, https://www.nature.com/articles/s41560-021-009066.epdf?sharing token=Egr3feb9FGpW4emPAcaJjNRgNOjAjWel9jnR3ZoTvOOYzNsetcKKlqoEWOup QAWXYJvg ScRmNI2440eLPpEgDHItOMtqZdZOcT3GZR3Q519BWTWdmVFNIr 129ijMP1exWUJ2W iFnQwCdXOTCn1FIpZXJkWIPnQWnCaKGTDJ8k\%3D

Lashbrook, A. (2021). “No Point in Anything Else': Gen Z Members Flock to Climate Careers.' Guardian, https://www.theguardian.com/environment/2021/sep/06/gen-z-climate-change-careers-jobs

Mayer, C., L. E. Strine Jr, and J. Winter (2020). '50 years later, Milton Friedman's Shareholder Doctrine is Dead.' Fortune, https://fortune.com/2020/09/13/milton-friedman-anniversary-businesspurpose/

Sustainable Accounting Standards Board (2021). 'Materiality Map.' SASB, https://www.sasb.org/standards/materiality-map/ 
Sabin Center for Climate Change Law (2021). 'Non-U.S. Climate Change Litigation.' Climate Case Chart, http://climatecasechart.com/climate-change-litigation/non-us-climate-change-litigation/

The Purposeful Company (2021). 'About us - What We Believe.' The Purposeful Company, https://thepurposefulcompany.org/about/

Transition Pathway Initiative (2021). Transition Pathway Initiative, https://www.transitionpathwayinitiative.org/

United Nations (2020). 'Climate crisis: 'Nowhere Near the Finish Line' - UN chief.' UN News, https://news.un.org/en/story/2020/11/1078082

United Nations Department of Economic and Social Affairs (n.d.). 'Sustainable Development - The 17 Goals.' United Nations, https://sdgs.un.org/goals

United Nations Environment Programme Finance Initiative. 'UN-Convened Net-Zero Asset Owner Alliance.' UNEPFI, https://www.unepfi.org/net-zero-alliance/

United Nations Human Rights, Office of the High Commissioner (2021). 'The Next Decade of Business and Human Rights.' United Nations Human Rights, https://www.ohchr.org/EN/Issues/Business/Pages/UNGPsBizHRsnext10.aspx

\section{Policy documents and legislation}

Action Plan: Financing Sustainable Growth 'Communication from the Commission to the European Parliament, the European Council, the Council, the European Central Bank, the European Economic And Social Committee and the Committee of the Regions - Action Plan: Financing Sustainable Growth.' COM/2018/097 final EUR-Lex, https://eur-lex.europa.eu/legalcontent/EN/TXT/?uri=CELEX\%3A52018DC0097

Communication from the Commission to the European Parliament, the European Council, the Council, the European Central Bank, the European Economic and Social Committee and the Committee of the Regions - The European Green Deal.' COM/2019/640 final EUR-Lex, https://eur-lex.europa.eu/legal-content/EN/TXT/?uri=COM\%3A2019\%3A640\%3AFIN.

CSRD Proposal for a directive of the European Parliament and the Council amending Directive 2013/34/EU, Directive 2004/109/EC, Directive 2006/43/EC and Regulation (EU) No 537/2014, as regards corporate sustainability reporting COM/2021/189 final https://eur-lex.europa.eu/legalcontent/EN/TXT/PDF/?uri=CELEX:52021PC0189\&from=EN

Delegated Regulation (EU) 2017/653 of 8 March 2017 supplementing Regulation (EU) No 1286/2014 of the European Parliament and of the Council on key information documents for packaged retail and insurance-based investment products (PRIIPs) by laying down regulatory technical standards with regard to the presentation, content, review and revision of key information documents and the conditions for fulfilling the requirement to provide such documents $2017 / 5653$. EUR-Lex, https://eur-lex.europa.eu/legal-content/EN/TXT/?uri=CELEX\%3A32017R0653 
Directive 2014/65/EU of the European Parliament and of the Council of 15 May 2014 on markets in financial instruments and amending Directive 2002/92/EC and Directive 2011/61/EU Text with EEA relevance. EUR-Lex, https://eur-lex.europa.eu/legal-content/en/ALL/?uri=CELEX:32014L0065

Directive 2014/95/EU of the European Parliament and of the Council of 22 October 2014 amending Directive 2013/34/EU as regards disclosure of non-financial and diversity information by certain large undertakings and groups. EUR-Lex, https://eur-lex.europa.eu/legalcontent/EN/TXT/?uri=CELEX\%3A32014L0095

Directive (EU) 2017/828 of the European Parliament and of the Council of 17 May 2017 amending Directive 2007/36/EC as regards the encouragement of long-term shareholder engagement. EURLex, https://eur-lex.europa.eu/legal-content/EN/TXT/?uri=CELEX\%3A32017L0828

Directive (EU) 2019/1937 of the European Parliament and of the Council of 23 October 2019 on the protection of persons who report breaches of Union law. Eur-Lex, https://eurlex.europa.eu/legal-content/EN/TXT/PDF/?uri=CELEX:32019L1937

Dutch Corporate Governance Code (2016). www.mccg.nl

European Commission, 'Summary Report of the Stakeholder Consultation on the Renewed Sustainable Finance Strategy.', https://ec.europa.eu/info/consultations/finance-2020sustainable-finance-strategy en

European Commission, 'Sustainable Corporate Governance Initiative', https://ec.europa.eu/info/law/better-regulation/have-your-say/initiatives/12548-Sustainablecorporate-governance en

European Commission, 'Sustainable Finance Package', https://ec.europa.eu/info/publications/210421-sustainable-finance-communication en

European Commission (n.d.). 'Corporate sustainability reporting.' European Commission, https://ec.europa.eu/info/business-economy-euro/company-reporting-and-auditing/companyreporting/corporate-sustainability-reporting en

European Commission (n.d.). 'Due Diligence Explained.' https://ec.europa.eu/growth/sectors/rawmaterials/due-diligence-ready/explained en

European Commission (n.d.). 'EU Taxonomy for Sustainable Activities.' European Commission, https://ec.europa.eu/info/business-economy-euro/banking-and-finance/sustainable-finance/eutaxonomy-sustainable-activities en

European Parliament, 'European Parliament resolution of 17 December 2020 on sustainable corporate governance (2020/2137(INI)).', https://www.europarl.europa.eu/doceo/document/TA9-2020-0372 EN.html.

European Parliament, 'European Parliament resolution of 10 March 2021 with recommendations to the Commission on corporate due diligence and corporate accountability (2020/2129(INL)).', https://www.europarl.europa.eu/doceo/document/TA-9-2021-0073 EN.html. 
Regulation (EU) 2019/2088 of the European Parliament and of the Council of 27 November 2019 on sustainability-related disclosures in the financial services sector. EUR-Lex, https://eurlex.europa.eu/legal-content/EN/TXT/?uri=celex\%3A32019R2088.

Regulation (EU) 2020/852 of the European Parliament and of the Council of 18 June 2020 on the establishment of a framework to facilitate sustainable investment, and amending Regulation (EU) 2019/2088 (Text with EEA relevance) PE/20/2020/INIT. https://eur-lex.europa.eu/legalcontent/EN/TXT/PDF/?uri=CELEX:32020R0852\&from=EN

Loi pacte - Loi n 2019-486 du 22 mai 2019 relative à la croissance et la transformation des entreprises, JORF $n^{\circ} 0119$ du 23 mai 2019 (texte ${ }^{\circ} 2$ ).

Ministerie van Buitenlandse Zaken (2019). 'Wet van 24 oktober 2019 houdende de invoering van een zorgplicht ter voorkoming van de levering van goederen en diensten die met behulp van kinderarbeid tot stand zijn gekomen (Wet zorgplicht kinderarbeid).' Staatsblad 2019, 401. https://zoek.officielebekendmakingen.nl/stb-2019-401.html

Tweede Kamer der Staten-General (2021). 'Wet verantwoord en duurzaam internationaal ondernemen.' Kamerstukken II 2020/2021 35761, https://www.tweedekamer.nl/kamerstukken/wetsvoorstellen/detail?id=2021Z04465\&dossier=3 $\underline{5761}$

\section{Reports and studies: International organisations, consultancies and practitioner groups}

Bertels, S. and J. Schulschenk (2015). 'Introduction to Framework.' Embedding Project. DOI:10.6084/m9.figshare.3899106

Brundtland, G. H. (1987). Report of the World Commission on Environment and Development: 'Our Common Future.' United Nations.

Business Roundtable (2019). 'Business Roundtable Redefines the Purpose of a Corporation to Promote 'An Economy That Serves All Americans.' Business Roundtable, https://www.businessroundtable.org/business-roundtable-redefines-the-purpose-of-acorporation-to-promote-an-economy-that-serves-all-americans

Dutch Sustainable Growth Coalition (2013), 'Leadership and corporate governance.' https://www.dsgc.nl/publications/dsgc---leadership-and-corporate-governance.pdf

Dutch Sustainable Growth Coalition (2020), 'Internal Transformation to a Purpose-Driven Organisation.' Whitepaper. https://www.dsgc.nl/publications/dsgc-internal-transformation.pdf

Ernst \& Young (2020). 'Study on directors' duties and sustainable corporate governance.' Publications Office of the European Union, https://op.europa.eu/en/publication-detail//publication/e47928a2-d20b-11ea-adf7-01aa75ed71a1/language-en

European Environmental Agency (2020). 'Is Europe Living within the Limits of Our Planet?' EEA Report No. 1/2020. https://www.eea.europa.eu/publications/is-europe-living-within-the-planets-limits 
Government of the Netherlands (2016). 'A Circular Economy in the Netherlands by 2050.' Ministry of Infrastructure and the Environment and the Ministry of Economic Affairs, also on behalf of the Ministry of Foreign Affairs and the Ministry of the Interior and Kingdom Relations, https://www.government.nl/binaries/government/documents/policy-notes/2016/09/14/acircular-economy-in-the-netherlands-by-2050/17037+Circulaire+Economie EN.PDF

Intergovernmental Panel on Climate Change (2021). 'Headline Statements from the Summary for Policymakers', IPCC, https://www.ipcc.ch/report/ar6/wg1/downloads/report/IPCC AR6 WGI Headline Statements.p df.

Organisation for Economic Cooperation and Development (2011). 'OECD Guidelines for Multinational Enterprises.' OECD, http://mneguidelines.oecd.org/guidelines/

Pouwels, B. and M. van den Brink (2020). 'Zonder Wet Geen Voortgang - Bedrijvenmonitor Topvrouwen 2020', Commissie Monitoring Topvrouwen, Bureau Powels, https://www.rijksoverheid.nl/binaries/rijksoverheid/documenten/kamerstukken/2021/01/29/ra pport-bedrijvenmonitor-topvrouwen-2020-zonder-wet-geen-voortgang/rapportbedrijvenmonitor-topvrouwen-2020-zonder-wet-geen-voortgang.pdf

PWC (2020). 'Pay Well by Paying for Good.' PWC. https://www.pwc.co.uk/services/human-resourceservices/insights/environmental-social-governance-exec-pay-report.html

PWC (2020). 'Executive and Non-executive Remuneration Survey 2020.' PWC. https://www.pwc.nl/nl/actueel-publicaties/assets/pdfs/pwc-executive-remuneration-survey2020.pdf

Ruggie, J. (2008). 'Protect, Respect and Remedy: a Framework for Business and Human Rights Report of the Special Representative of the Secretary-General on the Issue of Human Rights and Transnational Corporations and other Business Enterprises.' Human Rights Council A/HRC/8/5.

Social and Economic Council of the Netherlands (2019). 'Diversity in the Boardroom - Time to Accelerate.' SER, https://www.ser.nl/-/media/ser/downloads/engels/2019/diversityboardroom.pdf

Third G20 Finance Ministers And Central Bank Governors Meeting (2021). 'Communiqué'. https://www.g20.org/wp-content/uploads/2021/07/Communique-Third-G20-FMCBG-meeting-910-July-2021.pdf

United Nations Environment Programme (2019). 'Global Resources Outlook', International Resource Panel, https://www.resourcepanel.org/reports/global-resources-outlook

United Nations Environment Programme (2021). 'Making Peace with Nature Report', UNEP, https://www.unep.org/resources/making-peace-nature

United Nations Human Rights, Office of the High Commissioner (2011). 'Guiding Principles on Business and Human Rights', United Nations,

https://www.ohchr.org/documents/publications/guidingprinciplesbusinesshr en.pdf 
United Nations Working Group on Business and Human Rights (2021). 'Guiding Principles On Business And Human Rights At 10: Taking stock of the first decade.' United Nations Human Rights Special Procedures, A/HRC/47/39,

United Nations - Secretary-General's High-Level Panel on Global Sustainability (2012). 'Resilient People, Resilient Planet: A Future Worth Choosing.' New York: United Nations.

World Business Council for Sustainable Development (2010). 'Vision 2050 - The New Agenda for Business'. WBCSD, https://www.wbcsd.org/contentwbc/download/1746/21728/1

World Business Council for Sustainable Development (2020). 'Reinventing Capitalism: a Transformation Agenda. Vision 2050 Issue Brief.' WBCSD, https://www.wbcsd.org/contentwbc/download/10585/157859/1

World Business Council for Sustainable Development (2021). 'Vision 2050 - Time to Transform.' WBCSD, $\quad$ https://www.wbcsd.org/Overview/About-us/Vision-2050-Time-toTransform/Resources/Time-to-Transform

World Wildlife Fund (2020). 'Living Planet Report 2020.' World Wildlife Fund, https://www.worldwildlife.org/publications/living-planet-report-2020

World Meteorological Organization (2020). 'WMO Provisional Report on the State of the Global Climate 2020.' WMO, https://library.wmo.int/index. php?lvl=notice display\&id=21804\#.YUCp$\underline{\text { n2xWUk }}$

Younger, R., C. Mayer, and R. G. Eccles (2020). 'Enacting Purpose within the Modern Corporation - A Framework for Boards of Directors.' Enacting Purpose,

https://www.enactingpurpose.org/assets/enacting-purpose-initiative---eu-report-august2020.pdf

\section{Case law}

HR 04 April 2014, ECLI:NL:HR:2014:799, ECLI:NL:PHR:2013:1826 JOR 2014/290 m.nt. R.J.G. de Haan (Cancun).

The Hague District Court 26 May 2021, ECLI:NL:RBDHA:2021:5339 (Shell). 


\title{
Appendix I: Letter of invitation to companies
}

\section{Re: Invitation to participate in Sustainability Governance Research}

\section{Project}

\author{
Dear [name of Company Secretary],
}

Maastricht University and Eumedion would like to invite you to participate in an internationally groundbreaking research project focusing on the role of management and board of directors in anchoring sustainability in the governance and daily business of listed companies in The Netherlands. ${ }^{\text {TT }}$ Th letter of invitation serves to introduce the research project and to seek your company's commitment to participate in the interview module of the project.

Introducing the research project

The research project aims to collect and analyse current governance practices for embedding sustainability within a company's profile, strategy, risk management, culture, and so on. The aggregated and anonymised research results are expected to provide a well-founded overview and analysis of different governance mechanisms in relation to sustainability issues relevant and/or material for the companies in scope. The results will serve the needs of companies in search of goodpractices in this area, and can inform or substantiate a company's interaction with its various stakeholders. You will find a more detailed description of the research project in the annex to this letter. There we also provide more information on the measures for safeguarding the confidentiality ofcompany-specific research information.

\section{Registration of interest}

The voluntary participation (as interviewees) of a substantial number of non-executive directors, management team members and sustainability and/or IR managers of Dutch listed companies is paramount to the project's launch and success in an academically viable way. At this stage, we kindlyask you to register with us your company's interest in participation. Ideally, we would like to hold individual interviews with at least one non-executive board member, one management team member and the sustainability or IR-officer. If needed, these interviews can be held through an online channel.

If and when the required baseline number of registrations has been reached, we will gladly inform youof the project's timeline and further details. We would like to stress that your registration does by no means constitute any obligation towards Maastricht University or Eumedion. We kindly ask you to register your interest in participation by 31 July via info@eumedion.nl.

If you have any questions at this stage, we will be happy to answer them. Please contact [name redacted] policy advisor sustainability, at Eumedion [contact details redacted].

We are looking forward to your response.Yours faithfully,

[name redacted]

Maastricht University Eumedion

\footnotetext{
${ }^{1}$ The research team defines 'sustainability' in the context of this project as the environmental, social andgovernance opportunities and risks a company considers material or relevant.
} 


\section{Annex to the letter of invitation}

\section{Sustainability Governance: Description of the project}

The research project aims to collect and analyse the current spectrum of market practices regarding the role of executive and non-executive boards in embedding and anchoring sustainability in the company's purpose, profile, strategy, enterprise risk management, operations, culture etc. In scope of this project are all listed and, potentially, a limited number of large non-listed companies in The Netherlands.

Although there is a broadly accepted view that a company's board, as well as the interaction between an executive and non-executive board, has a major and defining influence on the way in which sustainability is embedded, this has until now not been systematically analysed in an academically viable way. The aggregated research results are expected to provide a well-founded overview and analysis of different governance mechanisms in relation to sustainability-related questions and issuesrelevant and/or material for the companies in scope. These insights can serve both the needs of companies in search of best practices in this area, as well as inform or substantiate a company's interaction with its various stakeholders. Given the groundbreaking character of the project, it is also expected that the research results will provide ample opportunity for further research into the way sustainability and other issues relevant for large companies can be effectively embedded in the governance structure.

The project methodology, still to be further developed, will ideally combine three activities: desk research (e.g. of annual (sustainability) reports, AGM reports, ESG ratings), (online) interviews, and in a later stage (short) company surveys. The interviews will be held with selected members of both the management team and non-executive board (ideally including those in charge of the sustainability agenda), and where applicable, dedicated sustainability and/or IR managers. The surveys can be conducted with a broader set of company employees. All research activities will be focused on identifying governance practices related to the embedding and anchoring of sustainability within the company. We would like to emphasise that it is not the focus of this research to analyse governance ofsustainability issues in relation to a company's overall performance.

\section{About the project partners}

The research will be conducted in full by Maastricht University, under the academic guidance of RobBauer, Professor of Finance (institutional investors chair) at the School of Business and Economics, and Mieke Olaerts, Professor of Comparative and National Company Law at the Faculty of Law.

Insights from this project will aim to contribute to existing academic knowledge on sustainability governance within the company as well as in its broader relation to shareholders and other stakeholders. A more detailed and focused project description will be outlined once preliminary interestand scope of participation is known. The project contributes well to the mission of the Elverding Chair on "Sustainable Business, Culture and Corporate Regulation" which is held by both Professor Rob Bauer and Professor Mieke Olaerts at the Law School of Maastricht University. The Elverding chair is made possible among others by DSM, DNB, ING and Qpark.

The project will be financially supported by Eumedion. As a platform for institutional investors 
on corporate governance and sustainability, Eumedion facilitates its members to regularly engage with a large number of Dutch listed companies. In these dialogues, the topics of sustainability and governance are regularly discussed. Eumedion and its members have expressed the need for a more systematic overview and analysis of current market practices, to serve as a basis for fruitful engagement with investee companies. For this purpose, Eumedion has made available funds for sponsoring a research project and has discussed with Maastricht University the general outlines of thisresearch question. Eumedion will continue to serve as a sounding board to the research team, but will 
not be involved in the execution of the research, the processing of research data, or the analysis of theresearch results.

Safeguarding the confidentiality of company-level data and outcomes

In order to safeguard the confidentiality of research data and outcomes on a companylevel, Maastricht University will establish and present to you the procedures to guarantee the confidentiality of company specific information obtained from interviews and surveys. Furthermore, Eumedion and its members will only have access to the aggregated and anonymised results as laid down in the (draft) publication(s) following this research, the final versions of which will be made publicly available. 


\section{Appendix II: Desk research questions}

This appendix presents the full list of desk research questions that we investigated, alongside the source of information that we relied on. 'Annual report' refers to the 2020 version, 'any report' refers to published reports anywhere on the company website, 'website' refers to anywhere on the company website, and 'governance documents' refers to documents which are available on the corporate governance section of the company website. Particular documents, and sections with documents, may also be identified in the source column.

\section{General items to include}

\begin{tabular}{|lll|}
\hline$\#$ & Question & Source \\
\hline 1 & $\begin{array}{l}\text { What instruments/legal tools do companies refer to when they set their sustainability goals or } \\
\text { make their sustainability definition/targets? }\end{array}$ & Annual report \\
\hline 2 & $\begin{array}{l}\text { Has the company committed to being climate neutral? (1) no, (2) yes, by 2030, (3) yes, by 2050, } \\
\text { (4) yes, other (5) yes, deadline unspecified, (6) yes, already there. }\end{array}$ & Annual report \\
\hline
\end{tabular}

\section{Management Board \& Supervisory Board}

\section{A. General sustainability governance}

\begin{tabular}{|lll|}
\hline$\#$ & Question & Source \\
\hline 3 & $\begin{array}{l}\text { How many dedicated sustainability committees does the company have? (0) zero, (1) one, (2) } \\
\text { two (3) three or more. N.b. this can be anywhere in the company, not just at board level. }\end{array}$ & $\begin{array}{l}\text { Any report, } \\
\text { Website }\end{array}$ \\
\hline 4 & $\begin{array}{l}\text { How many of these committees have details publicly available? (0) zero, (1) one, (2) two (3) } \\
\text { three or more. }\end{array}$ & $\begin{array}{l}\text { Any report, } \\
\text { Website }\end{array}$ \\
\hline 5 & $\begin{array}{l}\text { How many sustainability committees only include internal parties? (0) zero, (1) one, (2) two (3) } \\
\text { three or more. }\end{array}$ & $\begin{array}{l}\text { Any report, } \\
\text { Website }\end{array}$ \\
\hline 6 & $\begin{array}{l}\text { How many sustainability committees only include external parties? (0) zero, (1) one, (2) two (3) } \\
\text { three or more. }\end{array}$ & $\begin{array}{l}\text { Any report, } \\
\text { zoro, (1) one, (2) two (3) three or more. }\end{array}$ \\
\hline 8 & $\begin{array}{l}\text { If the committee is fully internal, then what governance structure does it have? (0) N/A, (1) } \\
\text { supervisory board only, (2) supervisory board and management board, (3) management and } \\
\text { executive board only, (4) includes a management board member as highest management, (5) } \\
\text { includes executive board member as highest management, (6) senior management only, (7) } \\
\text { business unit level, (8) production site level (can fill in more than one board). }\end{array}$ & Any report, \\
\hline 9 & $\begin{array}{l}\text { If the committee is fully external, then at what governance level does it interact with the } \\
\text { company? (0) N/A, (1) supervisory board level, (2) management board level, (3) executive board } \\
\text { level, (4) senior management level (can fill in more than one board). }\end{array}$ & Website \\
\hline 10 & $\begin{array}{l}\text { If the committee is mixed, then what governance structure does it have? (0) N/A, (1) chaired by } \\
\text { CEO or CFO, (2) supervisory board and management board, (3) includes executive board } \\
\text { member as highest management, (4) other, namely (can fill in more than one board). }\end{array}$ & Any report, \\
\hline
\end{tabular}

\section{B. Management board}

\begin{tabular}{|lll|}
\hline$\#$ & Question & Source \\
\hline 11 & $\begin{array}{l}\text { Is there a dedicated person responsible for sustainability? (1) no / unclear, (2) yes, CEO, (3) yes, } \\
\text { CFO, (4) yes, another top management team member. }\end{array}$ & $\begin{array}{l}\text { Governance / } \\
\text { sustainability }\end{array}$ \\
\hline
\end{tabular}




\begin{tabular}{|lll|}
\hline & & \multicolumn{1}{c|}{$\begin{array}{l}\text { sections of } \\
\text { annual report }\end{array}$} \\
\hline 12 & $\begin{array}{l}\text { Does the management board or top management team task allocation (i.e. tasks / duties / } \\
\text { responsibilities) in the articles of association, rules of procedure, by-laws, or elsewhere in the } \\
\text { company governance documents contain a reference to sustainability? (1) No, (2) Yes, but } \\
\text { diversity only (3) Yes, other sustainability-related topics (maybe including diversity). }\end{array}$ & $\begin{array}{l}\text { Governance } \\
\text { documents }\end{array}$ \\
\hline 13 & $\begin{array}{l}\text { Is there a specific profile for management board members or members of the top management } \\
\text { team? (1) No, (2) Yes. }\end{array}$ & $\begin{array}{l}\text { Governance } \\
\text { documents }\end{array}$ \\
\hline 14 & $\begin{array}{l}\text { Does this profile include sustainability? (0) N/a, (1) No, (2) Yes, but diversity only (3) Yes, other } \\
\text { sustainability-related topics (maybe including diversity). }\end{array}$ & $\begin{array}{l}\text { Governance } \\
\text { documents }\end{array}$ \\
\hline
\end{tabular}

\section{Supervisory board}

\begin{tabular}{|lll|}
\hline \# & Question & Source \\
\hline 15 & Is there a skills profile available for the supervisory board? (1) No, (2) yes. & $\begin{array}{l}\text { Governance } \\
\text { documents }\end{array}$ \\
\hline 16 & $\begin{array}{l}\text { Does the skill profile include any references to sustainability? (1) No, (2) corporate social } \\
\text { responsibility or sustainability, (3) safety, (4) environment, (5) balancing stakeholder interests, } \\
\text { (6) employee relations. }\end{array}$ & $\begin{array}{l}\text { Supervisory } \\
\text { board profile }\end{array}$ \\
\hline 17 & Is there a dedicated person responsible for sustainability? (1) No, (2) yes. & $\begin{array}{l}\text { Governance / } \\
\text { sustainability } \\
\text { sections of } \\
\text { annual report }\end{array}$ \\
\hline 18 & $\begin{array}{l}\text { Does the supervisory board task allocation (i.e. tasks / duties / responsibilities) in the articles of } \\
\text { association, rules of procedure, by-laws, or elsewhere in the company governance documents } \\
\text { contain a reference to sustainability? (1) No, (2) Yes, but diversity only (3) Yes, other } \\
\text { sustainability-related topics (maybe including diversity). }\end{array}$ & $\begin{array}{l}\text { Governance } \\
\text { documents }\end{array}$ \\
\hline
\end{tabular}

\section{Remuneration}

\begin{tabular}{|c|c|c|}
\hline \# & Question & Source \\
\hline 19 & Is sustainability part of the remuneration policy for the management board? (1) No, (2) yes. & $\begin{array}{l}\text { Remuneration } \\
\text { policy }\end{array}$ \\
\hline 20 & $\begin{array}{l}\text { Did the company reward any variable remuneration? (1) No remuneration granted, (2) Variable } \\
\text { remuneration was granted. }\end{array}$ & $\begin{array}{l}\text { Remuneration } \\
\text { policy }\end{array}$ \\
\hline 21 & $\begin{array}{l}\text { Are sustainability targets part of the fixed or the variable component of remuneration? (0) N/a } \\
\text { / neither, (1) fixed, (2) variable, (3) both. }\end{array}$ & $\begin{array}{l}\text { Remuneration } \\
\text { policy }\end{array}$ \\
\hline 22 & $\begin{array}{l}\text { What \% of the fixed components is potentially dedicated to sustainability? (0) N/a, (1) } \\
\text { unspecified, (2) X\%. }\end{array}$ & $\begin{array}{l}\text { Remuneration } \\
\text { policy }\end{array}$ \\
\hline 23 & $\begin{array}{l}\text { If variable, is it part of the long-term or short-term targets? (0) N/a, (1) long-term, (2) short- } \\
\text { term, (3) both, (4) not specified. }\end{array}$ & $\begin{array}{l}\text { Remuneration } \\
\text { policy }\end{array}$ \\
\hline 24 & $\begin{array}{l}\text { What \% of the variable short-term components is potentially dedicated to sustainability? (0) } \\
\text { N/a, (1) unspecified, (2) X\%. }\end{array}$ & $\begin{array}{l}\text { Remuneration } \\
\text { policy }\end{array}$ \\
\hline 25 & $\begin{array}{l}\text { Are the variable sustainability short-term components connected to performance areas and } \\
\text { KPIs? (0) N/a, (1) No, (2) general performance areas but no KPIs, (3) general performance areas } \\
\text { and KPIs. }\end{array}$ & $\begin{array}{l}\text { Remuneration } \\
\text { policy }\end{array}$ \\
\hline 26 & $\begin{array}{l}\text { What \% of the variable long-term components is potentially dedicated to sustainability? (0) } \\
\text { N/a, (1) unspecified, (2) X\%. }\end{array}$ & $\begin{array}{l}\text { Remuneration } \\
\text { policy }\end{array}$ \\
\hline 27 & $\begin{array}{l}\text { Are the variable sustainability long-term components connected to performance areas and } \\
\text { KPIs? (0) N/a, (1) No, (2) general performance areas but no KPIs, (3) general performance areas } \\
\text { and KPIs. }\end{array}$ & $\begin{array}{l}\text { Remuneration } \\
\text { policy }\end{array}$ \\
\hline
\end{tabular}


28 Are the variable sustainability targets, if present, connected to internal benchmarks (related to the company and its strategy) or external benchmarks (for example sustainability rankings)? (0) policy N/a, (1) unspecified, (2) internal, (3) external, (4) a mix of both.

\section{Strategy, risk management \& reporting}

\section{E. Strategy}

\begin{tabular}{|lll|}
\hline$\#$ & Question & Source \\
\hline 29 & $\begin{array}{l}\text { Does the company have a (sustainable) corporate purpose? (1) No, (2) Yes, does not include } \\
\text { sustainability, (3) Yes, includes sustainability indirectly, (4) Yes, includes sustainability directly. }\end{array}$ & Annual report \\
\hline 30 & $\begin{array}{l}\text { Does the corporate purpose have an internal or external orientation? (0) N/a, (1) internal, (2) } \\
\text { external. }\end{array}$ & Annual report \\
\hline 31 & Is the corporate purpose oriented towards solving a problem? (0) N/a, (1) No, (2) Yes. & Annual report \\
\hline 32 & $\begin{array}{l}\text { Does the purpose identify one or more material stakeholders for the business? (0) N/a, (1) No, } \\
\text { (2) Yes, X. }\end{array}$ & Annual report \\
\hline 33 & $\begin{array}{l}\text { Is sustainability included in the strategic objectives as: (1) not included or incidental, (2) a } \\
\text { separate sustainability strategy, (3) a foundation or pillar? }\end{array}$ & $\begin{array}{l}\text { Annual report / } \\
\text { Sust. report }\end{array}$ \\
\hline 34 & $\begin{array}{l}\text { Does the company have sustainability targets in their Annual Report or a separate Sustainability } \\
\text { Report? (1) no, (2) yes. }\end{array}$ & $\begin{array}{l}\text { Annual report / } \\
\text { Sust. report }\end{array}$ \\
\hline 35 & $\begin{array}{l}\text { Does the Annual Report or Sustainability Report show results for these targets for the previous } \\
\text { year(s)? (0) N/a, (1) no, (2) one year, (3) more than one year. }\end{array}$ & $\begin{array}{l}\text { Annual report / } \\
\text { Sust. report }\end{array}$ \\
\hline 36 & $\begin{array}{l}\text { Are future targets connected to specific years? (0) N/a, (1) no or only one, (2) mostly yes, (3) } \\
\text { yes. }\end{array}$ & $\begin{array}{l}\text { Annual report / } \\
\text { Sust. report }\end{array}$ \\
\hline 37 & $\begin{array}{l}\text { Does the independent auditor's report in the AR provide limited or reasonable assurance for } \\
\text { non-financial information? (1) no, (2) limited, (3) reasonable. }\end{array}$ & $\begin{array}{l}\text { Annual report / } \\
\text { Sust. report }\end{array}$ \\
\hline 38 & Does the company have a value creation model? (0) N/a, (1) no, (2) yes. & Annual report \\
\hline 39 & Is there reference to sustainable development goals? (1) No, (2) yes. & Annual report \\
\hline 40 & Which SDGs are mentioned (or does the company focus on)? & Annual report \\
\hline
\end{tabular}

\section{F. Risk management}

\begin{tabular}{|lll|}
\hline \# & Question & Source \\
\hline 41 & Does the company risk assessment evaluate non-financial risks? (1) No, (2) yes. & Risk \\
& & $\begin{array}{l}\text { management } \\
\text { section of the } \\
\text { annual report }\end{array}$ \\
\hline 42 & Does the company have a stakeholder materiality matrix? (1) No, (2) yes. & Risk \\
& & management \\
& & $\begin{array}{l}\text { section of the } \\
\text { annual report }\end{array}$ \\
\hline
\end{tabular}

\section{G. Reporting}

\begin{tabular}{|lll|}
\hline$\#$ & Question & Source \\
\hline 43 & Which sustainability-related reporting standard(s) does the company rely on? & Annual report \\
\hline 44 & Does the company report on their GHG emissions? (1) No, (2) yes. & Any report \\
\hline 45 & $\begin{array}{l}\text { Do they measure and disclose their scope 1, scope 2, scope 3 emissions? (0) N/a, (1) no, (2) } \\
\text { scope 1 only, (3) scope 1 and 2, (4) scope 1, 2 and 3 emissions. }\end{array}$ & Any report \\
\hline 46 & $\begin{array}{l}\text { Does the company report on their GHG emissions per euro earned, per product volume, or } \\
\text { some other kind of metric? (0) N/a, (1) no, (2) yes, namely X. }\end{array}$ & Any report \\
\hline
\end{tabular}




\begin{tabular}{|llc|}
\hline 47 & $\begin{array}{l}\text { Does the company report on their energy use? (1) No, (2) limited information, (3) yes, detailed } \\
\text { information. }\end{array}$ & Any report \\
\hline 48 & $\begin{array}{l}\text { Does the company report on their energy use per euro earned, per product volume, or some } \\
\text { other kind of metric? (0) N/a, (1) no, (2) yes, namely X. }\end{array}$ & Any report \\
\hline 49 & $\begin{array}{l}\text { Does the company report on the extent of their renewable energy (\% or total W/h)? (0) N/a, (1) } \\
\text { no, (2) yes, namely X. }\end{array}$ & Any report \\
\hline 50 & $\begin{array}{l}\text { Does the company report on their water use? (1) No, (2) limited information, (3) yes, detailed } \\
\text { information. }\end{array}$ & Any report \\
\hline 51 & $\begin{array}{l}\text { Does the company report on their water use per euro earned, per product volume, or some } \\
\text { other kind of metric? (0) N/a, (1) no, (2) yes, namely X. }\end{array}$ & Any report \\
\hline 52 & $\begin{array}{l}\text { Does the company report on their waste? (1) No, (2) limited information, (3) yes, detailed } \\
\text { information. }\end{array}$ & $\begin{array}{l}\text { Does the company report on their waste per euro earned, per product volume, or some other } \\
\text { kind of metric? (0) N/a, (1) no, (2) yes, namely X. }\end{array}$ \\
\hline 54 & $\begin{array}{l}\text { Does the company report on business travel in their AR or sustainability report? (1) No, (2) } \\
\text { limited information, (3) yes, detailed information. }\end{array}$ & Any report \\
\hline
\end{tabular}

\section{Culture and stakeholders}

\section{H. Employee KPIs}

\begin{tabular}{|lll|}
\hline$\#$ & Question & Source \\
\hline 55 & $\begin{array}{l}\text { (What) does the company report on employee diversity? (1) No, (2) Yes, male / female, (3) Yes, } \\
\text { age, (4) Yes, nationality (more than one can apply). }\end{array}$ & $\begin{array}{l}\text { Annual report / } \\
\text { Sust. report }\end{array}$ \\
\hline 56 & $\begin{array}{l}\text { Does the company provide a detailed breakdown of managerial / non-managerial diversity? (1) } \\
\text { No, (2) Yes, male / female, (3) Yes, age, (4) Yes, nationality (more than one can apply). }\end{array}$ & $\begin{array}{l}\text { Annual report / } \\
\text { Sust. report }\end{array}$ \\
\hline 57 & $\begin{array}{l}\text { Does the company provide a detailed breakdown of diversity \& inclusion in different parts of } \\
\text { the company? (1) No, (2) Yes, X. }\end{array}$ & $\begin{array}{l}\text { Annual report / } \\
\text { Sust. report }\end{array}$ \\
\hline 58 & $\begin{array}{l}\text { (What) does the company report on employee trainings? (1) No, (2) Yes, X hours per FTE, (3) } \\
\text { Yes, X\% code of conduct trainings, (4) Yes, other (more than one can apply). }\end{array}$ & Annual report \\
\hline 59 & $\begin{array}{l}\text { (What) does the company report on employee sustainability-related trainings and education? } \\
\text { (1) No, (2) Yes, X. }\end{array}$ & $\begin{array}{l}\text { Annual report / } \\
\text { Does the company do an employee survey and report on findings? (1) No, (2) Yes, they do a } \\
\text { survey but don't report on findings, (3) Yes, they do a survey and report only on employee } \\
\text { engagement (or satisfaction, happiness, etc.) levels, (4) Yes, they do a survey and report broadly } \\
\text { on the findings. }\end{array}$ \\
\hline $\begin{array}{l}\text { If the company reports on the findings of its employee survey, do they refer to sustainability? } \\
\text { (0) N/A, (1) No, (2) Yes. }\end{array}$ & Annual report \\
\hline
\end{tabular}

\section{Supply chain KPIs}

\begin{tabular}{|lll|}
\hline$\#$ & Question & Source \\
\hline 62 & $\begin{array}{l}\text { Does the company have a supplier code of ethics (various names)? (1) No, (2) Yes, not available, } \\
\text { (3) Yes, available online. }\end{array}$ & $\begin{array}{l}\text { Website } \\
\text { Any report }\end{array}$ \\
\hline 63 & Does the company report on the implementation of its supplier code? (0) N/A, (1) No, (2) Yes. & Any report \\
\hline 64 & Has the company established a named due diligence process for human rights? (1) no, (2) yes. & Annual report \\
\hline 65 & $\begin{array}{l}\text { How many of the four due diligence steps do they report on for their human rights due } \\
\text { diligence? (0) N/a, (1) assessing actual and potential impacts, (2) AND integrating and acting on } \\
\text { the findings, (3) AND tracking responses, (4) AND communicating about how impacts are } \\
\text { addressed. }\end{array}$ & Any report \\
\hline 66 & $\begin{array}{l}\text { Has the company established a named due diligence process for environmental impacts? (1) no, } \\
\text { (2) yes. }\end{array}$ & Annual report \\
\hline
\end{tabular}


67 How many of the four due diligence steps do they report on for environmental impact due diligence? (1) assessing actual and potential impacts, (2) AND integrating and acting on the findings, (3) AND tracking responses, (4) AND communicating about how impacts are addressed.

\section{J. Stakeholders}

\begin{tabular}{|lll|}
\hline$\#$ & Question & Source \\
\hline 68 & Which and how many of the following are explicitly identified as company stakeholders? (1) & Annual report \\
& society, (2) employees, (3) suppliers, (4) NGOs, (5) environment, (6) customers, (7) investors, (8) & \\
& community, (9) Media, (10) creditors, (11) business partners, (12) governments, (13) & \\
& educational institutions, (14) trade associations, (15) inter-governmental organisations, (16) & \\
& trade unions, (17) competitors, (18) future generations. & \\
\hline
\end{tabular}

\section{K. Company commitments and signalling}

\begin{tabular}{|lll|}
\hline$\#$ & Question & Source \\
\hline 69 & Does the company have a diversity policy for employees? (1) No, (2) Yes. & Annual report \\
\hline 70 & Does the company have a sustainable / responsible procurement policy? (1) No, (2) Yes. & Annual report \\
\hline 71 & Has the company commitment to respecting human rights? (1) No, (2) Yes. & Annual report \\
\hline 72 & $\begin{array}{l}\text { Has the company committed to circularity? (1) No, (2) yes, engaged with circularity, (3) yes, } \\
\text { aims to become fully circular. }\end{array}$ & Annual report \\
\hline 73 & Has the company committed to staying within planetary boundaries? (1) No, (2) yes. & Annual report \\
\hline 74 & $\begin{array}{l}\text { Is the company engaged with biodiversity? (1) No, (2) company recognises as important, } \\
\text { potential impact, risk or material issue, (3) charitable contribution, (4) participation in industry } \\
\text { commitment, (5) specific organisational policies and projects. }\end{array}$ & Annual report \\
\hline 75 & $\begin{array}{l}\text { Has the company committed to a fair tax policy, including a commitment to not using tax } \\
\text { havens? (1) No, (2) yes. }\end{array}$ & Annual report \\
\hline 76 & \begin{tabular}{l} 
Has the company committed to paying its employees a living wage? (1) No, (2) yes. \\
\hline
\end{tabular} & Annual report \\
\hline
\end{tabular}




\section{Appendix III: Interview analysis and questions}

All interviews were recorded and transcribed into text format. For this we used a reliable, external transcription provider with whom Maastricht University has a Data Processing Agreement (Uitgetypt.nl). The latter Agreement was arranged and approved by the University Data Protection Officers to ensure that our interviewee data could be transcribed in a GDPR-compliant manner. Our interview storage and transcription approach was approved by Maastricht University Data Privacy Officers and the Ethical Review Committee for the Inner City.

Interview transcription material was carefully read through and coded (labelled per topic) with Atlas.ti software. We created a preliminary list of codes based on the interview questions, and added new codes which we felt were interesting to investigate as our coding progressed. This approach followed the 'responsive interviewing' method of Rubin \& Rubin (2004) and the Coding manual of Saldaña (2013).

Interview data was subsequently aggregated at company level. For this purpose we created a summary document for each company which synthesised the narrative on the discussed themes and questions across the various interviewees, checking for consistency and complementarity. We subsequently created answer categories for each question (or additional code that we identified). Frequency of category occurrence was counted to identify the prevalence of a given response or practice. This was subsequently used as the empirical foundation for our interview findings.

Due to the semi-structured interviewing format, each interview followed a unique path in which different kinds of information were presented by the interviewees. The list of questions asked (below) differed according to the role of the interviewee(s); for instance, board members were asked more detailed questions about how sustainability was integrated into the processes of the board they were part of, while sustainability managers were asked in more detail about their role, the role of their teams and internal company processes they participated in. Due to the fact that different sets of participants in different roles were provided by different companies, the final types of information collected per company also differed.

\section{Questions in order of asking, organised by topic area:}

\section{Introduction}

- Could you shortly introduce yourself and describe your role at the company? What are your tasks and responsibilities?

- [sustainability managers/non-board members]: Who do you report to in your role?

$\circ \quad$ [sustainability managers] How many people are there in the sustainability team within the company?

- How long have you been at the company, and how long have you been at your current role?

- What would you say are the key sustainability issues your company is currently facing?

- In what ways would you say sustainability is already embedded, or integrated, in your company?

- In which areas do you still see gaps or room for improving sustainability embedding?

- How long is there an explicit focus on sustainability within the company? Was there a turning point? 
- When discussed with company leadership, is sustainability viewed more as a risk, an opportunity, a combination or something else altogether?

\section{Board and management}

- Who in the company is the key driver of sustainability, and sets the sustainability agenda and targets?

- Is there an executive board member or a group formally or informally responsible for sustainability?

- Is there a supervisory board member or a group formally or informally responsible for sustainability?

- Is there a group or committee responsible for sustainability on the board? If not, was this a deliberate decision? What were the reasons behind it?

- How often is sustainability discussed with(in) the management board?

- How often is sustainability discussed with(in) the supervisory board?

- What kinds of sustainability issues are discussed with(in) the board?

- Are there differences in perspectives among board members when sustainability is discussed, in endorsing sustainability, or what topics to focus on, the speed at which to move?

- Are you including sustainability knowledge or experience among selection criteria for board members (supervisory or management)?

- Is sustainability included in the onboarding and education of new board members at the company?

- In your view, to what extent have sustainability-related targets in executive remuneration been helpful (or unhelpful) in implementing sustainability?

\section{Strategy and business decisions}

- What role does sustainability play in your company's overall corporate strategy?

- Are there any tensions between business objectives and sustainability objectives, or long-term and short-term goals?

- Is sustainability in any way formally integrated into the evaluation of specific business decisions, such as investments?

\section{Employees and culture}

- In your view, is the current company culture supportive of sustainability?

- Does the company measure employees attitudes towards sustainability?

- Is the company management actively managing its culture towards sustainability?

- Is sustainability included in employee education or onboarding?

- Is sustainability included in employee remuneration, targets or performance evaluation?

- Are there any opportunities, or processes, to enable people to come up with and implement their ideas / initiative?

- How do you ensure a consistent sustainability practice among different company locations and cultural contexts? Are you proactively working at unifying the culture?

\section{Shareholders and other external stakeholders}

- Would you say the company's shareholders are generally supportive of sustainability?

- How often are you approached often by shareholders with sustainability questions? 
- What sustainability-related questions do shareholders usually ask?

- Do shareholders come up with their own ideas or suggestions of what the company should do to become more sustainable?

- How does the company handle sustainability-focused questions or initiatives coming from shareholders?

- Does sustainability emerge as question in negotiations on debt financing with banks?

- Are there any other stakeholders, whom you consider especially influential for your sustainability strategy, or with whom you engage extensively on sustainability issues?

- Does the company engage with governments or regulators on sustainability topics?

- Does the company engage with or is approached by NGOs regarding sustainability topics?

- Has the company's approach to sustainability changed since the outbreak of the COVID crisis? 


\section{Appendix IV: Dataset and FAIR guiding principles}

We have made the dataset for this project publicly available insofar as possible within the limits of our interview data protection and privacy requirements. Access for the dataset can be requested by searching the DataverseNL database for the following dataset:

"Aartsen, Constantijn van; Bauer, Rob; Bauer, Tereza; Olaerts, Mieke, 2021, "Corporate Sustainability Research Project - Elverding Chair", https://doi.org/10.34894/4UTK2C, DataverseNL"

The Maastricht University website explains these principles as follows:

\section{Fair Guiding Principles for scientific data management and stewardship ${ }^{91}$}

In 2016, the 'FAIR Guiding Principles for scientific data management and stewardship' were published in Scientific Data, an online Nature magazine journal. The authors intended to provide guidelines to improve the findability, accessibility, interoperability and reuse of digital assets.

The principles emphasise machine-actionability: the capacity of computational systems to find, access, interoperate, and reuse data with none or minimal human intervention. This is because people increasingly rely on computational support to deal with data in the face of a rapid increase in volume, complexity, and creation speed of data.

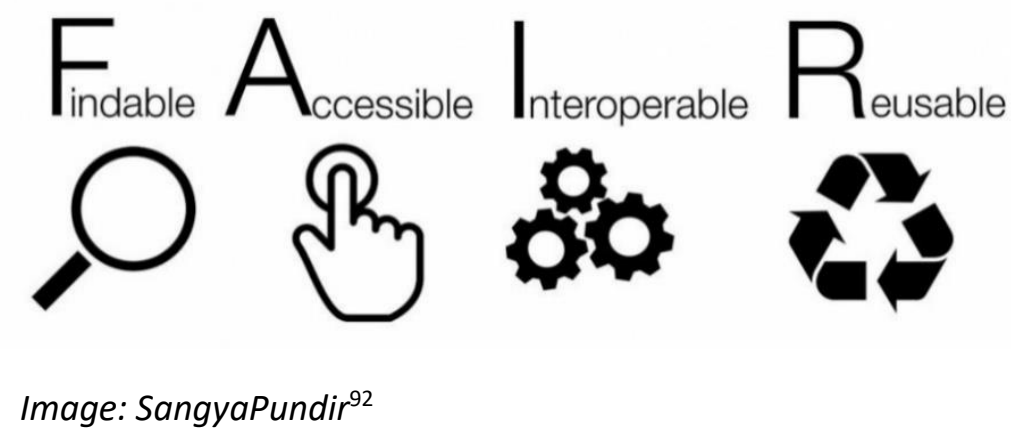

\section{FINDABLE}

The first step in (re)using data is to find them. Metadata and data should be easy to find for both humans and computers. Machine-readable metadata are essential for automatic discovery of datasets and services, so this is a crucial component of the FAIRification process.

\section{ACCESSIBLE}

Once the user finds the required data, she/he needs to know how they can be accessed, possibly including authentication and authorisation.

\section{INTEROPERABLE}

The data usually need to be integrated with other data. Also, the data need to interoperate with applications or workflows for analysis, storage, and processing.

\footnotetext{
${ }^{91}$ This information was copied from the Maastricht University website https://www.maastrichtuniversity.nl/research/openscience/fair-principles

92 https://forumgdi.rcaap.pt/wp-content/uploads/2017/11/keynote forum3.pdf
} 


\section{REUSABLE}

The ultimate goal of FAIR is to optimise the reuse of data. To achieve this, metadata and data should be well-described so that they can be replicated and/or combined in different settings.

The principles refer to three types of entities: data (or any digital object), metadata (information about that digital object), and infrastructure.

You can find detailed information at go-fair.org/fair-principles 


\section{Appendix V: List of reporting and normative standards used by companies}

1. Carbon Disclosure Project (CDP)

2. Dow Jones Sustainability Index (DJSI)

3. Dutch Climate Agreement (NL Klimaatakkoord)

4. Environmental Protection Agency (EPA)

5. European Green Deal

6. European Public Real Estate (EPRA)

7. Financial Times and Stock Exchange 4 Good (FTSE4GOOD)

8. French Agency for Ecological Transition (ADEME)

9. Global Real Estate Sustainability Benchmark (GRESB)

10. Global Reporting Initiative (GRI)

11. Good Manufacturing Practices (GMP+) Certification

12. Greenhouse Gas (GHG) Protocol

13. Institutional Shareholder Services (ISS)

14. Intergovernmental Panel on Climate Change (IPCC)

15. International association of Oil and Gas producers (IOGP)

16. International Financial Reporting Standards (IFRS)

17. International integrated Reporting Framework

18. International Labor Organization (ILO)

19. International Maritime Organisation (IMO)

20. International Safety Management (ISM) Code

21. Kyoto protocol

22. Leadership in Energy and Environmental) Design) LEED

23. Meerjarenafspraken energie-efficiëntie (MJA3/MEE)

24. Morgan Stanley Capital Investment (MSCl)

25. Non-financial Reporting Directive (NRFD)

26. Occupational Health and Safety Assessment Specification (OHSAS)

27. OECD Guidelines

28. Oekom

29. Paris Agreement

30. Platform Carbon Accounting Financials (PCAF)

31. Poseidon Principles (PP)

32. Principles for Responsible Investment (PRI)

33. Responsible Business Alliance (RBA)

34. Science Based Targets (SBT)

35. Sustainability Accounting Standards Board

36. Sustainable Developments Goals (SDGs)

37. Sustainalytics

38. Taskforce on Climate-related Financial Disclosures (TCFD) 
39. UN Environment Programme (UNEP)

40. UN Framework Convention on Climate Change (UNFCCC)

41. UN Global Compact

42. UN Guiding Principles (UNGPs)

43. UN Principles for Sustainable Insurance

44. World Economic Forum (WEF) 